\title{
WestVirginiaUniversity
}

THE RESEARCH REPOSITORY @ WVU

Graduate Theses, Dissertations, and Problem Reports

2015

\section{Three Essays on Financial Economics}

Li Sun

Follow this and additional works at: https://researchrepository.wvu.edu/etd

\section{Recommended Citation}

Sun, Li, "Three Essays on Financial Economics" (2015). Graduate Theses, Dissertations, and Problem Reports. 6743.

https://researchrepository.wvu.edu/etd/6743

This Dissertation is protected by copyright and/or related rights. It has been brought to you by the The Research Repository @ WVU with permission from the rights-holder(s). You are free to use this Dissertation in any way that is permitted by the copyright and related rights legislation that applies to your use. For other uses you must obtain permission from the rights-holder(s) directly, unless additional rights are indicated by a Creative Commons license in the record and/ or on the work itself. This Dissertation has been accepted for inclusion in WVU Graduate Theses, Dissertations, and Problem Reports collection by an authorized administrator of The Research Repository @ WVU.

For more information, please contact researchrepository@mail.wvu.edu. 


\title{
Three Essays on Financial Economics
}

\author{
Li Sun \\ Dissertation submitted to the \\ College of Business and Economics \\ at West Virginia University \\ in partial fulfillment of the requirements \\ for the degree of \\ Doctor of Philosophy \\ in \\ Economics
}

Victor K.Chow, Ph.D., Chair

Naomi E. Boyd, Ph.D.

Stratford M. Douglas, Ph.D.

William Riley, Ph.D.

Feng Yao, Ph.D.

Department of Economics

Morgantown, West Virginia

2015

Keywords: Asset Allocation, Precautionary Saving, Health Risk, Financial Crisis, Inequality Copyright (C) 2015 Li Sun 


\title{
ABSTRACT \\ Three Essays on Financial Economics
}

\author{
Li Sun
}

This dissertation analyzes households' asset allocation decisions and studies how the financial crisis affects income distribution using panel datasets from household surveys. The first essay focuses on how the precautionary saving motive can affect households' asset allocation decisions. It develops a life-cycle model that explicitly accounts for the effects of potential future expenditure shocks; the implications of this model better match the empirically observed investment behaviors of households. A precautionary index is constructed to measure the adequacy of households' precautionary saving, and it is found that this factor has significant explanatory power regarding households' stock market participation and risky asset allocation decisions. In the second essay, a life-cycle model is developed to investigate how health risk and rare event risk will affect retirees' optimal asset allocation decisions. Health Risk is modeled as a stochastic medical expenditure, calibrated using data from the Health and Retirement Survey. The rare event risk is modeled as a financial crisis risk where the stock market has a small but positive probability of crashing. Compared with models that do not take into account health risk or financial market risk, the optimal policy rules and the simulation results obtained from this model better explain retirees' equity holding behaviors as observed in the empirical data. In the third essay, a non-parametric decomposition methodology is applied to analyze the change of income distribution before and after the 2008 financial crisis in the United States. I decompose the Lorenz curve and its associated concentration curve by subgroups defined on the basis of race, gender, and retirement status using the 2007-2009 Survey of Consumer Finance (SCF) panel dataset. It is found that the income distribution shifted following the crisis. For households in the bottom to the 9th decile of the income distribution, income share increased, and the increases were more pronounced when measured by the concentration curve. 
To my mother 


\section{ACKNOWLEDGEMENTS}

Writing a dissertation is a journey, a journey that requires inspiration, perseverance, and deep commitment. For me, this journey could not have been completed without guidance and help from a large group of people. I wish to express my deepest gratitude to all of those who helped to make this journey a wonderful experience in my life and helped me contribute to the scholarly literature in economics.

Especially, I would like to thank my advisor, Victor K. Chow, for his remarkable patience and dedication in guiding me through this process. He has not only been a great mentor in guiding me in scholarly research, but also inspired me to seek the truth of humanity. I truly enjoyed the intellectual and lively discussions with him ranging from questions in financial research to philosophical inquiries on the deeper meaning of life.

I would also like to thank Prof. Naomi E. Boyd, whose positive energy is like a beam of light through which anyone close to her can feel her genuine support and encouragement, which can turn a dismaying situation into one full of hope. I would also like to express my great gratitude to Prof. Stratford Douglas, Prof. William Riley, and Prof. Feng Yao, for their remarkable understanding and help in this process.

This work could not have been completed without the support of the Department of Economics at West Virginia University, and I would like to thank Prof. Brian Cushing, Prof. Arabinda Basistha, and Prof. Clifford Hawley for their patience and encouragement. I would also like to thank my previous advisor, Prof. Ronald Balvers, whose intellectual depth in scholarly research has greatly deepened my understanding in the subject.

I am also very fortunate to have met many good friends whose support I am truly grateful for. I would like to express my gratitude to Chengjie Wu, Vikas Agrawal, Pragya Srivastava, Apoorva Ravishankar, Jingrui Li, and others who were always there when I needed them. I am also truly proud of what you have accomplished in your life as researchers and scholars.

Finally, I would like to express my great indebtedness to my parents, whose love and sacrifice have made the completion of this dissertation especially meaningful. 


\section{TABLE OF CONTENTS}

NOTICE OF COPYRIGHT.

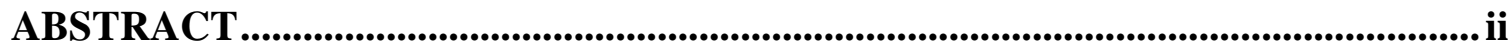

ACKNOWLEDGEMENTS ........................................................................................ iv

LIST OF TABLES .......................................................................................................... vii

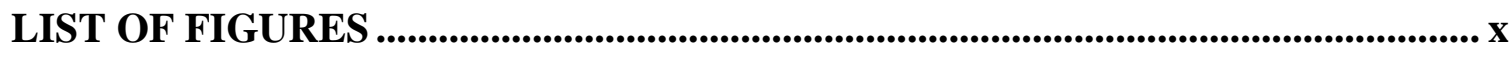

\section{CHAPTER 1}

Introduction ....................................................................................................................................... 1

\section{CHAPTER 2:}

Precautionary Saving and Asset Allocation .......................................................................... 8

2.1 Introduction .............................................................................................................. 9

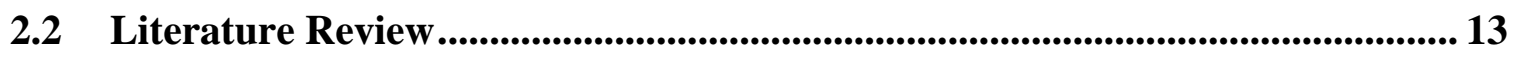

2.2.1 Precautionary saving behavior ........................................................................ 13

2.2.2 Background risk and portfolio choice ............................................................ 14

2.2.3 Limited participation in the stock market ...................................................... 15

2.3 Evidence on Households' Investment Behaviors..................................................... 16

2.3.1 General overview of the Survey of Consumer Finance (SCF) ................. 17

2.3.2 Normalized wealth and investment behavior ................................................ 18

2.3.3 The saving motive and investment behavior ................................................. 20

2.4 A Life Cycle Model Including Contingent Consumption ...................................... 21

2.4.1 Preferences.......................................................................................................... 21

2.4.2 The labor income process ................................................................................. 22

2.4.3 The financial market......................................................................................... 23

2.4.4 Households' optimization problem................................................................. 23

2.4.5 Parameters and model calibration ................................................................... 24

2.4.6 The model solution: optimal portfolio policy................................................. 25 
2.5 The Precautionary Index: Hypothesis Testing and Estimation ........................ 27

2.5.1 Construction of the precautionary saving index ..................................... 27

2.5.2 Market participation hypothesis and regression results .......................... 29

2.5.3 Portfolio shares in risky assets ................................................................ 31

2.6 Discussion ............................................................................................................... 33

2.6.1 Retirement accounts vs. non-retirement accounts ..................................... 33

2.6.2 Non-retired households vs. retired households ....................................... 35

2.6.3 Business owners vs. non-business owners ................................................ 36

2.6.4 Control for risk preference................................................................................ 37

2.6.5 The effect of low normalized wealth........................................................ 38

2.6.6 The impact of pension plans.......................................................................... 39

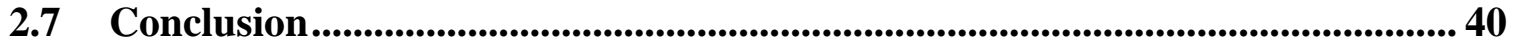

\section{CHAPTER 3:}

Tail Risk, Health Risk, and Portfolio Choices for Retirees ..................................... 68

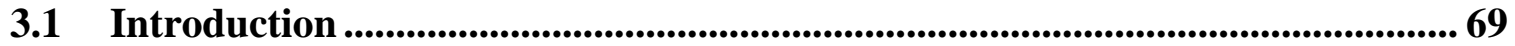

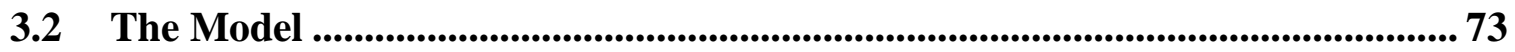

3.2.1 The preference ...................................................................................... 73

3.2.2 Modeling health shock .............................................................................................. 74

3.2.3 The financial market ........................................................................... 75

3.2.4 Retirees' optimization problem.................................................................. 75

3.3 Parameters and Model Calibration ............................................................... 78

3.3.1 Health expenditure calibration ............................................................................ 79

3.3.2 Problem with health ratio calibration .......................................................... 82

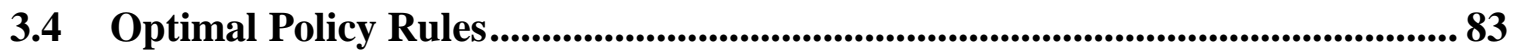

3.4.1 Policy rules without health risk...................................................................... 83

3.4.2 Policy rules with health shock ...................................................................... 85

3.5 Extension: Heterogeneous Health Risk .......................................................... 87

3.6 Simulation Results................................................................................... 88

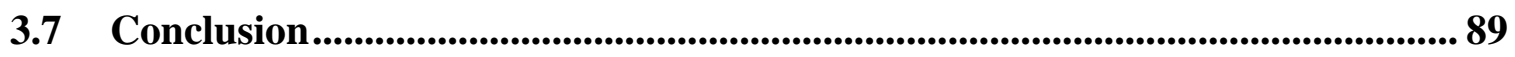




\section{CHAPTER 4:}

Impacts of Financial Crisis on Income Inequality: A Decomposed Approach ........ 114

4.1 Introduction ................................................................................................................... 115

4.2 Literature Review ......................................................................................................... 118

4.2.1 Inequality before and after the crisis............................................................. 118

4.2.2 Decomposing the inequality measure ............................................................. 119

4.2.3 Use of household survey data ....................................................................... 120

4.3 Methodology ............................................................................................................. 121

4.3.1 Decomposing the ordinates............................................................................. 121

4.3.2 Additive decomposition............................................................................... 123

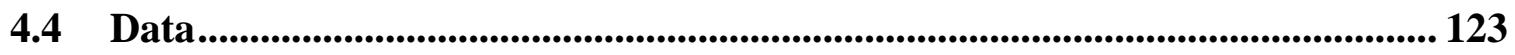

4.4.1 Income definition ............................................................................................... 125

4.5 Decomposition Results ............................................................................................... 126

4.5.1 Overall decomposition results .............................................................. 126

4.5.2 Decomposition by race ..................................................................................... 128

4.5.3 Decomposition by gender ................................................................................ 131

4.5.4 Decomposition by retirement status .............................................................. 133

4.6 Discussion .................................................................................................................. 135

4.6.1 Crisis effects in the longer run..................................................................... 135

4.6.2 Comparison with the 1987 stock market crash .......................................... 137

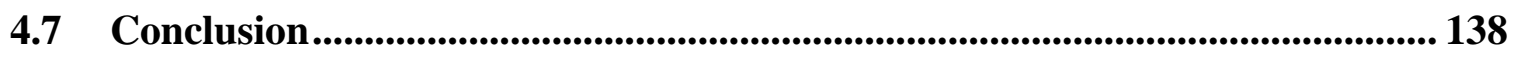

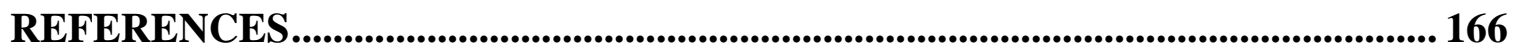




\section{LIST OF TABLES}

Table 2-1: Descriptive statistics for key variables in the SCF.............................................. 42

Table 2-2: Distribution of household normalized wealth level and risky asset share ................ 43

Table 2-3: Normalized wealth regression (Logit model) ............................................................ 44

Table 2-4: Average Marginal Effect for the normalized wealth regression....................................... 45

Table 2-5: Normalized wealth regression (risky share regression) ................................................ 46

Table 2-6: Risky asset share regression for different levels of normalized wealth .............................. 47

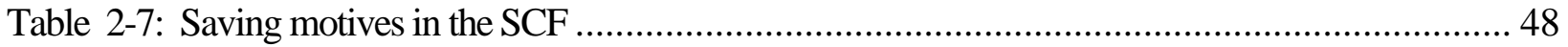

Table 2-8: Saving motive regression (Logit model) .......................................................... 49

Table 2-9: Average marginal effect for the saving motive regression...................................... 50

Table 2-10: Saving motive regression (linear probability model) ......................................... 51

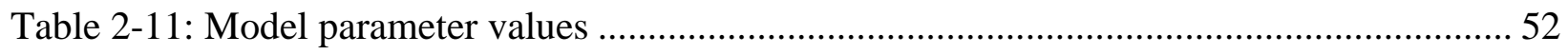

Table 2-12: Summary statistics for the emergency fund .................................................. 53

Table 2-13: Stock market participation regression (Logit model) ............................................54

Table 2-14: Average marginal effect for the stock market participation regression ................... 55

Table 2-15: Precautionary ratio regression (linear probability model) .................................... 56

Table 2-16: Risky Asset share regression (retirement account vs. non-retirement account)........ 57

Table 2-17: Stock market participation regression (control for different status)....................... 58

Table 2-18: Average marginal effect for Stock market participation regressions ...................... 59

Table 2-19: Risky asset share regressions (control for different status) .................................. 60

Table 2-20: Stock market participation regression (control for normalized wealth).................. 61

Table 2-21: Average marginal effect for the stock market participation regression .................. 62

Table 2-22: Risky asset share regression (ccontrol for normalized wealth) ............................ 63

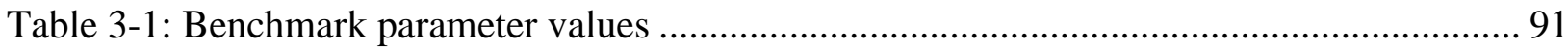

Table 3-2: Summary statistics for variables of interest in the HRS........................................ 92

Table 3-3: Summary statistics for health expenditure ...................................................... 93

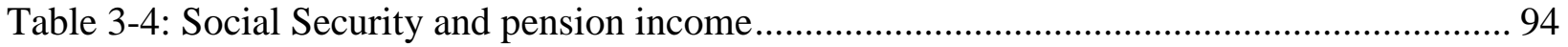

Table 3-5: Summary statistics for medical expense ratio .................................................. 95 


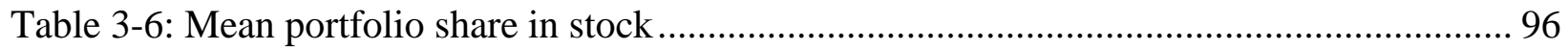

Table 3-7: Portfolio share for different cohorts by age ............................................................... 97

Table 4-1: Summary statistics for key variables in the SCF 2007 \& 2009........................................ 140

Table 4-2: Summary statistics for the income variable by group.......................................................... 141

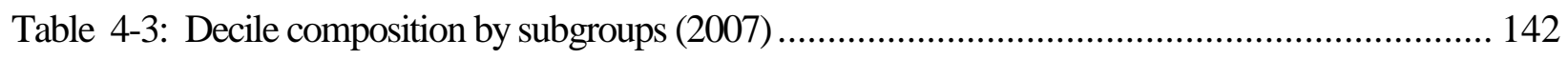

Table 4-4: Group composition by 2007 decile......................................................................... 143

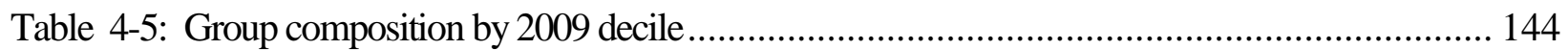

Table 4-6: Lorenz ordinates decomposition for the overall sample (2007 vs. 2009) .............................. 145

Table 4-7: Lorenz ordinates and subsample decomposition by race (2007) ........................................ 146

Table 4-8: Lorenz ordinates and subsample decomposition by race (2009) ....................................... 147

Table 4-9: Concentration ordinates and subsample decomposition by race (2009) ............................... 148

Table 4-10: Lorenz ordinates and subsample decomposition by gender (2007) ................................... 149

Table 4-11: Lorenz ordinates and subsample decomposition by gender (2009) ................................... 150

Table 4-12: Concentration ordinates and subsample decomposition by gender (2009) .......................... 151

Table 4-13: Lorenz ordinates and subsample decomposition by retirement status (2007)...................... 152

Table 4-14: Lorenz ordinates and subsample decomposition by retirement status (2009)...................... 153

Table 4-15: Concentration ordinates and subsample decomposition by retirement status (2009) ............ 154

Table 4-16: Lorenz ordinates decomposition for the overall sample (2006 vs. 2012)............................ 155

Table 4-17: Lorenz ordinates and subsample decomposition by race (2006) ....................................... 156

Table 4-18: Lorenz ordinates and subsample decomposition by race (2012) ...................................... 157

Table 4-19: Concentration ordinates and subsample decomposition by race (2012) .............................. 158

Table 4-20: Lorenz ordinates and subsample decomposition by race (1986) .................................... 159

Table 4-21: Lorenz ordinates and subsample decomposition by race (1988)...................................... 160

Table 4-22: Concentration ordinates and subsample decomposition by race (1988) .............................. 161

Table 4-23: Chi-Squared test results by race (2007 vs. 2009) ............................................................ 162

Table 4-24: Chi-Squared test results by gender (2007 vs. 2009) ...................................................... 162

Table 4-25: Chi-Squared test results by retirement status (2007 vs. 2009) ........................................... 163 


\section{LIST OF FIGURES}

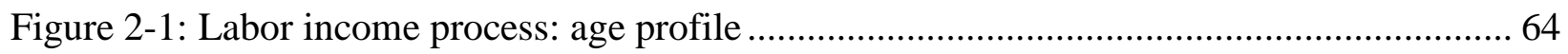

Figure 2-2: Policy rules for portfolio choice (without contingent consumption) ........................ 65

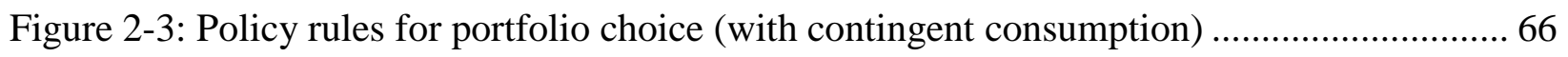

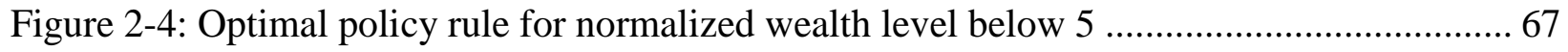

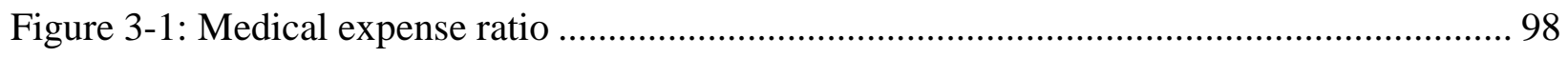

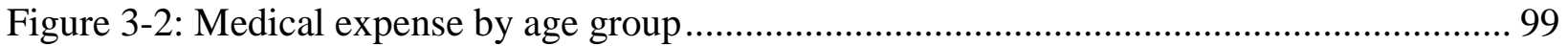

Figure 3-3: Medical expense ratio by health status .......................................................... 100

Figure 3-4: Policy rules for two cases......................................................................... 101

Figure 3-5: Policy function with health risk and financial crisis ............................................ 102

Figure 3-6: The portfolio rule for the good health group................................................... 103

Figure 3-7: The portfolio rule for the poor health group ...................................................... 104

Figure 3-8: Policy functions for retirees at different ages (without health risk but with

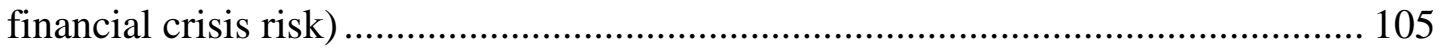

Figure 3-9: Policy functions for retirees at different age (with health risk but without

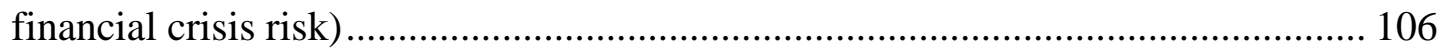

Figure 3-10: Policy functions for retirees at different ages (with health risk and financial

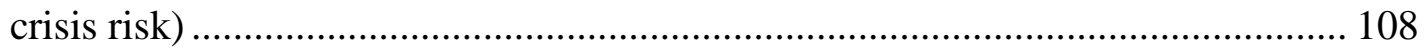

Figure 3-11: The portfolio rule at age 65 by health status ................................................. 108

Figure 3-12: The portfolio rule at age 75 by health status ................................................. 109

Figure 3-13: The portfolio rule at age 85 by health status ................................................ 110

Figure 3-14: Initial wealth distribution for retirees............................................................ 110

Figure 3-15: Simulation results: Without health risk....................................................... 112

Figure 3-16: Simulation results: With health risk............................................................. 113

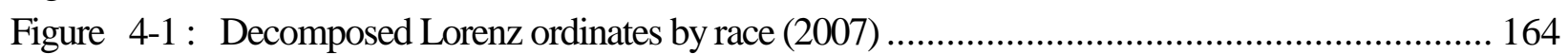

Figure 4-2: Decomposition histogram (by race) ............................................................. 165 


\title{
Chapter 1
}

\author{
Introduction
}




\section{Chapter 1}

\section{Introduction}

In the past several decades, the life cycle model, which applies stochastic optimal control methodology, has been used to study households' inter-temporal saving and consumption decisions. It also helps us understand how households allocate their wealth into risky and riskless assets, i.e., the asset allocation problem. In the seminal work developed by Merton (1971, 1973), it is found that, in the absence of the labor income or if labor income is perfectly tradable, investors' optimal allocation of wealth to risky assets should depend only on investors' risk preference and the mean and volatility of stock market returns. Subsequent research has extended the model to account for a more realistic characterization of households' budget constraints, where labor income is added to the model, and background risk is emphasized as an important factor which can affect households' investment decisions (Cocco et al., 2005; Gomes and Michaelides, 2005; Wachter and Yogo, 2010).

Another strand of literature focuses on the precautionary saving motives of households. Carroll (1992, 1994, and 1997) finds that current consumption is strongly related to future income uncertainty, which is contrary to the permanent income hypothesis that households' current consumption will depend on lifetime income. Analysis of the Survey of Consumer Finance indicates that precautionary saving is a strong motive for households to accumulate wealth and therefore can reduce current consumption. Precautionary saving can be seen as households' hedge against uncertainty in labor income and other types of background risks, such as unexpected health expenditure. While most previous literature has focused on uncertainty in labor income, few studies have analyzed how emergency expenditure shock can affect households' saving and 
portfolio choices. Future emergency expenditure shocks can be seen as a form of contingent consumption which can affect households' future consumption level if not properly hedged. Emergency expenditure can be seen as similar to spending on necessity goods, consumption of which households have little flexibility to reduce once they occur, such as unexpected medical expense. Compared to other types of consumption, spending related to medical expense is less discretionary and can crowd out households' other consumption.

In the first essay of the dissertation, I develop a simple life cycle model to account for the impact of the future emergency expenditure shock and analyze how households' saving and investment behavior will be affected by this expenditure shock. Instead of focusing on households' inter-temporal budget constraints, I argue that future expenditure shock can be modeled as a form of contingent consumption that can affect households' utility function. Households will not know when emergency expenditure shock will occur, but they can have prior knowledge of the distribution of the size of these shocks; therefore, they can estimate the expected value of this amount. Due to the uncertainty in its timing, households need to hedge this expenditure shock every period; thus, households' utility function will depend on both their current consumption and the expected value of this expenditure shock.

In spirit, this model shares features with the "habit formation" models, in which the agent' utility function depends on the difference between consumption and a "habit" (Constantinides, 1990; Campbell and Cochrane, 1999; Polkovnichenko, 2007). However, the crucial difference between my model and the habit formation model lies in the characterization of "habit." In much of the habit formation literature, habit is a representation of past aggregate consumption, while in 
my model, habit is defined as the value of expected emergency expenditure, which can reduce the effective consumption level of households once it occurs.

The policy function derived from the model implies that the optimal risky asset share starts very low when normalized wealth is low and increases as normalized wealth increases. Compared to models that do not account for the expenditure shock (Cocco, 2005), this model can better explain the empirical observation that households with higher normalized wealth have a higher share invested in risky assets.

As precautionary saving can be a major reason for households to accumulate wealth so they can have enough resources to meet future emergency expenditure shock, the sufficiency of this saving can affect households' investment risk taking. Using a reported variable of desired level of emergency funds and the actual households' asset data from the Survey of Consumer Finance, I construct a precautionary index to measure the adequacy of households' precautionary saving. The index is defined as the ratio of households' total available resources to the desirable amount of funds, and a higher value of this index indicates that the household will have greater ability to meet its emergency needs and therefore can increase the household's risk tolerance.

Using regression analysis, I further analyze how the index affects households' stock market participation and portfolio choice decisions. The regression results show that the precautionary index has a positive and statistically significant effect on the probability of households' decisions to participate in the stock market. The share invested in risky assets is also higher when the precautionary index is higher. Specifically, a one percent increase in the precautionary index will increase the predicted probability of holding equity by 0.0377 percentage points and will increase the risky asset share by 0.023 percentage points. In addition, the precautionary index's impact on 
the risky asset share is larger for investments held in households' retirement accounts than for directly held stocks.

In further research, it will be useful to see how other major future expenditure, such as that for housing purchase and medical expenses, can be incorporated into households' inter-temporal optimization models. Together with the emergency expenditure discussed in this essay, they can be seen as special types of contingent consumption households need to consider when they make saving and asset allocation decisions. Modeling these future spending needs as contingent consumption that would reduce the effective level of current consumption provides insights into households' asset allocation decisions.

In the second essay of this dissertation, I use the life-cycle model to analyze retirees' saving and asset allocation decisions. Previous literature has often modeled the labor income of retirees as a certain percentage of their last working year's wages, which is a fixed amount and will not be subjected to permanent income shock (Cocco, 2005). This implies that retirees' income is less risky and that they should have a higher percentage of their wealth invested in risky assets. However, empirical evidence has shown that the risky asset share actually decreases after retirement, which cannot be explained by the previous characterization of the labor income process in the retirement phase. On the other hand, a large body of literature has documented that health risk can play an important role in determining investors' risk taking behaviors (Yogo, 2009; De Nardi et al., 2010; Hugonnier et al., 2012; Scholz and Seshadri, 2013). The health risk factor can be particularly relevant for retirees because health risk increases as people age.

I develop a life cycle model where the health risk is modeled as stochastic expenditure which can effectively reduce retirees' income. I calibrate the health expenditure ratio using data 
from the Health and Retirement Survey (HRS), which provides the most comprehensive panel data on U.S. retirees' health condition, out-of-pocket health expenditure, income, and asset holding. In addition, I take into account the possibility of a financial crisis, the effect of which may be different between retirees and non-retirees, whose investment horizon is longer and who can have more time to recoup from the large loss caused by the financial crisis. This is an extension of the notion in the rare event or the tail risk literature, which tries to address the risk premium in asset pricing by considering the occurrence of rare events that could happen in the financial market and whose detrimental effect on wealth can raise the risk premium of stocks (Liu, 2005; Todorov, 2011; Gabaix, 2012; Wachter, 2013).

By incorporating these two important factors in the life cycle model, I derive the retirees' optimal consumption and portfolio choice functions. The optimal policy rules imply that for all age groups (except in the year before death), the portfolio share in stocks gradually increases as normalized wealth approaches 4.5 and slowly declines until leveling out when normalized wealth is higher than 15. This model can explain the investment decisions when normalized wealth is in the range of 1 to 6 , where that of $75 \%$ of retirees falls. Based on the optimal policy functions and initial wealth distribution, calibrated from the HRS, I conduct a simulation analysis for 5000 retirees and calculate the mean, $5^{\text {th }}$, and $95^{\text {th }}$ percentiles of the cross-sectional distribution of the risk asset share, and the results are very close to the actual holding level found in the HRS. In addition, I extend the model by incorporating heterogeneous health risk and find that the model implies that households with a higher mean health expenditure ratio would hold fewer risky assets, which is consistent with findings in the empirical literature (Rosen 2004, Edwards; 2008). 
In the third essay of this dissertation, I characterize the income distribution of the U.S. population using the Lorenz curve, which calculates the income share for households in each decile. Compared to a single index measurement, such as the Gini coefficient, the Lorenz curve offers a more complete description of income inequality. I then apply a decomposition methodology proposed in Bishop et al. (2004) to study the impact of the 2008 financial crisis on the change in income distribution of U.S. households. By analyzing the Lorenz curve and its associated concentration curve with panel data, this decomposition methodology can track the conditional change in income inequality before and after the financial crisis. Furthermore, this methodology allows us to decompose the Lorenz and the concentration ordinates by population subgroups, based on demographic characteristics, and examine how different groups contribute to the ordinates before and after the crisis.

The analysis results indicate that in the short run, overall income distribution shifted as a result of the financial crisis. The income share of households in the top decile declines, and it increases for households in the bottom nine deciles. This change is reflected in the cross year Lorenz ordinates but is more evident in the concentration ordinates, where households in each decile do not change. Households in the top $10 \%$ of the income distribution earned $47 \%$ of the total earnings in 2007 , and received only $37.7 \%$ of total income in 2009 , if we preserve the ranking of each household. In addition, the decomposed concentration ordinates for subgroups, characterized by race, gender, and retirement status, followed a pattern similar to that found for the overall sample. 


\section{Chapter 2}

Precautionary Saving and Asset Allocation 


\section{Chapter 2}

\section{Precautionary Saving and Asset Allocation}

\subsection{Introduction}

Life cycle models have been widely used in studying households' consumption and portfolio choice decisions. With power utility preference, most life cycle models imply that at low normalized wealth levels, households should invest all their wealth in risky assets. This implication fails to explain the phenomena of low stock market participation and the low share of the portfolio invested in risky assets (Cocco et al., 2005). Even after accounting for housing consumption (Cocco, 2005; Yao, 2005), the life cycle model's prediction for optimal risky asset holdings is still too high compared to the empirical data. This paper presents a simple model that incorporates households' unexpected future expenditure, or contingent consumption, into the power utility. The optimal portfolio rule derived from this model explains the low portfolio share of risky asset holdings when normalized wealth is low. It also explains why the investment share in risky assets increases along with normalized wealth when wealth level is relatively low.

This model is closely related to the habit model, according to which the household's utility depends not only on current consumption but also on a "habit" level of consumption. The habit model generates a more realistic optimal portfolio rule than the non-habit model (Polkovnichenko, 2007). However, in the habit formation model, the "habit" is usually related to past consumption levels or a minimum sustainable level of consumption. In my model, the "habit" is not internally 
formed, nor is it related to the past consumption level; rather, it represents the level of unexpected future expenditure that can be seen as a form of contingent consumption that a household has to spend when it occurs. With the anticipation of this type of emergency expenditure, households will hold fewer risky assets and engage more in precautionary saving behavior. After solving the model that explicitly accounts for this emergency expenditure, I further study how precautionary saving and the household's ability to meet its emergency needs can affect its investment risk-taking behavior.

Previous studies on consumer behaviors have found that the precautionary saving motive plays an important role in households' wealth accumulation. Uncertainty about future income and expenditure causes households to engage in buffer-stock saving behavior by reducing their current consumption. Precautionary saving can be seen as a hedge against households' background risks, which include but are not limited to labor income risk, unexpected health expenditure risk, longevity risk, and business risk. Studies on portfolio choices have documented that households with higher uninsured background risks will reduce their financial risk taking. Since precautionary saving can be used to insure against households' background risks, households are more likely to hold risky assets if their precautionary savings are sufficient to cover background risks. By contrast, if households' precautionary savings are not sufficient to protect them from uninsured background risks, they will hold more safe assets and reduce risk-taking behaviors. Therefore, the adequacy of precautionary saving is an important determinant of household financial risk-taking behavior. This paper contributes to the existing literature by quantitatively measuring the adequacy of households' precautionary saving and examining its impact on risky asset investment decisions.

Using a variable of reported desired level of emergency funds and the actual households' asset holding data from the Survey of Consumer Finance, I compute a precautionary index that 
captures the adequacy of households' precautionary saving and examine its effect on the households' stock market participation and asset allocation decisions. As documented in previous studies (Calvet and Sodini, 2014; Wachter and Yogo, 2010; Haliassos and Jappelli, 2003; Berkowitz and Qiu, 2006), wealthy households are more likely to participate in the stock market and to hold more risky assets than non-wealthy households. The elasticity of the share of risky assets with respect to financial wealth is large and significant. However, other studies (Cocco et al. 2005) find that non-participation exists even among wealthy households. Higher wealth alone cannot fully account for households' ability to manage background risks. The amounts desired in emergency funds reflect how much households need in case of an emergency, which can be interpreted as the amount of funds required for reducing background risk. The ratio of a household's actual assets to the amount of emergency funds desired, which combines information relating to both budgets and needs, can be a more effective measurement of households' ability to manage background risk and can better predict their risk-taking behaviors.

Households with higher background risks desire a higher amount of precautionary savings than households with lower background risks. For two households with similar levels of assets, the household which desires a higher amount of precautionary savings has a lower precautionary index. Its assets might not be sufficient to cover its emergency needs as compared to those of the household which desires a lower level of precautionary saving. A higher precautionary index value indicates that the households' available assets are high compared to their emergency needs, which can increase their abilities to manage background risk and can affect their risk-taking behavior.

To test this empirically, I use a logit model to estimate the precautionary index's impact on households' stock market participation decisions, and I use a linear probability model to estimate the risky asset share equation. The analysis yields the following findings. First, the effects of the 
precautionary index on the probability of participating in the stock market and on the share of risky assets held among the financial assets are both positive and statistically significant. A one percent increase in the precautionary index, which can be due to a decrease in the desired amount of emergency funds, will increase the predicted probability of holding equity by 0.0377 percentage points and will increase the risky asset share by 0.023 percentage points. These results are consistent with the previous results found in the limited participation and background risk literature (Haliassos and Jappelli, 2003; Calvet and Sodini, 2014; Guiso et al., 1996; Palia et al., 2014).

Second, many households hold equity both in their retirement accounts, such as $401(\mathrm{k})$, IRA, and Keogh Accounts, and outside these accounts, and I find the effect of the precautionary index on risky asset share in these two types of accounts is different in magnitude. Retirement accounts typically have a longer investment horizon and stricter withdrawal policies, so households are less likely to withdraw funds from these accounts when emergency funds are needed. The precautionary index's impact on risky asset share should be smaller for directly held stocks. The estimation results confirm this prediction. The last major finding of this paper is that the impact of the precautionary index is greater on the risky asset share for households who are retired or risk-averse and less for households which have actively managed businesses.

This Chapter will proceed as follows: Section 2.2 introduces the relevant literature. Section 2.3 provides empirical evidence for the relationship between households' investment behaviors and their wealth level. Section 2.4 presents a life cycle model that explicitly accounts for the emergency consumption by households. Section 2.5 develops hypothesis tests and provides estimation results regarding the precautionary index. Section 2.6 discusses the effects of the precautionary index in different subsamples. Section 2.7 concludes this Chapter. 


\subsection{Literature Review}

\subsubsection{Precautionary saving behavior}

The life cycle/permanent income hypothesis, first proposed by Friedman (1957) and Modigliani and Brumberg (1954), suggests that a household's current consumption should be affected not by current income but by expected lifetime income. The model implies that households save primarily for retirement in order to smooth consumption when their income after retirement drops. However, research on consumption behavior shows that the predictions from the permanent income hypothesis are not consistent with observed consumption behavior. Carroll (1992, 1994, and 1997) find current consumption is unrelated to predictable changes in income, but is strongly related to future unemployment expectation, and more generally, to future income uncertainty. Households reduce consumption and hold more assets to protect themselves from unpredictable future fluctuations in income. Deaton (1991) also shows that in the presence of borrowing constraints, the precautionary demand for saving provides a motive for a household to hold assets.

Subsequent empirical research has tried to quantify household risk and measure its impact on households' precautionary wealth accumulation. Carroll and Samwick (1998) find that about 40 percent of wealth accumulated can be attributed to a precautionary saving motive induced by income uncertainty. Lusardi (1998) finds that saving and wealth accumulation are associated with variance of income. Guariglia (2001) finds that labor income risk has a statistically significant effect on households' saving decisions. Cagetti (2003) finds that wealth accumulation is driven mostly by precautionary motives at the beginning of the life cycle, whereas savings for retirement purposes become significant only closer to retirement. 
Though empirical evidence shows some support for precautionary wealth accumulation, the analysis has its drawbacks. As pointed out by Hurst et al. (2005), households with high income uncertainty, such as business owners, will hold a large amount of wealth for non- precautionary reasons. Simply regressing wealth on risky labor income will lead to an overestimation of the importance of the precautionary motive in the wealth accumulation process. The availability of a direct measure of precautionary wealth in household surveys provides a better estimation of the precautionary motive in wealth accumulation; however, the results are mixed. Jappelli (2008) uses a precautionary wealth variable from Italian household survey data to test the precautionary saving/buffer stock model and finds no support for buffer stock behavior. For U.S. households, Kennickell and Lusardi (2004) use the desirable amount of emergency funds reported in the Survey of Consumer Finance as a proxy for precautionary saving and find that precautionary wealth exists but that it is not as large as previously estimated. They find that precautionary wealth accounts for only $8 \%$ of the total wealth holdings. They also find that precautionary saving is more important to older households and business owners.

\subsubsection{Background risk and portfolio choice}

In a perfect market environment, if income or background risk is perfectly insurable, investment behavior should not be affected by background risks. However, imperfection in the financial market and uninsured background risk induce risk-averse households to reduce their risky asset holdings when background risk exists. One of the biggest motives behind precautionary saving is to insure against unexpected income risk, which is an important background risk households face. Previous research has examined how labor income risk can affect portfolio choice. With Italian household data, Guiso et al. (1996) find uninsured labor income risk, as measured by 
the subjective expected labor income variance over the next 12 months, has a small but statistically significant negative effect on the share of risky assets held by households. Hochguertel (2003) finds subjective income uncertainty has an effect on risky asset holding; however, the effect is economically small and not as important as the level of financial asset holdings, age, education, and tax incentive.

In additional to the labor income risk, background risks can include health and longevity risk as well as unexpected change in housing expenditure or business risk, and studies find that the presence of these background risks can also affect households' asset allocation decisions. Fratantoni (1998) finds households with higher housing expenditure relative to labor income hold a lower share of risky assets among their financial wealth. Heaton (2000) finds that risky human capital is an important determinant of stock market participation and asset allocation decisions at different stages of an investor's life. Palia et al. (2014) find households' background risks, as measured by volatilities of labor income and its correlation with stock returns, housing risk, and business income, are statistically significant and economically important for households' stock market participation decisions and stock holdings.

\subsubsection{Limited participation in the stock market}

Merton (1971) and Samuelson (1969) indicate that the optimal holding of risky assets should depend only on an individual's risk aversion, risk premium, and stock volatility in a perfect market. However, it is a well-documented fact that a large number of households do not hold stocks at all. Many studies have attempted to explain these non-participation phenomena. The major thesis of the limited participation literature is that households face higher costs of participating in the stock market. Haliassos (1995) show that liquidity, information cost, and risk embedded human 
capital are the major determinants of the decision not to participate. Zhan (2015) finds credit constraints, occupation-linked income risk, and entrepreneurial risks, but not housing, are major factors reducing stock market participation in the Euro area.

Information cost can also affect the decision to participate in the stock market. Households with lower education and cognitive skills have higher costs in obtaining information necessary for stock market investment. Rooij et al. (2011) find that those with low financial literacy are much less likely to invest in stocks. Christelis et al. (2010) find that the propensity to invest in stocks is strongly correlated with cognitive abilities. Brown et al. (2008) find that social interaction matters in stock market participation decisions. In particular, the community stock participation rate has a causal effect on an individual household's decision to own stocks.

Studies also show personality traits and one's psychological profile can affect one's propensity to own stock. Guiso and Zingales (2008) find that lack of trust is an important factor in explaining limited stock market participation. Less trusting individuals are less likely to buy stocks as they feel a greater risk of being cheated. Dimmock and Kouwenberg (2010) find that higher loss aversion lowers stock market participation, along with the share of risky assets owned. Gyllenram and Hanes (2014) find that individuals who can better cope with stressful situations are more likely to own stocks. This effect is even more pronounced among the wealthiest households.

\subsection{Evidence on Households' Investment Behaviors}

The traditional life cycle models imply that the portfolio share in risky assets should decrease when normalized wealth level rises (Cocco et.al.,2005); households with lower normalized wealth levels should invest more in stocks. However, empirical data show that stock

holding rises with wealth. In this section, I present findings that show both stock participation and 
portfolio shares invested in risky assets are significantly lower when normalized wealth is below certain cutoff points. All household data are obtained from the Survey of Consumer Finance.

\subsubsection{General overview of the Survey of Consumer Finance (SCF)}

The SCF is triennial cross-sectional survey data published by the Federal Reserve. The survey provides detailed information on household finance, including households' asset holdings, credit and debts, income, and wealth, as well as a set of characteristic and preference questions. The SCF contains two important subsamples. The first sample uses a random statistical area probability model to choose households across the country, and it represents the characteristics of the general population in the United States when weighted. The second subsample focuses on the wealthy households; in this subsample, the SCF uses households' IRS filing information to select households in the top decile of the wealth distribution. The dual-frame sample design provides a comprehensive picture of U.S. households' balance sheets, as well as those of households in the top wealth distribution, whose financial situation may be different from that of the general public.

Since the SCF collects sensitive financial data which some households are reluctant to provide and information is consequently missing for some questions, the Federal Reserve developed a set of imputation techniques to correct for the missing data by imputing the missing values five times. Following Calati et al. (2008) and Lee and Carlin (2010), I use the average of all five imputations as an observation value. The survey unit in the SCF is the household, and all financial data are collected on a household basis. The survey respondent is determined to be the person "most knowledgeable about family finances" and is usually the head of the household. 


\section{[Insert Table 2-1 here]}

Table 2-1 presents a summary of the statistics for key variables in the SCF. All variables are weighted using the weight provided by the Federal Reserve. Liquid assets include assets in checking accounts, saving accounts, and money market funds. Financial assets include all liquid assets, CDs, stocks, assets in retirement accounts, saving bonds, cash values of whole life insurance policies, and other managed accounts (trusts, annuities, and managed investment accounts in which $\mathrm{HH}$ has an equity interest). Equity includes directly held stocks, stock mutual funds, and stocks in combination mutual funds. Distributions of the financial variables are skewed to the right; mean values of income, equity, assets, and net worth are substantially higher than the median values. Table 2-1 also provides summary statistics for a subjective measure of households' risk-taking attitudes regarding investment.

\subsubsection{Normalized wealth and investment behavior}

As shown in Wachter and Yogo (2010), the portfolio share of risky assets rises as net worth increases for middle-age households. They use the log of wealth as a measure of the wealth effect, which is not directly related to the normalized wealth concept typically used in the life-cycle model. In this section, I provide further evidence showing that a lower level of normalized wealth not only reduces a household's risky asset share but also decreases the probability of a household's participation in the stock market. I calculate the normalized wealth level by dividing the household's total financial wealth by the household's income. Ideally, I should use the household's permanent income as the denominator to calculate the normalized wealth, yet permanent income 
is not an observable variable, so I use the household's actual income ${ }^{1}$ as a proxy. I create two dummy variables to indicate that the household's normalized wealth is below 1 and 2, respectively.

[Insert Table 2-3 to Table 2-6 here]

As shown in the second and third column of Table 2-3, the coefficients on the normalized wealth dummy variables are significantly negative. After controlling for other demographic, income, and wealth variables, a household's probability of holding any stock will be reduced by 17.23 percentage points and 9.53 percentage points if the household's normalized wealth is below 1 and 2, respectively. Table 2-5 shows the effect of normalized wealth on portfolio share. A household's portfolio share in risky assets will be reduced by 14.17 percentage points if the household's normalized wealth is below 1 and will be reduced by 9.01 percentage points if the normalized wealth is below 2 .

Table 2-6 shows the normalized wealth regression results for subsamples of different normalized wealth levels. Model I restricts the sample to households whose normalized wealth is under 2 and for whom the coefficient on the normalized wealth variable is large and highly significant, indicating that when normalized wealth is low, risky asset share increases as normalized wealth rises. Model II restricts the sample to households whose normalized wealth is above 5 and for whom the coefficient on the normalized wealth variable is no longer significant. When normalized wealth is sufficiently high, the risky asset share does not rise when normalized wealth increases.

\footnotetext{
${ }^{1}$ The SCF asks if the household income is normal or typical of that year. A normal income is a better proxy for the permanent income.
} 


\subsubsection{The saving motive and investment behavior}

The traditional life-cycle model indicates that households save to smooth consumption over time, and they save during their working life and dis-save during their retirement stage, which implies that households should save primarily for retirement. However, as Carroll (1994, 1996, and 1997) and subsequent precautionary saving literature have found, households also engage in precautionary saving behavior. Different saving motives can influence households' investment behavior; this section provides evidence showing that households with different saving motives can have different investment behaviors.

\section{[Insert Table 2-7 here]}

The SCF surveys households' primary saving motives; Table 2-7 provides a description of households' major saving motives and the distribution of these motives. In the SCF sample, 35.5\% of the households report the primary reason for their saving is retirement, and $31.5 \%$ of the households save primarily for an emergency; i.e., they are precautionary savers.

[Insert Table 2-8 to Table 2-10 here]

The regression results show that households which save primarily for retirement have a $7.67 \%$ higher probability of participating in the stock market, and the part of their portfolio invested in risky assets is 6.13 percent higher than that of other households. On the other hand, precautionary savers, whose primary goal is saving for emergency needs, have a lower probability of participating in the stock market, and the part of their portfolio invested in risky assets is 2.78 percentage points lower than that of other households. These results suggest that the impact of precautionary saving on risky asset investment can be fundamentally different from that of long term saving behavior (i.e., saving for retirement), households perceive emergency needs as 
contingent expenditures that need to be made once they occur, and the existence of these emergency needs can change a household's investment behavior.

In the next section, I present a life cycle model that explicitly accounts for households' emergency needs and derive its implications for optimal portfolio choice. This model can better explain the empirical pattern observed in the data: stock market participation and risky asset share both rise with normalized wealth when the normalized wealth level is low.

\subsection{A Life Cycle Model Including Contingent Consumption}

\subsubsection{Preferences}

I model emergency needs as expenditure shock that can occur in each period and households' utility function depends both on current consumption and on this contingent expenditure shock. The model is similar to the habit model, where a household's utility depends on the difference between current consumption and a "habit," which can be seen as a general level of aggregate consumption or a subsistence level of consumption. In my model, households take their emergency needs into consideration, and they see emergency needs as a contingent expenditure, which can reduce consumption significantly if it occurs. This variable measures how much households need to spend if an emergency situation emerges; however, it does not affect a household's intertemporal budget constraints because households do not pay insurance premiums to reduce emergency risk in this model. The amount of the emergency fund is exogenous in this model, much like in the habit model, in which "habit formation is external." Emergency spending can also be seen as a type of expenditure shock which effectively reduces a household's 
consumption once it occurs. Taking this shock into consideration, household $i$ 's preference is characterized by a power utility function:

$$
U_{1}^{i}=E_{1} \sum_{t=1}^{T} \beta^{t-1}\left(\prod_{j=1}^{t-1} p_{j-1}\right) \frac{\left(C_{i t}-E_{i t}\right)^{1-\gamma}}{1-\gamma}
$$

where the household is assumed to a live maximum $T$ period. In each period, there is a possibility that the household will die. Let $p_{t}$ denote the probability that the household is alive at datet +1 , conditional on it being alive at date t. The household maximizes expected life utility with a constant relative risk aversion $\gamma$ and time preference parameter $\beta$. Values for these parameters will be discussed in Section 2.4.5.

\subsubsection{The labor income process}

Following previous literature (Carroll, 1997; Winter et al., 2012; Cocco et al., 2005), the labor income process can be modeled as comprising a deterministic component and two stochastic components, which can be specified as:

$$
y_{i t}=f\left(t, Z_{i t}\right)+u_{t}+e_{i t}
$$

where $y_{i t}$ is the log of labor income, $f\left(t, Z_{i t}\right)$ is a deterministic function, $Z_{i t}$ represents a vector of variables capturing information regarding individual characteristics, including demographics, education, and the number of years working. $u_{t}$ captures the permanent income shock, which is modeled as an $\mathrm{AR}(1)$ process, and the variance of the permanent income shock is $\sigma_{u}^{2} ; e_{i t}$ is the transitory shock, which is i.i.d and is distributed as $N\left(0, \sigma_{e}^{2}\right)$. 


\subsubsection{The financial market}

In each period, investors can invest in two assets in the financial market: a riskless and a risky asset. The riskless asset has a return $r_{f}$ for each period, and the risky asset is characterized by a mean risk premium of $\mu$ and an innovation component $\eta_{t+1}$ :

$$
\tilde{r}_{t}=r_{f}+\mu+\eta_{t+1}
$$

where $\eta_{t+1}$ is assumed to be independent and identically distributed (i.i.d) as $N\left(0, \sigma_{\eta}^{2}\right)$.

\subsubsection{Households' optimization problem}

After the household has made the consumption decision and the asset allocation decision, its financial wealth at the beginning of next period, $t+1$, will be:

$$
W_{i, t+1}=r_{i, t+1}^{p}\left(W_{i t}+Y_{i t}-C_{i t}\right)
$$

The return of the portfolio from time $t$ to time $t+1$ is given by:

$$
\tilde{r}_{i, t+1}^{p}=\alpha_{i t} \tilde{r}_{t+1}+\left(1-\alpha_{i t}\right) r_{f}
$$

where $\alpha_{i t}$ is the portfolio share invested in the risky assets and $1-\alpha_{i t}$ is the portfolio share invested in the risk-free assets. Assuming that the household faces borrowing constraints and cannot short sell the risk-free asset, $\alpha$ is restrained to be in the interval $[0,1]$. The household's optimization problem is to maximize the objective function (2-1) subject to the constraints (2-2) through (2-5). The state variables are $\left\{t, X_{t}, Y\right\}$, and the control (choice) variables are $\left\{C_{t}, \alpha_{t}\right\}$. For each period, the optimal rules of consumption and portfolio share are functions of the state variables $t, X_{t}$, and $Y$. The Bellman equation for a household's optimization problem is given by: 


$$
V_{i t}\left(X_{i t}\right)=\max _{C_{i t} \geq 0,0 \leq \alpha_{i t} \leq 1}\left[U\left(C_{i t}\right)+\beta p_{t} E_{t} V_{i, t+1}\left(X_{i, t+1}\right], \quad t \leq T\right.
$$

where $V_{i t}\left(X_{i t}\right)$ is the value function, denoting the maximized utility. Given $X_{i t}$, the next period total resource is:

$$
X_{i, t+1}=W_{i, t+1}+Y_{i, t+1}
$$

Substituting (2-4) and (2-5) into (2-7), $X_{i, t+1}$ can be expressed as:

$$
X_{i, t+1}=\left(X_{i t}-C_{i t}\right)\left(\alpha_{i t} r_{t+1}+\left(1-\alpha_{i t}\right) r_{f}\right)+Y_{i}
$$

\subsubsection{Parameters and model calibration}

Table 2-11 presents the parameter values of the model. Households retire at age 65 and have a maximum lifespan of 100 years. As shown in Cocco (2005), the deterministic part of the labor income process can be fitted to a third-degree polynomial, and the coefficients are estimated for different educational levels. I use their estimation coefficients for high school graduates as a benchmark case here. During their working life, the deterministic part of their labor income $f(t)$ is additively separable in $t$ and $Z_{i t}$, and can be specified as:

$$
f(t)=-2.1700+0.1682-0.00323 \times A g e^{2}+0.00002 \times A g e^{3}
$$

After retirement, the deterministic part of the labor income is replaced by a constant value, which is the household's last working year's income multiplied by a replacement ratio: 0.682 . Figure $2-$ 1 presents the graph of the age profile of the deterministic part of the labor income for both high school graduates and college graduates.

[Insert Figure 2-1 here]

The variance of the permanent and temporal labor income shock are also obtained from Cocco (2005). The mean value of the contingent consumption (emergency funds) to the permanent 
income ratio is estimated from the Survey of Consumer Finance. The mean value for the whole sample is 0.48 . Financial market parameters follow the standard benchmark values used in the literature.

\subsubsection{The model solution: optimal portfolio policy}

Using the parameter value discussed in Section 2.4.5, I solve the model numerically to obtain the optimal portfolio policy. This section presents these optimal rules under two different scenarios.

\subsubsection{Policy rules without considering emergency spending}

As discussed in the previous section, if we do not consider the effect of contingent consumption (i.e., $E=0$ ), the household's utility function will be $U_{t}^{i}=\frac{C_{i t}^{1-\gamma}}{1-\gamma}$. The optimal share invested in risky assets should be very high when the normalized wealth is low, as the present value of the riskless human capital is large compared to the wealth; therefore, the household should invest more in risky assets. This is the result implied by the life cycle model in Cocco et al. (2005). Figure 2-2 presents this case:

\section{[Insert Figure 2-2 here]}

Figure 2-2 shows that households should invest all their cash-at-hand in the risky assets when the normalized cash-at-hand is below 5, and this holds across all age groups. As normalized wealth increases, the optimal share invested in risky assets decreases. When the normalized wealth is high, the present value of the future human capital is smaller relative to the normalized wealth, and households should tilt their investment towards more riskless assets and reduce their risk exposure. This optimal portfolio policy, however, cannot explain some important empirical facts about households' behavior. In the SCF, the mean normalized wealth is 1.78 , and the mean risky 
asset share is 0.25 . The median normalized wealth is only 0.55 , and the median risky asset share is 0.10 . $75 \%$ of households have a normalized wealth ratio below 2 . The benchmark life cycle model fails to explain households' optimal behavior when normalized wealth is low, which is the case for most American households. In the next section, I present the optimal portfolio rule when the effect of contingent expenditure is considered.

\subsubsection{Policy rules considering emergency spending}

As discussed in Section 2.4.1, the presence of emergency spending can change a household's risk taking behavior. In this case, household utility depends on consumption as well as contingent consumption. Household utility is given by: $U=\frac{(C-E)_{i t}^{1-\gamma}}{1-\gamma}$.

[Insert Figure 2-3 and Figure 2-4 here]

Figure 2-3 presents the optimal portfolio rule when contingent consumption has been accounted for. This result is qualitatively similar to the one obtained from the "habit" model (Polkovnichenko, 2007). The optimal policy rules differ substantially from those in the benchmark case. The optimal risky asset share starts very low when normalized wealth is low and increases as normalized wealth increases. Since most households have a normalized wealth ratio below 2 , it is useful to further examine the optimal portfolio share when normalized wealth level is low. Figure 2-4 shows a more detailed portrait for households at different ages when normalized wealth is below 5. This model better captures the dynamics of stock investment, especially when normalized financial wealth is below 1.8, where that of half of the American households falls. The model implies that the mean optimal portfolio share is about 0.1 , closer to the actual mean portfolio share of 0.17 found in the SCF, when normalized wealth is below 1 . In the next section, I construct a precautionary index 
that measures households' ability to meet expenditure shock and quantify the effect of this index on households' risk-taking behaviors.

\subsection{The Precautionary Index: Hypothesis Testing and Estimation}

\subsubsection{Construction of the precautionary saving index}

From 1995 onwards, the SCF has asked a question about how much households will need in precautionary savings for emergencies. The question is stated as follows:

"About how much do you think you and your family need to have in savings for unanticipated emergencies and other unexpected things that may come up?"

Kennickell and Lusardi (2004) provides a comprehensive review for this variable. They argue that this variable captures the amount of precautionary wealth households wish to have.

[Insert Table 2-12 here]

Table 2-12 provides summary statistics of the desirable precautionary wealth for the whole sample and for subsamples. The mean value of the precautionary wealth is $\$ 25,511$, and the median value is $\$ 5,762$. Panel A shows the precautionary wealth by different net worth levels. Households with higher net worth demand a higher level of precautionary wealth in case of emergency as expenditure can be proportional to the household's wealth level. The median desirable precautionary wealth for households with above median wealth is $\$ 11,330$, three times higher than that for households whose wealth is below the median. Panel B shows that retired households have a higher need for precautionary wealth than non-retired households. The median value for retired households is $\$ 10,000$, whereas the median value for non-retired households is $\$ 5,665$. 
To measure households' ability to meet their emergency needs, I construct an index incorporating information from both the desirable level of emergency funds and households' available assets. Following Kennichell (2004), I calculate the household's available liquidity as a weighted sum of its total assets minus six months' debt payments. The weight of each class of assets is assigned to reflect the liquidity nature of the assets. Liquid assets, which include cash, checking accounts, saving accounts, and money market mutual funds, have a weight of 1 ; stock in non-retirement accounts has a weight of 0.8. Assets in retirement accounts have a weight of 0.3 , and non-financial assets have a weight of 0.5 . In practice, households can also borrow against their home equity or engage in other types of loans to manage their liquidity. However, I do not explicitly include these considerations in the available resources calculation. ${ }^{2}$

I compute the precautionary index by dividing the total available resources by the desirable amount of emergency funds. This index measures the extent to which households are able to cover the need for emergency funds using their available assets. A higher precautionary index indicates that a household's assets are abundant relative to the amount needed in an emergency situation, which can make the household more risk tolerant. A ratio equal to one indicates that a household needs to use all its liquidity resources to cover the expected emergency spending. A ratio above one indicates that the household's own assets are inadequate to cover the emergency needs. The inability to meet its precautionary needs can reduce a household's risk-taking capacity.

\footnotetext{
2 The value of the housing asset partially reflects the amount of home equity loan that households can borrow when facing emergency situations.
} 


\subsubsection{Market participation hypothesis and regression results}

In this section, I estimate how the precautionary index can affect households' stock market participation decisions using a logit model. The hypothesis is that a low precautionary index would reduce a household's probability of holding risky assets. As discussed in the previous section, holding other things constant, a low precautionary index indicates that a household's available assets are low compared to the desirable level of emergency funds. In this case, a household faces a relatively high risk of not being able to finance its needs using its assets when an emergency occurs. This can also be an indication of higher background risk, which can prevent households from holding equity in the stock market. The estimation equation can be stated as:

$$
\operatorname{logit}\left(\mathrm{E}\left[\text { hequity }_{i} \mid x_{1, i, \ldots, \ldots} x_{m, i}\right]\right)=\alpha_{0}+\alpha_{1} \text { precaution }_{i, t}+\sum_{j=1}^{n} \beta_{j} \text { controls }_{i, t}^{j}
$$

hequity is a dummy variable, which is equal to 1 if a household owns any equity and 0 otherwise. precaution is the precautionary saving index described in Section 2.5.1. controls is a set of control variables, including age, gender, education, race, marital status, number of children, employment status, income, and wealth. In the logistic regression, the dependent variable is the $\log$ of the odds ratio, which can be stated as follows:

$$
\log \frac{\hat{p}_{i}}{1-\hat{p}_{i}}=\alpha_{0}+\alpha_{1} \text { precaution }_{i, t}+\sum_{j=1}^{n} \beta_{j} \text { controls }_{i, t}^{j}
$$

The odds ratio is the probability of holding equity, $\tilde{p}_{i}$, divided by the probability of not holding any equity $1-\tilde{p}_{i}$, In the logistic regression, the $\log$ of the odds ratio is a linear function of the explanatory variables.

[Insert Table 2-13 here] 
Table 2-13 presents the estimation results of equation (2-11). The precautionary index has a significantly positive effect on a household's stock market participation decisions. However, the precise quantitative impact of this index cannot be obtained directly from the estimated coefficient as the estimated coefficient in the logistic results measures how a one-unit change in the explanatory variables results in a change in the log of the odds ratio, not the probability of holding equity. To interpret the results meaningfully, we need to estimate the marginal effect of the precautionary index on the probability of holding equity. The marginal effect is calculated for each observation, measuring how the change in the precautionary index will change the probability of holding equity:

$$
\text { Marginal Effect of } \mathrm{x}_{p}=\lim _{\Delta \rightarrow 0} \frac{\operatorname{Pr}\left(Y=1 \mid \mathrm{X}, \mathrm{x}_{p}+\Delta\right)-\operatorname{Pr}\left(Y=1 \mid \mathrm{X}, \mathrm{x}_{p}\right)}{\Delta}
$$

where $\mathrm{X}$ is a vector of the control variables, evaluated at their original value for each observation. The marginal effect of $x_{p}$ is calculated by computing the difference between the predicted probability before and after a small change in $x_{p}$, and its value also depends on the value of the control variables. As the control variables are different for each observation, the marginal effect of $x_{p}$ is different for each observation, and I take the average of the marginal effects across all observations.

\section{[Insert Table 2-14 here]}

Table 2-14 reports the average marginal effect of the explanatory variables on stock market participation decisions. For the categorical variables, the marginal effect is taken to be the change in the predicted probability when the categorical variable changes from 0 to 1 . For example, the average marginal effect for Race is 0.0794 , indicating that for a white household (Race=1), the probability of holding equity will be 7.94 percentage points higher than it will for a non-white 
household on average. For continuous variables, the interpretation of the coefficient is the effect of a small change in the explanatory variable on the change of predicted probability of holding equity. Since the log value of the precautionary index is used in estimating equation (2-11), the marginal effect can be used to assess the impact of a one percent change in the precautionary ratio on the change of the predicted probability of holding equity.

The results show that a one percent increase in the precautionary ratio will increase the predicted probability of holding equity by 0.0377 percentage points. A change in the precautionary index can be caused by a change in the desirable amount of emergency funds and/or a change in the available assets. The change in the precautionary index is not bounded by $100 \%$, and its effect on the probability of holding equity can be quite substantial. Take a hypothetical scenario: for example, consider two households which have the same assets of $\$ 50,000$ but one of which has a desirable amount of precautionary wealth of $\$ 10,000$ and the other has a desirable amount of precautionary wealth of $\$ 20,000$. The first household's precautionary index is twice that of the second. Taking the average marginal effect as an approximation, the lower precautionary index of the second household will decrease the probability of holding equity by 3.77 percentage points compared to the first household.

\subsubsection{Portfolio shares in risky assets}

In this section, I estimate how the precautionary index affects the portfolio share invested in risky assets. The estimation equation can be stated as:

$$
\text { share }_{i, t}=\alpha_{0}+\alpha_{1} \text { precaution }_{i, t}+\sum_{j=1}^{n} \beta_{j} \text { controls }_{i, t}^{j}+\varepsilon_{i, t}
$$


where share measures the ratio of a household's equity to its financial assets. For a robustness check, I also examine different measures of the portfolio share. I use a linear probability model to estimate equation (2-13).

\section{[Insert Table 2-15 here]}

Table 2-15 presents the regression results of the impact of the precautionary index on share of the portfolio in risky assets. For the linear probability model, we can directly interpret the effect from the estimated coefficient of the regression results. The estimated coefficient of the precautionary index is positive and statistically significant. Taking the previously discussed hypothetical scenario, consider two households which have the same assets of $\$ 50,000$ but one of which has a desirable amount of precautionary wealth of $\$ 10,000$ and the other has a desirable amount of precautionary wealth of $\$ 20,000$. The first household's precautionary index is twice that of the second. Based on the estimation results shown in Table 2-15, the second household's risky asset share would be 2.27 percentage points lower than that of the first.

Other variables, race, gender, education, marital status, unemployment status, income, and wealth, are also statistically significant and have the expected signs. Age has a non-linear effect on risky asset holdings as households typically hold a higher percentage of equity during their middle age than during either their young age or their old age. The number of children does not appear to have a significant impact on the portfolio share of risky assets.

Using only the desirable amount of precautionary wealth, Telyukova (2013) finds there is a positive relationship between desirable precautionary wealth and investment share in risky assets. He argues that a causality relationship exists between holding risky assets and the amount of desirable precautionary wealth. The risk entailed by holding stock enables households to hold more precautionary wealth as the risk in the overall household portfolio increases. By contrast, 
households which hold only safe assets will significantly reduce the desirable level of precautionary wealth. In other words, the stronger demand for precautionary wealth reflects a higher level of risk incurred from investing in stocks. In his analysis, the desirable amount of precautionary wealth is endogenously determined by an exogenous level of risky asset holdings. However, the precautionary index, which is the ratio of total weighted assets to the desirable amount of emergency funds, can serve as a proxy for measuring the risk-bearing ability of the household, and the risk can include income risk as well as other background risks. The higher the value of the precautionary index, the better households can handle emergency risk, which can induce them to hold more equities. In other words, the share invested in risky assets is endogenously chosen to be commensurate with their ability to handle risk.

\subsection{Discussion}

\subsubsection{Retirement accounts vs. non-retirement accounts}

As argued in Carroll (1997, 1998), precautionary saving is an important reason for households to save, while saving for retirement does not seem to be a priority, especially for young households. In the $1983 \mathrm{SCF}$, only $15 \%$ of the respondents said they were saving for retirement. However, as defined contribution plans become the major source of retirement funds and with the gradual phase-out of defined benefit plans, households have to save for their own retirement income by investing in bonds and stocks. In recent waves of the SCF, the percentage of households' saving for retirement has increased: as shown in Table 2-7,35\% of all respondents indicate that they are saving mainly for retirement. Despite the increase in retirement saving, saving for precautionary purposes is also prevalent: $32 \%$ of all respondents in the SCF said they were saving 
mainly for emergency and precautionary purposes. If households have equity invested both in their retirement accounts and outside their retirement accounts (in non-retirement accounts), the effect of the precautionary index on investments in these two types of accounts may be different. The hypothesis is that the precautionary ratio would have a smaller effect on investment behavior with regard to the retirement accounts as the investment horizon for retirement saving is usually longer than it is for precautionary saving. Emergency needs often occur in the short run and demand more liquidity. The SCF provides detailed financial information on households' retirement accounts and non-retirement accounts, and I estimate equations (2-11) and (2-13) for both retirement accounts and non-retirement accounts. For non-retirement accounts, equation (2-11) can be estimated as

$$
\operatorname{logit}\left(\mathrm{E}\left[\text { hdeq }_{i} \mid x_{1, i, \ldots,} x_{m, i}\right]\right)=\alpha_{0}+\alpha_{1} \text { precaution }_{i, t}+\sum_{j=1}^{n} \beta_{j} \text { controls }_{i, t}^{j}
$$

for the market participation decision, where hdeq is a dummy variable indicating whether households hold any equity directly (i.e., outside their retirement accounts). For retirement accounts, the equation is:

$$
\left.\operatorname{logit}\left(\mathrm{E}_{\text {hreteq }_{i}} \mid x_{1, i, \ldots,} x_{m, i}\right]\right)=\alpha_{0}+\alpha_{1} \text { precaution }_{i, t}+\sum_{j=1}^{n} \beta_{j} \text { controls }_{i, t}^{j}
$$

where hequity is a dummy variable indicating whether households hold any equity in their retirement accounts, such as 401(k) plans, IRAs, Keogh accounts, etc. The logistic results (not shown here) indicate that the effects of the precautionary index on households' participation decisions do not differ much between retirement accounts and non-retirement accounts. However, the risky asset shares invested in these two types of accounts differ, so I will estimate (2-16) for these two types of accounts separately: 


$$
\text { share }_{i, t}=\alpha_{0}+\alpha_{1} \text { precaution }_{i, t}+\sum_{j=1}^{n} \beta_{j} \text { controls }_{i, t}^{j}+\varepsilon_{i, t}
$$

For retirement accounts, the share is calculated by dividing the equity held in the retirement account by the total retirement assets. For the non-retirement accounts, the share is calculated by dividing directly held equity by total financial assets excluding retirement assets.

[Insert Table 2-16 here]

Table 2-16 presents the estimation results using the linear probability model. Model I is for overall risky asset share. Model II and Model III show the results for non-retirement accounts and retirement accounts, respectively. A one-percent increase in the precautionary index will increase risky asset share in non-retirement accounts by 0.0176 percentage points and will increase the risky asset share in retirement accounts by 0.0109 percentage points. An increase in the precautionary index increases the risky asset share in both types of accounts; however, the impact is smaller for equity held in retirement accounts, and this is consistent with the hypothesis that the precautionary index should have a lower impact on long horizon investment behavior.

\subsubsection{Non-retired households vs. retired households}

As documented in Kennickell and Lusardi (2004), the desirable level of precautionary saving is important for two groups: older people and business owners. As shown in Table 2-12, the mean and the median desirable amounts of emergency funds are substantially higher for retired households. In this section, I investigate whether the precautionary index has different effects for households with different retirement status. The next section will look at the behavior of the business owners. 
[Insert Table 2-17 here]

Model I in Table 2-17 presents the results for the market participation decision regression with two additional variables: a dummy variable indicating the household head's retirement status and an interaction term between the retirement dummy and the precautionary ratio. Being retired lowers the probability of participating in the stock market, holding other variables constant. However, the coefficient of the interaction term is positive and significant, indicating that the effect of the precautionary index is larger for retired households. Similar results also hold for the risky asset share regression. The precautionary ratio has a larger impact on retired households' risky asset share. For non-retired households, a one-percent increase in the precautionary index will increase the risky asset share by 0.0213 percentage points, but for retired households, it will increase the risky asset share by an additional 0.0074 percentage points. For retired households, having more available resources can have an even more significant effect on their investment risktaking behavior. Further, not having enough resources to meet emergency needs can discourage retired households, more than non-retired households, from investing in risky assets.

\subsubsection{Business owners vs. non-business owners}

Also as pointed out in Kennickell and Lusardi (2004), business owners have a significantly higher desired level of precautionary saving. Heaton (2001) and Yilmazer and Scharff (2014) show that business owners are less likely to hold risky equity investment. In this subsection, I construct a dummy variable indicating a household's business ownership status and add an interaction term between the business ownership dummy variable and the precautionary index in the regression analysis. Following the SCF documentation and Kennickell and Lusardi (2004), business owners are households that own a business in which they have an active management interest. In the 1995- 
2010 SCF sample, $30.2 \%$, or 7,762 households, are identified as business owners. Households owning businesses have substantially higher median income, equity holding, and assets than nonbusiness owners. The median (weighted) equity holding for business owners is $\$ 20,000$, whereas for non-business households, the median is $\$ 919$. As business owners have higher net worth and can face higher background risk, the desirable level of precautionary wealth is also higher. For business owners, the median value is $\$ 12,254$, but for non-business owners, the median value is $\$ 5,753$.

Model II of Table 2-19 presents the estimation results by explicitly controlling for business ownership. We see that having a business increases the probability of participating in the stock market and investing in risky assets; however, having a business reduces the effects of the precautionary index on risk-taking behavior. The coefficient for the interaction term is negative and significant. For households having a business, a higher precautionary index still increases the risky asset share. However, the increase is 0.016 percentage points smaller as compared to households that do not have a business. As shown by the analysis regarding retirement status, having insufficient funds to meet emergency needs can be a major reason for retirees to be less likely to participate in the stock market, or to hold a lower share in risky assets if they do participate. For business owners, having sufficient funds to meet emergency needs is less important in determining their investment risk-taking behavior. There can be factors that affect business owners other than precautionary motives.

\subsubsection{Control for risk preference}

As Kimball (1990) points out, the precautionary saving motive is closely related to the Arrow-Pratt theory of risk aversion. It may be the case that households that are more risk averse 
wish to hold more emergency funds than others when facing similar emergency situations. We cannot rule out the possibility that a higher precautionary index is the result of a more risk-averse preference. To address whether the precautionary index contains more information than just risk preference, I add a household risk taking preference variable as an additional control variable in the regression analysis, and it does not greatly change the previous results, which suggests that the precautionary ratio itself, independent of risk preference, is important in determining households' risk taking decisions. Moreover, in Model III of Table 2-19, an interaction term between the risk averse dummy variable and the precautionary index is added to the regression analysis, and it has a positive and marginally significant effect. For households who are relatively more risk averse, a $1 \%$ increase in the precautionary index will increase their risky asset share by an additional 0.0037 percentage points as compared to households that are less risk averse.

\subsubsection{The effect of low normalized wealth}

[Insert Table 2-20 to Table 2-22 here]

As the empirical evidence in Section 2.3.2 and the optimal policy rule derived in Section 2.4.6 show, households having a low normalized wealth level are less likely to participate in the stock market, and their risky asset share is lower when they do participate. Households' ability to meet emergency consumption spending needs can be lower when their normalized wealth level is low, which reduces their investment risk-taking behavior. Other things being equal, a higher precautionary index can be particularly valuable for households whose normalized wealth level is low. In this section, I examine whether the precautionary index has a larger impact for households whose normalized wealth is relatively low. The mean normalized wealth ratio from the SCF is 1.8 . I construct a dummy variable that is equal to 1 if the household's normalized wealth is below 2 
and equal to 0 otherwise. I also add an interaction term between the normalized wealth dummy variable and the precautionary ratio. Table 2-20 presents the results for the logit model. Table 2-22 presents the results for the risky asset share model.

Households whose normalized wealth is below 2 are $26.5 \%$ less likely to participate in the stock market, and the risky asset share of their portfolios is 16.8 percentage points lower than that of households whose normalized wealth is above 2 . However, the coefficients of the interaction term are positive and significant, indicating that for relatively low normalized wealth households, having a higher precautionary index can be more important in their investment behavior as compared to high wealth households. For low normalized wealth households, a one percent increase in the precautionary ratio increases the probability of stock market participation by an additional 0.01 percentage point and increases the risky asset share of their portfolios by an additional 0.009 percentage point.

\subsubsection{The impact of pension plans}

Households' saving and investment behavior can be affected if they have pension plans. Among the 25,647 households in the SCF 1995-2010 sample, 15,050 households had some pension plan, and 10,419 households reported no pension plan for either household head or spouse. It is interesting to observe whether the precautionary index has different effects for those who have a pension plan and those who do not have one. In addition, the type of the pension plan also differs

among households. Generally, households have a defined contribution pension plan, a defined benefit pension plan, or both. Households with a defined contribution plan have to take more responsibility for their own retirement savings, and the composition of the retirement account is 
entirely determined by the household's choice. It is of interest to observe whether the precautionary index has a different impact for households with different types of pension plans.

To investigate these two issues, I conduct two sets of tests. First, I divide the whole sample into two subsamples: those who have a pension plan and those who do not. The regression results show there are no significant differences in their stock market participation decisions or in the risky asset share of their portfolios. In the second set of the test, I obtain a subsample which consists of 6,379 households with only a defined contribution plan and no defined benefit plan. I also obtain another subsample of 4,988 households that have only a defined benefit pension plan and no defined contribution plan. Among households that have defined benefit plans, half $(2,453)$ still hold some additional retirement account, such as an IRA, Keogh, or thrift type account. I find no significant difference in the estimated effects of the precautionary index for households that have defined contribution plans versus those with defined benefit plans. The precautionary index reduces the risky asset share in both their non-retirement accounts and their retirement accounts, and the magnitude of reduction is similar for households regardless of their pension account type.

\subsection{Conclusion}

This paper incorporates desired emergency saving for future expenditure shock into the power utility function and derives the optimal portfolio choice given this type of preference. Unexpected future expenditure or emergency needs can have a significant impact on a household's risk taking behavior. Implications from the model better match the investment behavior observed in the empirical data. When the normalized wealth level is low, households' stock market participation probability and risky asset share of their portfolios both increase as normalized wealth increases. Traditional "habit" models produce qualitatively similar results. However, the "habit" 
models do not take emergency expenditure into consideration. The precautionary saving motive from these models arises purely from income shocks, not from expenditure shocks, which can be another major source of households' background risk. This paper explicitly models this risk into households' preferences.

After incorporating emergency expenditure into the habit model, this paper further constructs an index to measure how well households can manage emergency needs using their available assets. Better ability to meet unexpected expenditure or emergency needs can increase a household's risk holding capacity and induce them to hold more risky investments. This research potentially expands on analyses found in the current literature to analyze asset allocation decisions in a more "liability induced" environment, where households need to take a certain type of future expenditure into consideration. 


\section{Table 2-1: Descriptive statistics for key variables in the SCF}

This table provides summary statistics for key variables in the SCF from 1995 to 2010. Liquid assets include assets in checking accounts, saving accounts, and money market funds. Financial assets include all liquid assets, CDs, Stocks, assets in retirement accounts, saving bonds, cash values of whole life insurance accounts, and other managed accounts. Equity includes directly held stocks, stock mutual funds, and stocks in combination mutual funds. All dollar amounts are in 2010 dollar value. All values are weighted using the weight provided by the SCF.

\begin{tabular}{|c|c|c|c|c|c|}
\hline Variable & Definition & Mean & Median & Std. Dev. & $\mathrm{N}$ \\
\hline Age & In Years & 49.4 & 47 & 17.24 & 28464 \\
\hline Education & Number of years & 13.2 & 13 & 2.86 & 28464 \\
\hline Gender & $=1$ if male $;=0$ female & 0.72 & 1 & 0.44 & 28464 \\
\hline Married & $=1$ if married & 0.59 & 1 & 0.49 & 28464 \\
\hline Children & Number of Children & 0.82 & 0 & 1.15 & 28464 \\
\hline Race & $=1$ if white $;=0$ others & 0.73 & 1 & 0.44 & 28464 \\
\hline Unemployed & $=1$ if unemployed in past 12 months & 0.11 & 0 & 0.33 & 28464 \\
\hline Health Status & $\begin{array}{l}\text { Ordered Categorical Variable (1-4) } \\
\text { 1=Excellent; } 2=\text { Good; 3=Fair 4=Poor }\end{array}$ & 2.03 & 2 & 0.78 & 28464 \\
\hline Risk Aversion Index & $\begin{array}{l}\text { Ordered Categorical Variable (1-4) } \\
\text { 1=Least Risk Averse } \\
\text { 4=Most Risk Averse }\end{array}$ & 3.19 & 3 & 0.85 & 28464 \\
\hline Income & Total Household Income & 78,106 & 47,169 & 292,236 & 28464 \\
\hline Liquid Asset & Total Liquid Assets & 25,175 & 3,221 & 234,633 & 28464 \\
\hline Equity & Total Equity Holdings & 105,607 & 325 & 947,510 & 28464 \\
\hline Financial Asset & Total Financial Assets & 206,382 & 22,497 & $1,360,228$ & 28464 \\
\hline Total Asset & All Household Assets & 546,386 & 173,714 & $2,821,554$ & 28464 \\
\hline Net Worth & Total Household Wealth & 466,671 & 98,511 & $2,763,062$ & 28464 \\
\hline
\end{tabular}




\section{Table 2-2: Distribution of household normalized wealth level and risky asset share}

This table presents the distribution of households' normalized wealth level and the risky asset share. Normalized wealth is defined as the ratio of the total financial wealth to the household's income. Risky asset share is defined as the ratio of households' total equity to total financial assets. All data are obtained from the SCF 1995-2010 waves and in 2010 dollars. Values are weighted using the weight provided by the SCF.

\begin{tabular}{lccccc}
\hline & Mean & P25 & Median & P75 & P90 \\
\hline Normalized Wealth Level & 1.78 & 0.10 & 0.55 & 1.90 & 4.83 \\
Risky Asset Share & & & & \\
\hline All sample & 0.25 & 0 & 0.10 & 0.48 & 0.77 \\
For Normalized Wealth >5 & 0.43 & 0.14 & 0.43 & 0.69 & 0.90 \\
& & & & & \\
For Normalized Wealth $<5$ & 0.21 & 0 & 0 & 0.38 & 0.70 \\
\end{tabular}




\section{Table 2-3: Normalized wealth regression (Logit model)}

This table presents the regression results for the normalized wealth regression. The dependent variable is a dummy variable, equal to 1 if household holds any equity, and zero otherwise. Normalized wealth is defined as the ratio of the total financial wealth to the household's income. NormD1 is a dummy variable indicating that the household's normalized wealth is below 1 and NormD2 is a dummy variable indicating that the household's normalized wealth is below 2 . The standard error is in parentheses. *, **, and *** indicate significance at the $10 \%, 5 \%$, and $1 \%$ levels of confidence, respectively.

\begin{tabular}{|c|c|c|c|}
\hline Variables & Model I & Model II & Model III \\
\hline Intercept & $\begin{array}{l}-11.77 * * * \\
(0.266)\end{array}$ & $\begin{array}{l}-10.045 * * * \\
(0.2727)\end{array}$ & $\begin{array}{l}-11.041 * * * \\
(0.2755)\end{array}$ \\
\hline Normalized Wealth & $\begin{array}{l}0.2744 * * * \\
(0.0133)\end{array}$ & $\begin{array}{l}0.1313 * * * \\
(0.0100)\end{array}$ & $\begin{array}{l}0.1797 * * * \\
(0.0133)\end{array}$ \\
\hline NormD1 & & $\begin{array}{l}-1.2914 * * * \\
(0.0532)\end{array}$ & \\
\hline NormD2 & & & $\begin{array}{l}-0.6911 * * * \\
(0.0711)\end{array}$ \\
\hline Gender & $\begin{array}{l}-0.1688^{* * *} \\
(0.0592)\end{array}$ & $\begin{array}{l}-0.1443 * * \\
(0.0601)\end{array}$ & $\begin{array}{l}-0.1639 * * * \\
(0.593)\end{array}$ \\
\hline Age & $\begin{array}{l}0.0412 * * * \\
(0.0066)\end{array}$ & $\begin{array}{l}0.0354 * * * \\
(0.0066)\end{array}$ & $\begin{array}{l}0.0414 * * * \\
(0.0066)\end{array}$ \\
\hline $\mathrm{Age}^{2}$ & $\begin{array}{l}-0.0007 * * * \\
(0.0001)\end{array}$ & $\begin{array}{l}-0.0006 * * * \\
(0.0001)\end{array}$ & $\begin{array}{l}-0.0007 * * * \\
(0.0001)\end{array}$ \\
\hline Education & $\begin{array}{l}0.1332 * * * \\
(0.0077)\end{array}$ & $\begin{array}{l}0.1277 * * * \\
(0.0078)\end{array}$ & $\begin{array}{l}0.1333 * * * \\
(0.0077)\end{array}$ \\
\hline Race & $\begin{array}{l}0.364 * * * \\
(0.0421)\end{array}$ & $\begin{array}{l}0.3449 * * * \\
(0.0430)\end{array}$ & $\begin{array}{l}0.3597 * * * \\
(0.0421)\end{array}$ \\
\hline Married & $\begin{array}{l}0.177 * * * \\
(0.0542)\end{array}$ & $\begin{array}{l}0.2006 * * * \\
(0.0550)\end{array}$ & $\begin{array}{l}0.1802 * * * \\
(0.0542)\end{array}$ \\
\hline Kids & $\begin{array}{l}-0.0695 * * * \\
(0.0168)\end{array}$ & $\begin{array}{l}-0.0527 * * * \\
(0.0171)\end{array}$ & $\begin{array}{l}-0.0682 * * * \\
(0.0168)\end{array}$ \\
\hline Unemployed & $\begin{array}{l}-0.063 \\
(0.0578)\end{array}$ & $\begin{array}{l}-0.0388 \\
(0.0589)\end{array}$ & $\begin{array}{l}-0.0667 * * * \\
(0.0579)\end{array}$ \\
\hline Log(Income) & $\begin{array}{l}0.6789 * * * \\
(0.0283)\end{array}$ & $\begin{array}{l}0.724 * * * \\
(0.0283)\end{array}$ & $\begin{array}{l}0.6877 * * * \\
(0.0283)\end{array}$ \\
\hline Log(Net Worth) & $\begin{array}{l}0.1827 * * * \\
(0.0139)\end{array}$ & $\begin{array}{l}0.1021 * * * \\
(0.0140)\end{array}$ & $\begin{array}{l}0.1708 * * * \\
(0.0138)\end{array}$ \\
\hline $\mathrm{N}$ & 20137 & 20137 & 20137 \\
\hline
\end{tabular}




\section{Table 2-4: Average Marginal Effect for the normalized wealth regression}

This table calculates the average marginal effect from the results of the logistic regressions in Table 2-3. Normalized wealth is defined as the ratio of the total financial wealth to the household's income. NormD1 is a dummy variable indicating that the household's normalized wealth is below 1, and NormD2 is a dummy variable indicating that the household's normalized wealth is below 2 .

\begin{tabular}{lccc}
\hline Variables & Model I & Model II & Model III \\
\hline Normalized Wealth & 0.0381 & 0.0175 & 0.0248 \\
NormD1 & & -0.1723 & -0.0953 \\
NormD2 & & & -0.0226 \\
Gender & -0.0234 & -0.0193 & 0.0057 \\
Age & 0.0057 & 0.0047 & -0.0001 \\
Age ${ }^{2}$ & -0.0001 & -0.0001 & 0.0184 \\
Education & 0.0185 & 0.0170 & 0.0496 \\
Race & 0.0505 & 0.0460 & 0.0249 \\
Married & 0.0246 & 0.0268 & -0.0094 \\
Kids & -0.0096 & -0.0070 & -0.0092 \\
Unemployed & -0.0087 & -0.0052 & 0.0949 \\
Log(Income) & 0.0942 & 0.0966 & 20137 \\
Log(Net Worth) & 20137 & 0.0136 & \\
\hline $\mathrm{N}$ & & 20137 & \\
\hline
\end{tabular}


Table 2-5: Normalized wealth regression (risky share regression)

This table presents the results of the linear probability model for the normalized wealth regression. The dependent variable is the portfolio share invested in equity. Normalized wealth is defined as the ratio of the total financial wealth to the household's income. NormD1 is a dummy variable indicating that the household's normalized wealth is below 1 and NormD2 is a dummy variable indicating that the household's normalized wealth is below 2 . The standard error is in parentheses. *, **, and $* * *$ indicate significance at the $10 \%, 5 \%$, and $1 \%$ levels of confidence, respectively.

\begin{tabular}{|c|c|c|c|}
\hline Variables & Model I & Model II & Model III \\
\hline Intercept & $\begin{array}{l}-0.6659 * * * \\
(0.022)\end{array}$ & $\begin{array}{l}-0.4373 * * * \\
(0.0229)\end{array}$ & $\begin{array}{l}-0.5347 * * * \\
(0.0232)\end{array}$ \\
\hline Normalized Wealth & $\begin{array}{l}0.0106^{* * * *} \\
(0.0005)\end{array}$ & $\begin{array}{l}0.0061 * * * \\
(0.0005)\end{array}$ & $\begin{array}{l}0.0059 * * * \\
(0.0006)\end{array}$ \\
\hline NormD1 & & $\begin{array}{l}-0.1417 * * * \\
(0.0048)\end{array}$ & \\
\hline NormD2 & & & $\begin{array}{l}-0.0901 * * * \\
(0.0054)\end{array}$ \\
\hline Gender & $\begin{array}{l}0.0155^{* *} \\
(0.0066)\end{array}$ & $\begin{array}{l}0.0177 * * * \\
(0.0065)\end{array}$ & $\begin{array}{l}0.0163 * * \\
(0.0066)\end{array}$ \\
\hline Age & $\begin{array}{l}0.0061 * * * \\
(0.0007)\end{array}$ & $\begin{array}{l}0.0049 * * * \\
(0.0007)\end{array}$ & $\begin{array}{l}0.0058 * * * \\
(0.0007)\end{array}$ \\
\hline $\mathrm{Age}^{2}$ & $\begin{array}{l}-0.0001 * * * * \\
(0.0000)\end{array}$ & $\begin{array}{l}-0.0001 * * * \\
(0.0000)\end{array}$ & $\begin{array}{l}-0.0001 * * * \\
(0.0000)\end{array}$ \\
\hline Education & $\begin{array}{l}0.0191 * * * \\
(0.0008)\end{array}$ & $\begin{array}{l}0.0164 * * * \\
(0.0008)\end{array}$ & $\begin{array}{l}0.0181 * * * \\
(0.0008)\end{array}$ \\
\hline Race & $\begin{array}{l}0.0574 * * * \\
(0.0048)\end{array}$ & $\begin{array}{l}0.0501 * * * \\
(0.0048)\end{array}$ & $\begin{array}{l}0.0547 * * * \\
(0.0048)\end{array}$ \\
\hline Married & $\begin{array}{l}0.0068 \\
(0.0058)\end{array}$ & $\begin{array}{l}0.0065 \\
(0.0057)\end{array}$ & $\begin{array}{l}0.0069 \\
(0.0058)\end{array}$ \\
\hline Kids & $\begin{array}{l}-0.0017 \\
(0.0018)^{* * *}\end{array}$ & $\begin{array}{l}-0.0005 \\
(0.0017)\end{array}$ & $\begin{array}{l}-0.0012 \\
(0.0017)\end{array}$ \\
\hline Unemployed & $\begin{array}{l}-0.0334 \\
(0.0067)\end{array}$ & $\begin{array}{l}-0.0283 * * * \\
(0.0066)\end{array}$ & $\begin{array}{l}-0.0331 * * * \\
(0.0067)\end{array}$ \\
\hline $\log ($ Income $)$ & $\begin{array}{l}0.027 * * * \\
(0.0021)\end{array}$ & $\begin{array}{l}0.0355^{* * *} \\
(0.0021)\end{array}$ & $\begin{array}{l}0.0301 * * * \\
(0.0021)\end{array}$ \\
\hline Log(Net Worth) & $\begin{array}{l}0.0181 * * * \\
(0.0014)\end{array}$ & $\begin{array}{l}0.0051 * * * \\
(0.0014)\end{array}$ & $\begin{array}{l}0.0129 * * * \\
(0.0014)\end{array}$ \\
\hline $\mathrm{R}^{2}$ & 0.2472 & 0.2734 & 0.2558 \\
\hline $\mathrm{N}$ & 23702 & 23702 & 23702 \\
\hline
\end{tabular}


Table 2-6: Risky asset share regression for different levels of normalized wealth

This table presents the results of the linear probability model for the normalized wealth regression. The dependent variable is the portfolio share invested in equity. Normalized wealth is defined as the ratio of the total financial wealth to the household's income. Model I is estimated based on the subsample where the household's normalized wealth is below 2, and Model II is estimated based on the subsample where household's normalized wealth is above 5. The standard error is in parentheses. *, **, and *** indicate significance at the $10 \%, 5 \%$, and $1 \%$ levels of confidence, respectively.

\begin{tabular}{lll}
\hline Variables & Model I & Model II \\
\hline Intercept & $0.1087^{* * *}$ & 0.0636 \\
Normalized Wealth & $(0.0361)$ & $(0.0084)$ \\
& $0.0634^{* * *}$ & -0.00002 \\
Gender & $(0.0057)$ & $(0.00003)$ \\
& $0.0435^{* *}$ & $0.0289^{*}$ \\
Age & $(0.0112)$ & $(0.0177)$ \\
& $0.0067^{* * *}$ & 0.0040 \\
Age & $(0.0007)$ & $(0.0025)$ \\
& $-0.0001 * * *$ & -0.0001 \\
Education & $(0.0000)$ & $(0.0000)$ \\
& $0.0009^{* * *}$ & $0.0188^{* * *}$ \\
Race & $(0.0013)$ & $(0.0023)$ \\
& $0.0369^{* * *}$ & $0.0733^{* * *}$ \\
Married & $(0.0075)$ & $(0.0191)$ \\
& -0.0344 & -0.0090 \\
Kids & $(0.0058)$ & $(0.0144)$ \\
& 0.0022 & 0.0052 \\
$\mathrm{R}^{2}$ & $(0.0018)^{* * *}$ & $(0.0054)$ \\
$\mathrm{N}$ & 0.0362 & 0.0264 \\
\hline
\end{tabular}




\section{Table 2-7: Saving motives in the SCF}

This table presents the distribution of different saving motives reported in the SCF 1995-2010 waves.

\begin{tabular}{lc}
\hline Saving Motives & Percentages in all samples \\
\hline For emergence, precautionary & $31.5 \%$ \\
For retirement & $35.5 \%$ \\
For education & $10.0 \%$ \\
& \\
For buying a house & $3.3 \%$ \\
For future expenditure on house improvement, vehicle, durable & $8.1 \%$ \\
goods, vacations & \\
Other saving motive & $8.6 \%$ \\
Don't/can't save & $3.1 \%$ \\
\hline
\end{tabular}


Table 2-8: Saving motive regression (Logit model)

This table presents the regression results for the saving motive regression. The dependent variable is a dummy variable, equal to 1 if the household holds any equity, and zero otherwise. Save1 is equal to 1 if the household is saving for precautionary purpose; Save 2 is equal to 1 if the household is saving for retirement purposes; Save 3 is equal to 1 if the household is saving for purchasing housing/durable goods and vacation purposes; Save4 is equal to 1 if the household is saving for other purposes. The standard error is in parentheses. *, **, and *** indicate significance at the $10 \%, 5 \%$, and $1 \%$ levels of confidence, respectively.

\begin{tabular}{|c|c|c|c|c|}
\hline Variables & Model I & Model II & Model III & Model IV \\
\hline Save1 & $\begin{array}{l}-0.2008 * * * \\
(0.0363)\end{array}$ & & & \\
\hline Save2 & & $\begin{array}{l}0.5409^{* * *} \\
(0.0383)\end{array}$ & & \\
\hline Save3 & & & $\begin{array}{l}-0.1343 * * * \\
(0.0516)\end{array}$ & \\
\hline Save4 & & & & $\begin{array}{l}-0.0501 \\
(0.0603)\end{array}$ \\
\hline Gender & $\begin{array}{l}-0.1935 * * * \\
(0.0572)\end{array}$ & $\begin{array}{l}-0.1861 * * * \\
(0.0575)\end{array}$ & $\begin{array}{l}-0.1880^{* *} \\
(0.0572)\end{array}$ & $\begin{array}{l}-0.1899 \\
(0.0572)\end{array}$ \\
\hline Age & $\begin{array}{l}0.0051 * * * \\
(0.0063)\end{array}$ & $\begin{array}{l}-0.0112 * \\
(0.0064)\end{array}$ & $\begin{array}{l}0.0051^{*} \\
(0.0063)\end{array}$ & $\begin{array}{l}0.0062 \\
(0.0063)\end{array}$ \\
\hline $\mathrm{Age}^{2}$ & $\begin{array}{l}-0.0002 * * * \\
(0.0001)\end{array}$ & $\begin{array}{l}-0.0001 \\
(0.0001)\end{array}$ & $\begin{array}{l}-0.0002 \\
(0.0001)\end{array}$ & $\begin{array}{l}-0.0003 \\
(0.0001)\end{array}$ \\
\hline Education & $\begin{array}{l}0.1537 * * * \\
(0.0074)\end{array}$ & $\begin{array}{l}0.1534 * * * \\
(0.0074)\end{array}$ & $\begin{array}{l}0.1539 * * * \\
(0.0074)\end{array}$ & $\begin{array}{l}0.1542 \\
(0.0074)\end{array}$ \\
\hline Race & $\begin{array}{l}0.3890^{* * * *} \\
(0.0418)\end{array}$ & $\begin{array}{l}0.3618 \text { *** } \\
(0.0421)\end{array}$ & $\begin{array}{l}0.4008 * * * \\
(0.0418)\end{array}$ & $\begin{array}{l}0.3996 \\
(0.0418)\end{array}$ \\
\hline Married & $\begin{array}{l}0.1190 * * * \\
(0.0525)\end{array}$ & $\begin{array}{l}0.1051 * * \\
(0.0528)\end{array}$ & $\begin{array}{l}0.124 * \\
(0.0525)\end{array}$ & $\begin{array}{l}0.1242 \\
(0.0525)\end{array}$ \\
\hline Kids & $\begin{array}{l}-0.0822 * * * \\
(0.0168)\end{array}$ & $\begin{array}{l}-0.0547 * * * \\
(0.0169)\end{array}$ & $\begin{array}{l}-0.0827 * * \\
(0.0168)\end{array}$ & $\begin{array}{l}-0.0772 \\
(0.0172)\end{array}$ \\
\hline Unemployed & $\begin{array}{l}-0.0678 \\
(0.0597)\end{array}$ & $\begin{array}{l}-0.065 \\
(0.0583)\end{array}$ & $\begin{array}{l}-0.068 \\
(0.0578)\end{array}$ & $\begin{array}{l}-0.0677 \\
(0.0578)\end{array}$ \\
\hline Log(Income) & $\begin{array}{l}0.5377 * * * \\
(0.0265)\end{array}$ & $\begin{array}{l}0.5178 * * * \\
(0.0264)\end{array}$ & $\begin{array}{l}0.5408^{* * *} \\
(0.265)\end{array}$ & $\begin{array}{l}0.5425 \\
(0.0265)\end{array}$ \\
\hline Log(Net Worth) & $\begin{array}{l}0.3772 * * * \\
(0.0128\end{array}$ & $\begin{array}{l}0.3711 \text { *** } \\
(0.0128)\end{array}$ & $\begin{array}{l}0.3737 * * * \\
(0.0128)\end{array}$ & $\begin{array}{l}0.3765 \\
(0.0127)\end{array}$ \\
\hline $\mathrm{N}$ & 24131 & 24131 & 24131 & 24131 \\
\hline
\end{tabular}


Table 2-9: Average marginal effect for the saving motive regression

This table calculates the average marginal effect from the results of the logistic regressions in Table 2-8. Save1 is equal to 1 if the household is saving for precautionary purposes; Save2 is equal to 1 if the household is saving for retirement purposes; Save3 is equal to 1 if the household is saving for housing/durable goods and vacation purposes; Save 4 is equal to 1 if the household is saving for other purposes.

\begin{tabular}{|c|c|c|c|c|}
\hline Variables & Model I & Model II & Model III & Model IV \\
\hline Save1 & -0.0288 & & & \\
\hline Save2 & & 0.0767 & & \\
\hline Save3 & & & -0.0193 & \\
\hline Save4 & & & & -0.0072 \\
\hline Gender & -0.0277 & -0.0263 & -0.027 & -0.0272 \\
\hline Age & 0.0007 & -0.0016 & 0.0007 & 0.0009 \\
\hline $\mathrm{Age}^{2}$ & 0.0000 & 0.0000 & 0.0000 & 0.0000 \\
\hline Education & 0.0220 & 0.0217 & 0.0221 & 0.0221 \\
\hline Race & 0.0557 & 0.0512 & 0.0575 & 0.0573 \\
\hline Married & 0.0170 & 0.0149 & 0.0178 & 0.0178 \\
\hline Kids & -0.0118 & -0.0077 & -0.0119 & -0.0111 \\
\hline Unemployed & -0.0097 & -0.0092 & -0.0097 & -0.0097 \\
\hline Log(Income) & 0.0770 & 0.0733 & 0.0776 & 0.0778 \\
\hline Log(Net Worth) & 0.0540 & 0.0526 & 0.0536 & 0.0540 \\
\hline $\mathrm{N}$ & 24131 & 24131 & 24131 & 24131 \\
\hline
\end{tabular}


Table 2-10: Saving motive regression (linear probability model)

This table presents the regression results for the saving motive regression. The dependent variable is the portfolio share invested in equity. Save1 is equal to 1 if the household is saving for precautionary purposes; Save2 is equal to 1 if the household is saving for retirement purposes; Save3 is equal to 1 if the household is saving for housing/durable goods and vacation purposes; Save4 is equal to 1 if the household is saving for other purposes. The standard error is in parentheses. *,**, and *** indicate significance at the $10 \%, 5 \%$, and $1 \%$ levels of confidence, respectively.

\begin{tabular}{|c|c|c|c|c|}
\hline Variables & Model I & Model II & Model III & Model IV \\
\hline Intercept & $\begin{array}{l}-0.6727 * * * \\
(0.0221)\end{array}$ & $\begin{array}{l}-0.6451 * * * \\
(0.022)\end{array}$ & $\begin{array}{l}-0.6744 * * * \\
(0.0222)\end{array}$ & $\begin{array}{l}-0.6903^{* * * *} \\
(0.0220)\end{array}$ \\
\hline Save1 & $\begin{array}{l}-0.0278 * * * \\
(0.0040)\end{array}$ & & & \\
\hline Save2 & & $\begin{array}{l}0.0613 \text { *** } \\
(0.0040)\end{array}$ & & \\
\hline Save3 & & & $\begin{array}{l}-0.0256 * * * \\
(0.0061)\end{array}$ & \\
\hline Save4 & & & & $\begin{array}{l}0.0017 \\
(0.0064)\end{array}$ \\
\hline Gender & $\begin{array}{l}0.0130 * * \\
(0.0066)\end{array}$ & $\begin{array}{l}0.0131 * * \\
(0.0066)\end{array}$ & $\begin{array}{l}0.0138 * * \\
(0.0066)\end{array}$ & $\begin{array}{l}0.0136 * * \\
(0.0066)\end{array}$ \\
\hline Age & $\begin{array}{l}0.0040 * * * \\
(0.0007)\end{array}$ & $\begin{array}{l}0.0019 * * \\
(0.0007)\end{array}$ & $\begin{array}{l}0.004 * * * \\
(0.0007)\end{array}$ & $\begin{array}{l}0.0042 \text { *** } \\
(0.0007)\end{array}$ \\
\hline $\mathrm{Age}^{2}$ & $\begin{array}{l}-0.0001 * * * \\
(0.0000)\end{array}$ & $\begin{array}{l}0.0000 * * * \\
(0.0000)\end{array}$ & $\begin{array}{l}-0.0001 * * * \\
(0.0000)\end{array}$ & $\begin{array}{l}-0.0001 * * * \\
(0.0000)\end{array}$ \\
\hline Education & $\begin{array}{l}0.0209 * * * \\
(0.0008)\end{array}$ & $\begin{array}{l}0.0204 * * * \\
(0.0008)\end{array}$ & $\begin{array}{l}0.021 * * * \\
(0.0008)\end{array}$ & $\begin{array}{l}0.0211^{* * * *} \\
(0.0008)\end{array}$ \\
\hline Race & $\begin{array}{l}0.0554 * * * \\
(0.0049)\end{array}$ & $\begin{array}{l}0.0515^{* * *} \\
(0.0049)\end{array}$ & $\begin{array}{l}0.0570 * * * \\
(0.0049)\end{array}$ & $\begin{array}{l}0.0570 \text { *** } \\
(0.0049)\end{array}$ \\
\hline Married & $\begin{array}{l}0.0019 \\
(0.0058)\end{array}$ & $\begin{array}{l}-0.0017 \\
(0.0058)\end{array}$ & $\begin{array}{l}0.0029 \\
(0.0059)\end{array}$ & $\begin{array}{l}0.0031 \\
(0.0059)\end{array}$ \\
\hline Kids & $\begin{array}{l}-0.0037 * * \\
(0.0018)\end{array}$ & $\begin{array}{l}-0.0006 \\
(0.0018)\end{array}$ & $\begin{array}{l}-0.0038^{* * *} \\
(0.0018)\end{array}$ & $\begin{array}{l}-0.0036^{* *} \\
(0.0018)\end{array}$ \\
\hline Unemployed & $\begin{array}{l}-0.0293 * * * \\
(0.0068)\end{array}$ & $\begin{array}{l}-0.0276 * * * \\
(0.0068)\end{array}$ & $\begin{array}{l}-0.0294 * * * \\
(0.0068)\end{array}$ & $\begin{array}{l}-0.0296^{* * *} \\
(0.0068)\end{array}$ \\
\hline Log(Income) & $\begin{array}{l}0.0194 * * * \\
(0.0021)\end{array}$ & $\begin{array}{l}0.0202 * * * \\
(0.0021)\end{array}$ & $\begin{array}{l}0.0194 * * * \\
(0.0021)\end{array}$ & $\begin{array}{l}0.0194 * * * \\
(0.0021)\end{array}$ \\
\hline Log(Net Worth) & $\begin{array}{l}0.0306 * * * \\
(0.0013)\end{array}$ & $\begin{array}{l}0.0299 * * * \\
(0.0013)\end{array}$ & $\begin{array}{l}0.0300 * * * \\
(0.0013)\end{array}$ & $\begin{array}{l}0.0304 * * * \\
(0.0013)\end{array}$ \\
\hline $\mathrm{R}^{2}$ & 0.2372 & 0.2429 & 0.2358 & 0.2429 \\
\hline $\mathrm{N}$ & 24131 & 24131 & 24131 & 24131 \\
\hline
\end{tabular}




\section{Table 2-11: Model parameter values}

This table presents the benchmark parameter values for the model calibration. Preference parameters, labor income parameters, and financial market parameters are obtained from Cocco et al. (2005). The emergency fund/permanent income ratio is calibrated from data from the Survey of Consumer Finance.

\begin{tabular}{ll}
\hline Description & Parameter Value \\
\hline Preference Parameters: & 65 \\
Retirement age $(K)$ & 100 \\
Life span $(\mathrm{T})$ & 0.96 \\
Discount factor $(\delta)$ & 7 \\
Risk aversion $(\gamma)$ & \\
\hline Labor Income Parameters: & 0.074 \\
Variance of Permanent Labor Income Shock & 0.011 \\
Variance of Transitory Labor Income Shock & 0.682 \\
Replacement rate & 0.48 \\
\hline Emergency fund / Permanent Income ratio & \\
\hline Financial Market Parameters: & 0.02 \\
Riskless rate $\left(r_{f}\right)$ & 0.06 \\
Mean of stock return $(\mu)$ & 0.157 \\
Standard Deviation of stock return $\left(\sigma_{\eta}\right)$ & \\
\hline
\end{tabular}




\section{Table 2-12: Summary statistics for the emergency fund}

This table presents the summary statistics for the desirable amount of emergency funds for the overall sample, and for subsamples based on wealth status, health status, and retirement status. All samples are weighted using the weight provided by the SCF.

\begin{tabular}{llllc}
\hline Sample & Mean & Median & St Dev & N \\
\hline Overall Sample: & 25,511 & 5,762 & 196,974 & 28,464 \\
\hline Panel A: By Wealth Status: & & & & \\
$\quad$ Above Median & 38,194 & 11,330 & 67,662 & 16,822 \\
$\quad$ Below Median & 9,635 & 3,000 & 141,702 & 11,058 \\
\hline Panel B: By Retirement Status: & & & & \\
$\quad$ Non-Retired & 21,839 & 5,665 & 162,536 & 4,935 \\
$\quad$ Retired & 40,600 & 10,000 & 298,971 & 28,464 \\
\hline
\end{tabular}




\section{Table 2-13: Stock market participation regression (Logit model)}

This table presents the logistic regression results for stock market participation. The dependent variable is a dummy variable, equal to 1 if the household holds any equity and 0, otherwise. PRatio1 is log of (weighted available resource/desirable amount of emergency funds), PRatio2 is log of (income/ desirable amount of emergency funds), and PRatio3 is log of ((financial asset-retirement asset)/ desirable amount of emergency funds). Standard error is in parentheses. *, $* *$, and $* * *$ indicate significance at the $10 \%, 5 \%$, and $1 \%$ levels of confidence, respectively.

\begin{tabular}{|c|c|c|c|}
\hline Variables & Model I & Model II & Model III \\
\hline Intercept & $\begin{array}{l}-13.2541 \text { *** } \\
(0.2457)\end{array}$ & $\begin{array}{l}-7.1634 * * * \\
(0.1681)\end{array}$ & $\begin{array}{l}-12.5954 * * * \\
(0.2479)\end{array}$ \\
\hline PRatio1 & $\begin{array}{l}0.2532 * * * \\
(0.0108)\end{array}$ & & \\
\hline PRatio2 & & $\begin{array}{l}0.0342 * * * \\
(0.0114)\end{array}$ & \\
\hline PRatio3 & & & $\begin{array}{l}0.2803 * * * \\
(0.0088)\end{array}$ \\
\hline Gender & $\begin{array}{l}-0.0529 \\
(0.0541)\end{array}$ & $\begin{array}{l}0.2395 * * * \\
(0.0495)\end{array}$ & $\begin{array}{l}-0.0384 \\
(0.0543)\end{array}$ \\
\hline Age & $\begin{array}{l}0.0336 * * \\
(0.0059)\end{array}$ & $\begin{array}{l}0.0990 \text { *** } \\
(0.0054)\end{array}$ & $\begin{array}{l}0.0599 * * * \\
(0.0059)\end{array}$ \\
\hline $\mathrm{Age}^{2}$ & $\begin{array}{l}-0.0003 * * * \\
(0.0001)\end{array}$ & $\begin{array}{l}-0.0009 * * * \\
(0.0001)\end{array}$ & $\begin{array}{l}-0.0006 * * * \\
(0.0001)\end{array}$ \\
\hline Education & $\begin{array}{l}0.1808 * * * \\
(0.0071)\end{array}$ & $\begin{array}{l}0.2915 * * * \\
(0.0066)\end{array}$ & $\begin{array}{l}0.1637 * * * \\
(0.0072)\end{array}$ \\
\hline Race & $\begin{array}{l}0.4564 * * * \\
(0.0397)\end{array}$ & $\begin{array}{l}0.686 * * * \\
(0.0368)\end{array}$ & $\begin{array}{l}0.4366^{* * * *} \\
(0.0398)\end{array}$ \\
\hline Married & $\begin{array}{l}0.0873 * \\
(0.0501)\end{array}$ & $\begin{array}{l}0.6036 * * * \\
(0.0453)\end{array}$ & $\begin{array}{l}0.1653 * * * \\
(0.0503)\end{array}$ \\
\hline Kids & $\begin{array}{l}-0.092 * * \\
(0.0159)\end{array}$ & $\begin{array}{l}-0.0248^{*} \\
(0.0148)\end{array}$ & $\begin{array}{l}-0.0479 * * * \\
(0.0161)\end{array}$ \\
\hline Unemployed & $\begin{array}{l}-0.1183 * * * \\
(0.054)\end{array}$ & $\begin{array}{l}-0.5411 * * * \\
(0.0508)\end{array}$ & $\begin{array}{l}-0.1165^{* *} \\
(0.0545)\end{array}$ \\
\hline Income & & $\begin{array}{l}0.0059 * * * \\
(0.0007)\end{array}$ & \\
\hline Log(Income) & $\begin{array}{l}0.8799 * * \\
(0.0234)\end{array}$ & & $\begin{array}{l}0.8246 * * * \\
(0.0235)\end{array}$ \\
\hline Net Worth & $\begin{array}{l}-0.0001 \\
(0.0000)\end{array}$ & $\begin{array}{l}0.0002 * * * \\
(0.0000)\end{array}$ & $\begin{array}{l}-0.0001 \\
(0.0000)\end{array}$ \\
\hline $\mathrm{N}$ & 25465 & 25465 & 25465 \\
\hline
\end{tabular}


Table 2-14: Average marginal effect for the stock market participation regression

This table calculates the average marginal effect from the results of the logistic regressions in Table 2-13. PRatio1 is $\log$ of (weighted available resource/desirable amount of emergency funds), PRatio2 is $\log$ of (income/ desirable amount of emergency funds), and PRatio3 is log of ((financial asset-retirement asset)/ desirable amount of emergency funds).

\begin{tabular}{llll}
\hline Variables & Model I & Model II & Model III \\
\hline PRatio1 & 0.0377 & & \\
PRatio2 & & 0.0058 & 0.0406 \\
PRatio3 & & & -0.0056 \\
Gender & -0.0079 & 0.0407 & 0.0087 \\
Age & 0.0050 & 0.0168 & -0.0001 \\
Age & -0.0001 & -0.0002 & 0.0237 \\
Education & 0.0269 & 0.0495 & 0.0632 \\
Race & 0.0679 & 0.1165 & 0.0239 \\
Married & 0.013 & 0.1026 & -0.0069 \\
Kids & -0.0137 & -0.0042 & -0.0169 \\
Unemployed & -0.0176 & -0.0919 & 0.00001 \\
Income & & 0.0010 & 25465 \\
Log(Income) & 0.00001 & 0.00001 & \\
Net Worth & 25465 & 25465 & 0.1193 \\
\hline
\end{tabular}




\section{Table 2-15: Precautionary ratio regression (linear probability model)}

This table presents the results for the linear probability model of the precautionary ratio regression. The dependent variable is the risky asset share in financial assets. PRatio1 is $\log$ of (weighted available resource/desirable amount of emergency funds), PRatio2 is log of (income/ desirable amount of emergency funds), and PRatio3 is log of ((financial asset-retirement asset)/ desirable amount of emergency funds). The standard error is in parentheses. *, **, and $* * *$ indicate significance at the $10 \%, 5 \%$, and $1 \%$ levels of confidence, respectively.

\begin{tabular}{|c|c|c|c|}
\hline Variables & Model I & Model II & Model III \\
\hline Intercept & $\begin{array}{l}-0.8833 * * * \\
(0.0207)\end{array}$ & $\begin{array}{l}-0.6728 * * * \\
(0.0193)\end{array}$ & $\begin{array}{l}-0.8333 * * * \\
(0.0212)\end{array}$ \\
\hline PRatio1 & $\begin{array}{l}0.0227 * * * \\
(0.0011)\end{array}$ & & \\
\hline PRatio2 & & $\begin{array}{l}0.0083 * * * \\
(0.0013)\end{array}$ & \\
\hline PRatio3 & & & $\begin{array}{l}0.0192 * * * \\
(0.0009)\end{array}$ \\
\hline Gender & $\begin{array}{l}0.0227 * * * \\
(0.0063)\end{array}$ & $\begin{array}{l}0.0538 * * * \\
(0.0065)\end{array}$ & $\begin{array}{l}0.0245^{* * * *} \\
(0.0063)\end{array}$ \\
\hline Age & $\begin{array}{l}0.0063 * * * \\
(0.0007)\end{array}$ & $\begin{array}{l}0.0128 * * * \\
(0.0007)\end{array}$ & $\begin{array}{l}0.0081 * * * \\
(0.0007)\end{array}$ \\
\hline $\mathrm{Age}^{2}$ & $\begin{array}{l}-0.0001 \text { *** } \\
(0.0000)\end{array}$ & $\begin{array}{l}-0.0001 * * * \\
(0.0000)\end{array}$ & $\begin{array}{l}-0.0001 * * * \\
(0.0000)\end{array}$ \\
\hline Education & $\begin{array}{l}0.0222 * * * \\
(0.0008)\end{array}$ & $\begin{array}{l}0.0352 * * * \\
(0.0007)\end{array}$ & $\begin{array}{l}0.0208 * * * * \\
(0.0008)\end{array}$ \\
\hline Race & $\begin{array}{l}0.0596 * * * \\
(0.0047)\end{array}$ & $\begin{array}{l}0.0883 * * * \\
(0.0048)\end{array}$ & $\begin{array}{l}0.0594 * * * \\
(0.0047)\end{array}$ \\
\hline Married & $\begin{array}{l}-0.0037 \\
(0.0057)\end{array}$ & $\begin{array}{l}0.0393 * * * * \\
(0.0058)\end{array}$ & $\begin{array}{l}0.0023 \\
(0.0056)\end{array}$ \\
\hline Kids & $\begin{array}{l}-0.0041 * * \\
(0.0017)\end{array}$ & $\begin{array}{l}0.0018 \\
(0.0018)\end{array}$ & $\begin{array}{l}-0.0014 \\
(0.0017)\end{array}$ \\
\hline Unemployed & $\begin{array}{l}-0.0288 * * * \\
(0.0063)\end{array}$ & $\begin{array}{l}-0.0638 * * * \\
(0.0065)\end{array}$ & $\begin{array}{l}-0.0293 * * * \\
(0.0063)\end{array}$ \\
\hline Income & $\begin{array}{l}0.0547 * * * \\
(0.0017)\end{array}$ & $\begin{array}{l}0.00001 \\
(0.0000)\end{array}$ & \\
\hline Log(Income) & & & $\begin{array}{l}0.0516^{* * * *} \\
(0.0018)\end{array}$ \\
\hline Net Worth & $\begin{array}{l}-0.00001 \\
(0.0000)\end{array}$ & $\begin{array}{l}0.00001 * * * \\
(0.0000)\end{array}$ & $\begin{array}{l}-0.00005^{* * *} \\
(0.0000)\end{array}$ \\
\hline Adj $R^{2}$ & 25465 & 25465 & 25465 \\
\hline $\mathrm{N}$ & 0.2379 & 0.1847 & 0.2394 \\
\hline
\end{tabular}




\section{Table 2-16: Risky Asset share regression (retirement account vs. non-retirement account)}

This table presents the results for the linear probability model of the risky asset share regression. In Model I, the dependent variable is the ratio of total risky assets to all financial assets. In Model II, the dependent variable is the ratio of total direct held equity to all non-retirement financial assets. In Model III, the dependent variable is the share of risky assets in a retirement account. PRatio is log of (weighted available resource/desirable amount of emergency funds). The standard error is in parentheses. $*, * *$, and $* * *$ indicate significance at the $10 \%, 5 \%$, and $1 \%$ levels of confidence, respectively.

\begin{tabular}{|c|c|c|c|}
\hline Variables & Model I & Model II & Model III \\
\hline Intercept & $\begin{array}{l}-0.3532 * * * \\
(0.0310)\end{array}$ & $\begin{array}{l}-0.7817 * * * \\
(0.0309)\end{array}$ & $\begin{array}{l}-0.0135 \\
(0.0386)\end{array}$ \\
\hline PRatio & $\begin{array}{l}0.0147 * * * \\
(0.0016)\end{array}$ & $\begin{array}{l}0.0176^{* * *} \\
(0.0016)\end{array}$ & $\begin{array}{l}0.0109 * * * \\
(0.0021)\end{array}$ \\
\hline Gender & $\begin{array}{l}0.0481 * * * \\
((0.0092)\end{array}$ & $\begin{array}{l}0.0376 * * * \\
(0.0092)\end{array}$ & $\begin{array}{l}0.0517 * * * \\
(0.0115)\end{array}$ \\
\hline Age & $\begin{array}{l}0.0051 * * * \\
(0.0011)\end{array}$ & $\begin{array}{l}-0.0013 * * * \\
(0.0011)\end{array}$ & $\begin{array}{l}-0.0001 \\
(0.9641)\end{array}$ \\
\hline $\mathrm{Age}^{2}$ & $\begin{array}{l}-0.0001 * * * \\
(0.0000)\end{array}$ & $\begin{array}{l}0.00001 * * * \\
(0.0000)\end{array}$ & $\begin{array}{l}0.00001^{* * * *} \\
(0.0000)\end{array}$ \\
\hline Education & $\begin{array}{l}0.0188 * * * \\
(0.0011)\end{array}$ & $\begin{array}{l}0.0212 * * * \\
(0.0011)\end{array}$ & $\begin{array}{l}0.0161 * * * \\
(0.0014)\end{array}$ \\
\hline Race & $\begin{array}{l}0.0516^{* * * *} \\
(0.0066)\end{array}$ & $\begin{array}{l}0.0542 * * * \\
(0.0066)\end{array}$ & $\begin{array}{l}0.0466 * * * \\
(0.0082)\end{array}$ \\
\hline Married & $\begin{array}{l}-0.0352 * * * \\
(0.0077)\end{array}$ & $\begin{array}{l}-0.0206 * * * * \\
(0.0077)\end{array}$ & $\begin{array}{l}-0.0294 * * * \\
(0.0096)\end{array}$ \\
\hline Kids & $\begin{array}{l}0.0002 \\
(0.0022)\end{array}$ & $\begin{array}{l}-0.006 * * * \\
(0.0022)\end{array}$ & $\begin{array}{l}-0.0027 \\
(0.0027)\end{array}$ \\
\hline Unemployed & $\begin{array}{l}-0.0104 \\
(0.0096)\end{array}$ & $\begin{array}{l}0.0047 \\
(0.0096)\end{array}$ & $\begin{array}{l}-0.0156 \\
(0.012)\end{array}$ \\
\hline $\log ($ Income $)$ & $\begin{array}{l}0.0264 * * * \\
(0.0022)\end{array}$ & $\begin{array}{l}0.0496 * * * \\
(0.0022)\end{array}$ & $\begin{array}{l}0.0298 * * * \\
(0.0027)\end{array}$ \\
\hline Net Worth & $\begin{array}{l}-0.00001 * * \\
(0.0000)\end{array}$ & $\begin{array}{l}-0.00001 * * * \\
(0.0000)\end{array}$ & $\begin{array}{l}-0.00001^{*} \\
(0.0000)\end{array}$ \\
\hline Adj $R^{2}$ & 0.0798 & 0.1532 & 0.0583 \\
\hline $\mathrm{N}$ & 16058 & 16058 & 16058 \\
\hline
\end{tabular}




\section{Table 2-17: Stock market participation regression (control for different status)}

This table presents the results for the stock market participation regression of different groups. The dependent variable is a dummy variable, equal to 1 if the household holds any equity and 0, otherwise. Model I controls for retirement status; Model II controls for business ownership status; Model III controls for investment risk preferences. The standard error is in parenthesis. *,**, and *** indicate significance at the $10 \%, 5 \%$, and $1 \%$ levels of confidence, respectively.

\begin{tabular}{llll}
\hline Variables & Model I & Model II & Model III \\
\hline Intercept & -13.3294 & $-6.8721^{* * *}$ & $-12.2270^{* * *}$ \\
PRatio & $(0.2495)$ & $(0.1700)$ & $(0.2523)$ \\
& $0.2417^{* * *}$ & $0.3680^{* * *}$ & $0.2254^{* * *}$ \\
Retired & $(0.0119)$ & $(0.0117)$ & $(0.0244)$ \\
& -0.0646 & & \\
PRatio*Retired & $(0.0983)$ & & \\
& $0.0622^{* *}$ & & \\
HBUS & $(0.0276)$ & $0.5917^{* * *}$ & \\
& & $(0.0900)$ & \\
PRatio*HBUS & & $-0.1845^{* * * *}$ & $-0.7476^{* * * *}$ \\
& & $(0.0265)$ & $(0.0789)$ \\
Riska & & & 0.0280 \\
PRatio*Riska & & & $(0.0265)$ \\
Controls & & & Yes \\
\hline $\mathrm{N}$ & & & 25859 \\
\hline
\end{tabular}




\section{Table 2-18: Average marginal effect for Stock market participation regressions}

This table calculates the average marginal effect from the results of the logistic regressions in Table 2-17. Model I controls for retirement status; Model II controls for business ownership status; Model III controls for investment risk preferences.

\begin{tabular}{lccc}
\hline Variables & Model I & Model II & Model III \\
\hline PRatio & 0.0360 & 0.0588 & \\
Retired & -0.0095 & & \\
PRatio*Retired & 0.0093 & & \\
HBUS & & & \\
PRatio*HBUS & & 0.0945 & \\
Riska & & -0.0295 & -0.1098 \\
PRatio*Riska & & & 0.0041 \\
\hline $\mathrm{N}$ & & & 25859 \\
\hline
\end{tabular}




\section{Table 2-19: Risky asset share regressions (control for different status)}

This table presents the results for the linear probability regression of the risky asset share model. Model I controls for retirement status; Model II controls for business ownership status; Model III controls for investment risk preferences. The standard error is in parentheses. *, **, and $* * *$ indicate significance at the $10 \%, 5 \%$, and $1 \%$ levels of confidence, respectively.

\begin{tabular}{llll}
\hline Variables & Model I & Model II & Model III \\
\hline Intercept & $-0.8846^{* * *}$ & $-0.9390^{* * *}$ & $-0.6869^{* * *}$ \\
PRatio & $(0.0210)$ & $(0.0220)$ & $(0.0220)$ \\
& $0.0213^{* * *}$ & $0.02708^{* * *}$ & $0.0186^{* * *}$ \\
Retired & $(0.0012)$ & $(0.0013)$ & $(0.0021)$ \\
& $-0.0178^{*}$ & & \\
PRatio*Retired & $(0.0101)$ & & \\
& $0.0074^{* * *}$ & & \\
HBUS & $(0.0026)$ & & \\
& & $0.02155^{* * *}$ & \\
PRatio*HBUS & & $(0.0094)$ & $-0.1302^{* * *}$ \\
& & $-0.0160^{* * * *}$ & $(0.0081)$ \\
Riska & & $(0.0025)$ & $0.0037^{*}$ \\
PRatio*Riska & & & $(0.0023)$ \\
Controls & & & Yes \\
\hline R & & & 0.2613 \\
$\mathrm{~N}$ & & & 25465 \\
\hline
\end{tabular}




\section{Table 2-20: Stock market participation regression (control for normalized wealth)}

This table presents the logistic regression results for stock market participation, controlling for normalized wealth. The dependent variable is a dummy variable, equal to 1 if the household holds any equity and 0, otherwise. PRatio is $\log$ (weighted available resource/desirable amount of emergency funds). Normd is a dummy variable indicating whether a household's normalized wealth is below 2 or not. Normd*PRatio is the interaction term between PRatio and Normd. The standard error is in parentheses. * **, and *** indicate significance at the $10 \%, 5 \%$, and $1 \%$ levels of confidence, respectively.

\begin{tabular}{|c|c|c|}
\hline Variables & Model I & Model II \\
\hline Intercept & $\begin{array}{l}-13.2541 * * * \\
(0.2457)\end{array}$ & $\begin{array}{l}-10.5081 \text { *** } \\
(0.2702)\end{array}$ \\
\hline PRatio & $\begin{array}{l}0.2532 * * * \\
(0.0108)\end{array}$ & $\begin{array}{l}0.1286^{* * * *} \\
(0.0282)\end{array}$ \\
\hline Normd & & $\begin{array}{l}-1.8921 * * * \\
(0.1061)\end{array}$ \\
\hline Normd*PRatio & & $\begin{array}{l}0.0731 * * \\
(0.0304)\end{array}$ \\
\hline Gender & $\begin{array}{l}-0.0529 \\
(0.0541)\end{array}$ & $\begin{array}{l}-0.0695 \\
(0.0558)\end{array}$ \\
\hline Age & $\begin{array}{l}0.0336 \text { ** } \\
(0.0059)\end{array}$ & $\begin{array}{l}0.0429 * * * \\
(0.0061)\end{array}$ \\
\hline $\mathrm{Age}^{2}$ & $\begin{array}{l}-0.0003 * * * \\
(0.0001)\end{array}$ & $\begin{array}{l}-0.0006 * * * \\
(0.0001)\end{array}$ \\
\hline Education & $\begin{array}{l}0.1808^{* * * *} \\
(0.0071)\end{array}$ & $\begin{array}{l}0.1539 * * * \\
(0.0074)\end{array}$ \\
\hline Race & $\begin{array}{l}0.4564 * * * \\
(0.0397)\end{array}$ & $\begin{array}{l}0.3607 * * * \\
(0.0404)\end{array}$ \\
\hline Married & $\begin{array}{l}0.0873 * \\
(0.0501)\end{array}$ & $\begin{array}{l}0.1253 * * \\
(0.0516)\end{array}$ \\
\hline Kids & $\begin{array}{l}-0.092 * * \\
(0.0159)\end{array}$ & $\begin{array}{l}-0.0758 * * * \\
(0.0161)\end{array}$ \\
\hline Unemployed & $\begin{array}{l}-0.1183 * * * \\
(0.054)\end{array}$ & $\begin{array}{l}-0.0970^{*} \\
(0.0545)\end{array}$ \\
\hline Log(Income) & $\begin{array}{l}0.8799 * * \\
(0.0234)\end{array}$ & $\begin{array}{l}0.8351 * * * \\
(0.0239)\end{array}$ \\
\hline Net Worth & $\begin{array}{l}-0.0001 \\
(0.0000)\end{array}$ & $\begin{array}{l}-0.0001 \\
(0.0000)\end{array}$ \\
\hline $\mathrm{N}$ & 25465 & 25465 \\
\hline
\end{tabular}




\section{Table 2-21: Average marginal effect for the stock market participation regression}

This table calculates the average marginal effect from the logistic regression in Table 2-20. PRatio1 is log (weighted available resource/desirable amount of emergency funds). Normd is a dummy variable indicating whether a household's normalized wealth is below 2 or not. Normd*PRatio is the interaction term between PRatio and Normd.

\begin{tabular}{lcc}
\hline Variables & Model II & Model I \\
\hline PRatio1 & 0.0180 & 0.0377 \\
Normd & -0.2652 & \\
PRatio*Normd & 0.0102 & \\
Gender & -0.0097 & -0.0079 \\
Age & 0.006 & 0.005 \\
Age ${ }^{2}$ & -0.0001 & -0.0001 \\
Education & 0.0216 & 0.0269 \\
Race & 0.0506 & 0.0679 \\
Married & 0.0176 & 0.013 \\
Kids & & -0.0137 \\
Unemployed & -0.0106 & -0.0176 \\
Log(Income) & & 0.00001 \\
\hline Net Worth & -0.0136 & 25465 \\
\hline
\end{tabular}




\section{Table 2-22: Risky asset share regression (control for normalized wealth)}

This table presents the results for the linear probability regression of the risky asset share estimation. PRatio is $\log$ (weighted available resource/desirable amount of emergency funds). Normd is a dummy variable indicating whether a household's normalized wealth is below 2 or not. Normd*PRatio is the interaction term between PRatio and Normd. The standard error is in parentheses. *,**, and *** indicate significance at the $10 \%, 5 \%$, and $1 \%$ levels of confidence, respectively.

\begin{tabular}{|c|c|c|}
\hline Variables & Model I & Model II \\
\hline Intercept & $\begin{array}{l}-0.8833 * * * \\
(0.0207)\end{array}$ & $\begin{array}{l}-0.5607 * * * \\
(0.0237)\end{array}$ \\
\hline PRatio1 & $\begin{array}{l}0.0227 * * * \\
(0.0011)\end{array}$ & $\begin{array}{l}0.0100 * * * \\
(0.0021)\end{array}$ \\
\hline Normd & & $\begin{array}{l}-0.1658 * * * \\
(0.0090)\end{array}$ \\
\hline PRatio*Normd & & $\begin{array}{l}0.0090 * * * \\
(0.0024)\end{array}$ \\
\hline Gender & $\begin{array}{l}0.0227 * * * \\
(0.0063)\end{array}$ & $\begin{array}{l}0.0205 * * * \\
(0.0062)\end{array}$ \\
\hline Age & $\begin{array}{l}0.0063 * * * \\
(0.0007)\end{array}$ & $\begin{array}{l}0.0055^{* * *} \\
(0.0007)\end{array}$ \\
\hline $\mathrm{Age}^{2}$ & $\begin{array}{l}-0.0001 * * * \\
(0.0000)\end{array}$ & $\begin{array}{l}-0.0001 * * * \\
(0.0000)\end{array}$ \\
\hline Education & $\begin{array}{l}0.0222 * * * \\
(0.0008)\end{array}$ & $\begin{array}{l}0.0181 \text { *** } \\
(0.0008)\end{array}$ \\
\hline Race & $\begin{array}{l}0.0596 * * * \\
(0.0047)\end{array}$ & $\begin{array}{l}0.0488 * * * \\
(0.0046)\end{array}$ \\
\hline Married & $\begin{array}{l}-0.0037 \\
(0.0057)\end{array}$ & $\begin{array}{l}-0.003 \\
(0.0056)\end{array}$ \\
\hline Kids & $\begin{array}{l}-0.0041 * * \\
(0.0017)\end{array}$ & $\begin{array}{l}-0.0023 \\
(0.0017)\end{array}$ \\
\hline Unemployed & $\begin{array}{l}-0.0288 * * * \\
(0.0063)\end{array}$ & $\begin{array}{l}-0.0274 * * * \\
(0.0062)\end{array}$ \\
\hline Log(Income) & $\begin{array}{l}0.0547 * * * \\
(0.0017)\end{array}$ & $\begin{array}{l}0.0481 * * * \\
(0.0017)\end{array}$ \\
\hline Net Worth & $\begin{array}{l}-0.00001 \\
(0.0000)\end{array}$ & $\begin{array}{l}-0.00001 \text { *** } \\
(0.0000)\end{array}$ \\
\hline $\operatorname{Adj} R^{2}$ & 0.2379 & 0.2662 \\
\hline $\mathrm{N}$ & 25465 & 25465 \\
\hline
\end{tabular}


Figure 2-1: Labor income process: age profile

This figures plots fitted third-order polynomials of the labor income process for both high school graduates and college graduates.

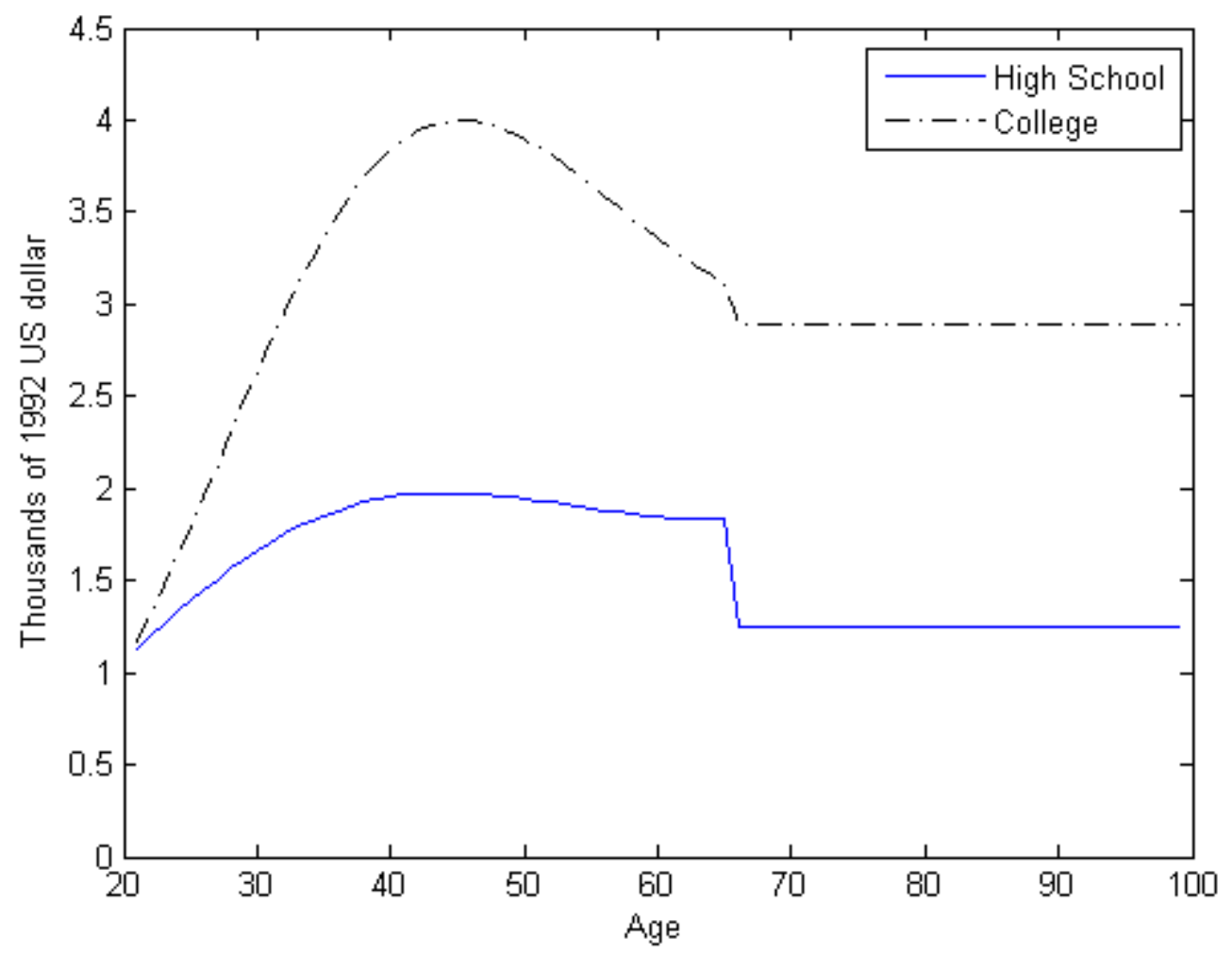




\section{Figure 2-2: Policy rules for portfolio choice (without contingent consumption)}

This figure plots the optimal portfolio share invested in stocks at different normalized wealth levels and for different stages of the life cycle when no contingent consumption is considered.

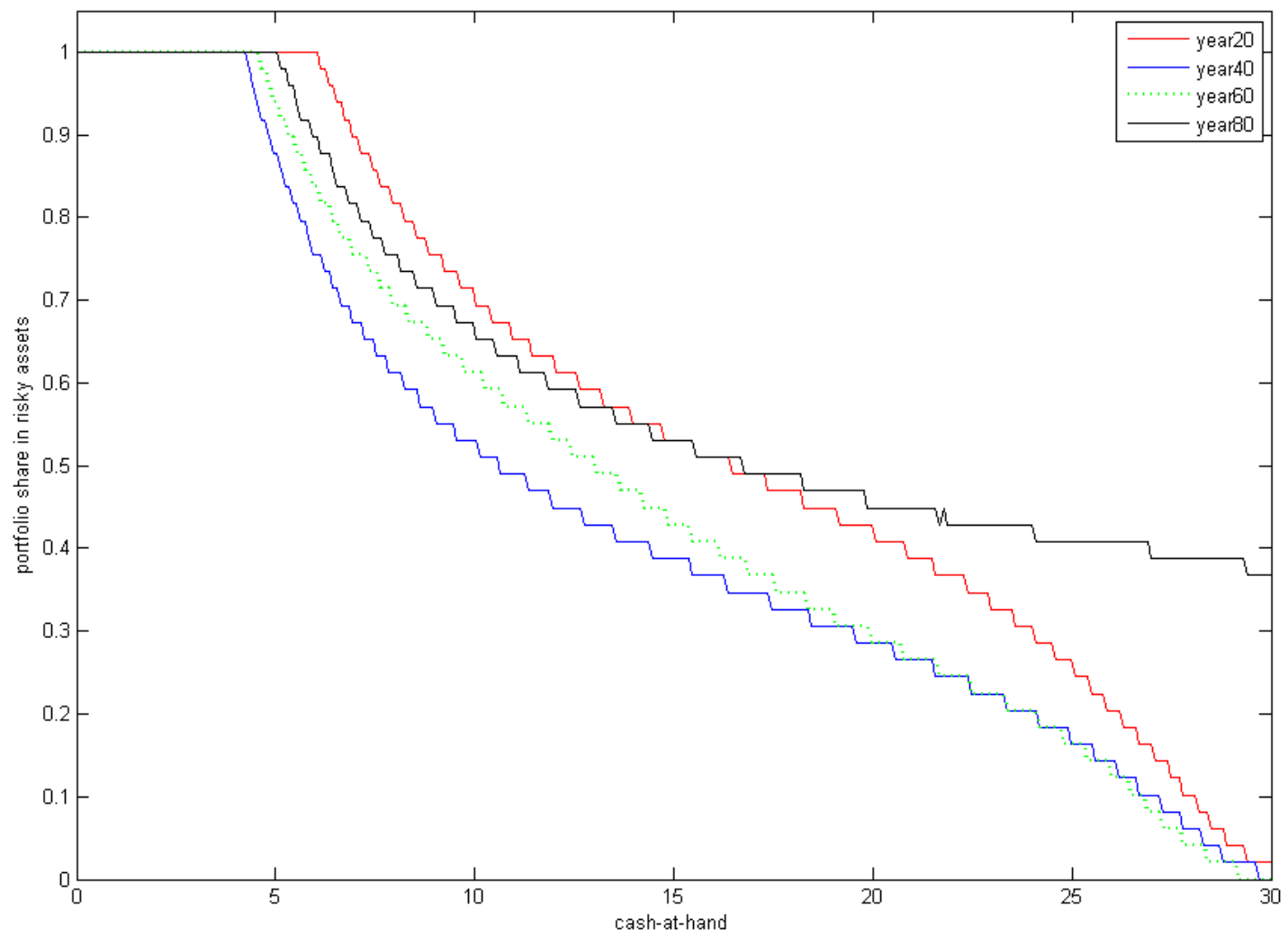


Figure 2-3: Policy rules for portfolio choice (with contingent consumption)

This figure plots the optimal portfolio share invested in stocks at different normalized wealth levels and for different stages of the life cycle when contingent consumption is considered.

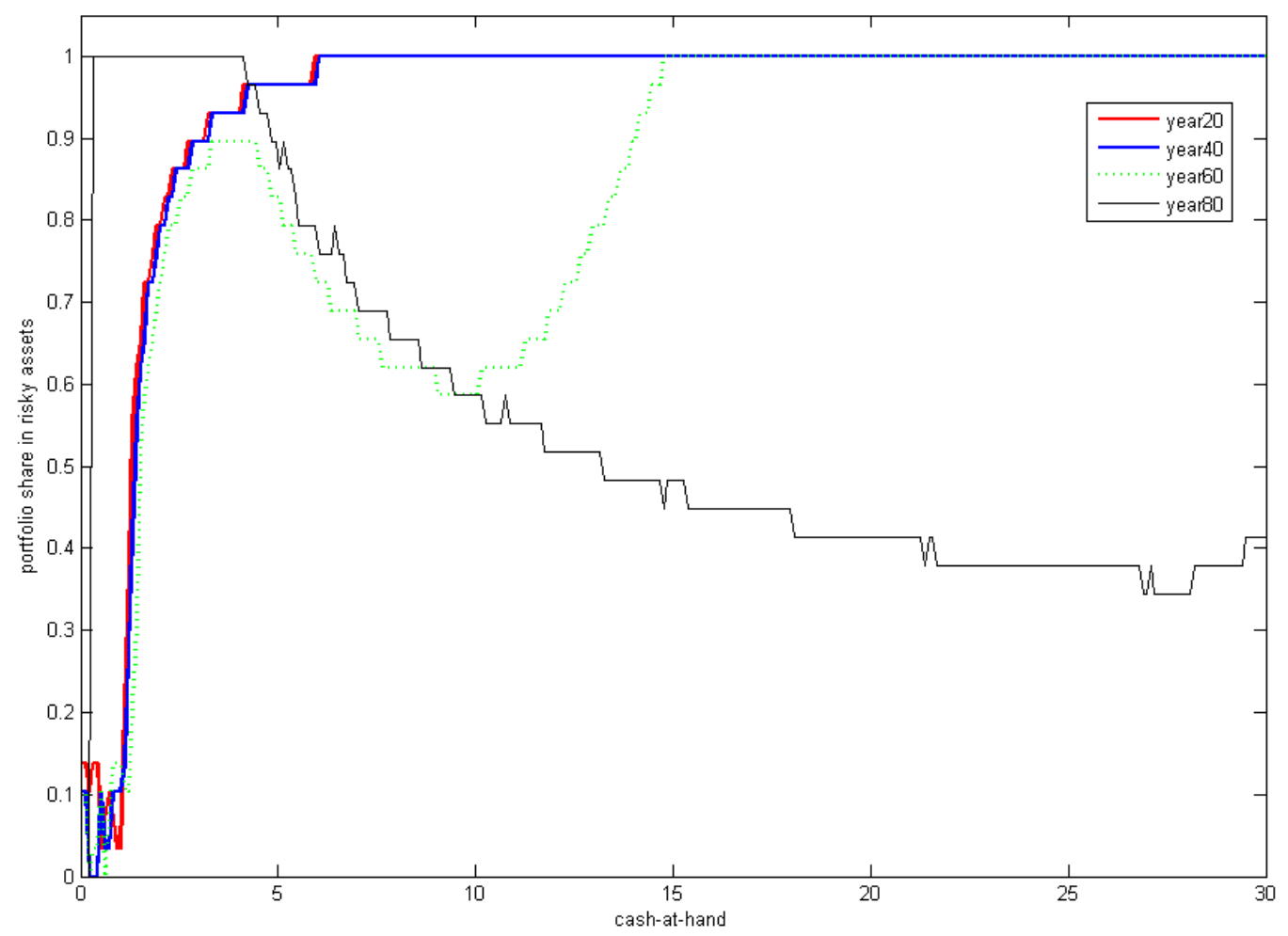


Figure 2-4: Optimal policy rule for normalized wealth level below 5

This figure plots the optimal portfolio share invested in stocks at different normalized levels (below 5) and for different stages of the life cycle when contingent consumption is considered.

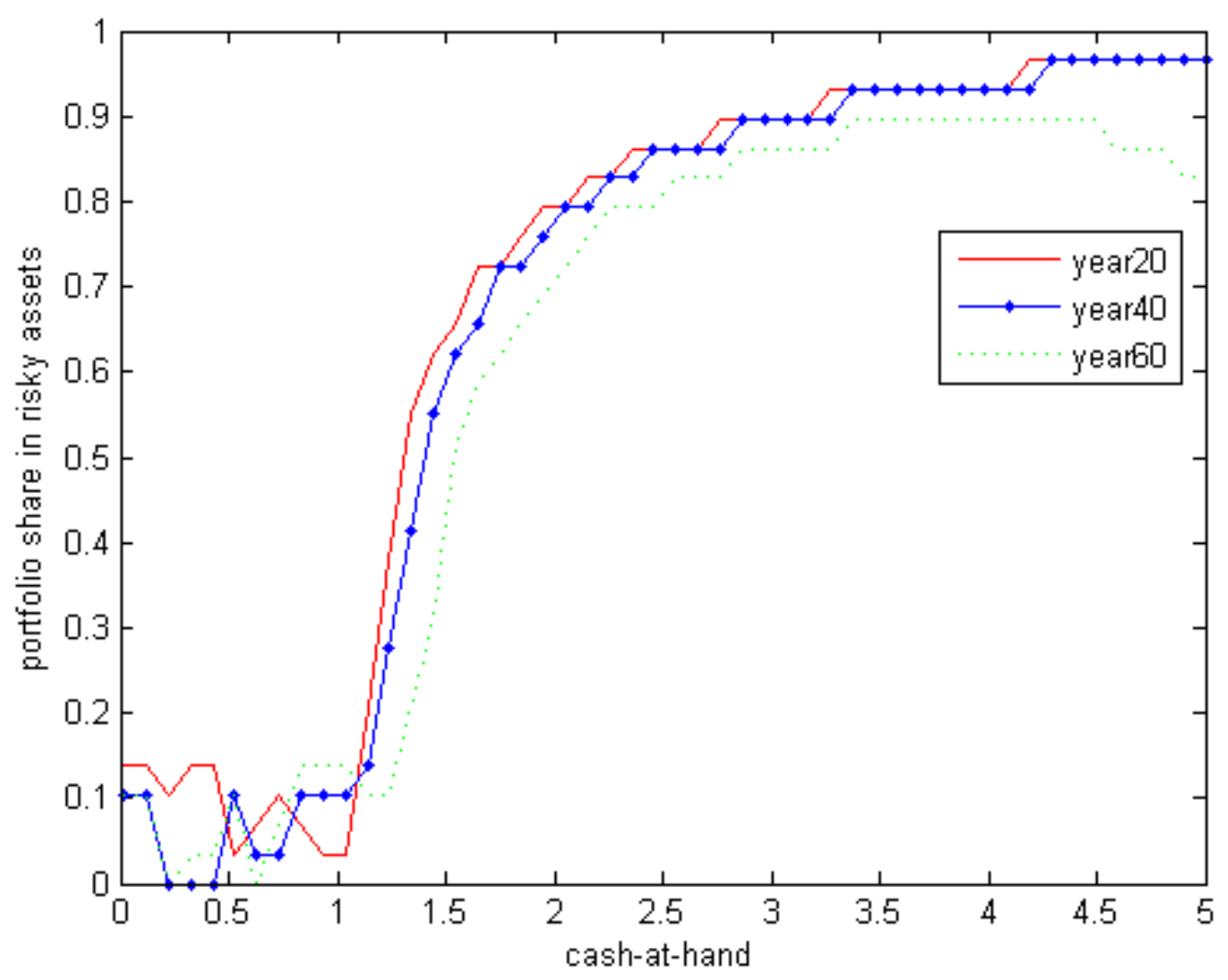




\section{Chapter 3}

Tail Risk, Health Risk, and Portfolio Choice for Retirees 


\section{Chapter 3}

\section{Tail Risk, Health Risk, and Portfolio Choice for Retirees}

\subsection{Introduction}

The theory of asset allocation predicts that investment in risky assets depends on investors' risk preference, along with the mean and the volatility of stock market returns (Merton, 1971). Empirical evidence, however, shows that individual investment behavior is affected by factors that are not emphasized in classical portfolio choice theory. One factor that has important implications for asset allocation decisions is investors' human capital. In an incomplete financial market, individuals cannot fully hedge their labor risk. Fluctuations in labor income, therefore, is a major risk associated with human capital. Subsequent research on the life cycle model has incorporated human capital risk into the analysis and derived the optimal behavior that better matches the empirical data.

For retirees, the risk of human capital can be different. Major income sources for retirees are from Social Security and pension benefits, which normally are not subject to business cycles or periods of unemployment; therefore, their income is less risky compared to working individuals' income. However, increased health risk among retirees can be seen as another type of shock to their human capital. Health shock can significantly affect their budget constraints, consumption behaviors, and financial decisions. In additional to health risks, another important risk of investing in the stock market for retirees is the risk of financial crisis. A financial crisis is characterized by a disastrous outcome in the stock market, which has a small probability of occurrence. Since 
retirees' investment horizon is shorter, and their ability to recover from a loss is lower than that of working individuals, a financial disaster's detrimental effect on wealth can be large enough to reduce their equity holdings. This paper contributes to the literature by analyzing retirees' consumption and financial decisions when they are faced with these two important risks, using a structural life-cycle model.

This study is related to three strands of research: work on the application of the life cycle model to the study of households' optimal behavior, work on health and portfolio choice, and work on the tail risk associated with rare events in financial markets. By unifying these three strands in the literature, I attempt to study retirees' consumption decisions and portfolio choices when they are faced with realistic health risk and rare event risk in the financial markets.

The literature on the life cycle of consumption starts with Friedman's life cycle and the permanent income hypothesis, which state that individuals' current consumption should be determined by their expected lifetime income, not just by their current income. The life cycle model has since become the basis for studying dynamic household behavior (Cocco and Maenhout, 2005; Gomes and Michaelides, 2005; Wachter and Yogo, 2010). The life cycle model has also been used to study retirement behavior. Blau (2008) studies a life cycle model where households, uncertain about the time of retirement, experience a sharp decline in consumption at the time of retirement. Huang et al. (2012) solve for retirees' optimal consumption rate in a life cycle model where the mortality rate is stochastic and learnable from health status. Kremer et al. (2013) derive retirees' optimal consumption and portfolio choices using a logistic model of mortality. Ding (2014) develops a life-cycle model incorporating a bequest motive, housing decisions, and public pensions for retirees. The model is calibrated to ABS data from the Household Expenditure Survey 
and the Survey of Income and Housing. Their model can reasonably explain the financial behavior of surveyed households and the concentration of wealth in housing for retirees in Australia.

This paper is also related to the study of health and portfolio choice. Health risk is one of the important background risks that affect households' financial decisions. Rosen (2004) finds that households in poor health are less likely to hold risky financial assets after controlling for their attitudes toward risk, planning horizon, and health insurance availability. Edwards (2008) finds that adverse health shocks to retirees in the future may explain twenty percent of the age-related decline in financial risk-taking after retirement. De Nardi et al. (2010) argue that the most important reason that the elderly save is longevity risk and rising out-of-pocket medical expense with age. Coile and Milligan (2009) find that households decrease their ownership of housing, vehicles, financial assets, and businesses as they age and increase their share in safe assets in the presence of a health shock. They also find that the effect of health shocks on safe asset holding strengthens with time after the shock. Finkelstein et al. (2013) find that the marginal utility of consumption declines as health deteriorates.

In addition to the reduced form estimation, some studies use a structural model to explain how health affects households' financial decisions. Yogo (2009) develops a life-cycle model where retirees choose health expenditures endogenously in response to the stochastic depreciation of health. The model is calibrated to explain the joint dynamics of health expenditure, health, and asset allocation for retirees in the Health and Retirement Study. Hugonnier et al. (2012) develop a dynamic model where households make consumption, portfolio, health investment, and health insurance decisions jointly. Scholz and Seshadri (2013) develop a life cycle model to study consumption and health investment choices where health affects both longevity and the utility 
function. The model's result matches the distribution of medical expenses across households in the data.

Third, this paper is related to the literature on tail risk and rare events in financial markets. Liu et al. (2005) find that uncertainty aversion to rare events plays an important role in option premium. Bollerslev and Todorov (2011) find that compensation for rare events accounts for a large fraction of the equity and variance risk premium in the S\&P 500 market index. Gabaix (2012) finds that the possibility of rare, large disasters affects risk premium, and suggests that fear of disaster can be viewed as a tractable way to model time-varying risk-aversion or investor sentiment. Wachter (2013) finds that a small possibility of a large decline in consumption can substantially increase equity premium. Time-variation in the probability of this outcome drives high stock market volatility and excess return predictability.

While many rare event studies focus on their effects on asset pricing, fewer look at how they directly affect investors' decisions in a life-cycle model context. One study that has incorporated the disaster factor into the life-cycle model is reported in Kolusheva (2011), where she develops a life-cycle model with possible rare disasters in the stock market and the labor market to analyze investors' consumption and asset allocation decisions. In her paper, rare disasters are calibrated to match the joint empirical distribution of stock market crashes and macroeconomic contractions. She finds that a small probability of disaster is sufficient to deter median investors from investing in stocks during their working life.

The model in this paper differs from that in Kolusheva (2011) in two important aspects: First, the length of the investment horizon; and second, the nature of human capital shock. Her paper emphasizes the whole life cycle, from early working life until death, whereas mine focuses on retirees' behavior. In her model, the shock to permanent income comes from the risk of 
macroeconomic contraction, which affects an investor only during his working life. The insulation from labor market risk after retirement implies that retirees will hold more risky assets than before retirement, an implication which does not hold empirically. This paper addresses this issue by considering health risk as a shock to retirees' human capital; the shock is idiosyncratic and does not correlate with general stock market crisis.

This paper will proceed as follows: Section 3.2 sets up the model. Section 3.3 describes parameter values and calibrates the model using data from the Health and Retirement Survey (HRS). Section 3.4 describes the model and presents the results of optimal behavior under different scenarios. Section 3.5 extends the model to incorporate heterogeneous health risk. Section 3.6 presents the simulation results and compares the results with the empirical distribution of risky asset holdings in the Health and Retirement Survey, and Section 3.7 concludes.

\subsection{The Model}

\subsubsection{The preference}

Retiree $i$ 's preference is characterized by a time-separable power utility function:

$$
U_{1}^{i}=E_{1} \sum_{t=1}^{T} \beta^{t-1}\left(\prod_{j=1}^{t-1} p_{j-1}\right) \frac{C_{i t}^{1-\gamma}}{1-\gamma}
$$

The retiree is assumed to live a maximum of $T$ periods. In each period, there is a possibility that the retiree will die. Let $p_{t}$ denote the probability that the retiree is alive at date $t+1$, conditional on being alive at date $t$. The retiree maximizes expected life utility with a constant relative risk aversion $\gamma$ and time preference parameter $\beta$. Values for these parameters will be discussed in Section 3.3. 


\subsubsection{Modeling health shock}

Each period, retirees will receive pension and Social Security benefits as labor income. The riskiness of labor income plays an important role in an investor's investment behavior and needs to be taken into consideration when solving the life-cycle model. Previous literature (e.g. Carroll, 1997; Winter et al. 2012) show that the risky labor income process can be modeled as having a deterministic component and stochastic components. In my model, labor income is assumed to be at a fixed level, as income from social security and pension is normally not subjected to labor market fluctuation ${ }^{3}$. For retirees, however, health risk can be a major shock to their income stream. I model the magnitude of a health shock to be proportional to their income, and the income after health shock is specified as:

$$
Y_{i, t}=Y_{i}-Y_{i} \times h_{i, t}
$$

where $h_{i, t} \in[0,1]$. When $h_{i, t}=0$, there will be no health shock for the period; health expenditure will be zero, and the retiree's disposable income will be equal to his social security/pension income. When $h_{i, t}>0$, there will be a health shock for the period, and the retiree's disposable income will be reduced. $h_{i, t}$ is bounded above by 1 , so the maximum health expenditure will not exceed current income; i.e., $Y_{i, t}$ has a lower bound of zero. For each period, the health expenditure ratio, $h_{i, t}$, can be different, and the retiree knows the realization of $h_{i, t}$ only when he enters that period. However, the retiree has prior knowledge of the distribution of $h_{i, t}$ and optimizes his

\footnotetext{
${ }^{3}$ In the life-cycle model developed by Cocco et al. (2005), retirement income is modeled as a constant fraction of permanent labor income in the last working year before retirement.
} 
behavior based on his expectation of $h_{i, t}$. The distribution of $h_{i, t}$ is estimated using data from the Health and Retirement Survey and will be discussed in more detail in Section 3.3.

\subsubsection{The financial market}

Each period, investors can invest in two assets in the financial market: a riskless and a risky asset. The riskless asset has a return $r_{f}$ for each period. For the risky asset, there are two states: a non-crisis state characterized by a mean risk premium of $\mu$ and an innovation component $\eta_{t+1}$ :

$$
\tilde{r}_{t}^{\text {noncrash }}=r_{f}+\mu+\eta_{t+1}
$$

where $\eta_{t+1}$ is assumed to be independent and identically distributed (i.i.d) as $N\left(0, \sigma_{\eta}^{2}\right)$. There is also a non-zero probability $\pi^{\text {crash }}$ that the stock market will crash, and stock return will be $\tilde{r}^{\text {crash }}$ if the market crashes. Combining these two states, we can express the risky asset return as:

$$
\tilde{r}_{t}=\left\{\begin{array}{c}
\tilde{r}^{\text {noncrash }}, \text { with probability } 1-\pi^{\text {crash }} \\
\tilde{r}^{\text {crash }}, \quad \text { with probability } \pi^{\text {crash }}
\end{array}\right.
$$

The parametrizations of $r_{f}, \mu, \sigma_{\eta}^{2}, \pi^{\text {crash }}$, and $\tilde{r}^{\text {crash }}$ will be discussed in Section 3.3.

\subsubsection{Retirees' optimization problem}

For simplicity, this model assumes that the health risk is exogenous and that the retiree does not choose the amount of health care; rather, he takes it as a shock which reduces his disposable income, and he makes his optimal consumption and asset allocation decisions accordingly. The timing of the events is as follows: at the beginning of each period t, the retiree starts with financial wealth $W_{t}$, receives a pension income $Y_{i}$, And observes the health shock $h_{i, t}$ to his income. The uncertainty associated with disposable income dissipates once the retiree enters 
period t. Following Deaton (1991) and Cocco et al. (2005), I denote the total available resources as cash-at-hand $X_{i, t}$, where $X_{i, t}=W_{i, t}+Y_{i, t} \cdot X_{i, t}$ is the total amount of available resources for the retiree during the period $\mathrm{t}$, and his problem is to decide how much to consume in this period $C_{t}$. The resources not consumed will be saved and used to generate the next period's financial wealth, $W_{i, t+1}$. The financial market offers two available assets for saving: one risk-free asset and one risky asset. The retiree needs to make an allocation decision (i.e., the portfolio share that will be invested in risky assets, $a_{i, t}$ ). After the consumption decision and the asset allocation decision have been made, his financial wealth at the beginning of the next period $t+1$, will be:

$$
W_{i, t+1}=r_{i, t+1}^{p}\left(W_{i t}+Y_{i t}-C_{i t}\right)
$$

The return of the portfolio from time $t$ to time $t+1$ is given by:

$$
\tilde{r}_{i, t+1}^{p}=\alpha_{i t} \tilde{r}_{t+1}+\left(1-\alpha_{i t}\right) r_{f}
$$

where $\alpha_{i t}$ is the portfolio share invested in risky assets and $\left(1-\alpha_{i t}\right)$ is the portfolio share invested in the risk-free asset. Assuming the retiree faces borrowing constraints and cannot short-sell the risk-free asset, $\alpha$ is restrained to 1 . The retiree's optimization problem is to maximize the objective function (3-1) subject to constraints (3-2) through (3-6). The state variables are $\left\{t, X_{t}, Y\right\}$, and the control (choice) variables are $\left\{C_{t}, \alpha_{t}\right\}$. For each period, the optimal rules of consumption and portfolio share are functions of the state variables $t, X_{t}$, and $Y$.

The Bellman equation for a retiree's optimization problem is given by:

$$
V_{i t}\left(X_{i t}\right)=\max _{C_{i t} \geq 0,0 \leq \alpha_{i t} \leq 1}\left[U\left(C_{i t}\right)+\beta p_{t} E_{t} V_{i, t+1}\left(X_{i, t+1}\right], \quad t \leq T\right.
$$


where $V_{i t}\left(X_{i t}\right)$ is the value function, denoting the maximized utility given $X_{i t}$, and the next period total resource $X_{i, t+1}$ is:

$$
X_{i, t+1}=W_{i, t+1}+Y_{i, t+1} \times\left(1-h_{i, t+1}\right)
$$

Substituting (3-5) and (3-6) into (3-8), $X_{i, t+1}$ can be expressed as:

$$
X_{i, t+1}=\left(X_{i t}-C_{i t}\right)\left(\alpha_{i t} r_{t+1}+\left(1-\alpha_{i t}\right) r_{f}\right)+Y_{i} \times\left(1-h_{i, t+1}\right)
$$

where $X_{i, t+1}$ depends on the amount of saving this period, the return on the savings (which in term depends on the portfolio choice $\alpha_{i t}$ ), and the next period's health shock.

Since this model does not have a closed form analytical solution, I use a numerical method to find the value function and the associated optimal policy rules. Unlike an infinite period dynamic programming problem, this model has finite periods as the retiree can live only a maximum of $T$ years. Specifically, the retiree retires at 65 and is expected to live 30 years after retirement. A finite period setting allows us to solve the model recursively from the last period. The procedure is as follows: set the retiree's last period value function $V_{T}$ equal to zero as he dies at time $T$, and assume there is no bequest motive. Given this condition, substitute $V_{T}=0$ into the Bellman equation (3-7), and the optimal value for $V_{T-1}$, which is the utility function evaluated at total cash-at-hand, at T1. Having found $V_{T-1}$, we can solve for $V_{T-2}$, and so on. The process continues until $V_{1}(x)$, which is the value function at the beginning of the period, is found. The value functions of a finite horizon discrete Markov decision model are always well defined. By finding the value functions for each period, we can also obtain the optimal consumption and portfolio choice for each period, which generate the value function. 
As demonstrated in previous literature (Carrol, 1997; Cocco et al., 2005; Kolusheva, 2011), it is possible to reduce the state variable space by normalizing wealth with respect to permanent income, which is a constant pension level $Y$ in this case. Results in Section 3.4 will be expressed in terms of the normalized version of the cash-at-hand variable and the consumption variable.

\subsection{Parameters and Model Calibration}

\section{[Insert Table 3-1 here]}

To solve the model, we need to choose appropriate parameter values for retirees' preference and financial market parameters. For retirees' risk preference and standard financial market parameters, I use the standard values obtained from Cocco et al. (2005) and Kolusheva (2011). Table 3-1 provides a summary of the values of the benchmark parameters. The coefficient of relative risk aversion is set to 7 , and the risk-free rate, mean of stock market return, and standard deviation of stock market return are set to $0.02,0.06$ and 0.15 , respectively. The retiree dies with a probability of one at age 95 . Prior to this age, the conditional survival probability value, $p_{j}$, is obtained from the mortality tables of the National Center for Health Statistics.

The parameter values for $\pi^{\text {crash }}$ and $\tilde{r}^{\text {crash }}$ are obtained from Barro and Ursua (2009) and Kolusheva (2011), where market crashes are defined as peak-to-trough cumulative real returns of $-25 \%$ or worse. Kolusheva (2011) finds that the unconditional probability of a stock market crash is $10.11 \%$, and the probability of a stock market crash and no economic contraction is $7.47 \%$. Ideally, the model used in this paper should also be calibrated using the empirical distribution of historical stock market crashes. To simplify the analysis, however, I set the stock return of a market crash, $\tilde{r}^{\text {crash }}$, to be $-20 \%$, close to the upper bound of the market crash return documented in Barro 
and Urusa (2009). I set the probability of a crash to be $8 \%$, close to the value found in Kolusheva (2011). With this parameterization, the market crash can happen with a probability of $8 \%$, and the return will be $-20 \%$ when it happens. Similar optimal policy rules can be drawn when the crash return is set to $-25 \%$ and the crash probability is $10 \%$. The only parameter that needs to be estimated is the magnitude and distributional properties of the health expenditure shock.

\subsubsection{Health expenditure calibration}

In this section, I use the data from the Health and Retirement Survey (HRS) to characterize the empirical distribution of the health expenditure ratio. The Health and Retirement Survey is a biannual study conducted by the Institute for Social Research at the University of Michigan and funded by the National Institute on Aging. This survey provides a comprehensive set of variables including the demographics, health, income, wealth, and pensions of American elderly. The survey starts in 1992 and interviews 22,000 Americans aged 50 or older. RAND provides an easy-to-use version of the HRS, which combines all the waves from 1992 to 2010 and calculates imputations for income, assets, and medical expenditures from the original survey data. Based on when the respondent was born, the HRS further divides the respondents into different cohorts. The largest cohort is the HRS cohort, who were born between 1931 and 1941. Other cohorts include the AHEAD, who were born before 1924; Children of Depression (CODA), born between 1924 and 1930; War Babies (WBs), born from 1942 to 1947; and Early Baby Boomers (EBBs), born between 1948 and 1953. In this study, I use data from all of the cohorts.

[Insert Table 3-2 and Table 3-3 here]

Since the model intends to explain the saving and investment decisions of retirees, I restrict the sample to retired households only. For married couples, retirement status means that both 
husband and wife are retired. Table 3-2 provides summary statistics for some key variables for retirees. Health expense E, which includes all private insurance premiums and all out-of-pocket medical expenses, has a mean value of $\$ 2,707$, and its standard deviation is $\$ 8,350$, implying that a large variation in health expense exists among retirees. Table 3-3 provides more detailed summary statistics for the medical expenses for different cohorts across years. For Social Security and pension income, the mean value is $\$ 24,314$. Financial net worth, which is the sum of the dollar amounts in checking accounts, saving accounts, CDs, money market accounts, bonds, stocks, and mutual funds, has a mean value of $\$ 129,970$. Total net worth is the difference between total assets and total liability and has a mean value of $\$ 370,754$. Since this study focuses on the portfolio choice problem, financial wealth is a more relevant wealth measure as the allocation is made from financial wealth, not total household wealth, which includes non-liquid assets.

\section{[Insert Table 3-4 here]}

As discussed in Section 3.2, I use Social Security and pension income P as a proxy for permanent income after retirement. Table 3-4 provides a more detailed description of this variable for different cohorts across years. The numbers show that income is relatively stable across years after adjusting for inflation, which is consistent with the assumption that permanent income does not grow or decline significantly for retirees. Therefore, permanent income can be used to normalize wealth, and normalized cash-at-hand is the key state variable for this model. The health expense ratio is calculated as the ratio of annual health expenditure $\mathrm{E}$ to permanent income $\mathrm{P}$. As discussed above, retirees have a relatively constant stream of Social Security/pension income each year. Health shocks, however, are more stochastic, and health expenditures are often unavoidable. This expense can be seen as a reduction in the retiree's income, which is similar to a negative 
transitory shock to the usual labor income process. To determine the distribution of this shock's magnitude, I calculate the ratio for each household annually.

[Insert Table 3-5 here]

Table 3-5 provides summary statistics for the medical expense ratio. The mean annual health expenditure to permanent income ratio is $17.7 \%$ for the overall sample, with a median of $5.4 \%$ and a standard deviation of $89.3 \%$. As health expenditures are closely related to health status, I further classify the whole sample into two subsamples by respondents' health status. HRS has a self-reported health status variable, ranking from 1 to 5 , with 1 as excellent health and 5 as poor health. If a retiree said his health is excellent, very good, or good, the health status is set to be good, and if a retiree said his health is fair or poor, the health status is set to be poor. I then calculated the health expenditure ratio for these two groups separately. As shown in Table 3-5, the good health group has a mean health expenditure ratio of $13.2 \%$, whereas the poor health group's ratio is $23.8 \%$, substantially higher than that of the good health group.

In addition to health status, another factor that can significantly affect the medical expense ratio is age. Older people, especially those who are at the end of their life-span, can have large medical expenses which are not covered by Medicare or private health insurance. An example is long-term care expenses, which are not typically covered in standard insurance programs. To assess the age effect, I divide the whole sample into two groups: those between 65 and 85 years old and those who are older than 85 . The younger group has an average $15.8 \%$ medical expense ratio, while the older group has an average ratio of $31.2 \%$. If we further divide the age group into different health categories, substantial heterogeneity exists among different groups. The healthy younger retirees have an average ratio of $11.8 \%$, whereas for the older group with poor health, the average health expenditure to income ratio climbs to $40 \%$. 
[Insert Figure 3-1 here]

Figure 3-1 shows the empirical frequency distribution of the medical expense ratio for the overall sample, and I fit it to a lognormal distribution with mean equal to -2.8 and a standard deviation of 1.4. The parameters of the fitted distribution will be used as inputs for the model calibration to characterize the shocks to the retirees' income. The results in the next section are based on the assumption that all retirees face the same health shock distribution. In an extension section of this study, I calibrate the health expenditure ratio and solve the model for the good health and poor health groups separately, and the results are presented in Section 3.5.

\subsubsection{Problem with health ratio calibration}

Among the several known distributions, log-normal distribution best fits the health expenditure ratio. However, the Kolmogorov-Smirnov test still rejects the hypothesis that the health expenditure ratio comes from a log-normal distribution. One reason is that the parameters specified in the KS test are estimated from the actual data, which violates the assumption that the parameters should be pre-specified and should not come from the data. In a robust check, I apply the Monte-Carlo simulation to find the expected value of the value function. In the simulation, I do not calibrate the health expenditure ratio to any parametric distribution. Instead, I randomly draw 500 samples from the empirical distribution of the health expenditure ratio and incorporate them in the numerical analysis. This method does not rely on any parameterization assumption, but can reasonably capture the distributional property of health shock. The simulation analysis generates results similar to those obtained when the health expenditure ratio is calibrated to the log-normal distribution. 


\subsection{Optimal Policy Rules}

Using the parameter value discussed in Section 3.3, I solve the model numerically to obtain the optimal consumption and portfolio choice rules. This section presents the optimal rules under different scenarios. As a benchmark analysis, Section 3.4.1 discusses retirees' optimal policy rules when there is no health risk. In this case, retirees do not have any health shock to their Social Security/pension income, but they are still subject to financial crisis risk. Section 3.4.2 adds health risk to retirees' income, which is the main feature of this model. Section 3.4.2.1 presents a case where I only consider the health risk but do not account for the financial crisis risk. Finally, Section 3.4.2.2 discusses the results of the full model where both health risk and financial crisis risk are considered.

\subsubsection{Policy rules without health risk}

[Insert Figure 3-4 here]

Figure 3-4 (a) shows the results of the portfolio choice when there is no health shock to the income. In this case, the optimal share invested in risky assets decreases as normalized wealth rises. Retirees with higher (normalized) wealth level have a lower share of their financial wealth invested in risky assets. This result is consistent with the implications of the study by Cocco et al. (2005). The reason for the result is that if labor income does not have any risk after retirement, it is equivalent to risk-free assets. Therefore, retirees' total wealth can be seen as a combination of financial wealth and human capital wealth (the discounted value of all future Social Security and pension income). For retirees with lower normalized financial wealth, the proportion of risk-free human capital out of total wealth is higher than it is for retirees with a large amount of financial wealth. It is the relative weight of risk-free assets as a portion of one's total wealth that determines 
how much risky assets one should hold. Retirees with lower normalized financial wealth have a higher proportion of risk-free assets (discounted future Social Security/pension income) in their wealth holding; therefore, they will invest more aggressively in stocks. The optimal share invested in stocks also decreases with age, except for the case when the normalized wealth is smaller than 4. As the retiree ages, he will reduce his optimal risky asset holdings.

[Insert Figure 3-8 here]

To provide a better illustration of the optimal portfolio choice, Figure 3-8 (a) presents the two-dimensional graph for retirees' behavior for each level of normalized wealth at different ages. For retirees who are older than 65 , the share invested in stocks monotonically decreases as normalized wealth increases, and with a given level of normalized wealth, older retirees will have a lower share invested in risky assets.

Financial crisis risk makes investing in stocks riskier. Compared with the case without any financial crisis (results not shown here) ${ }^{4}$, the difference is that at each level of normalized wealth, the optimal share invested in stocks is lower if we consider a financial crisis. The lower level of stock investment is consistent with the empirical observations found in the HRS. However, the result predicted by this case implies that as normalized wealth decreases, optimal share in stocks should increase, which is not consistent with the fact that wealthy investors generally have a higher portfolio share in stocks than do poor investors (Wachter, 2010). In the HRS, the 75 percentile value of the normalized financial wealth is 5.87; a more accurate model should be able to generate the optimal policy rule for the majority of retirees (i.e., those who have a normalized wealth ratio below 6). The baseline model's failure can be attributed to its failure to take health risk into account.

\footnotetext{
${ }^{4}$ Results available upon request.
} 
Though retirees receive a fixed amount of income after retirement, due to health risks and the nature of health expenditures, the effective income of the retiree is not without risk. In the next section, I incorporate health shocks into the model and analyze how health shock affects retirees' optimal behavior.

\subsubsection{Policy rules with health shock}

In this section, health shocks are added to retirees' income. The average value of their health expenditure is $17 \%$ of their income. The health shock is assumed to be i.i.d for each period. First, I examine the case when there is no financial crisis.

\subsubsection{Without Financial Crisis}

[Insert Figure 3-4, Figure 3-9 and Table 3-6 here]

Figure 3-4 (b) shows the portfolio rule when income is subjected to a health shock but there is no financial crisis. The results show that the portfolio share is lower when normalized wealth is low and gradually increases as normalized wealth increases and then decreases when normalized wealth increases further; the implication of this model can partly explain the phenomenon that the portfolio share increases with wealth as shown in Table 3-6.

Figure 3-9 presents a 2-dimensional graph for retirees at each normalized wealth level at different ages. The pattern is not very clear when the normalized wealth is below 1 . However, when the normalized wealth is above 1 , the portfolio share increases with normalized wealth for all age groups (except for the 94-year-old case) and gradually declines after normalized wealth reaches 4.5. This result is more aligned with the actual observations. However, one drawback of this model is that the optimal portfolio share is much higher than that shown by the actual observations, especially for people who have recently retired, for whom it increases from $20 \%$ to 
$90 \%$ when normalized wealth reaches 4 and stays above $50 \%$ when normalized wealth level further increases. And for those who are 75 years old, the optimal share also increases to a significantly high level of $75 \%$ when normalized wealth is around 5, which is not consistent with what we observe in the real data. The substantially high level of risky asset share can be attributed to the fact that financial crisis risk is not accounted for.

\subsubsection{With financial crisis}

[Insert Figure 3-5 and Figure 3-10 here]

This section presents the results of the full model where both health risk and financial crisis risk are considered. From Figure 3-5(a) we see that the optimal portfolio share drops slightly when normalized wealth is low and gradually increases as normalized wealth increases. Figure 3-10 (a) shows a more detailed portrait for retirees at each normalized wealth level at different ages. We can see that for all age groups (except at 94 years old), the portfolio share in stocks gradually increases as normalized wealth approaches 4.5 and then declines slowly until leveling out when normalized wealth is higher than 15 . When these results are compared with the empirical data, it is clear that this model better captures the dynamics of stock investment, especially when normalized wealth is in the range of 1 to 6 , where the normalized wealth of $75 \%$ of retirees falls. The magnitude of the risky asset share is also captured reasonably well. For example, for the 65 age group, the portfolio share increases from $20 \%$ to around $45 \%$ and remains at $30 \%$ as normalized wealth further increases. For the 75 age group, the portfolio share increases to $35 \%$ when the normalized wealth level is 3 and stays at a relatively constant level of $20 \%$ when the normalized wealth level is higher than 9. 
Despite the better prediction generated by this model for the majority of retirees, it fails to explain the behavior of retirees whose normalized wealth is very high (i.e., those in the highest decile of the normalized wealth distribution) as shown in Table 3-6, where the mean risky asset holding increases with the mean normalized wealth ratio. In addition, the optimal behavior predicted by this model underestimates the risky asset share observed in the HRS, which is about $50 \%$ for those whose normalized wealth level is above 30 . One possible explanation is that in this model, every retiree is assumed to face the same financial crisis risk. However, it is possible that very wealthy retirees (as measured by high normalized financial wealth ratio) may be more risk tolerant and have better risk management skills, and more knowledge about financial market that would enable them to mitigate the detrimental effects of the financial crisis, so their behavior shows a closer resemblance to that predicted by the no financial crisis scenario as shown in Figure 3-9 (a).

\subsection{Extension: Heterogeneous Health Risk}

In the previous discussion, I assume all retirees have the same health shock risk. However, as shown in Section 3.3, the health expenditure ratio can differ substantially between the good health group and the poor health group. This section examines how different health status affects retirees' optimal portfolio choice. Figure 3-3 presents the empirical distribution as well as the fitted distribution of the health expenditure ratio for the good health group versus the poor health group. Each group is fitted to a lognormal distribution; for the good health group, $\mu=-3.0$ best captures the features of the data, while for the poor health group, $\mu=-2.5$ fits better. Using these parametric values, I solve the model for the good health group and the poor health group separately. 
[Insert Figure 3-11 to Figure 3-13 here]

Figure 3-11 to Figure 3-13 compare the portfolio choices for the good health and poor health groups at different ages. We see that the good health group consistently holds more stocks than the poor health group, with or without a financial crisis. The result is consistent with the empirical observation from the HRS and also with the results found in previous studies (Rosen, 2004; Edwards, 2008) that investors' poor health reduces their risky asset holdings.

\subsection{Simulation Results}

[Insert Figure 3-14 to Figure 3-16 here]

To assess the distributional properties of consumption and the risky asset share, I simulate the consumption and investment profiles of 5,000 retirees using the policy function obtained in Section 3.4. The retirees' initial normalized wealth is drawn from the empirical distribution of the normalized wealth calculated from the HRS. Figure 3-14 presents the histogram of this empirical distribution. The frequency distribution of normalized wealth shows that the majority of retirees in the HRS have a normalized financial wealth ratio below 10.

I first simulate the case discussed in Section 3.4.1 where there is no health shock to retirees' income. Figure 3-15 presents the mean and the $5^{\text {th }}$ and $95^{\text {th }}$ percentiles of the cross-sectional distribution of risky asset share. Figure 3-16 displays the results when financial crisis risk is present. The mean of the simulated risky asset share is close to $100 \%$ until the end of life. The simulation results do not match the empirical mean risky share shown in Table 3-7, where the mean risky share is about $25 \%$ after retirement. This result is also higher than the results in Kolusheva (2011); where her model implies that the mean risky asset share is about $50 \%$ after retirement with disastrous stock market risk. Despite being lower than the results shown here, Kolusheva's results 
are still too high to match the empirical distribution of the risky asset share. Failure to consider health risk can be a major factor leading to the prediction of this unrealistically high portfolio share.

I then simulate the case where there is health shock to the retirees' income. Figure 3-16 presents the mean and the $5^{\text {th }}$ and $95^{\text {th }}$ percentiles of the cross-sectional distribution of the simulated risky asset share. Part (a) of Figure 3-16 presents the results when there is no financial crisis risk, and Part (b) shows the results when the financial crisis risk is considered. After the addition of health risk, the model better explains the actual risky asset holding behavior of retirees. From the simulation results, we can see that the mean risky share decreases after the age of 75 . However, if we consider only health risk but not the financial crisis risk, the mean risky asset share is $60 \%$ for retirees in their 70 s, which is still too high when compared with the empirical findings. After both risks are added to the simulation, the mean optimal risky share decreases to $30 \%$ for retirees at 75 years old, and it decreases further when retirees get older, results which are very close to the actual holding level found in the Health and Retirement Survey. Though retirees start with different levels of normalized wealth and there is more variation in investing risky assets when retirees first retire, the heterogeneity in the risky asset share decreases as retirees approach very old age. We can see the $5^{\text {th }}$ percentile, the mean, and the $95^{\text {th }}$ percentile gradually converge as retirees approach very old age.

\subsection{Conclusion}

Most life cycle literature assumes retirees' income is not subject to the income shocks that occur during the working life. The lack of income shocks during the retirement stage predicts that households will hold a slightly higher share in risky assets after retirement (Cocco et al., 2005). However, empirical studies have found that investment in stocks normally drops after retirement. 
This paper extends the life cycle model by incorporating health risk and financial crisis risk into the analysis of retirees' optimization problem. By modeling health risk as a stochastic shock to retirees' income and adding financial crisis to the retirees' optimization problem, this model generates policy functions that can better explain the observed investment behaviors of retirees.

For relatively young retirees with normalized wealth levels between 1.5 and 4.5 , the optimal share invested in the risky assets increases as normalized wealth rises, and declines as normalized wealth increases beyond 4.5. For older retirees, i.e., those who are over 85 years old, the optimal share in risky assets remains rather flat and does not rise or decline when the normalized wealth level is higher than 3 . In addition, the optimal policy rules derived from the model imply that retirees with good health status should hold a higher level of risky assets compared to retirees whose health status is poor. This result is consistent with the findings of several empirical studies (Rosen, 2004; Edwards, 2008) that poor health can reduce a household's investment in risky assets. 


\section{Table 3-1: Benchmark parameter values}

This table presents the benchmark parameters for the model. Preference parameters and financial market parameters are obtained from Cocco et al. (2005), and health expenditure parameters are calibrated to the data from the Health and Retirement Survey.

\begin{tabular}{ll}
\hline Description & Parameter Value \\
\hline Preference Parameters: & \\
\hline Retirement age $(K)$ & 65 \\
Discount factor $(\delta)$ & 0.96 \\
Risk aversion $(\gamma)$ & 7 \\
\hline Health Expenditure Parameters: & \\
\hline Mean of $\log \left(\frac{\text { Health Expenditure }}{\text { Income }}\left(\mu_{h}\right)\right.$ & -2.5 \\
Standard Deviation of log $\left(\frac{\text { Health Expenditure }}{\text { Income }}\right)\left(\sigma_{h}\right)$ & 1.2 \\
\hline Financial Market Parameters: & \\
\hline Riskless rate $\left(r_{f}\right)$ & \\
Mean of stock return $(\mu)$ & 0.02 \\
Standard Deviation of Stock return $\left(\sigma_{\eta}\right)$ & 0.06 \\
Crash Probability $\left(\pi^{\text {crash }}\right)$ & 0.157 \\
Return when market crashes $\left(r^{\text {crash }}\right)$ & 0.08 \\
\hline
\end{tabular}


Table 3-2: Summary statistics for variables of interest in the HRS

This table presents summary statistics for key variables of the Health and Retirement Survey from 1992 to 2010. Values are in 2010 dollars, adjusted using CPI data from the Federal Reserve of Minneapolis.

\begin{tabular}{lllll}
\hline Variable & Mean & Median & Standard Deviation & $\mathrm{N}$ \\
\hline Age & 73.11 & 73.00 & 9.36 & 59043 \\
Education & 12.08 & 12.00 & 3.21 & 59017 \\
Health Expenditure & 3046.08 & 1265.59 & 9213.04 & 59044 \\
Pension/Social Security Income & 26803.64 & 19987.63 & 255303.71 & 59044 \\
Total Income & 42062.61 & 27492.00 & 263385.69 & 59044 \\
Stock & 75903.71 & 0 & 439745.68 & 59044 \\
Financial Net Worth & 210203.11 & 34116.45 & 710615.72 & 59044 \\
Net Home Equity & 127011.97 & 80843.50 & 267053.19 & 59044 \\
$\begin{array}{l}\text { Net Worth } \\
\text { (Excluding Primary Residence) }\end{array}$ & 293861.83 & 62967.56 & 878640.35 & 59044 \\
Total Net Worth & & & & 59044 \\
\hline
\end{tabular}


Table 3-3: Summary statistics for health expenditure

This table presents summary statistics for annual health expenditure for different cohorts of the Health and Retirement Survey from 1992 to 2010. AHEAD were born 1923 or earlier; CODA (Children of Depression) were born from 1924 from 1930; HRS were born 1931-1941; WBs (War Babies) were born from 1942 to 1947; EBBs (Early Boomers) were born from 1948 to 1953; MBB (Mid Boomers) were born from 1954 to 1959. All dollar amounts are in 2010 dollars using CPI data from the Federal Reserve of Minneapolis.

\begin{tabular}{llllll}
\hline & 1992 & 1996 & 2000 & 2006 & 2012 \\
\hline COHORT & & & & &
\end{tabular}

AHEAD

\begin{tabular}{|c|c|c|c|c|c|}
\hline Mean & 2251 & 2776 & 2731 & 4040 & 4151 \\
\hline Median & 1220 & 1043 & 1146 & 1298 & 1046 \\
\hline Std Dev & 3119 & 6156 & 5985 & 9585 & 9631 \\
\hline $\mathrm{N}$ & 21 & 1638 & 2212 & 1737 & 889 \\
\hline
\end{tabular}

HRS

\begin{tabular}{llllll}
\hline Mean & 2069 & 2661 & 2256 & 2782 & 2674 \\
Median & 945 & 1210 & 1228 & 1558 & 1352 \\
Std Dev & 4466 & 4955 & 3971 & 17,609 & 5571 \\
$\mathrm{~N}$ & 514 & 1253 & 1963 & 3608 & 4396 \\
\hline
\end{tabular}

\begin{tabular}{lll}
$\mathrm{N}$ & 514 & 1253 \\
\hline $\mathrm{CODA}$ & &
\end{tabular}

\begin{tabular}{|c|c|c|c|c|c|}
\hline Mean & - & - & 2049 & 3586 & 3038 \\
\hline Median & - & - & 1140 & 1558 & 1226 \\
\hline Std Dev & - & - & 3364 & 9129 & 7100 \\
\hline $\mathrm{N}$ & - & - & 961 & 1048 & 857 \\
\hline
\end{tabular}

\begin{tabular}{|c|c|c|c|c|c|}
\hline Mean & - & - & 1465 & 3225 & 2879 \\
\hline Median & - & - & 430 & 1525 & 1562 \\
\hline Std Dev & - & - & 1892 & 4867 & 5077 \\
\hline $\mathrm{N}$ & - & - & 53 & 227 & 683 \\
\hline
\end{tabular}

Early Baby Boomers

\begin{tabular}{|c|c|c|c|c|c|}
\hline Mean & - & - & - & 2781 & 2081 \\
\hline Median & - & - & - & 773 & 956 \\
\hline Std Dev & - & - & - & 7058 & 3048 \\
\hline $\mathrm{N}$ & - & - & - & 45 & 348 \\
\hline
\end{tabular}

Mid Baby Boomers

\begin{tabular}{llllll} 
Mean & - & - & - & - & 1501 \\
Median & - & - & - & - & 401 \\
Std Dev & - & - & - & - & 2987 \\
N & - & - & - & - & 93 \\
\hline
\end{tabular}


Table 3-4: Social Security and pension income

This table presents summary statistics for Social Security \& Pension income for different cohorts of the Health and Retirement Survey from 1992 to 2010. AHEAD were born 1923 or earlier; CODA (Children of Depression) were born from 1924 from 1930; HRS were born 1931-1941; WBs (War Babies) were born from 1942 to 1947; EBBs (Early Boomers) were born from 1948 to 1953; MBBs (Mid Boomers) were born from 1954 to 1959. All dollar amounts are in 2010 dollars using CPI data from the Federal Reserve of Minneapolis.

\begin{tabular}{llllll}
\hline COHORT & 1992 & 1996 & 2000 & 2006 & 2012 \\
\hline AHEAD & & & & \\
\hline Mean & 22304 & 25711 & 24819 & 22863 & 20922 \\
Median & 21443 & 21807 & 20309 & 18302 & 15750 \\
Std Dev & 7921 & 19000 & 23475 & 17317 & 26580 \\
N & 21 & 1638 & 2212 & 1737 & 889 \\
\hline
\end{tabular}

\section{HRS}

\begin{tabular}{llllll} 
Mean & 24501 & 28704 & 30067 & 31186 & 24016 \\
Median & 18656 & 23367 & 24295 & 24716 & 20401 \\
Std Dev & 19716 & 28512 & 23338 & 35205 & 18410 \\
$\mathrm{~N}$ & 514 & 1253 & 1963 & 3608 & 4396 \\
\hline
\end{tabular}

CODA

\begin{tabular}{|c|c|c|c|c|c|}
\hline Mean & - & - & 29066 & 29187 & 25220 \\
\hline Median & - & - & 23553 & 22826 & 20270 \\
\hline Std Dev & - & - & 21580 & 23850 & 20227 \\
\hline $\mathrm{N}$ & - & - & 961 & 1048 & 857 \\
\hline
\end{tabular}

War Babies

\begin{tabular}{|c|c|c|c|c|c|}
\hline Mean & - & - & 24390 & 26291 & 24937 \\
\hline Median & - & - & 17597 & 18173 & 20924 \\
\hline Std Dev & - & - & 18641 & 27233 & 18374 \\
\hline $\mathrm{N}$ & - & - & 53 & 227 & 683 \\
\hline
\end{tabular}

Early Baby Boomers

Mean

Median

Std Dev

$\mathrm{N}$

Mid Baby Boomers

\begin{tabular}{llllll} 
Mean & - & - & - & - & 13093 \\
Median & - & - & - & - & 8322 \\
Std Dev & - & - & - & - & 12743 \\
N & - & - & - & - & 93 \\
\hline
\end{tabular}




\section{Table 3-5: Summary statistics for medical expense ratio}

This table presents the summary statistics for the medical expense ratio for the overall sample and for subsamples based on health status and age from the Health and Retirement Survey.

\begin{tabular}{|c|c|c|c|c|}
\hline Sample & Mean & Median & St Dev & $\mathrm{N}$ \\
\hline Overall Sample: & 0.175 & 0.055 & 0.577 & 54342 \\
\hline \multicolumn{5}{|l|}{ By Health Status: } \\
\hline Excellent/Good & 0.135 & 0.044 & 0.505 & 23109 \\
\hline Fair/Poor & 0.230 & 0.076 & 0.658 & 31233 \\
\hline \multicolumn{5}{|c|}{ Subsample A: $65<=$ Age $<=85$} \\
\hline & 0.163 & 0.054 & 0.543 & 48407 \\
\hline \multicolumn{5}{|l|}{ By Health Status: } \\
\hline Excellent/Good: & 0.125 & 0.043 & 0.472 & 27995 \\
\hline Fair/Poor: & 0.215 & 0.075 & 0.624 & 20412 \\
\hline \multicolumn{5}{|l|}{ Subsample B: Age $>85$} \\
\hline & 0.274 & 0.065 & 0.794 & 5935 \\
\hline \multicolumn{5}{|l|}{ By Health Status: } \\
\hline Excellent/Good: & 0.217 & 0.053 & 0.722 & 3238 \\
\hline Fair/Poor: & 0.343 & 0.084 & 0.867 & 2697 \\
\hline
\end{tabular}


Table 3-6: Mean portfolio share in stock

This table divides the retirees into 10 decile groups based on the normalized wealth level. Panel A presents the mean portfolio share for different normalized wealth deciles of the overall sample; Panel B presents the mean portfolio share for different normalized wealth deciles by age; Panel $\mathrm{C}$ presents the mean portfolio share for different wealth deciles by health status.

\begin{tabular}{lllllllllll}
\hline Decile & 1 & 2 & 3 & 4 & 5 & 6 & 7 & 8 & 9 & 10 \\
\hline Mean WRatio & 0.030 & 0.132 & 0.351 & 0.736 & 1.372 & 2.371 & 3.897 & 6.386 & 11.574 & 31.391 \\
\hline
\end{tabular}

Panel A: Mean Stock Holding Ratio

\begin{tabular}{lllllllllll}
\hline All Sample: & 0.021 & 0.035 & 0.066 & 0.114 & 0.166 & 0.220 & 0.272 & 0.345 & 0.399 & 0.496 \\
\hline
\end{tabular}

Panel B: By Age Group:

\begin{tabular}{lllllllllll}
\hline $60<=$ Age $<70$ & 0.033 & 0.047 & 0.069 & 0.152 & 0.184 & 0.276 & 0.290 & 0.380 & 0.422 & 0.498 \\
$70<=$ Age $<80$ & 0.014 & 0.033 & 0.067 & 0.115 & 0.181 & 0.214 & 0.275 & 0.351 & 0.421 & 0.506 \\
$80<=$ Age $<90$ & 0.022 & 0.035 & 0.063 & 0.092 & 0.124 & 0.192 & 0.254 & 0.323 & 0.365 & 0.488 \\
Age $>=90$ & 0.021 & 0.009 & 0.052 & 0.062 & 0.103 & 0.144 & 0.257 & 0.271 & 0.340 & 0.453 \\
\hline
\end{tabular}

Panel C: By Health Status:

\begin{tabular}{lllllllllll}
\hline Excellent/Good & 0.018 & 0.040 & 0.071 & 0.121 & 0.188 & 0.237 & 0.286 & 0.361 & 0.412 & 0.508 \\
Fair/Poor & 0.023 & 0.030 & 0.058 & 0.105 & 0.131 & 0.191 & 0.244 & 0.314 & 0.356 & 0.468 \\
\hline
\end{tabular}


Table 3-7: Portfolio share for different cohorts by age

This table presents the mean portfolio share for different age by cohorts. The HRS cohort members were born between 1931 and 1941 . The Children of Depression (CODA), were born between 1924 and 1930; The AHEAD cohort members were born before1924.

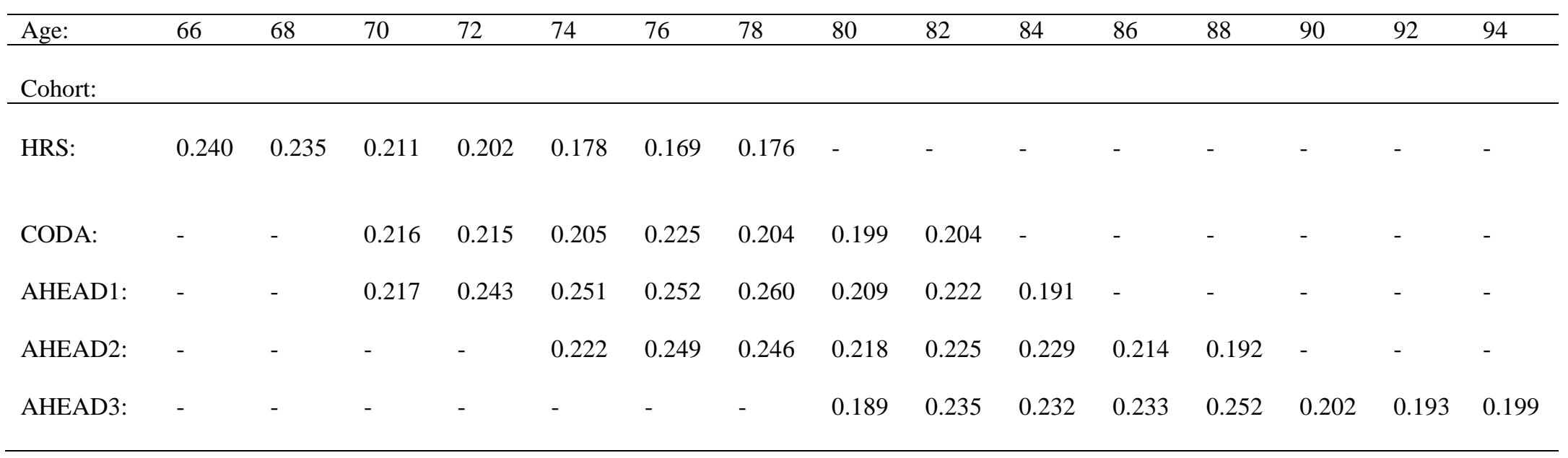


Figure 3-1: Medical expense ratio

This figure displays the histogram of the empirical medical expense ratio and the fitted lognormal distribution.

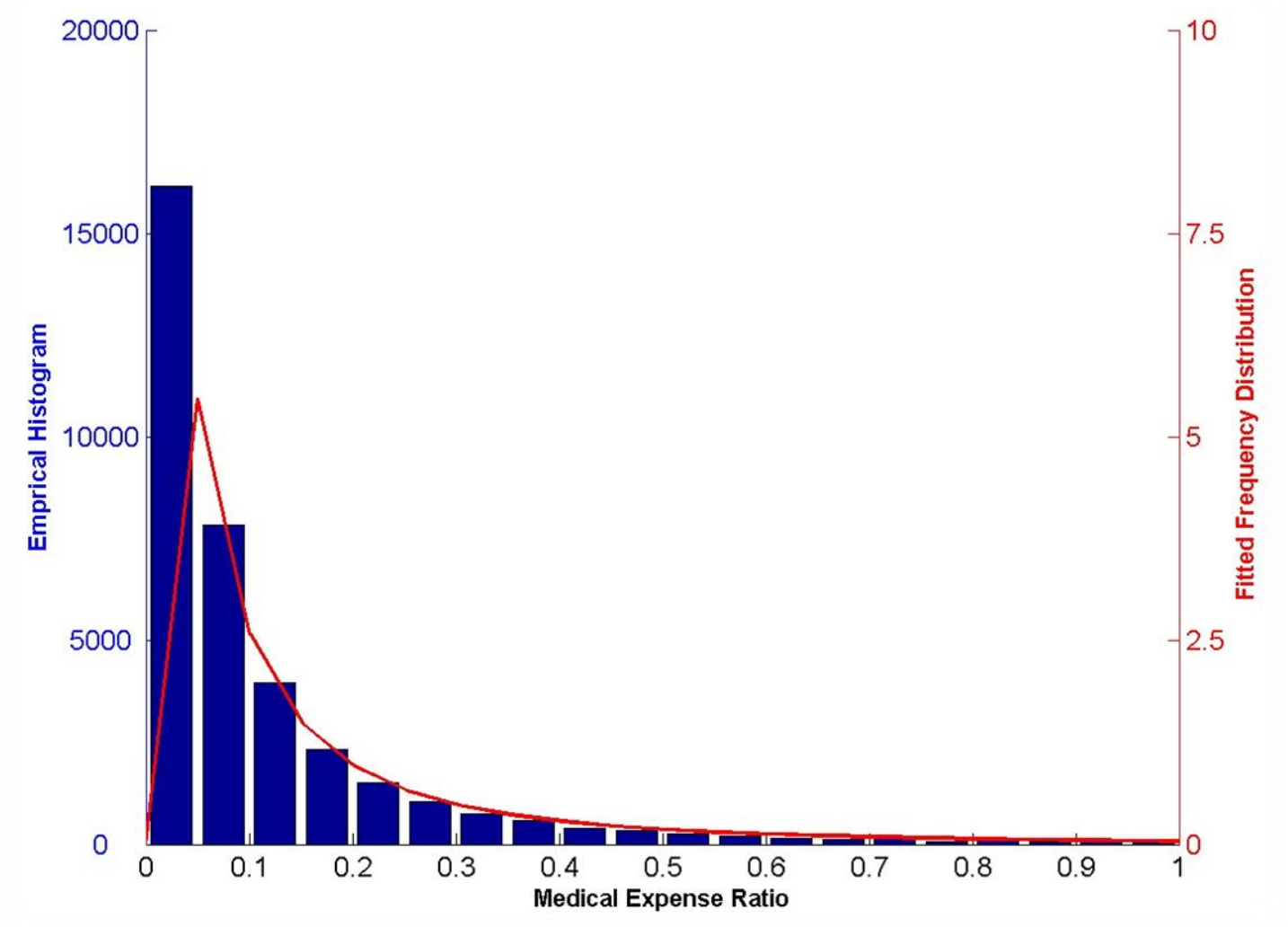


Figure 3-2: Medical expense by age group

This figure displays the histogram of the medical expense ratio and the fitted lognormal distribution for the younger age group and older age group, respectively.

(a) Age Group 1: $65<=$ Age $<=85$

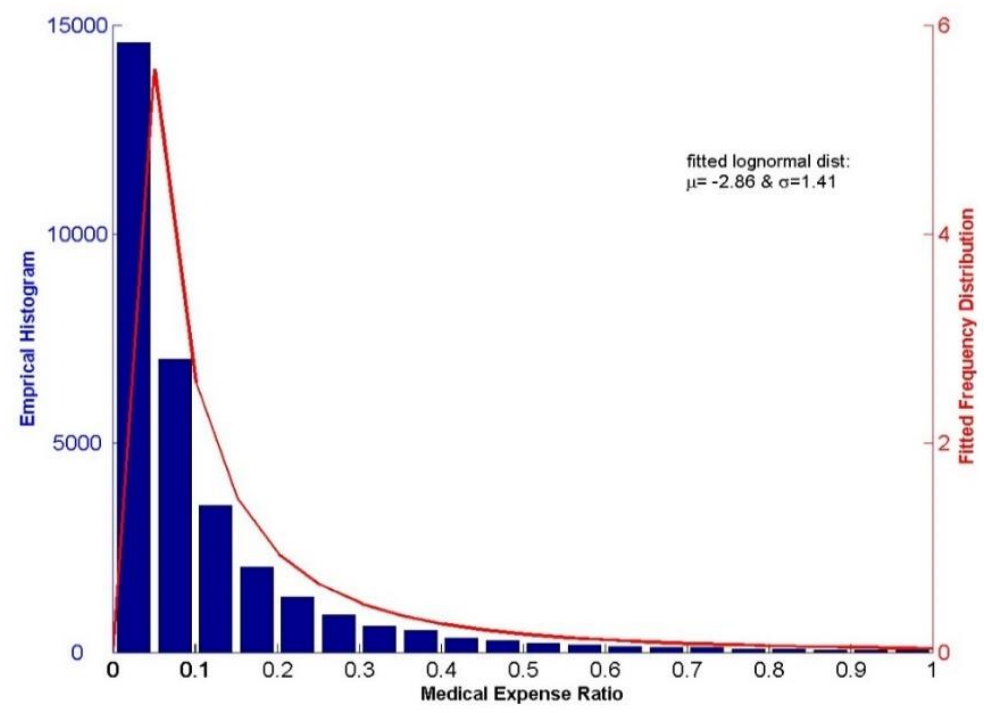

(b) Age Group 2: Age >=85

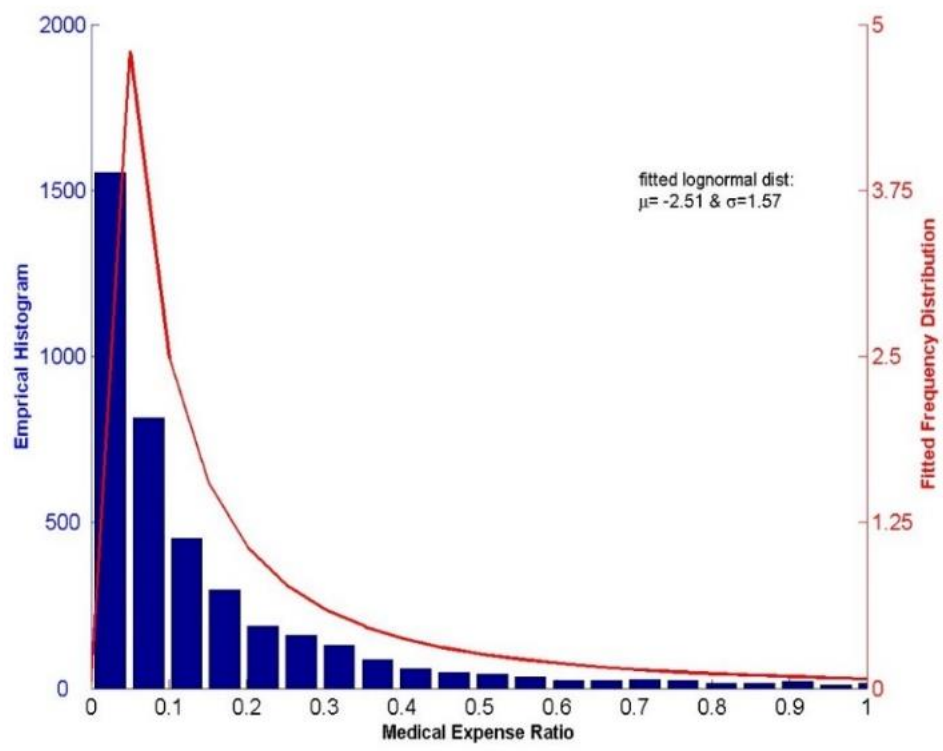


Figure 3-3: Medical expense ratio by health status

This figure displays the histogram of the medical expense ratio and the fitted lognormal distribution for the excellent/good health group and the fair/poor health group, respectively.

(a) Excellent/Good Health

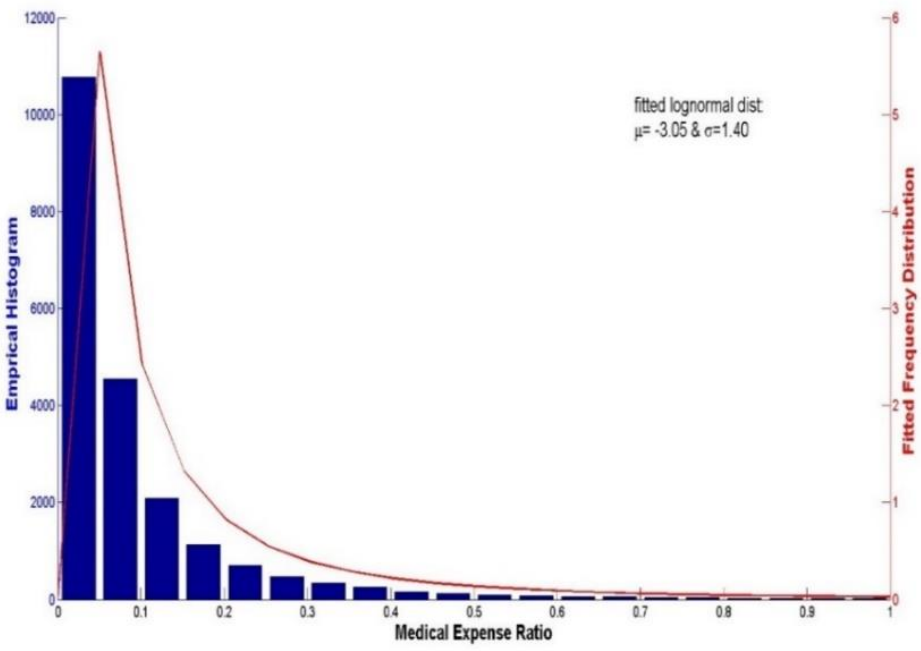

(b) Poor/Fair Health

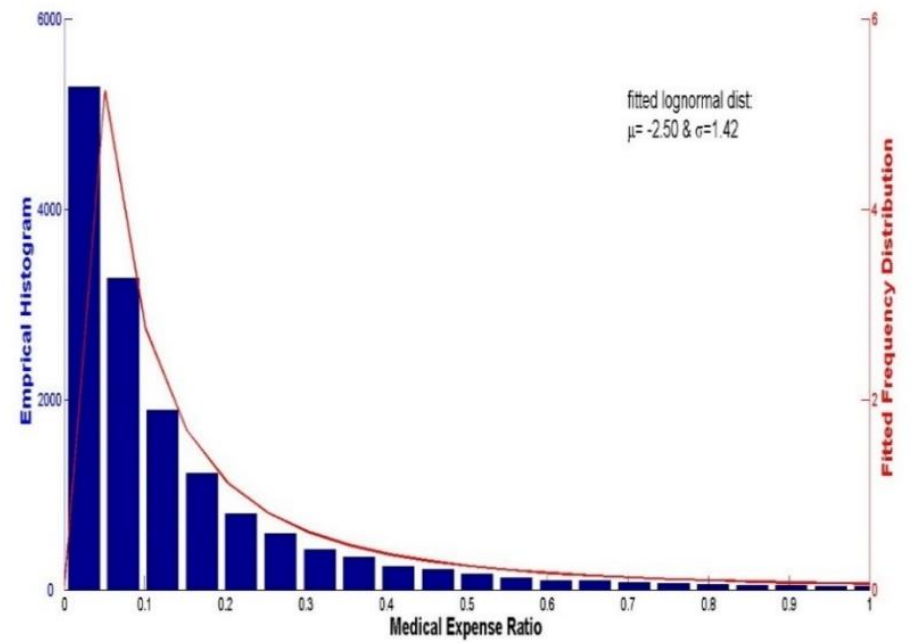


Figure 3-4: The portfolio rule for two cases

The surface plot in panel (a) displays the policy functions for the portfolio share invested in stocks at different normalized wealth levels and ages when there is financial crisis risk but no health risk. The surface plot in panel (b) displays the policy functions for the portfolio share invested in stocks at different normalized wealth level and age when there is health risk but no financial crisis risk.

(a) Without health risk but with financial crisis risk

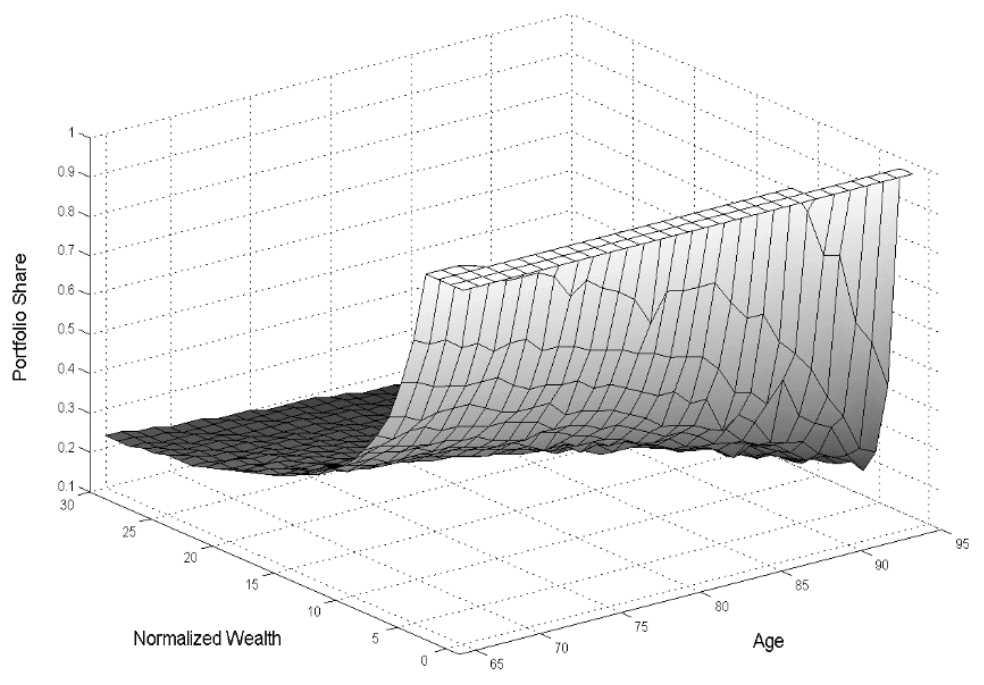

(b) With health risk but without financial crisis risk

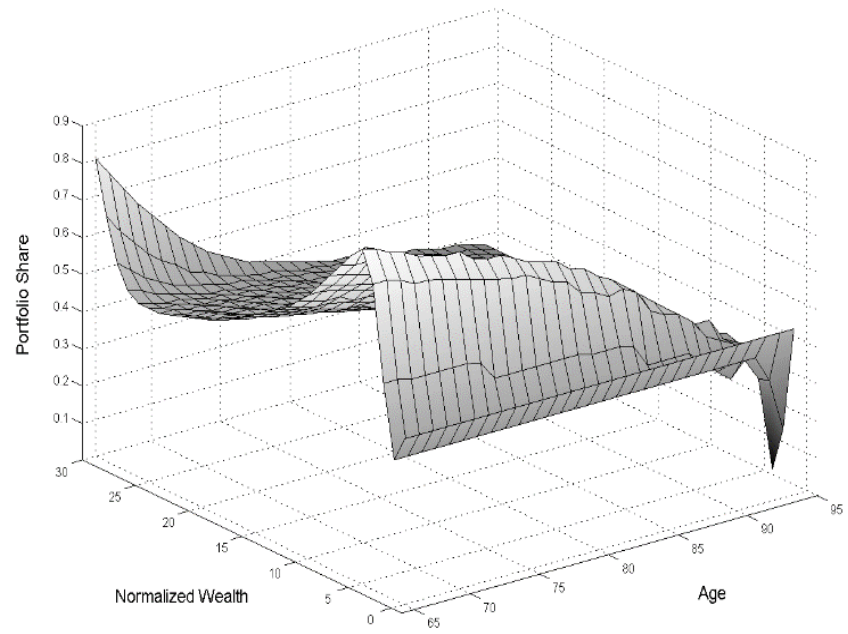


Figure 3-5: Policy function with health risk and financial crisis

The surface plots display the policy functions for the portfolio share invested in stocks and the consumption rule at different normalized wealth levels and ages when there are both health risk and financial crisis risk.

(a) The portfolio rule under both health risk and financial crisis risk

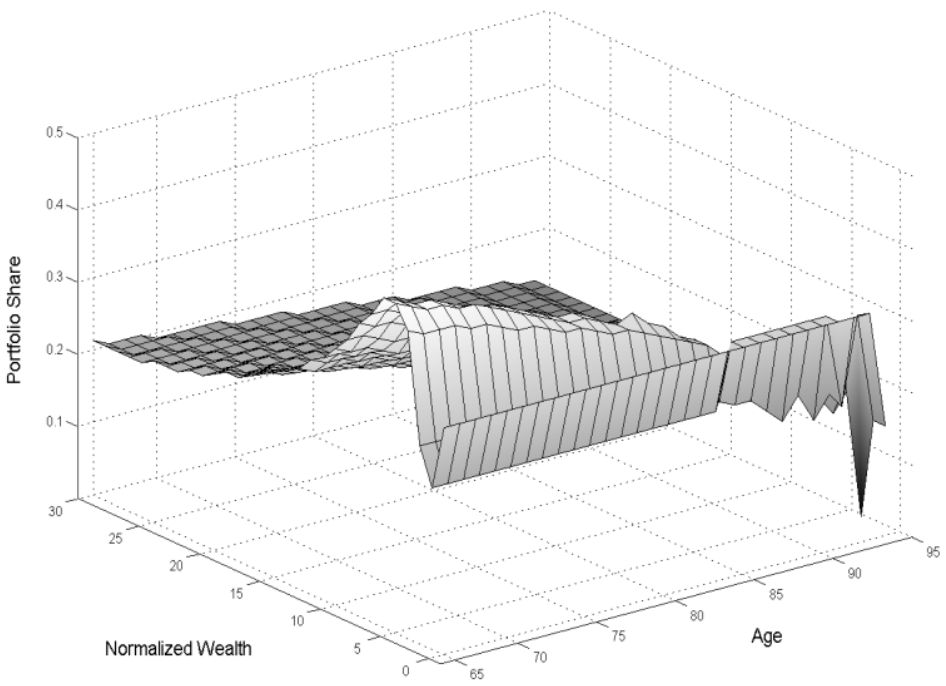

(b) The consumption rule under both health risk and financial crisis risk

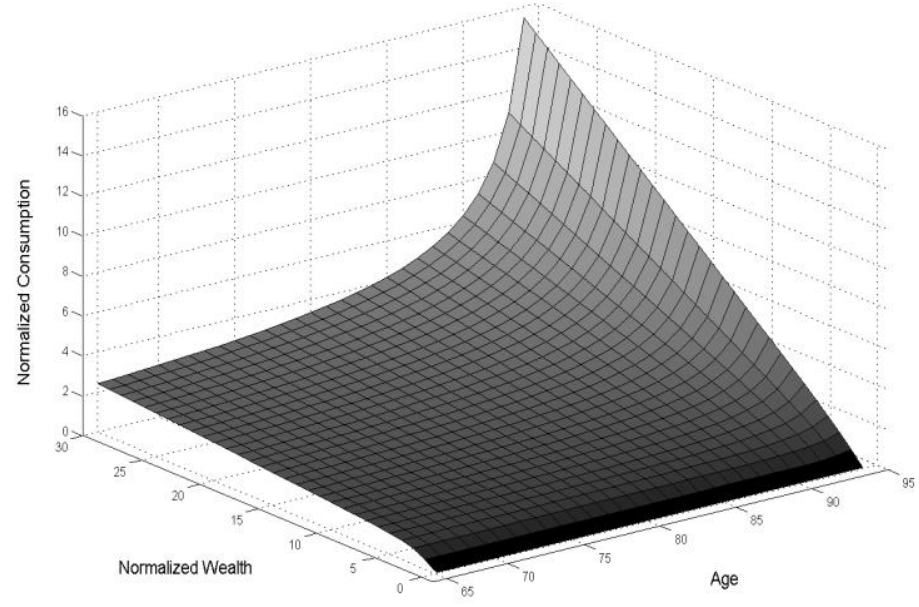


Figure 3-6: The portfolio rule for the good health group

The surface plots display the policy functions for the portfolio share invested in stocks at different ages for the good health group (a) without considering financial crisis, and (b) considering financial crisis, respectively.

(a) Portfolio Rule for good health group (without financial crisis risk)

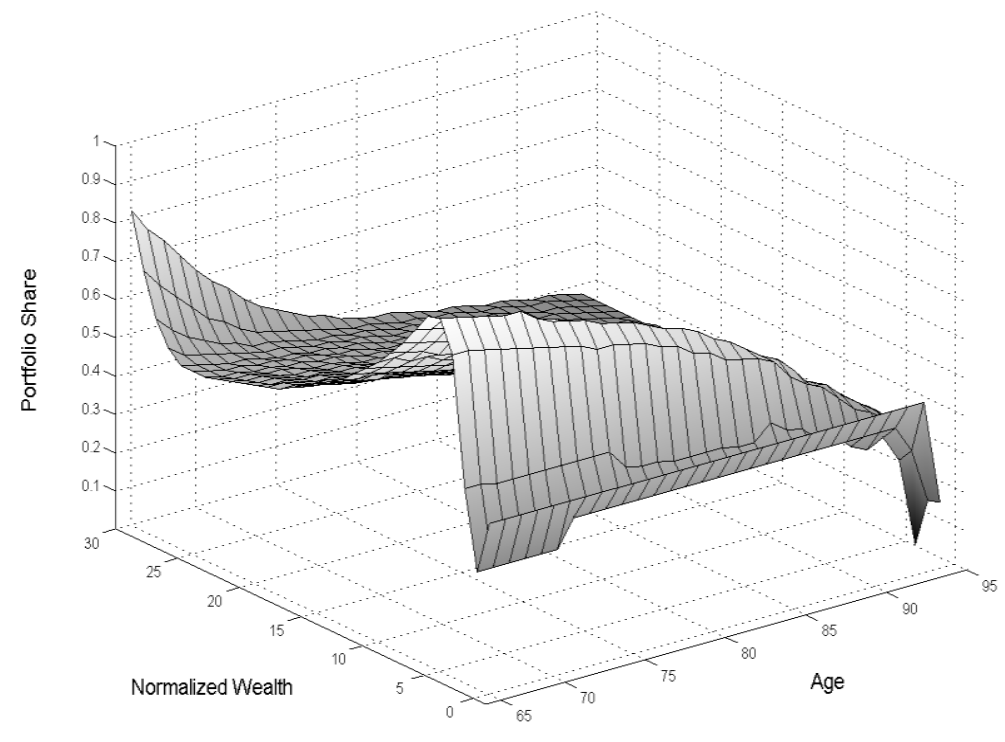

(b) The portfolio rule for the good health group (with financial crisis risk)

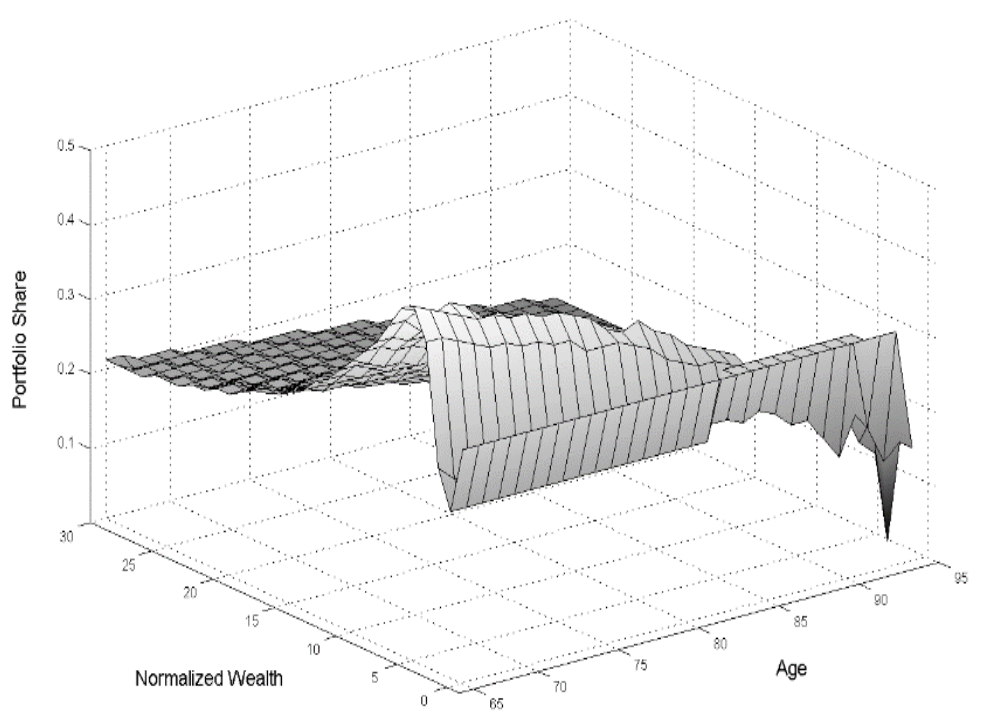




\section{Figure 3-7: The portfolio rule for the poor health group}

The surface plots display the policy functions for the portfolio share invested in stocks at different ages for the poor health group (a) without considering financial crisis, and (b) considering financial crisis, respectively.

(a) The portfolio rule for the poor health group (without financial crisis risk)

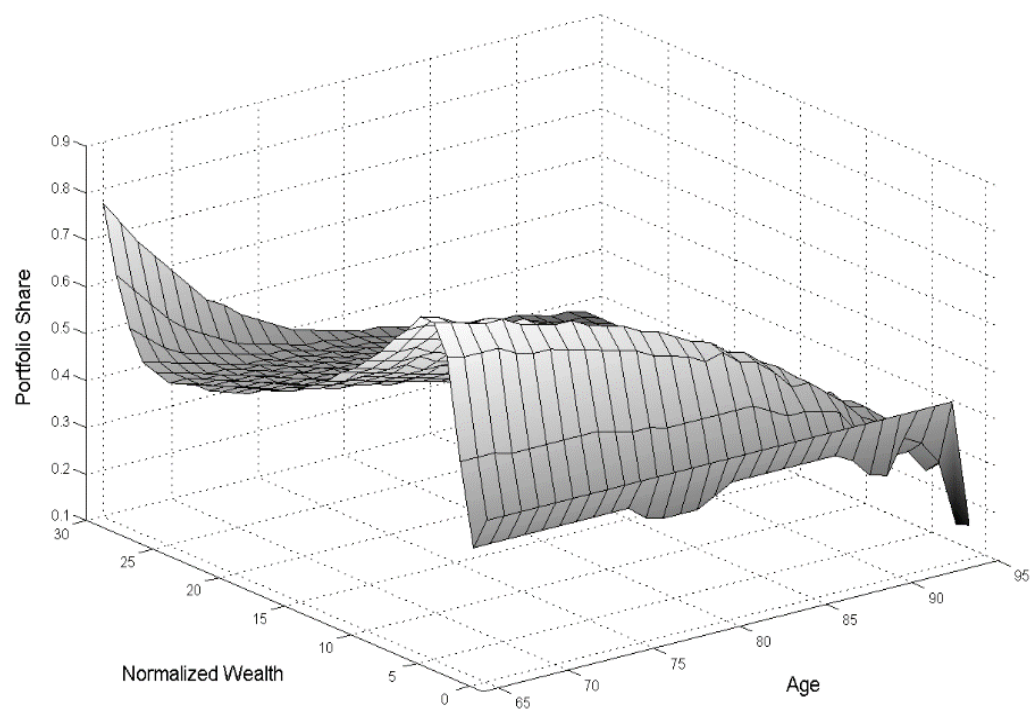

(b) The portfolio rule for the poor health group (with financial crisis risk)

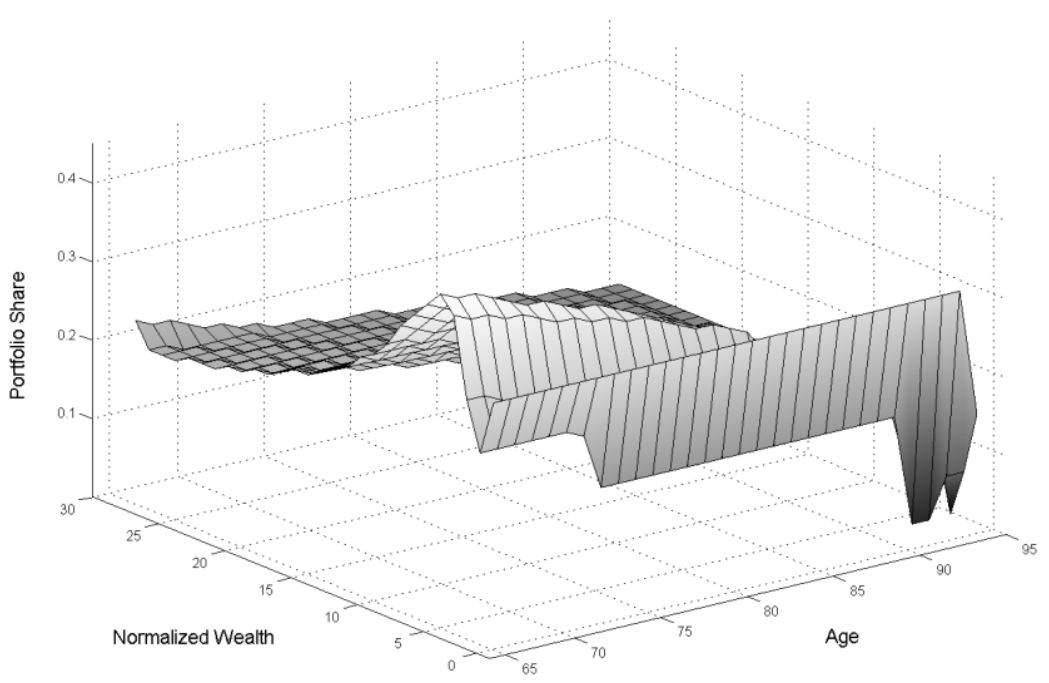


Figure 3-8: Policy functions for retirees at different ages (without health risk but with financial crisis risk)

This graph plots the policy functions for the portfolio share invested in stocks (a) and the saving rule (b) at different ages when there is financial crisis risk but no health risk.

(a) The portfolio rule for retirees at different ages (perfect income, no health risk)

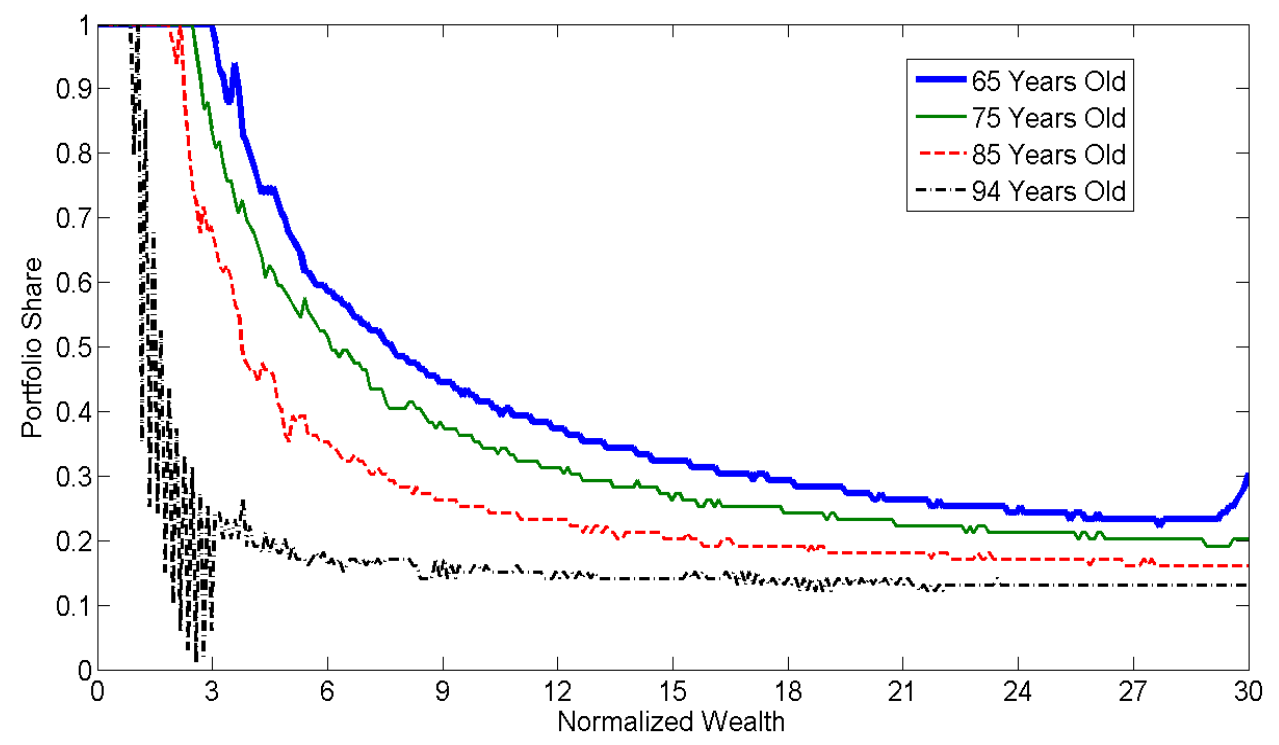

(b) The saving rule for retirees at different ages (perfect income, no health risk)

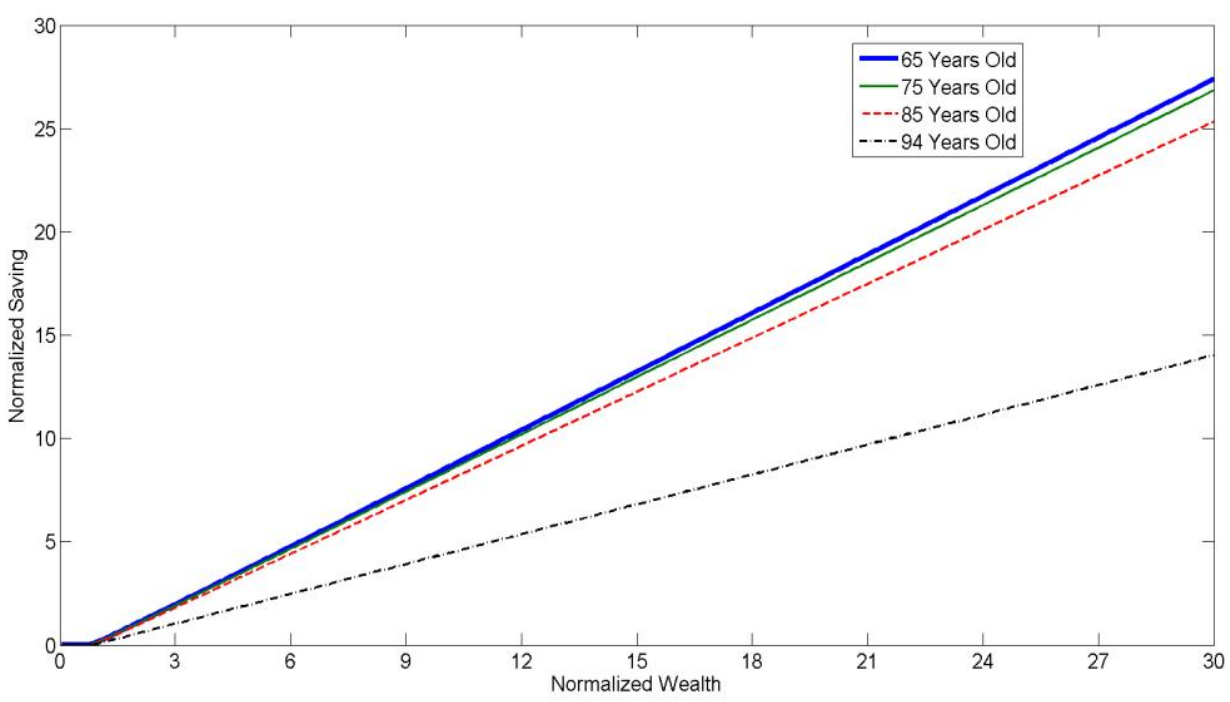


Figure 3-9: Policy functions for retirees at different age (with health risk but without financial crisis risk)

This graph plots the policy functions for the portfolio share invested in stocks (a) and the saving rule (b) at different ages when there is health risk but no financial crisis risk.

(a) The portfolio rule for retirees at different ages (with health shocks)

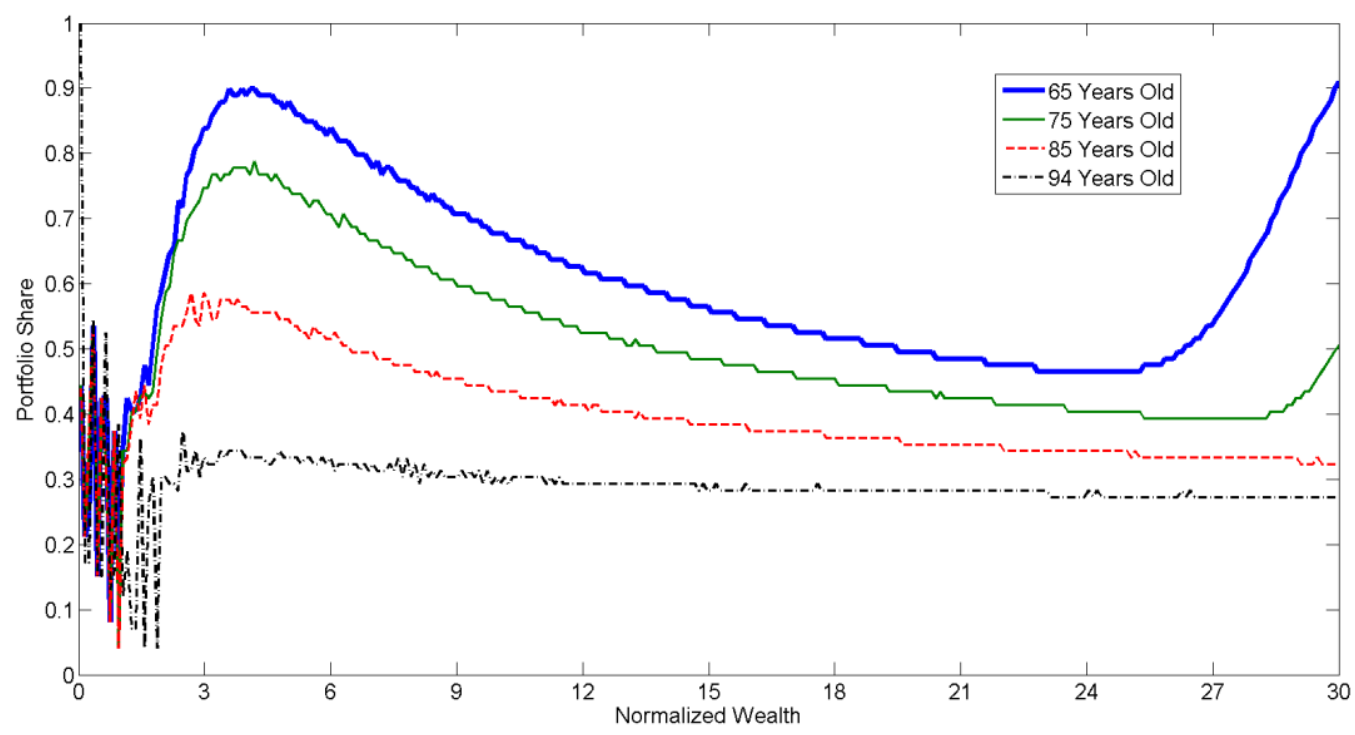

(b) The saving rule for retirees at different ages (with health shocks)

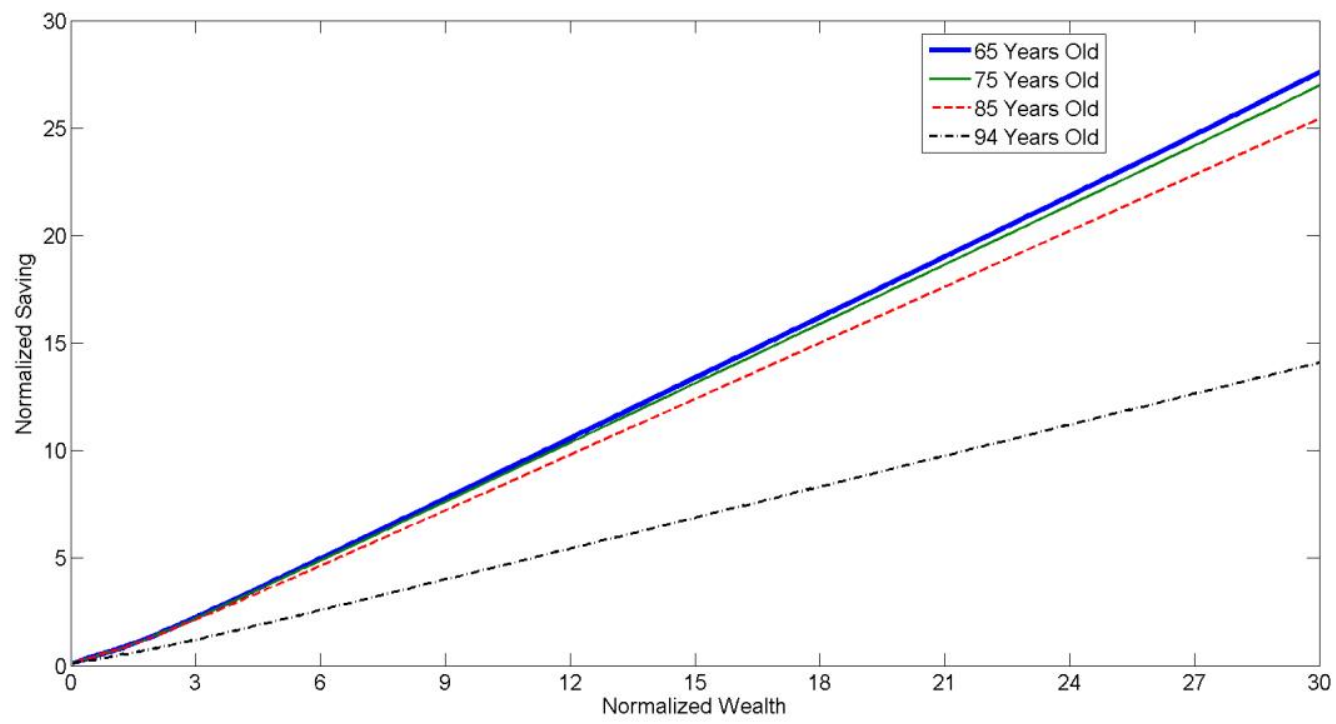




\section{Figure 3-10: Policy functions for retirees at different ages (with health risk and financial crisis risk)}

This graph plots the policy functions for the portfolio share invested in stocks (a) and the saving rule (b) at different ages when there are both health risk and financial crisis risk.

(a) The portfolio rule for retirees at different ages (with health and financial crisis risk)

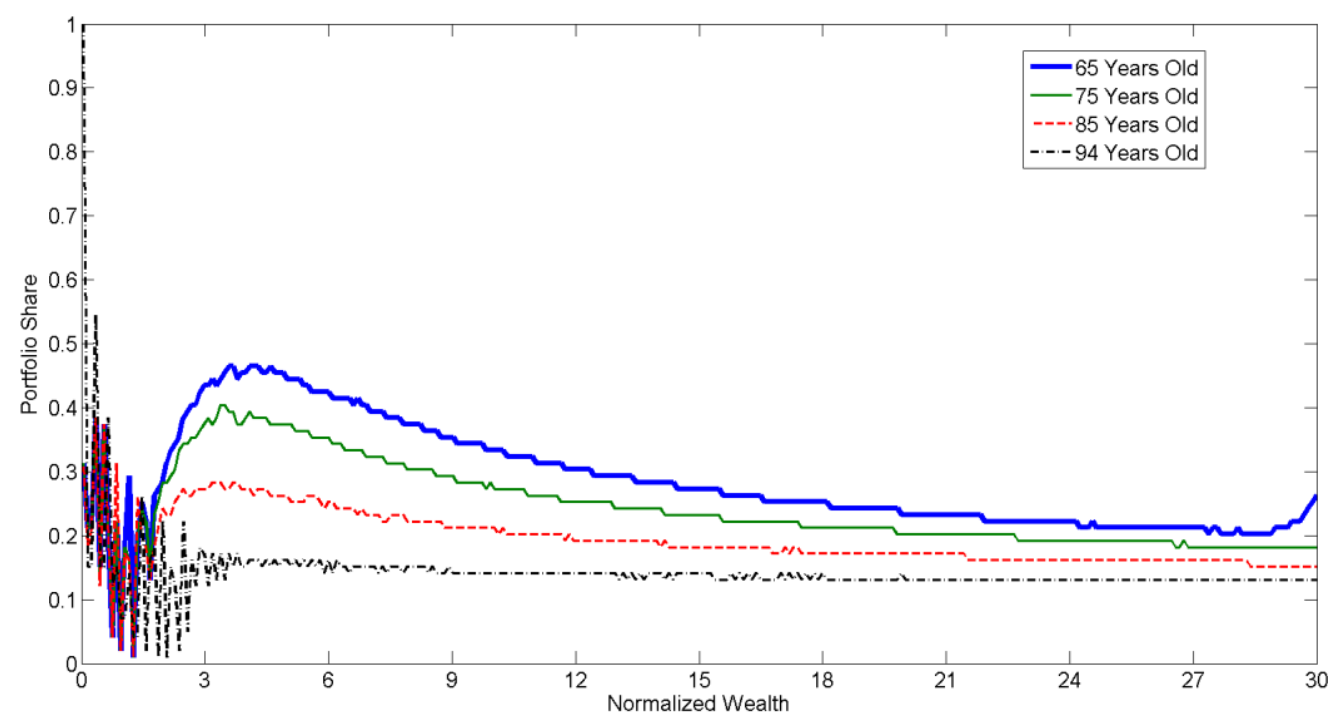

(b) The saving rule for retirees at different ages (with health and financial crisis risk)

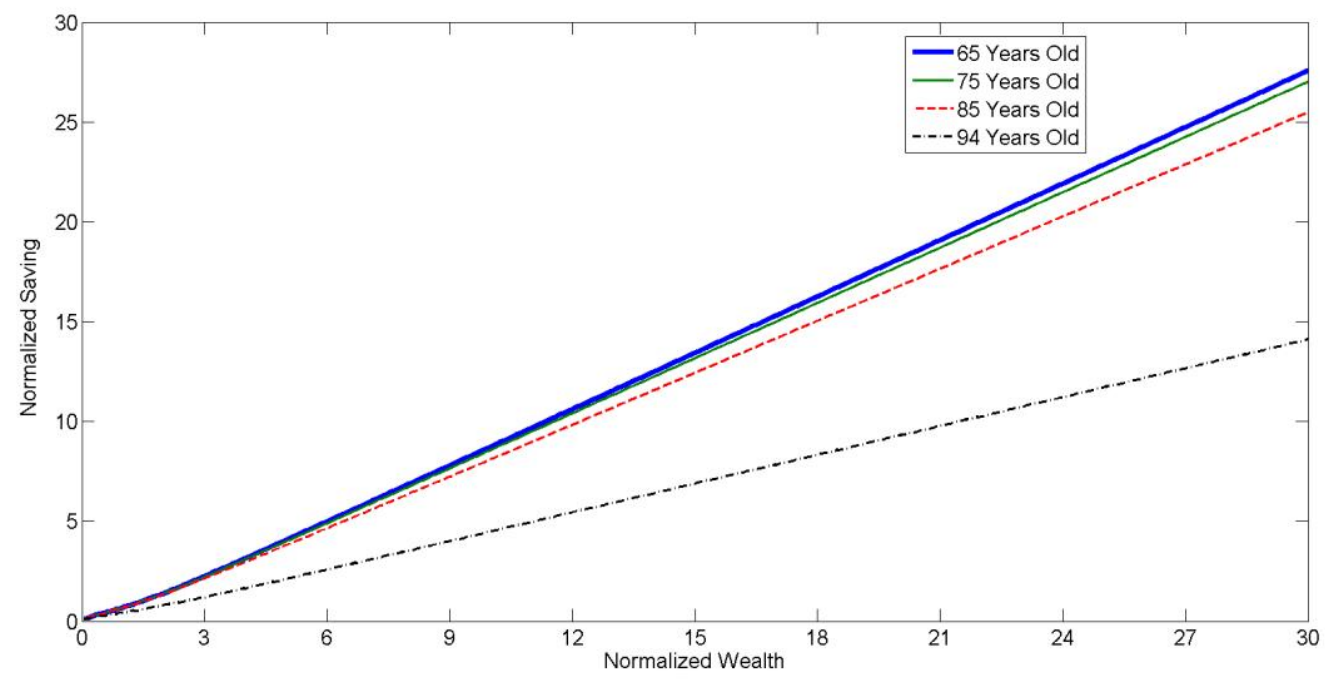


Figure 3-11: The portfolio rule at age 65 by health status

This graph plots the policy functions for the portfolio share invested in stocks for the good health group vs. the poor health group at age of 65; part (a) plots the no financial crisis case and part (b) plots the financial crisis case.

(a) The portfolio rule for good health vs. poor health at 65 (without financial crisis risk)

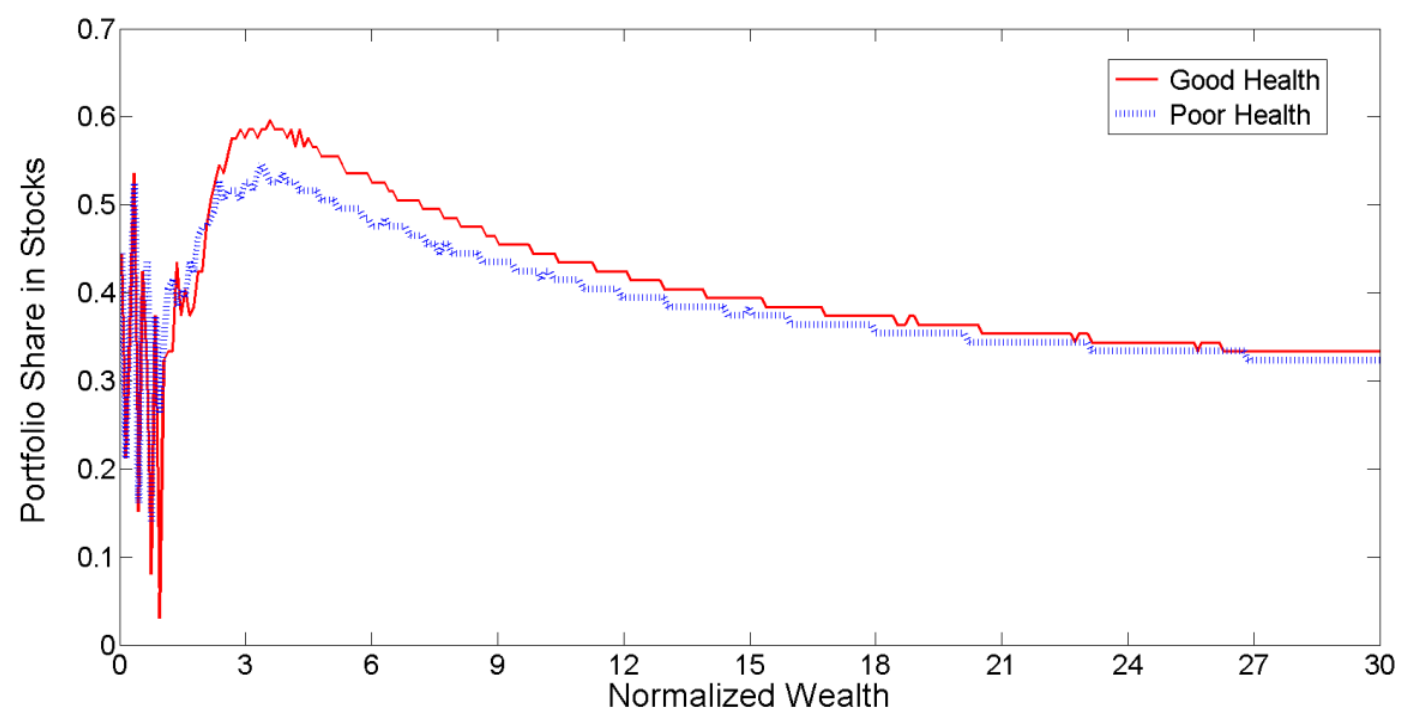

(b) The portfolio rule for good health vs. poor health at 65 (with financial crisis risk)

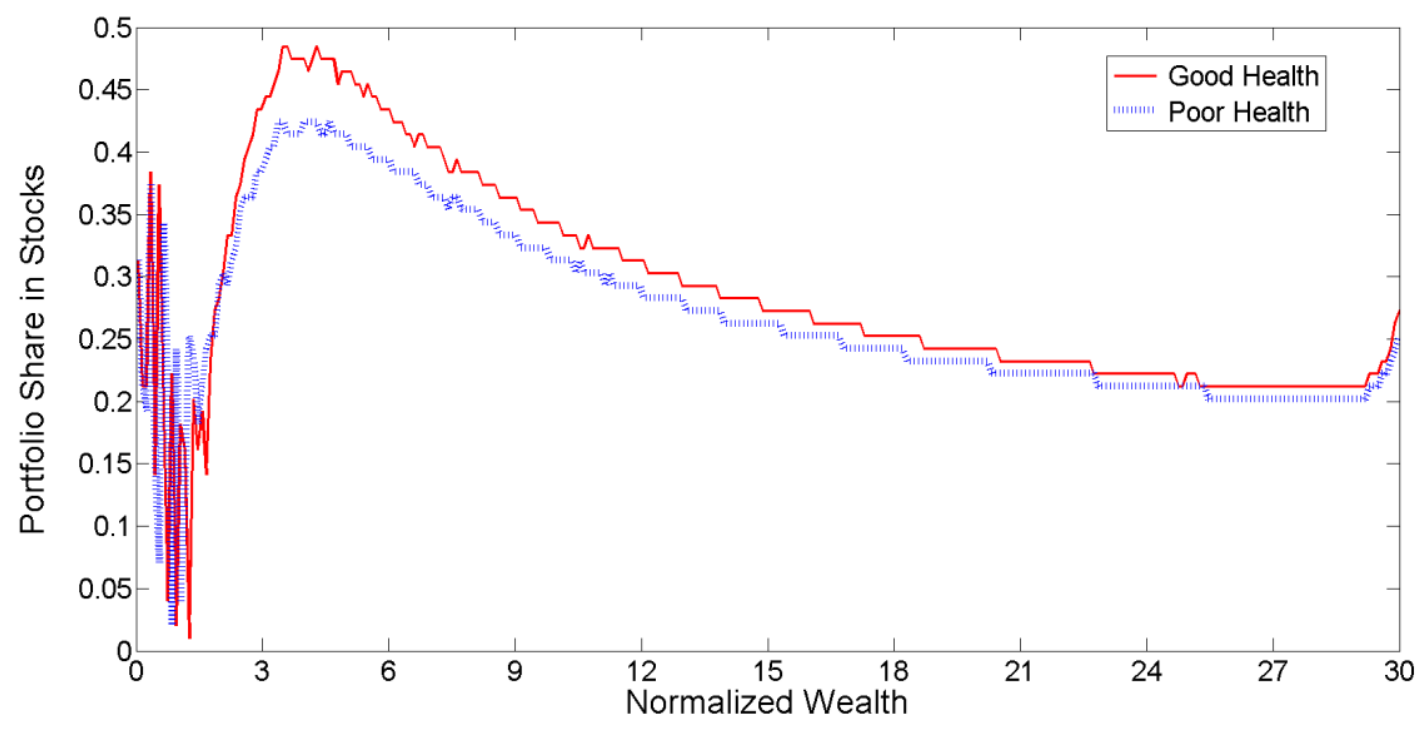


Figure 3-12: The portfolio rule at age 75 by health status

This graph plots the policy functions for the portfolio share invested in stocks for the good health group vs. the poor health group at age of 75; part (a) plots the no financial crisis case and part (b) plots the financial crisis case.

(a) The portfolio rule for good health vs. poor health at 75 (without financial crisis risk)

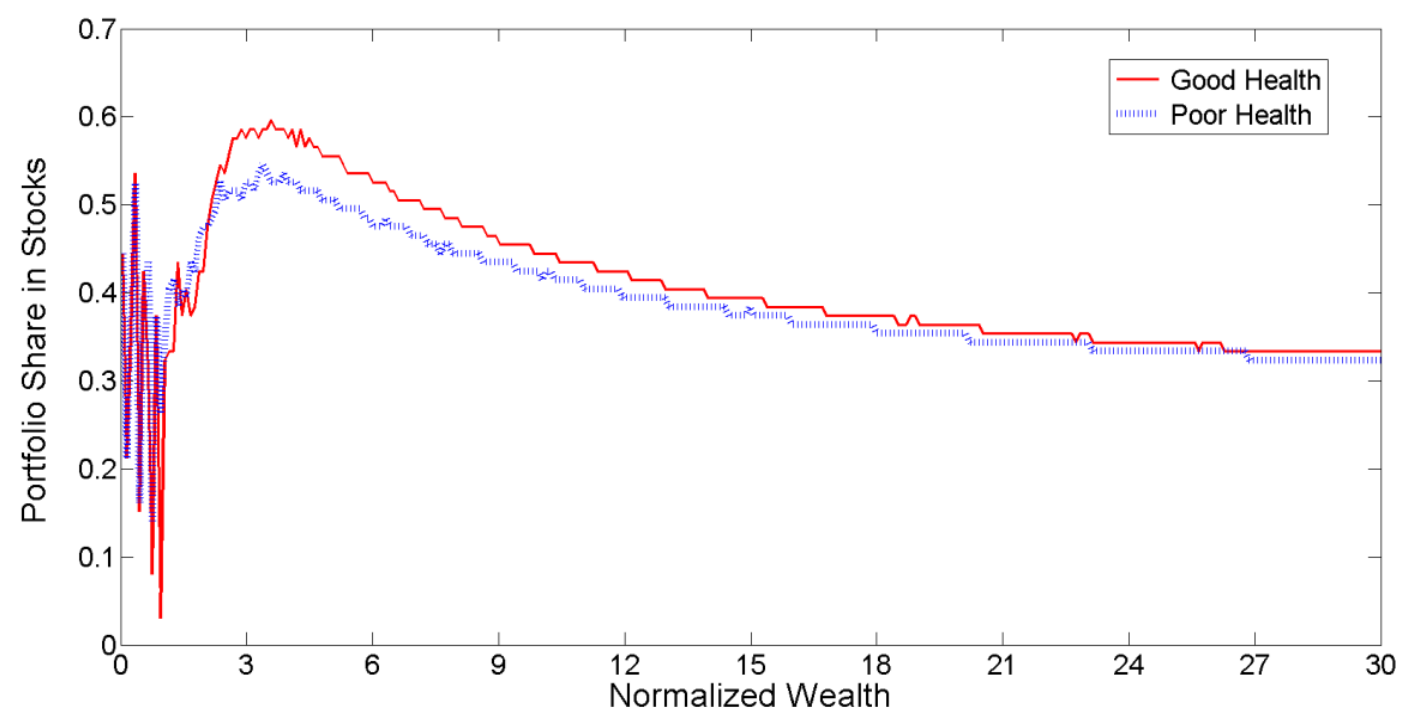

(b) The portfolio rule for good health vs. poor health at 75 (with financial crisis risk)

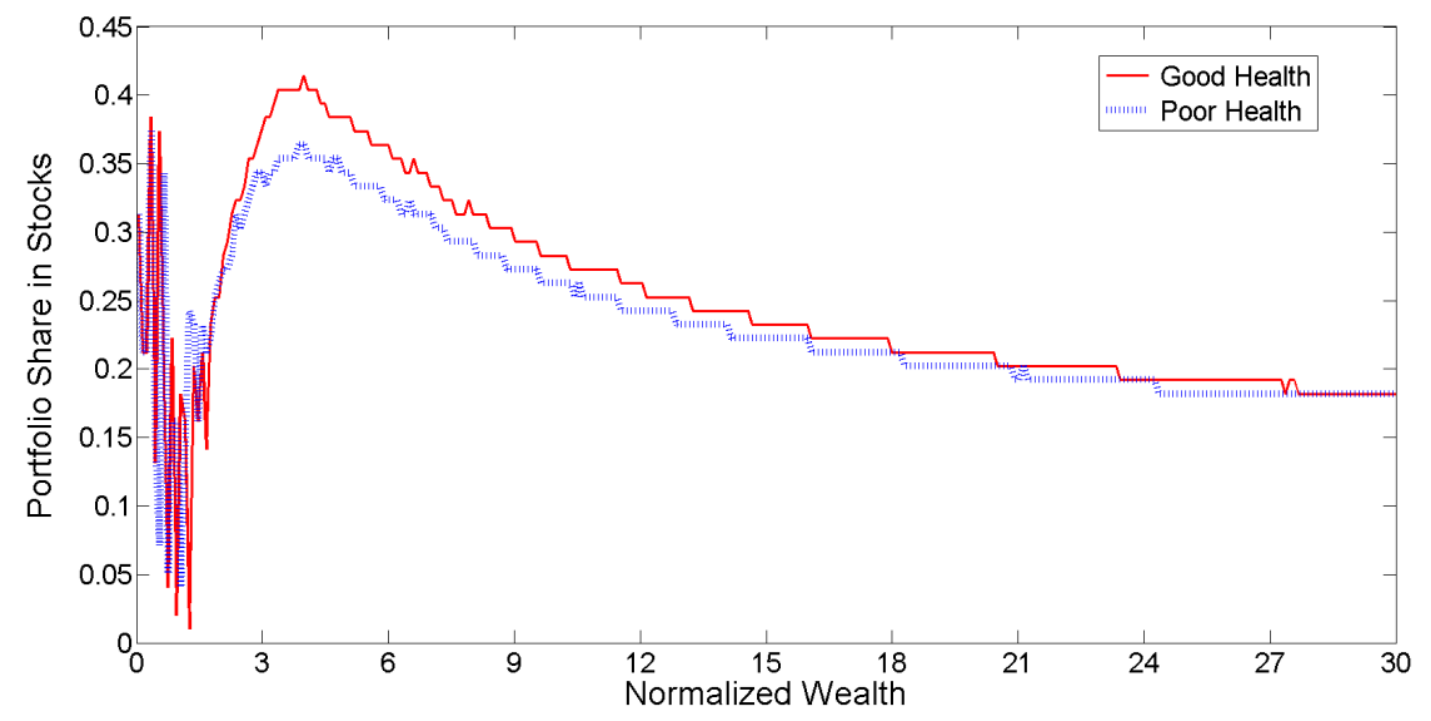


Figure 3-13: The portfolio rule at age 85 by health status

This graph plots the policy functions for the portfolio share invested in stocks for the good health group vs. the poor health group at age of 85; part (a) plots the no financial crisis case and part (b) plots the financial crisis case.

(a) The portfolio rule for good health vs. poor health at 85 (without financial crisis risk)

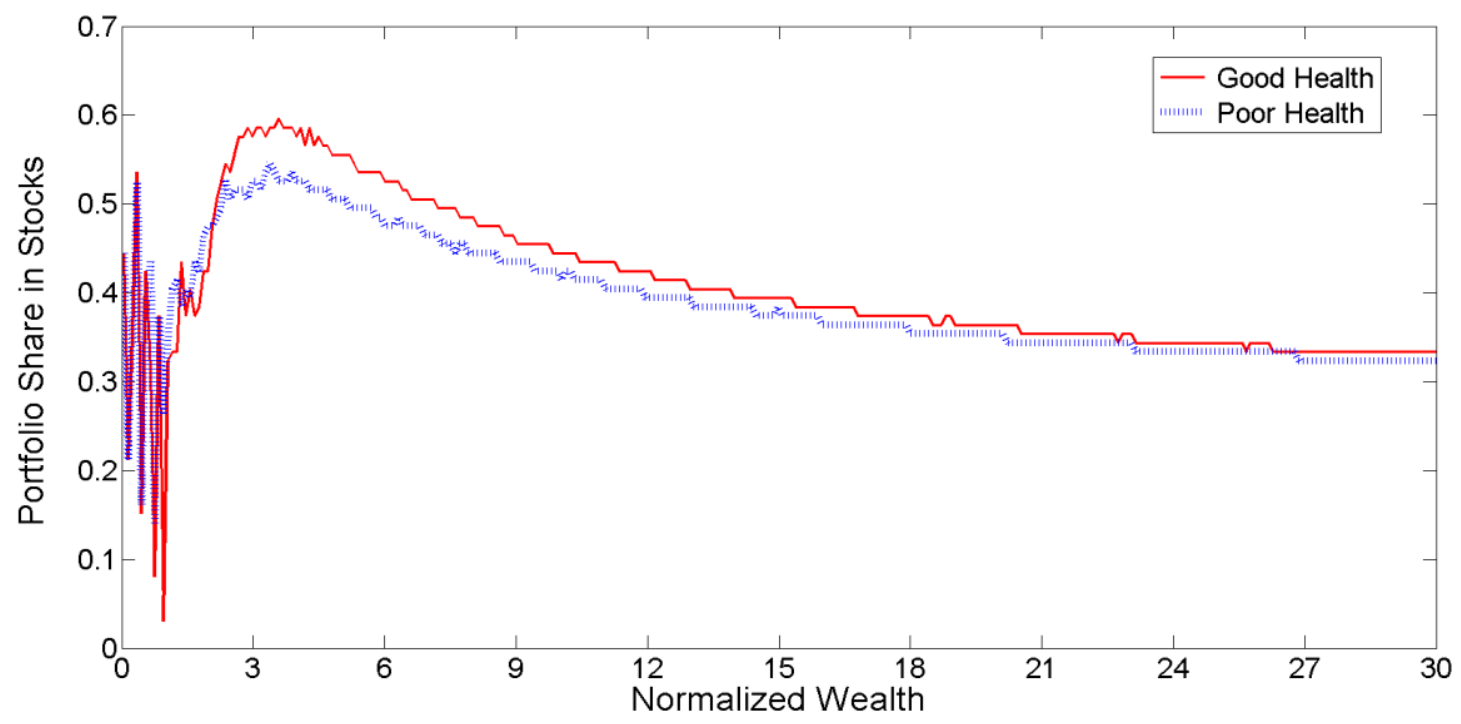

(b) The portfolio rule for good health vs. poor health at 85 (with financial crisis risk)

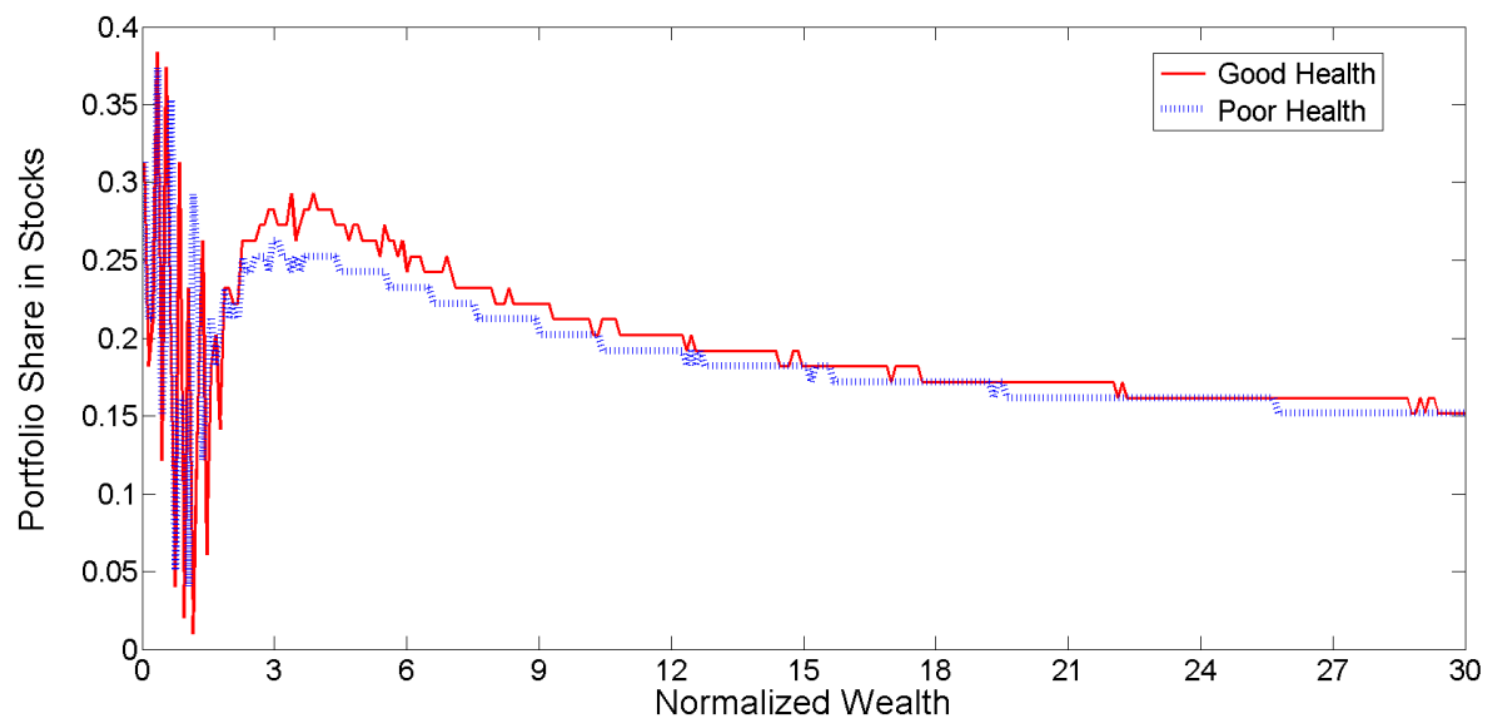




\section{Figure 3-14: Initial wealth distribution for retirees}

This figure presents the empirical distribution of the normalized wealth ratio obtained from the Health and Retirement Survey. The normalized wealth ratio is calculated by dividing total household financial wealth by pension/Social Security income.

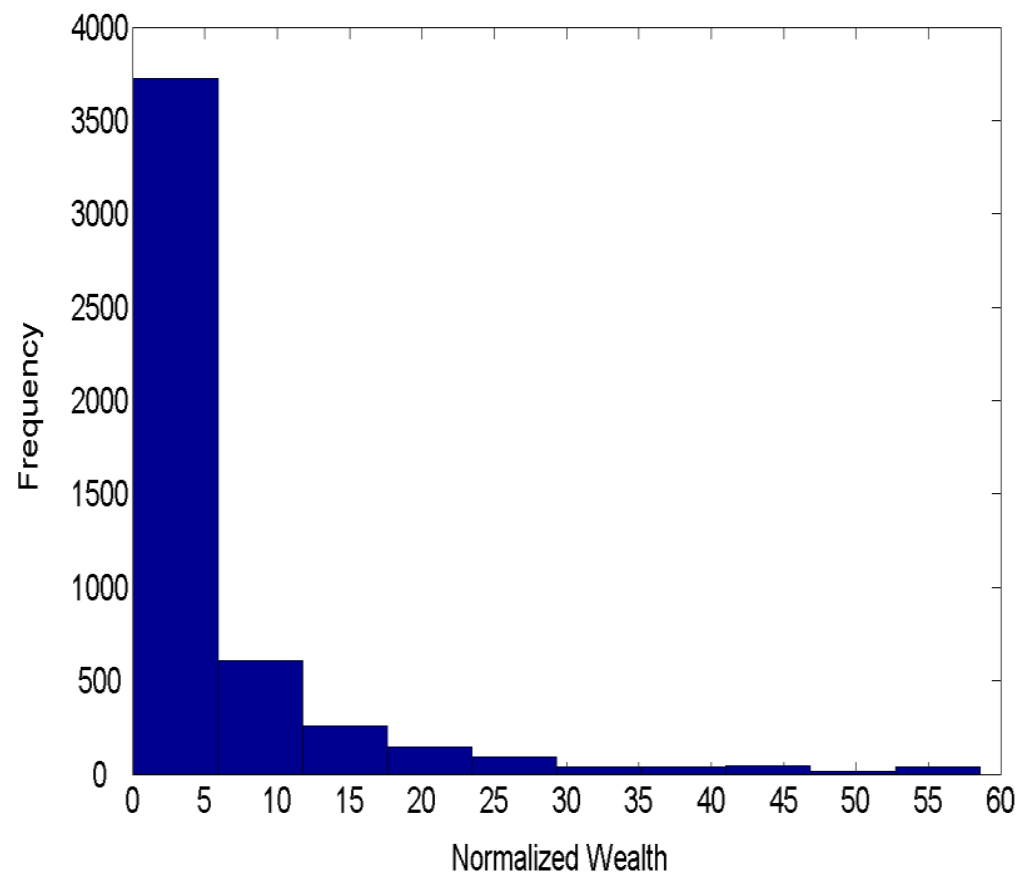




\section{Figure 3-15: Simulation results: Without health risk}

This figure plots the mean, $5^{\text {th }}$, and $95^{\text {th }}$ percentile of the cross-sectional distribution of the simulated portfolio share in risky assets when there is financial crisis risk but no health risk.

Simulated portfolio share (with financial crisis risk but no health risk)

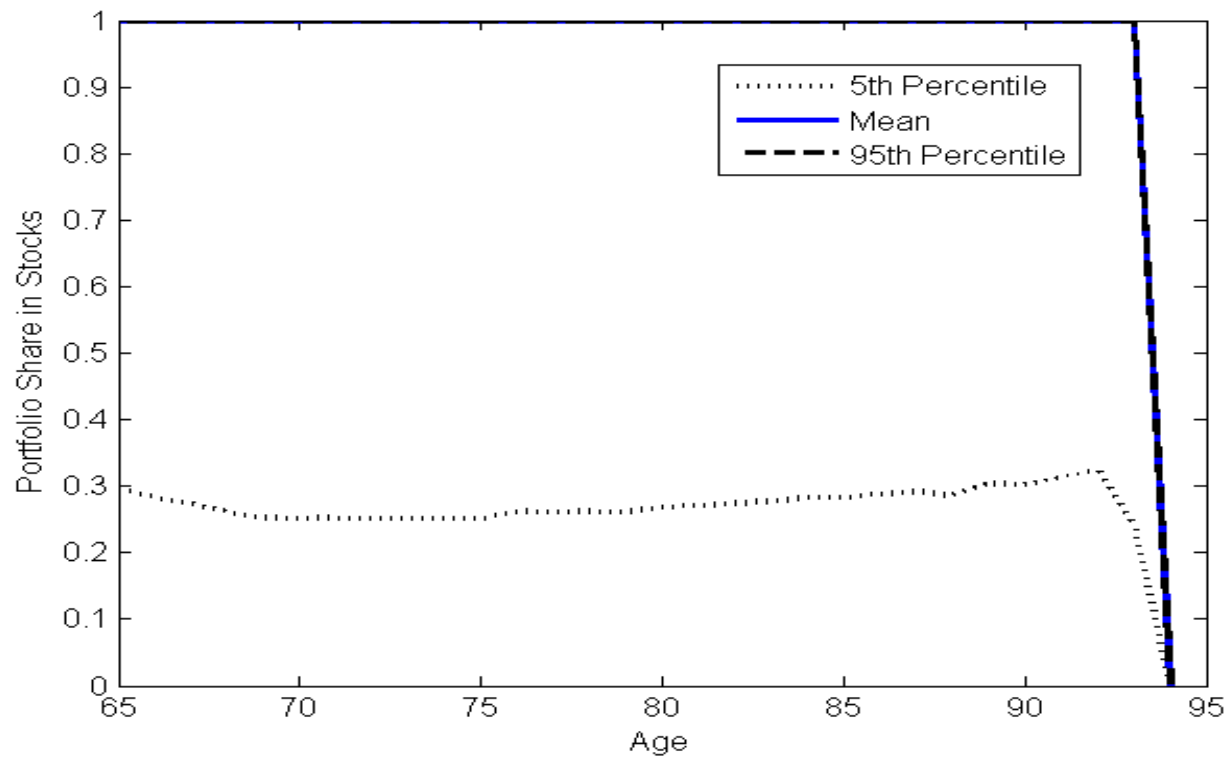


Figure 3-16: Simulation results: With health risk

This figure plots the mean, $5^{\text {th }}$, and $95^{\text {th }}$ percentile of the cross-sectional distribution of the simulated portfolio share in risky assets when there is health risk and (a) no financial crisis risk and (b) financial crisis risk.

(a) Simulated portfolio share (with health risk but no financial crisis risk)

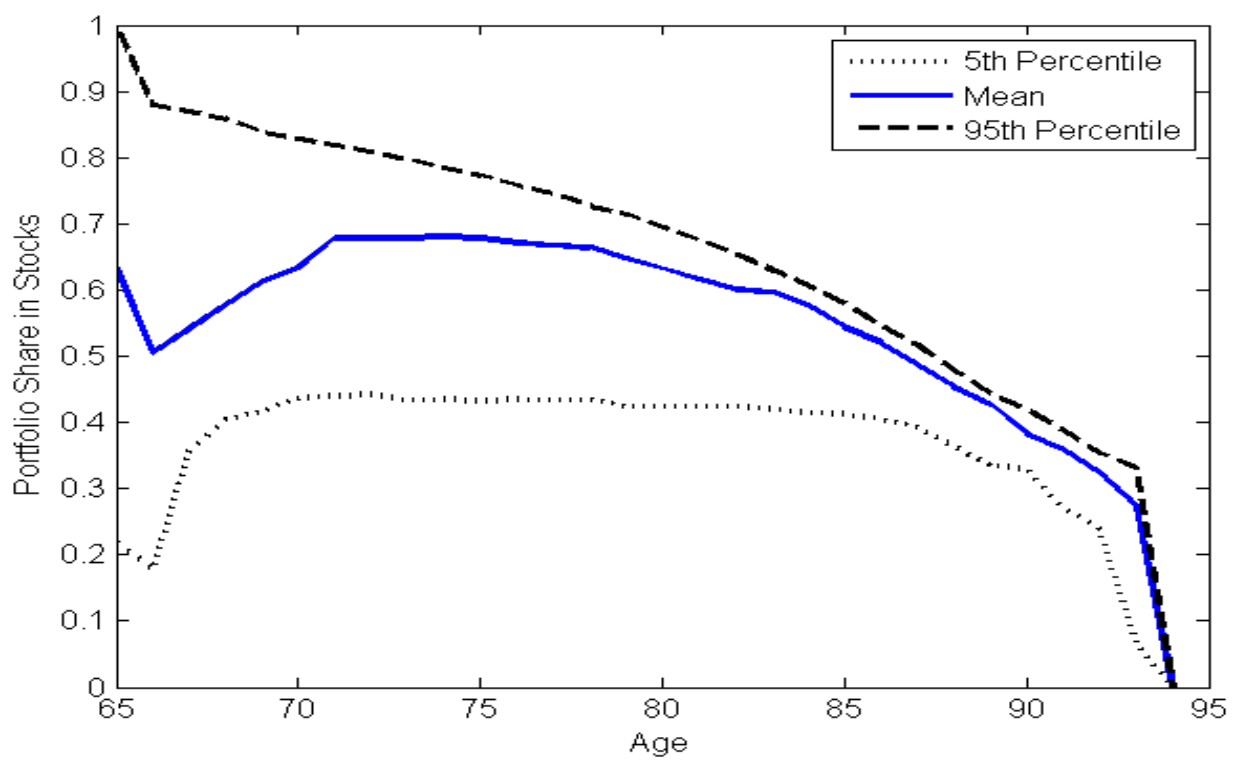

(b) Simulated portfolio share (with both health risk and financial crisis risk)

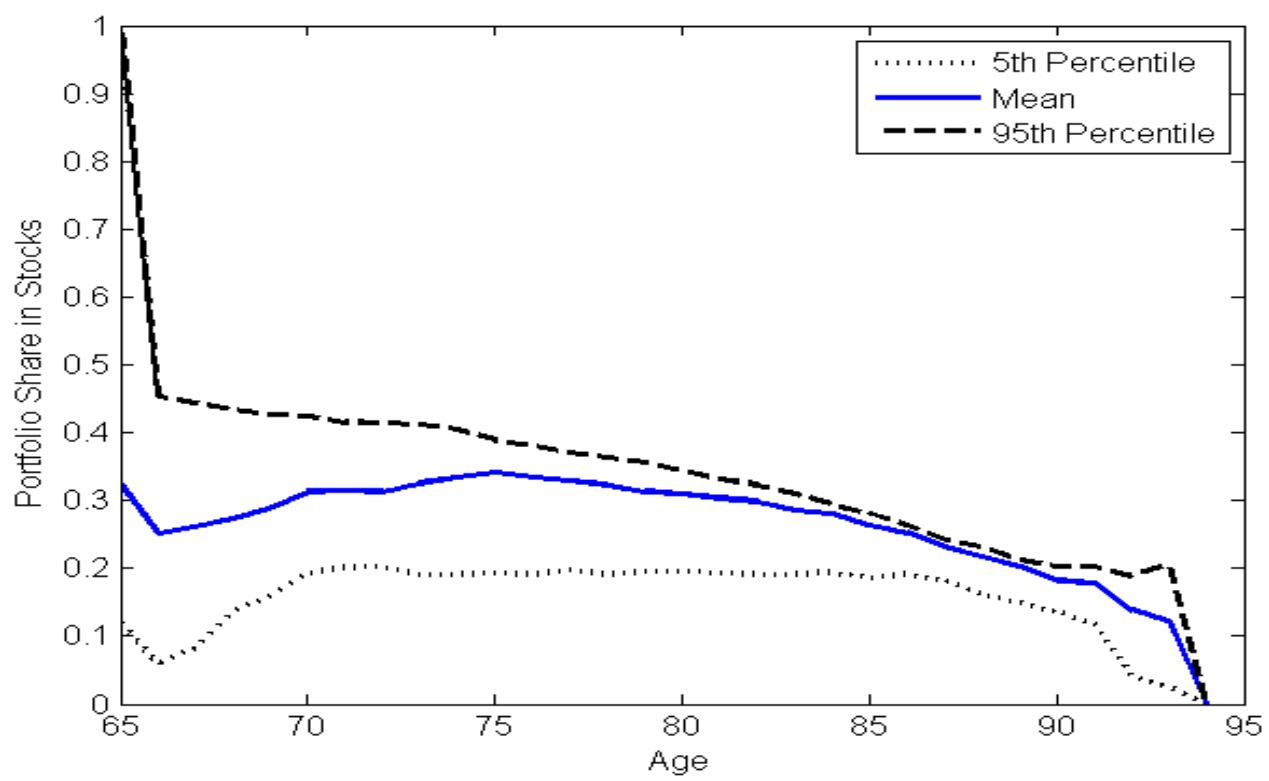




\section{Chapter 4}

\section{Impacts of Financial Crisis on Income Inequality: A Decomposed Approach}




\section{Chapter 4}

\section{Impacts of Financial Crisis on Income Inequality: A Decomposed Approach}

\subsection{Introduction}

Income inequality has been rising steadily over the last 40 years in the United States. Among the papers written on the subject, many focus on the long run trends in income distribution, which are more closely related to economic development and productivity change. However, shocks to the economy, especially those like the 2008 financial crisis, have a major impact on the production and allocation of economic resources, and can potentially cause a substantial change to the income distribution of households. This paper provides a quantitative measure of how income distribution changed following the crisis. To gain a more complete picture of the change in the income distribution, I analyze the Lorenz curve and its associated concentration curve instead of choosing a single inequality measure, such as the Gini coefficient. The use of the Lorenz curve provides us with a means to decompose the overall population income distribution by subgroups and allows us to capture how different subgroups, defined by race, gender, or other household characteristics, contributed to overall income inequality before and after the financial crisis.

This study is closely related to three strands of research: work on how major economic shocks, particularly financial crisis, affect income distribution in the economy; work on top income share change in the United States; and work on the application of non-parametric approaches to decompose income inequality by subgroups. Two approaches have been used in empirical studies 
to assess the impacts of economic crises on income level and income distribution. One approach uses economic models to calibrate household behaviors to the real economy and uses microsimulation analysis to measure the impact of the shocks (Robilliard et al., 2001; Habib et al., 2010). This approach is often used when real time economic data are not available during the crisis, but immediate analysis is needed to make important policy assessments. The other approach utilizes available income data to conduct a descriptive study of the impact of the crisis. The results obtained using this approach have been inconclusive; some studies have found that financial crisis has a lasting effect on income distribution (Cerra and Saxena, 2008), while other studies have found that the effect of crisis on income distribution is temporary and that income distribution reverts back to its previous state in the longer term (Faik, 2012; Morelli,2014).

In addition to the study of changes in overall income distribution, examination of the change in top income shares also plays an important role in income inequality analysis. Top income shares indicate how much total income is earned by people in the top tail of the income distribution, such as the top $1 \%$, the top $5 \%$, and the top $10 \%$ of the income distribution. In the United States, households in the top $10 \%$ of the income distribution earned 47\% of the total earnings in 2007. Financial crisis can have a large impact on the income of the top earners as many wealthy households hold a substantial amount of stocks. A large drop in capital income caused by the financial crisis can severely reduce their income. By analyzing the ordinates of the Lorenz curve and its associated concentration curve, I am able to assess the top earners' income share before and after the crisis and to examine how the crisis changed their income share.

Furthermore, in analyzing how the financial crisis affects income distribution by subgroups, I adopt the decomposition methodology proposed in Bishop et al. (1993, 2004). As compared to 
other decomposition studies (Shorrocks, 1984; Deutsch and Silber 1999), the application of Bishop et al.'s (2004) methodology allowed me to track the subgroup changes for the whole income distribution, instead of just the change in a single index. The SCF 2007-2009 panel dataset provides detailed household income data as well as demographic variables, which are ideal for constructing a decomposed Lorenz curve and its associated concentration curve.

The analysis yielded three key findings. First, I find that the overall income distributions shifted from 2007 to 2009 . Income shares for the bottom to $9^{\text {th }}$ decile increased, and top earners, defined as households in the top $10 \%$ of the income distribution, had a lower income share after the crisis. Comparing Lorenz curves in 2007 and 2009, I find that the top 10\% of households in the income distribution earned $47.2 \%$ in 2007 , and their income share decreased to $42.3 \%$ in 2009 . In particular, the decreases in the income share for the top earners was more pronounced in the concentration ordinates, which measure the income share changes for households ranked based on their pre-crisis income level. Households which were in the top $10 \%$ of the income distribution in 2007 received only $37.7 \%$ of total income in 2009 , a 5 percentage point reduction compared to the results implied by the 2009 Lorenz curve.

Second, I find that the decomposed concentration ordinates for subgroups, characterized by race, gender, and retirement status, followed a pattern similar to that found for the overall sample. The decomposed concentration ordinates for each of the subgroups rose from the bottom to the $9^{\text {th }}$ decile and decreased substantially for the top decile group. However, the decomposed ordinates of the 2009 Lorenz curve showed a less uniform pattern: not all subgroups' decomposed Lorenz ordinates increased. Non-white groups' Lorenz ordinates fell from the $7^{\text {th }}$ decile to the $9^{\text {th }}$ 
decile and rose for the top decile group in 2009. Female groups' Lorenz ordinates decreased in all deciles, except for the $9^{\text {th }}$ and the top decile.

Third, the additive decomposition based on race and retirement status did not change much from the 2007 Lorenz curve to the 2009 Lorenz curve. With regard to subgroups based on gender, males' contribution share increased in the bottom 6 deciles, whereas female groups' contribution share decreased in those deciles.

The results are consistent with previous findings (Faik, 2012; Morelli, 2014) that overall income inequality dropped immediately after the crisis. In an extension study, I use the Panel Study of Income Dynamics (PSID) as a supplementary dataset to analyze longer-term effects of the financial crisis. For a comparison study, I also use the PSID to assess the impacts of the 1987 stock market crash on the income distribution to see how it differed from the 2008 financial crisis in terms of its impacts on household income distribution.

The rest of this Chapter is organized as follows. Section 4.2 presents the relevant literature review. Section 4.3 describes the decomposition methodology of the Lorenz and concentration curves. Section 4.4 describes the data used for constructing the inequality measure and defines the income variable for my analysis. Section 4.5 analyzes the decomposition results based on race, gender, and retirement status. Section 4.6 extends the study using the PSID. Section 4.7 concludes.

\subsection{Literature Review}

\subsubsection{Inequality before and after the crisis}

Literature on the effects of financial crises on income distribution falls mainly into two broad categories: the first one focuses on financial crises in the developing countries and their 
impact on income distribution and poverty. These crises are often associated with rapid depreciation of the local currency, and have a detrimental effect on the local economy, such as happened in the 1997 Asian Financial Crisis. For example, Baldacci et al. (2002) focus on the effects of currency crashes, and they examine income changes in Mexico after the Peso's crash in December 1994. They find that income inequality increases as the result of a more-thanproportional fall in the income share of the lowest income quintile of the population. Robilliard et al. (2001) and Habib et al. (2010) use a microsimulation approach to examine the distributional effects of financial crises. They find that income shocks are relatively large in the middle parts of the income distribution. But such shocks will not automatically lead to higher inequality, as measured by the Gini coefficient. Overall inequality worsens when the losses are disproportionately high among the poor. Only in Mexico, where a larger shock is projected at the lower end of the distribution, was there an increase in the aggregate inequality.

The second category of the literature focuses on income inequality in the U.S. and other OECD countries before and after the 2008-2009 financial crisis. Several studies have provided descriptive analysis, and their results are mixed. De Beer (2012) finds that there is no uniform pattern in the impact of the crisis on earnings and income distribution among the EU countries. Faik (2012) uses data from the German Social-Economic Panel (SOEP) to study inequality and poverty before and during the economic crisis, and he finds that inequality dropped at the peak of the crisis but increased afterwards.

\subsubsection{Decomposing the inequality measure}

Studies on income inequality usually use a single inequality measure, such as the Gini coefficient, to provide summary statistics for the overall income distribution. Despite its simplicity, 
this measurement, because of its aggregate nature, fails to account for the sources of the inequality. To better understand how different subgroups contribute to the total income inequality, several studies have attempted to decompose the inequality measure. Deutsch and Silber (1999) analyze total inequality in the population as a consequence of the income difference between population subgroups, classified by characteristics such as age, gender, race, and education level. They focus on decomposing a single inequality index, and they consider the issue of inequality decomposition by population subgroups as an index number problem. Shorrocks (1984) uses income inequality measures from population subgroups to determine the aggregate inequality index. Bishop et al. (2011) look at the interdistributional inequality among population subgroups. My study differs from those in the previous literature in two major aspects. Previous studies have focused on decomposing a single inequality index, such as the Gini coefficient. My study, however, decomposes the whole Lorenz curve, and hence does not suffer from the index selection problem (Bishop et al. 2003). In addition, I use panel data from the Survey of Consumer Finance to construct a concentration curve, in which after-crisis earnings are arranged by the households' positions in the pre-crisis income distributions. The concentration curve is a more accurate measure of the conditional change in the household income distribution.

\subsubsection{Use of household survey data}

Household survey data, which often include detailed household financial information, can be useful in studying income distribution changes. Milanovic (2002) uses household surveys to conduct a cross-country analysis focusing on the Gini coefficient. Zietz and Zhao (2009) use the Panel Study of Income Dynamics (PSID) to study the effects of a stock price change on U.S. income inequality. Their study focuses on the short run effects, but instead of looking at a crisis, 
they examine how stock market appreciation affects U.S. income inequality. Using a regressionbased method to calculate the Gini coefficient, they find that the stock market appreciation raised the Gini coefficient by about $2 \%$ in the 1980 s and by $3 \%$ in the 1990 s.

\subsection{Methodology}

\subsubsection{Decomposing the ordinates}

Following the decomposition methodology in Bishop et al. (2003), let $(x, y)$ be a vector of continuous income variables, where $x, y$ are jointly distributed with a probability density function $\mathrm{f}(x, y) ; x$ and $y$ represent the earnings of the same household in the pre-crisis year and the aftercrisis year, respectively. Using an indicator variable approach, each household is assigned a decile group using the binary indicator variable, $I_{\tau}^{x}=1$ if $x \leq \tau$ and $I_{\tau}^{x}=0$ otherwise. The overall Lorenz ordinate and the concentration ordinate can be expressed as:

$$
\begin{gathered}
L(\tau ; x)=\frac{\int_{0}^{x} x f(x) d x}{\mu_{x}}=\frac{\int_{0}^{\infty} x I_{\tau}^{x} d F(x)}{\mu_{x}}=\frac{E\left(x \cdot I_{\tau}^{x}\right)}{E(x)} \\
C(\tau ; y)=\frac{\int_{0}^{\tau} \int_{0}^{\infty} y f(x, y) \mathrm{dy} d x=\frac{\int_{0}^{\infty} \int_{0}^{\infty} y I_{\tau}^{x} f(x, y) d y d x}{\mu_{y}}=\frac{E\left(\mathrm{y} \cdot I_{\tau}^{x}\right)}{E(\mathrm{y})}}{\mu_{y}}
\end{gathered}
$$

where $\mu_{x}$ is the mean of $\mathrm{x}$ and $\mu_{y}$ is the mean of $\mathrm{y}, L(\tau, x)$ represents the proportion of total 2007 income received by households whose income level is less than or equal to $\tau$, $C(\tau, y)$ represents the proportion of total 2009 income received by households whose 2007 income is less than or equal to $\tau$, and $\tau$ is the inverse CDF of the base year income: $\tau=F^{-1}(p)$. 
To decompose the overall Lorenz ordinates and concentration ordinates by subgroups, I create K mutually exclusive population groups: $\Phi_{k}, k=1,2, \ldots, K$ and define an indicator variable $G_{k}^{x}$ such that $G_{k}^{x}=1$ if the household belongs to group $k$ and $G_{k}^{x}=0$, otherwise. I use 2007 precrisis data to create the groups, and the group identification remains the same for constructing the decomposed 2009 concentration curve. Following Bishop et al. (2003), the decomposed Lorenz curve and concentration curve for group $\mathrm{k}$ can be expressed as:

$$
\begin{aligned}
& L\left(\tau, \mathrm{x}^{(k)}\right)=\frac{E\left(x \cdot G_{k}^{x} \cdot I_{\tau}^{x}\right)}{E\left(x \cdot G_{k}^{x}\right)} \\
& C\left(\tau, y^{(k)}\right)=\frac{E\left(y \cdot G_{k}^{y} \cdot I_{\tau}^{x}\right)}{E\left(y \cdot G_{k}^{y}\right)}
\end{aligned}
$$

where $\mathrm{k}=1,2, \ldots \mathrm{K}$. By the law of large numbers, (4-3) and (4-4) can be empirically estimated as the ratio of two sample means:

$$
\begin{gathered}
\hat{L}^{(k)}=\hat{L}\left(\tau_{i}, x^{(k)}\right)=\frac{N^{-1} \sum_{j=1}^{N} x_{j} \cdot G_{k}^{x_{j}} \cdot I_{\tau_{i}}^{x_{j}}}{N^{-1} \sum_{j=1}^{N} x_{j} \cdot G_{k}^{x_{j}}} \\
\hat{C}_{i, t}^{k}=\hat{C}\left(\tau_{i}, y^{k}\right)=\frac{N^{-1} \sum_{j=1}^{N} y_{j} G_{k}^{y_{t}} I_{\tau_{i}}^{x_{j}}}{N^{-1} \sum_{j=1}^{N} y_{j} G_{k}^{y_{t}}}
\end{gathered}
$$




\subsubsection{Additive decomposition}

For a particular decile, Group k's contribution to the overall Lorenz ordinate in that decile can be expressed as:

$$
\begin{aligned}
p_{\tau}^{k} & =\frac{E\left(x \cdot G_{k}^{x} \cdot I_{\tau}^{x}\right)}{E\left(x \cdot I_{\tau}^{x}\right)} \\
& =\frac{E\left(x \cdot G_{k}^{x} \cdot I_{\tau}^{x}\right)}{E\left(x \cdot I_{\tau}^{x}\right)} \times \frac{E(x)}{E\left(x \cdot G_{k}^{x}\right)} \times \frac{E\left(x \cdot G_{k}^{x}\right)}{E(x)} \\
& =\frac{L\left(\tau, \mathrm{x}^{(k)}\right)}{L(\tau, \mathrm{x})} \times p^{(k)}
\end{aligned}
$$

From (4-7), the additive decomposition can be calculated as the ratio of the decomposed Lorenz ordinates to the overall Lorenz ordinates, multiplied by the income of group $k, p^{k}$.

\subsection{Data}

In the main analysis, I use the Survey of Consumer Finance (SCF) published by the Federal Reserve. This triennial survey includes household demographics, income, and balance sheet information. I use the 2007 sample data, which were collected before the onset of the 2008 financial crisis. In 2009, The Federal Reserve decided to do a panel ${ }^{5}$ study following the crisis and re-interviewed the same households surveyed in 2007 with similar questions ${ }^{6}$ to assess how their financial situations had changed after the crisis. The 2007 and 2009 waves of the SCF panel dataset included 3,862 families, and five observations were deleted from the public available dataset to

\footnotetext{
${ }^{5}$ Federal Reserve samples a different set of households every three years. The 2009 panel is a rare exception. The only previous panel was done for the 1983-1989 wave.

${ }^{6}$ The 2009 survey added a set of attitudinal questions regarding the 2008 financial crisis and its consequences.
} 
protect the privacy of the households. Because the SCF asks about sensitive financial data, some households are reluctant or unable to provide accurate answers. The Federal Reserve has developed a set of imputation techniques to correct for the missing data problem ${ }^{7}$. Each missing record is imputed 5 times, and there are a total 19,285 records in the public dataset. Following Calati et al. (2008) and Lee and Carlin (2010), I use the average of the five imputations as the observed value for a household.

The SCF adopts a dual-frame design in the data collection process. One subsample uses a multi-stage area-probability model to choose the households across the country, and it represents the characteristics of the general population in the United States. In addition to this sample, the SCF also samples households with high net worth, selected from the IRS tax return filings. Compared to other panel studies, the dual-frame design of the SCF provides more complete information on the households in the top decile of the income distribution, whose income can change substantially during a financial crisis. Neither subsample has an equal-probability design; therefore, weight is assigned to each observation, and this needs to be taken into consideration when an inference is made about the population.

[Insert Table 4-1 here]

Table 4-1 provides summary statistics for some key variables in the SCF 2007-2009 panel dataset. The mean income dropped significantly, from $\$ 89,036$ in 2007 to $\$ 80,816$ in 2009. Median income also dropped slightly, from $\$ 49,841$ to $\$ 49,810$. For assets and net worth, both mean and median value dropped significantly after the crisis.

\footnotetext{
${ }^{7}$ The imputation procedure is described in "Multiple Imputation in the Survey of Consumer Finances," Arthur B. Kennickell, September 1998, http://www.federalreserve.gov/pubs/oss/oss2/method.html.
} 


\subsubsection{Income definition}

Since the focus of this paper is on the effects of the financial crisis on the overall and subgroup income distributions, the definition of the income variable is important to the analysis. Following Piketty and Saez (2003, 2014), I use pre-tax gross income for the calculation, and this includes wage and salary income, business income, interest and dividend income, capital gain/loss income ${ }^{8}$, pension, social security, and income from transfer payments. To examine how changes occur in different demographic subgroups, I divide the whole sample into mutually exclusively population subsamples based on households' characteristics. The variables used in the subgroup analysis are race, gender, and retirement status.

\section{[Insert Table 4-2 here]}

Table 4-2 presents summary statistics for the income variable based on each group classification. As the SCF uses the household as the unit of observation, race, gender, and retirement status are based on the information about the household head. In the SCF, if a household does not include a couple, the head is taken to be the single core individual in that household. If a household has a central couple, the head is taken to be either the male in a mixed-sex couple or the older individual in a same-sex couple. The first two panels display income information based on race and gender. Panel A displays the results by race; I divide the whole sample into two racial categories: white and non-white. Both groups' median income dropped after the crisis, but that of the white group dropped more, from $\$ 103,552$ to $\$ 91,750$. For the non-white group, median household income dropped from $\$ 58,211$ to $\$ 57,490$. Panel B presents the results based on gender;

\footnotetext{
${ }^{8}$ This is annual income from net gains or losses from mutual funds or from the sale of stocks, bonds, or real estate, before deductions for taxes.
} 
773 observations in the SCF 2007-2009 panel dataset are for female households. For the whole population, the percentage of female households is $27.4 \%$, and they contribute $11.3 \%$ to the total income. Households with a female head have a significantly lower level of median income compared to households with a male head. However, the median income for a household with a female head did not drop after the crisis; on the contrary, it increased from $\$ 36,905$ in 2007 to $\$ 38,987$ in 2009.

Panel C presents the income information based on the household head's retirement status. Retirement often marks a significant change in income source and level, and it is interesting to examine how the crisis affected retired households versus non-retired households. In the sample, 677 observations had a retired household head; for the overall population, $18.8 \%$ of the households had a retired household head, and retired households earned $15 \%$ of the total income. The median income for both retired and non-retired households dropped after the crisis, and the degree of the drop was similar in both groups.

\subsection{Decomposition Results}

\subsubsection{Overall decomposition results}

\section{[Insert Table 4-6 here]}

Table 4-6 provides the Lorenz ordinates for the overall sample. The first row in each panel presents the order statistics, which are the upper cutoff income levels of the overall sample for 2007 and 2009, respectively. Each observation is weighted when the order statistics are calculated. For 2007 , the order statistic for the bottom decile is 13,632 , indicating that the bottom $10 \%$ of the total population had income less than $\$ 13,632$. Comparing the order statistics before and after the 
financial crisis, I find that the order statistics generally decreased, with the exception of the bottom decile, where the order statistic increased from $\$ 13,632$ to $\$ 13,947$.

The second row of each panel calculates the ordinates for the overall Lorenz curve at each decile level for 2007 and 2009, respectively. The standard error is given in parentheses. The Lorenz ordinate for the bottom decile is 0.0098 in 2007 , indicating that the bottom $10 \%$ of the overall population received less than $1 \%$ of the total earnings in 2007 . The Lorenz ordinate for the ninth decile is 0.5218 , indicating that the bottom $90 \%$ of the overall population received $52.18 \%$ of the total income in 2007 , and this implies that the top $10 \%$ of the population received $48 \%$ of the total income. The Lorenz ordinates uniformly drop after the crisis, and the decrease for the highest decile is the most significant. The bottom $90 \%$ of the population received $57.8 \%$ of the total income in 2009 , a $5 \%$ increase from the 2007 level. Correspondingly, the top $10 \%$ of the population's income share dropped from $48 \%$ to $43 \%$ from 2007 to 2009 . It is not surprising to see that their income share dropped substantially, as capital gain income was significantly reduced due to the financial crisis. The effect is even more pronounced among the top $1 \%$ of income earners, who may have a large proportion of their income come from capital gain. This finding is consistent with Piketty and Saez (2012), where it is found that the income growth for the bottom $99 \%$ of earners was $-11.6 \%$ during the 2007 to 2009 period, while for the top $1 \%$ of earners, the real income growth was $-36.3 \%$. The loss in earnings for the top $1 \%$ of earners was much more severe than it was for the rest of the population. In the next section, I decompose the overall Lorenz curve by race and examine how each group contributed to the overall Lorenz ordinates and how their contribution changed after the financial crisis. 


\subsubsection{Decomposition by race}

\section{[Insert Table 4-7 to Table 4-9 here]}

Table 4-7 to Table 4-9 present the ordinate decomposition by race. I divide the whole population into two subgroups, the white group and non-white group, and track the ordinate changes within these subgroups before and after the crisis. Table 4-7 shows the decomposed Lorenz ordinates for 2007. The decomposed ordinates of the bottom decile of the white group is 0.0077 , which means that only $0.77 \%$ of the total white group's income was accrued to those in the bottom decile of the overall earning distribution. Similarly, the decomposed ordinates for the bottom decile of the non-white group is 0.023 , which indicates that $2.3 \%$ of the non-white group's income was received by those in the bottom $10 \%$ of the population. It is not surprising to see that the top decile earners were mostly in the white group, and more than half of the total white group income was received by workers in the top decile, while only about $25 \%$ of the non-white group income was earned by those in the top decile.

Panel B in Table 4-7 shows the additive decomposition results by subgroup. The contribution of the white group to the bottom decile was $53.4 \%$, and the non-white group contributed $46.6 \%$. The white group's contribution share increased for each subsequent decile. For the $9^{\text {th }}$ decile, the white group contributed $70.7 \%$ to the overall Lorenz ordinates in that decile, while the remaining $29 \%$ was contributed by the non-white group.

Table 4-8 presents the decomposed Lorenz ordinates and the additive decomposition for the 2009 data. Though the overall Lorenz ordinates increased after the crisis, the decomposed Lorenz ordinates for the two subgroups exhibited different patterns: the white group's decomposed Lorenz ordinates increased for each decile, while the non-white group's decomposed Lorenz 
ordinates actually decreased for the $7^{\text {th }}$ to the $9^{\text {th }}$ deciles. For example, in $2007,74.2 \%$ of the total non-white group's income accrued to the bottom $90 \%$ of workers, while in $2009,72.2 \%$ of total non-white income was earned by the bottom $90 \%$ of workers. In other words, the non-white households in the top $10 \%$ of the income distribution received 2 percent more of the income after the crisis, which implies that a crisis can have different impacts on the within-group income distribution. Despite the different patterns of changes in the decomposed Lorenz ordinates for the white vs. the non-white group, no significant change was found in the additive decomposition for these two subgroups.

\section{[Insert Table 4-9 here]}

Table 4-9 Panel A presents the concentration ordinates for the subsample. Households who were in the bottom earning decile before the crisis received $0.98 \%$ of the total 2007 income, whereas the same group of households received $2.25 \%$ of the total 2009 income. The top $10 \%$ of households received $47.82 \%$ of 2007 income, but their income share dropped to $42.12 \%$ after the crisis. Both white and non-white decomposed concentration ordinates exhibited patterns similar to those of the overall ordinates. Measured by the income share of each decile, income inequality decreased in both groups. Panel B shows the additive decomposition result; the only significant change in the contribution share occurred in the bottom decile, where the white group's contribution increased from $53.4 \%$ to $60.4 \%$. For other deciles, no significant change was found in terms of percentage contributions. 
[Insert Table 4-23 here]

To test the significance of the differences in the decomposed Lorenz ordinates between the white and the non-white group, I conduct a chi-square test. The null hypothesis is that there will be no difference in the Lorenz ordinates between the two subgroups. It can be defined as:

$$
H_{0}: \gamma=\mathbf{0}
$$

where $\gamma=\left(\widehat{L}_{1}^{(\text {white })}-\widehat{L}_{1}^{(\text {non-white })}, \ldots, \hat{L}_{9}^{(\text {white })}-\widehat{L}_{9}^{(\text {non-white })}\right)$ is a $1 \times 9$ vector of sample estimates of the differences between the decomposed white group's Lorenz ordinates and the nonwhite group's Lorenz ordinates. Table 4-23 panel A and B provide the test results for the difference between the white and the non-white groups' Lorenz ordinates in 2007 and 2009, respectively. The chi-square test results are statistically significant, indicating that differences exist between the subgroups. The magnitude of the chi-square test statistics increased from 32,602 in 2007 to 50,321 in 2009, indicating that the white and the non-white groups become less alike after the crisis.

The chi-square test can also be used to test whether the subgroups' ordinates are different across years. The null hypothesis can be specified as:

$$
H_{0}: \boldsymbol{\psi}=\mathbf{0}
$$

where $\psi=\left(\hat{L}_{1}^{(\text {white })}-\hat{C}_{1}^{(\text {white })}, \ldots, \hat{L}_{9}^{(\text {white })}-\hat{C}_{9}^{(\text {white })}\right)$ is a $1 \times 9$ vector of sample estimates of the differences between the white group's decomposed Lorenz ordinates and its concentration ordinates before and after the crisis. Panel $\mathrm{C}$ of Table 4-23 provides the chi-square statistics, and we can see that for both the white and the non-white group, the difference between the concentration ordinates and the Lorenz ordinates is significant, indicating that the financial crisis had an effect on the conditional change in the income share. 


\subsubsection{Decomposition by gender}

[Insert Table 4-10 to Table 4-12 here]

Table 4-10 shows the decomposed Lorenz ordinates for 2007. Female-headed households had a more equal distribution of income across deciles. For example, $48 \%$ of the female-headed households' income accrued to those below the median income level, while for the male-headed households, only $10.5 \%$ of the income was received by those below the median income level. Moreover, as shown in Table 4-4, only $1.45 \%$ of female-headed households are in the top $10 \%$ of the overall income distribution, while $13.25 \%$ of male-headed households are in the top $10 \%$ of the overall income distribution. The decomposed Lorenz ordinates in the top decile reflect a similar pattern: $52.5 \%$ of all male-headed households' earnings was earned by those in the top $10 \%$ decile, while only $11 \%$ of all female-headed households' earnings was earned by those in the top $10 \%$ decile.

Panel B of Table 4-10 presents the additive decomposition results by subgroup based on gender. The contribution of the male group to the overall sample ordinates for the bottom decile was $38.2 \%$, and the female group contributed the remaining $61.8 \%$. The male group's contribution share increased for each subsequent decile. For the $9^{\text {th }}$ decile, the male group contributed $80.8 \%$ to the overall Lorenz ordinates, while the female group contributed only $11.3 \%$ to the Lorenz ordinates in the top decile. This is consistent with the findings in Table 4-3, where we can see that the female group accounts for a much smaller proportion in the top earning decile.

Table 4-11 presents the decomposed 2009 Lorenz curve, and Table 4-12 presents the decomposed 2009 concentration curve. For the male group, ordinates in each decile increased for both the Lorenz curve and concentration curve after the crisis, but the increases in the concentration 
ordinates were more pronounced. For example, the decomposed Lorenz ordinates for the bottom decile was 0.0042 for the male group in 2007 , and it increased to 0.0055 in 2009 , whereas the increase in the decomposed concentration ordinates for the bottom decile of the male group was larger: 0.0132 in 2009. As discussed before, the concentration curve is a conditional Lorenz curve, and in it the decile cutoff point did not change from before to after the crisis. It was the same group of households in each decile, and only their income share changed. In 2007 , only $0.42 \%$ of total male group income was earned by the male-headed households in the bottom decile of the population, this same group of male households earned $1.32 \%$ of the total male group income in 2009. The male group's income became more equally distributed, measured either by the 2009 Lorenz ordinates or the concentration ordinates, but the conditional ordinates showed even more equality.

The change in the female group is interesting: the decomposed Lorenz ordinates, in which all households have been re-ordered according to their 2009 income level, decreased in each decile except the $9^{\text {th }}$. For example, the decomposed Lorenz ordinates of the female group in the bottom decile are 0.0541 in 2007 and 0.0481 in 2009. If only these two numbers were compared, we would conclude that the female-headed households in the bottom decile of the income distribution had received a smaller proportion $(4.81 \%)$ of the female group's income after the crisis. However, if we examine the decomposed ordinates of the concentration curve, which is 0.0842 for the female group in the bottom decile, we find that the female-headed households who were in the bottom decile of the 2007 income distribution received $8.42 \%$ of the entire female group's income in 2009. This different pattern indicates that some female-headed households migrated from the bottom decile of the income distribution in 2007 to a higher decile income group in 2009. It can also be 
seen from Table 4-4 and Table 4-5 that based on the 2007 income ranking, $22.2 \%$ of all femaleheaded households were located in the bottom decile, whereas based on the 2009 income ranking, only $20.27 \%$ of female-headed households were located in the bottom decile in that year. The location of the female group's distribution shifted relative to the male group's distribution. Income inequality among the female-headed households decreased after the crisis.

[Insert Table 4-24 here]

Table 4-24 shows the chi-square test statistics for the difference in the decomposed Lorenz ordinates between the male- and female-headed households. The difference was significant for both 2007 and 2009; however, the test statistics indicated that the male- and female-headed households became more alike after the crisis, as the chi-square statistics dropped from 92,704 in 2007 to 17,414 in 2009 . The chi-square statistics were also significant for the tests that compared the decomposed Lorenz and concentration curve ordinates within each gender group before and after the crisis. The results are similar to the ones obtained in the previous section, where the subgroups were created based on racial characteristics.

\subsubsection{Decomposition by retirement status}

[Insert Table 4-13 here]

In this section, I present the decomposition results based on the retirement status of the household head. Retirement can significantly change households' income level and composition, and it is useful to examine whether the financial crisis had different effects on households with different retirement statuses. Table 4-15 presents the decomposed 2007 Lorenz ordinates by retirement status. In 2007, retired households in the bottom $50 \%$ of the income distribution received $23.3 \%$ of their group's income, while non-retired households in the bottom $50 \%$ of the 
2007 income distribution received $13.2 \%$ of their group's income. The retired households had a more equal income distribution. This is consistent with the finding from Panel C of Table 4-4, which shows that $67.5 \%$ of the retired households were in the bottom $50 \%$ of the income distribution, while only $46.1 \%$ of the non-retired households were in the bottom $50 \%$ of the income distribution, and this can partly explain why the retired households in the bottom $50 \%$ of the income distribution received a higher share of their group's income compared to the non-retired households.

It is interesting to note that the decomposed ordinates are very similar in the top decile of the income distribution for both groups. However, combining information from Table 4-4 and Table $4-13$, we can see that $6.3 \%$ of retired households were in the top $10 \%$ income distribution and they received $47 \%$ of their group's income, whereas $10.7 \%$ of the non-retired households were in the top $10 \%$ income distribution, and they also received about $47 \%$ of their group's income in 2007. Both groups had the same decomposed Lorenz ordinates for the top decile, but the retired group had a smaller percentage of households in the top decile, which implies that the income was more skewed to the right within the retirement group.

Panel B of Table 4-13 presents the additive decomposition results by subgroup. The contribution of the retired group to the overall sample ordinates in the bottom decile was $30.9 \%$, and the non-retired group contributed $69.1 \%$. The retired group's contribution share decreased for each subsequent decile. In the $9^{\text {th }}$ decile, the retired group contributed only $14.8 \%$ to the overall Lorenz ordinates, while the non-retired group contributed the remaining $85.2 \%$.

[Insert Table 4-14 and Table 4-15 here] 
Table 4-14 and Table 4-15 present the results for the decomposed Lorenz curve and the concentration curve in 2009. For both the retired group and the non-retired group, the decomposed Lorenz ordinates and the concentration ordinates increased in all 9 deciles. However, the decomposed concentration ordinates increased even more. In 2007, the retired households in the bottom decile of the income distribution received $1.83 \%$ of their group's income, whereas this same group of households received $3.65 \%$ of the total retirement income in 2009 . But if we focus only on the change in the decomposed Lorenz ordinates, the change was smaller, i.e., from 0.0183 in 2007 to 0.0240 in 2009, which can be interpreted as a result of the fact that the retired households in the bottom decile of the 2009 income distribution received $2.4 \%$ of their group's income in 2009. Despite the difference in magnitude, both the decomposed 2009 Lorenz curve and concentration curve indicate that income inequality decreased for both subgroups after the crisis.

\subsection{Discussion}

\subsubsection{Crisis effects in the longer run.}

Though the SCF provides more complete information with which to study the income distribution of American households, especially for households in the top decile, where incomes were most affected by the negative impact of the financial crisis, the panel dataset has its drawbacks. It has observations for only two waves, which makes it impossible to study the longer term effect of financial crisis using the decomposition method. In this section, I supplement the

analysis by using data from the Panel Study of Income Dynamics (PSID), a panel dataset of a nationally representative sample of 5,000 households since 1968. The PSID has collected social, economic, and income data from the originally interviewed families, as well as from families 
started by the descendants of the original families, for over four decades. This longitudinal dataset allows researchers to track households' income change over a longer period of time. Nevertheless, one drawback of the PSID is that the households surveyed were a representative national sample in 1968 but might fail to consist of the most updated representative sample for the recent decade. And unlike the SCF, which provides more accurate measurement for high-income earners, the PSID does not cover enough wealthy households, and this makes it less than ideal for studying change in the top decile of the income distribution. Despite the limitations of the PSID, some useful inferences can still be made for studying the longer term effects of the financial crisis.

[Insert Table 4-16 to Table 4-19 here]

To study the longer term effects of the 2008 financial crisis, I use the PSID 2006 and 2012 waves, the latter being the most recent available one. In this analysis, I focus on decomposing the overall Lorenz curve and the concentration curve into the white and the non-white groups. ${ }^{9}$ In 2012, four years after the financial crisis, while the U.S. stock market rebounded to its previous level and continued to rise, the decomposed ordinates of the Lorenz curve for the white group reverted back to their pre-crisis level. However, the decomposed ordinates for the non-white group were still higher in 2012. In addition, for both groups, the decomposed concentration ordinates remained higher than the pre-crisis level. For example, measured by the PSID data, non-white households in the bottom 9 deciles of the income distribution received $78.7 \%$ of their groups' income in 2006. And these same sets of households received 85\% of their group's income in 2012. Similar results hold for the white group. In 2006, white households in the bottom 9 deciles of the

\footnotetext{
${ }^{9}$ Decomposition based on other characteristics such as gender and retirement status can be done similarly; the results are not shown here.
} 
income distribution received $63.7 \%$ of their group's income, and the same households received $68.7 \%$ of their group's income in 2012, a five percent increase from their 2006 level. These results imply that the longer term effects of the financial crisis do exist as measured by the concentration ordinates.

\subsubsection{Comparison with the 1987 stock market crash}

In addition to the usefulness of the PSID for studying the longer term effects of the 2008 financial crisis, the span of the PSID also provides us with a means to study the change in the income distribution in relation to previous stock market crashes, and to see if they had impacts on the income distribution similar to those found for the 2008 financial crisis. Historically, another dramatic decline in the stock market happened in October, 1987. To compare the impacts of these two financial crises, I conducted a similar decomposition analysis to examine the impact of the 1987 stock market crash on U.S. households' income distribution. For this analysis, I used two years of PSID data: those from the 1986 and 1988 waves.

[Insert Table 4-20 to Table 4-22 here]

Table 4-20 to Table 4-22 present the decomposition results. I find that the 1987 stock market crash had a similar immediate effect on income distribution, measured by the 1988 concentration ordinates. Both the white and the non-white groups' conditional income share in the bottom 9 deciles increased after the crisis. The results also hold for the decomposed 1988 Lorenz ordinates from the bottom to the $7^{\text {th }}$ deciles for the white group, but the magnitude was smaller. Despite the lower stock market participation rate of the average household 20 years ago, the 1987 stock market crash still led to a change in the income distribution in the short run, especially for the non-white group, but the magnitude appears to be smaller. 


\subsection{Conclusion}

Income inequality has risen substantially in the last 40 years in the U.S., and many studies have attempted to explain the cause of this trend. In addition to other events, economy-wide shocks can have a large impact on the distribution of income. The 2008 Financial Crisis, the largest economic recession since World War II, reduced many households' income level, and the reduction was not uniform for all households, which led to a change in the income distribution among U.S. households. This paper documents income distribution changes before and after the Financial Crisis. Using the Survey of Consumer Finance 2007-2009 panel dataset, I apply a nonparametric decomposition method to quantify the change in the income distribution, measured by the Lorenz curve and its associated concentration curve. Instead of focusing on a single inequality index, this approach analyzes the whole income distribution, and can thus better track income share changes of the households in each decile. Moreover, the decomposition approach allows me to examine how different subgroups, defined based on households' demographic characteristics, contribute to the overall income inequality.

The findings show that income inequality dropped immediately after the financial crisis, and most of the drop came from the decrease in the income share of the top income earners, defined as the households in the top $10 \%$ of the income distribution. The drop was more substantial in the associated concentration ordinates, a conditional measure of the Lorenz ordinates. Subgroup decomposition shows that non-white, female-headed, or retired households contributed relatively more to the lower deciles of the overall Lorenz and concentration ordinates, while white, maleheaded, or non-retired households contributed more to the higher deciles of the overall Lorenz and the concentration ordinates. All decomposed concentration ordinates increased for each subgroup 
in 2009, and the bottom nine deciles' ordinates remained larger 4 years after the financial crisis, while the decomposed Lorenz ordinates reverted back to their pre-crisis level during this longer time span. In addition, compared to the impact of the 1987 stock market crash on income distribution, the short run effect of the 2008 financial crisis was larger, measured by both the Lorenz ordinates and the concentration ordinates. 
Table 4-1: Summary statistics for key variables in the SCF 2007 \& 2009

This table provides summary statistics for the key variables of the SCF 2007-2009 panel data; all data are weighted using the weight provided by the SCF.

\begin{tabular}{lllll}
\hline Variable & Mean & Median & Standard Deviation & N \\
\hline Age & 49.4 & 48.0 & 16.8 & 3857 \\
Education & 13.4 & 13.0 & 2.8 & 3857 \\
Income & & & & 3857 \\
2007 & 89,036 & 49,841 & & 3857 \\
2009 & 80,816 & 49,810 & & 3857 \\
Assets & & & & 3857 \\
2007 & 698,251 & 226,796 & $3,501,309$ & 3857 \\
2009 & 583,014 & 197,900 & $2,858,847$ & 3857 \\
Debts & & & & 3847 \\
2007 & 102,509 & 33,346 & 193,751 & 3847 \\
2009 & 103,939 & 33,000 & 206,227 & 3857 \\
Leverage Ratio & & & & 3857 \\
2007 & 22 & 0.227 & 419 & 528 \\
2009 & 26 & 0.257 & & $3,446,799$ \\
Net Worth & & & $2,801,402$ & \\
2007 & 595,742 & 128,000 & 96,900 & \\
2009 & 479,074 & & & \\
\hline
\end{tabular}


Table 4-2: Summary statistics for the income variable by group

This table provides summary statistics for the income variable based on race, gender, and retirement status.

\begin{tabular}{|c|c|c|c|c|c|c|}
\hline \multirow[t]{2}{*}{ Sample } & \multirow[t]{2}{*}{$\begin{array}{l}\text { Number of } \\
\text { Observations }\end{array}$} & \multirow{2}{*}{$\begin{array}{l}\text { Weighed } \\
\text { Percentage } \\
\text { Of Observations }\end{array}$} & \multicolumn{2}{|c|}{$\begin{array}{l}\text { Percentage of Earnings } \\
\text { Contributed }\end{array}$} & \multicolumn{2}{|c|}{ Median Equivalent Earnings } \\
\hline & & & 2007 & 2009 & 2007 & 2009 \\
\hline \multicolumn{7}{|c|}{ Panel A: By Race } \\
\hline White & 2,915 & $68.2 \%$ & $79.2 \%$ & $77.4 \%$ & 103,552 & 91,750 \\
\hline Non-White & 942 & $31.8 \%$ & $20.8 \%$ & $22.6 \%$ & 58,211 & 57,490 \\
\hline \multicolumn{7}{|c|}{ Panel B: By Gender } \\
\hline Male & 3084 & $72.6 \%$ & $88.7 \%$ & $86.7 \%$ & 108,795 & 96,617 \\
\hline Female & 773 & $27.4 \%$ & $11.3 \%$ & $13.3 \%$ & 36,905 & 38,987 \\
\hline \multicolumn{7}{|c|}{ Panel C: By Retirement Status } \\
\hline Retired & 677 & $18.8 \%$ & $15 \%$ & $14.3 \%$ & 71,550 & 61,770 \\
\hline Non-Retired & 3180 & $81.2 \%$ & $85 \%$ & $85.7 \%$ & 93,183 & 85,253 \\
\hline
\end{tabular}


Table 4-3: Decile composition by subgroups (2007)

This table presents the decile composition by race, gender, and retirement status.

\begin{tabular}{|c|c|c|c|c|c|c|c|c|c|c|c|}
\hline Decile & & 1 & 2 & 3 & 4 & 5 & 6 & 7 & 8 & 9 & 10 \\
\hline \multicolumn{12}{|c|}{ Panel A: By Race } \\
\hline \multirow[t]{2}{*}{ White } & Count & 1219273 & 1278994 & 1446992 & 1461333 & 1541349 & 1733279 & 1381665 & 1714052 & 1753806 & 1904269 \\
\hline & $\%$ & $53 \%$ & $57 \%$ & $64 \%$ & $66 \%$ & $66 \%$ & $72 \%$ & $66 \%$ & $75 \%$ & $77 \%$ & $85 \%$ \\
\hline Non- & Count & 1061083 & 965562.5 & 813174.6 & 758644 & 792150.6 & 683053.9 & 704699.8 & 564386.5 & 517524.1 & 340882.7 \\
\hline White & $\%$ & $47 \%$ & $43 \%$ & $36 \%$ & $34 \%$ & $34 \%$ & $28 \%$ & $34 \%$ & $25 \%$ & $23 \%$ & $15 \%$ \\
\hline \multicolumn{12}{|c|}{ Panel B: By Gender } \\
\hline \multirow[t]{2}{*}{ Male } & Count & 905990 & 1027826 & 1254534 & 1536606 & 1754497 & 1881030 & 1784549 & 2062950 & 2074390 & 2161062 \\
\hline & $\%$ & $40 \%$ & $46 \%$ & $56 \%$ & $69 \%$ & $75 \%$ & $78 \%$ & $86 \%$ & $91 \%$ & $91 \%$ & $96 \%$ \\
\hline \multirow[t]{2}{*}{ Female } & Count & 1374366 & 1216730 & 1005633 & 683371 & 579002 & 535303 & 301816 & 215488 & 196940 & 84090 \\
\hline & $\%$ & $60 \%$ & $54 \%$ & $44 \%$ & $31 \%$ & $25 \%$ & $22 \%$ & $14 \%$ & $9 \%$ & $9 \%$ & $4 \%$ \\
\hline \multicolumn{12}{|c|}{ Panel C: By Retirement Status } \\
\hline \multirow[t]{2}{*}{ Retired } & Count & 581360 & 729254 & 624325 & 487138 & 443648 & 357490 & 294779 & 227597 & 229637 & 268365 \\
\hline & $\%$ & $25 \%$ & $32 \%$ & $28 \%$ & $22 \%$ & $19 \%$ & $15 \%$ & $14 \%$ & $10 \%$ & $10 \%$ & $12 \%$ \\
\hline Non- & Count & 1698996 & 1515302 & 1635842 & 1732839 & 1889851 & 2058843 & 1791585 & 2050842 & 2041693 & 1976786 \\
\hline Retired & $\%$ & $75 \%$ & $68 \%$ & $72 \%$ & $78 \%$ & $81 \%$ & $85 \%$ & $86 \%$ & $90 \%$ & $90 \%$ & $88 \%$ \\
\hline
\end{tabular}


Table 4-4: Group composition by 2007 decile

This table presents the population distribution in each decile by groups. The decile cut-off points are calculated using the 2007 income data.

\begin{tabular}{|c|c|c|c|c|c|c|c|c|c|c|c|}
\hline Decile & & 1 & 2 & 3 & 4 & 5 & 6 & 7 & 8 & 9 & 10 \\
\hline \multicolumn{12}{|c|}{ Panel A: By Race } \\
\hline \multirow[t]{3}{*}{ White } & Count & 1219273 & 1278994 & 1446992 & 1461333 & 1541349 & 1733279 & 1381665 & 1714052 & 1753806 & 1904269 \\
\hline & $\%$ & $7.9 \%$ & $8.3 \%$ & $9.4 \%$ & $9.5 \%$ & $10.0 \%$ & $11.2 \%$ & $9.0 \%$ & $11.1 \%$ & $11.4 \%$ & $12.3 \%$ \\
\hline & Cumulative $\%$ & $7.9 \%$ & $16.2 \%$ & $25.6 \%$ & $35.0 \%$ & $45.0 \%$ & $56.2 \%$ & $65.2 \%$ & $76.3 \%$ & $87.7 \%$ & $100.0 \%$ \\
\hline \multirow{3}{*}{$\begin{array}{l}\text { Non- } \\
\text { White }\end{array}$} & Count & 1061083 & 965562 & 813174 & 758644 & 792150 & 683053 & 704699 & 564386 & 517524 & 340882 \\
\hline & & $14.7 \%$ & $13.4 \%$ & $11.3 \%$ & $10.5 \%$ & $11.0 \%$ & $9.5 \%$ & $9.8 \%$ & $7.8 \%$ & $7.2 \%$ & $4.7 \%$ \\
\hline & Cumulative $\%$ & $14.7 \%$ & $28.1 \%$ & $39.4 \%$ & $50.0 \%$ & $61.0 \%$ & $70.5 \%$ & $80.2 \%$ & $88.1 \%$ & $95.3 \%$ & $100.0 \%$ \\
\hline \multicolumn{12}{|c|}{ Panel B: By Gender } \\
\hline \multirow[t]{3}{*}{ Male } & Count & 905990 & 1027826 & 1254534 & 1536606 & 1754497 & 1881030 & 1784549 & 2062950 & 2074390 & 2161062 \\
\hline & & $5.5 \%$ & $6.3 \%$ & $7.6 \%$ & $9.3 \%$ & $10.7 \%$ & $11.4 \%$ & $10.9 \%$ & $12.5 \%$ & $12.6 \%$ & $13.1 \%$ \\
\hline & Cumulative $\%$ & $5.5 \%$ & $11.8 \%$ & $19.4 \%$ & $28.7 \%$ & $39.4 \%$ & $50.8 \%$ & $61.7 \%$ & $74.2 \%$ & $86.9 \%$ & $100.0 \%$ \\
\hline \multirow[t]{3}{*}{ Female } & Count & 1374366 & 1216730 & 1005633 & 683371 & 579002 & 535303 & 301816 & 215488 & 196940 & 84090 \\
\hline & & $22.2 \%$ & $19.6 \%$ & $16.2 \%$ & $11.0 \%$ & $9.3 \%$ & $8.6 \%$ & $4.9 \%$ & $3.5 \%$ & $3.2 \%$ & $1.4 \%$ \\
\hline & Cumulative $\%$ & $22.2 \%$ & $41.8 \%$ & $58.1 \%$ & $69.1 \%$ & $78.5 \%$ & $87.1 \%$ & $92.0 \%$ & $95.5 \%$ & $98.6 \%$ & $100.0 \%$ \\
\hline \multicolumn{12}{|c|}{ Panel C: By Retirement Status } \\
\hline \multirow[t]{3}{*}{ Retired } & Count & 581360 & 729254 & 624325 & 487138 & 443648 & 357490 & 294779 & 227597 & 229637 & 268365 \\
\hline & $\%$ & $13.7 \%$ & $17.2 \%$ & $14.7 \%$ & $11.5 \%$ & $10.5 \%$ & $8.4 \%$ & $6.9 \%$ & $5.4 \%$ & $5.4 \%$ & $6.3 \%$ \\
\hline & Cumulative $\%$ & $13.7 \%$ & $30.9 \%$ & $45.6 \%$ & $57.1 \%$ & $67.5 \%$ & $76.0 \%$ & $82.9 \%$ & $88.3 \%$ & $93.7 \%$ & $100.0 \%$ \\
\hline \multirow{3}{*}{$\begin{array}{l}\text { Non- } \\
\text { Retired }\end{array}$} & Count & 1698996 & 1515302 & 1635842 & 1732839 & 1889851 & 2058843 & 1791585 & 2050842 & 2041693 & 1976786 \\
\hline & $\%$ & $9.2 \%$ & $8.2 \%$ & $8.9 \%$ & $9.4 \%$ & $10.3 \%$ & $11.2 \%$ & $9.7 \%$ & $11.2 \%$ & $11.1 \%$ & $10.7 \%$ \\
\hline & Cumulative $\%$ & $9.2 \%$ & $17.5 \%$ & $26.4 \%$ & $35.8 \%$ & $46.1 \%$ & $57.3 \%$ & $67.0 \%$ & $78.2 \%$ & $89.3 \%$ & $100.0 \%$ \\
\hline
\end{tabular}


Table 4-5: Group composition by 2009 decile

This table presents the population distribution in each decile by groups. The decile cut-off points are calculated using the 2009 income data.

\begin{tabular}{|c|c|c|c|c|c|c|c|c|c|c|c|}
\hline Decile & & 1 & 2 & 3 & 4 & 5 & 6 & 7 & 8 & 9 & 10 \\
\hline \multicolumn{12}{|c|}{ Panel A: By Race } \\
\hline \multirow[t]{3}{*}{ White } & Count & 1249094 & 1301192 & 1349647 & 1468930 & 1526066 & 1552331 & 1669147 & 1748652 & 1782662 & 1828168 \\
\hline & $\%$ & $8.07 \%$ & $8.41 \%$ & $8.72 \%$ & $9.49 \%$ & $9.86 \%$ & $10.03 \%$ & $10.79 \%$ & $11.30 \%$ & $11.52 \%$ & $11.81 \%$ \\
\hline & Cumulative $\%$ & $8.07 \%$ & $16.48 \%$ & $25.20 \%$ & $34.69 \%$ & $44.55 \%$ & $54.58 \%$ & $65.37 \%$ & $76.67 \%$ & $88.19 \%$ & $100.00 \%$ \\
\hline Non- & Count & 1034499 & 983916 & 767146 & 884123 & 706670 & 631180 & 675068 & 555812 & 480704 & 441168 \\
\hline \multirow{2}{*}{ White } & $\%$ & $14.45 \%$ & $13.74 \%$ & $10.71 \%$ & $12.35 \%$ & $9.87 \%$ & $8.82 \%$ & $9.43 \%$ & $7.76 \%$ & $6.71 \%$ & $6.16 \%$ \\
\hline & Cumulative $\%$ & $14.45 \%$ & $28.19 \%$ & $38.90 \%$ & $51.25 \%$ & $61.12 \%$ & $69.93 \%$ & $79.36 \%$ & $87.13 \%$ & $93.84 \%$ & $100.00 \%$ \\
\hline \multicolumn{12}{|c|}{ Panel B: By Gender } \\
\hline \multirow[t]{3}{*}{ Male } & Count & 1028128 & 1090440 & 1330348 & 1637062 & 1532749 & 1720845 & 1841906 & 2074227 & 2008307 & 2179423 \\
\hline & $\%$ & $6.25 \%$ & $6.63 \%$ & $8.09 \%$ & $9.96 \%$ & $9.32 \%$ & $10.47 \%$ & $11.20 \%$ & $12.61 \%$ & $12.21 \%$ & $13.25 \%$ \\
\hline & Cumulative $\%$ & $6.25 \%$ & $12.88 \%$ & $20.97 \%$ & $30.93 \%$ & $40.25 \%$ & $50.72 \%$ & $61.92 \%$ & $74.53 \%$ & $86.75 \%$ & $100.00 \%$ \\
\hline \multirow[t]{3}{*}{ Female } & Count & 1255465 & 1194668 & 786445 & 715992 & 699986 & 462665 & 502308 & 230236 & 255058 & 89914 \\
\hline & $\%$ & $20.27 \%$ & $19.29 \%$ & $12.70 \%$ & $11.56 \%$ & $11.30 \%$ & $7.47 \%$ & $8.11 \%$ & $3.72 \%$ & $4.12 \%$ & $1.45 \%$ \\
\hline & Cumulative $\%$ & $20.27 \%$ & $39.56 \%$ & $52.26 \%$ & $63.83 \%$ & $75.13 \%$ & $82.60 \%$ & $90.71 \%$ & $94.43 \%$ & $98.55 \%$ & $100.00 \%$ \\
\hline \multicolumn{12}{|c|}{ Panel C: By Retirement Status } \\
\hline \multirow[t]{3}{*}{ Retired } & Count & 691663 & 670328.8 & 553461.4 & 657576 & 362662.8 & 360751.1 & 337121.8 & 251245 & 153635.5 & 205149.3 \\
\hline & $\%$ & $16.30 \%$ & $15.80 \%$ & $13.04 \%$ & $15.50 \%$ & $8.55 \%$ & $8.50 \%$ & $7.94 \%$ & $5.92 \%$ & $3.62 \%$ & $4.83 \%$ \\
\hline & Cumulative \% & $16.30 \%$ & $32.10 \%$ & $45.14 \%$ & $60.63 \%$ & $69.18 \%$ & $77.68 \%$ & $85.62 \%$ & $91.55 \%$ & $95.17 \%$ & $100.00 \%$ \\
\hline \multirow{3}{*}{$\begin{array}{l}\text { Non- } \\
\text { Retired }\end{array}$} & Count & 1591930 & 1614779 & 1563332 & 1695478 & 1870073 & 1822760 & 2007093 & 2053218 & 2109730 & 2064187 \\
\hline & $\%$ & $8.66 \%$ & $8.78 \%$ & $8.50 \%$ & $9.22 \%$ & $10.17 \%$ & $9.91 \%$ & $10.91 \%$ & $11.16 \%$ & $11.47 \%$ & $11.22 \%$ \\
\hline & Cumulative $\%$ & $8.66 \%$ & $17.43 \%$ & $25.93 \%$ & $35.15 \%$ & $45.32 \%$ & $55.23 \%$ & $66.14 \%$ & $77.31 \%$ & $88.78 \%$ & $100.00 \%$ \\
\hline
\end{tabular}


Table 4-6: Lorenz ordinates decomposition for the overall sample (2007 vs. 2009)

This table presents the order statistics (upper cutoff values) and the Lorenz ordinates for 2007 and 2009 data from the SCF. The standard error for the Lorenz ordinates are in parentheses.

\begin{tabular}{|c|c|c|c|c|c|c|c|c|c|c|}
\hline & $\begin{array}{l}\text { Bottom } \\
\text { Decile }\end{array}$ & 2 & 3 & 4 & 5 & 6 & 7 & 8 & 9 & $\begin{array}{l}\text { Total } \\
\text { Sample }\end{array}$ \\
\hline \multicolumn{11}{|c|}{ Panel A: Lorenz Ordinates 2007} \\
\hline Order Statistic & 13,632 & 22,577 & 31,736 & 39,191 & 49,841 & 63,899 & 77,956 & 102,238 & 149,097 & - \\
\hline $\begin{array}{l}\text { Overall } \\
\text { Sample }\end{array}$ & $\begin{array}{l}0.0098 \\
(0.0016) \\
\end{array}$ & $\begin{array}{l}0.0301 \\
(0.0044) \\
\end{array}$ & $\begin{array}{l}0.0600 \\
(0.0085) \\
\end{array}$ & $\begin{array}{l}0.0992 \\
(0.0138) \\
\end{array}$ & $\begin{array}{l}0.1473 \\
(0.0203) \\
\end{array}$ & $\begin{array}{l}0.2095 \\
(0.0286) \\
\end{array}$ & $\begin{array}{l}0.2884 \\
(0.0391) \\
\end{array}$ & $\begin{array}{l}0.3862 \\
(0.0520) \\
\end{array}$ & $\begin{array}{l}0.5218 \\
(0.0697) \\
\end{array}$ & 1.0000 \\
\hline \multicolumn{11}{|c|}{ Panel B : Lorenz Ordinates 2009} \\
\hline Order Statistic & 13,947 & 22,116 & 29,886 & 38,851 & 49,810 & 61,760 & 79,696 & 102,011 & 147,039 & - \\
\hline $\begin{array}{l}\text { Overall } \\
\text { Sample }\end{array}$ & $\begin{array}{l}0.0111 \\
(0.0013)\end{array}$ & $\begin{array}{l}0.0335 \\
(0.0034)\end{array}$ & $\begin{array}{l}0.0641 \\
(0.0060)\end{array}$ & $\begin{array}{l}0.1076 \\
(0.0096)\end{array}$ & $\begin{array}{l}0.1608 \\
(0.0140)\end{array}$ & $\begin{array}{l}0.2299 \\
(0.0195)\end{array}$ & $\begin{array}{l}0.3158 \\
(0.0263) \\
\end{array}$ & $\begin{array}{l}0.4285 \\
(0.0349) \\
\end{array}$ & $\begin{array}{l}0.5778 \\
(0.0458) \\
\end{array}$ & 1.0000 \\
\hline
\end{tabular}


Table 4-7: Lorenz ordinates and subsample decomposition by race (2007)

Panel A of this table presents the decomposed order statistics and the Lorenz ordinates for the 2007 data by race. The standard errors for the decomposed Lorenz ordinates are in parentheses. Panel B presents the additive decomposition in each decile by race.

\begin{tabular}{|c|c|c|c|c|c|c|c|c|c|c|}
\hline & $\begin{array}{l}\text { Bottom } \\
\text { Decile }\end{array}$ & 2 & 3 & 4 & 5 & 6 & 7 & 8 & 9 & $\begin{array}{l}\text { Total } \\
\text { Sample }\end{array}$ \\
\hline \multicolumn{11}{|c|}{ Panel A: Lorenz Ordinates } \\
\hline Order Statistic & 13,632 & 22,577 & 31,736 & 39,191 & 49,841 & 63,899 & 77,956 & 102,238 & 149,097 & - \\
\hline Overall Sample & $\begin{array}{l}0.0098 \\
(0.0016)\end{array}$ & $\begin{array}{l}0.0301 \\
(0.0044)\end{array}$ & $\begin{array}{l}0.0600 \\
(0.0085)\end{array}$ & $\begin{array}{l}0.0992 \\
(0.0138)\end{array}$ & $\begin{array}{l}0.1473 \\
(0.0203)\end{array}$ & $\begin{array}{l}0.2095 \\
(0.0286)\end{array}$ & $\begin{array}{l}0.2884 \\
(0.0391)\end{array}$ & $\begin{array}{l}0.3862 \\
(0.0520)\end{array}$ & $\begin{array}{l}0.5218 \\
(0.0697)\end{array}$ & 1.0000 \\
\hline White & $\begin{array}{l}0.0067 \\
(0.0013)\end{array}$ & $\begin{array}{l}0.0213 \\
(0.0039)\end{array}$ & $\begin{array}{l}0.0453 \\
(0.0080)\end{array}$ & $\begin{array}{l}0.0776 \\
(0.0134)\end{array}$ & $\begin{array}{l}0.1175 \\
(0.0201)\end{array}$ & $\begin{array}{l}0.1732 \\
(0.0293)\end{array}$ & $\begin{array}{l}0.2404 \\
(0.0403)\end{array}$ & $\begin{array}{l}0.3321 \\
(0.0533)\end{array}$ & $\begin{array}{l}0.4646 \\
(0.0768)\end{array}$ & 1.0000 \\
\hline Non-White & $\begin{array}{l}0.0222 \\
(0.0040)\end{array}$ & $\begin{array}{l}0.0643 \\
(0.0101) \\
\end{array}$ & $\begin{array}{l}0.1167 \\
(0.0174) \\
\end{array}$ & $\begin{array}{l}0.1827 \\
(0.0261)\end{array}$ & $\begin{array}{l}0.2621 \\
(0.0364) \\
\end{array}$ & $\begin{array}{l}0.3495 \\
(0.0474) \\
\end{array}$ & $\begin{array}{l}0.4738 \\
(0.0625) \\
\end{array}$ & $\begin{array}{l}0.5951 \\
(0.0766)\end{array}$ & $\begin{array}{l}0.7422 \\
(0.0926) \\
\end{array}$ & 1.0000 \\
\hline \multicolumn{11}{|c|}{ Panel B: Additive Decomposition by Subsample - Percentage Contribution } \\
\hline White & $53.4 \%$ & $56.1 \%$ & $59.9 \%$ & $62.1 \%$ & $63.4 \%$ & $65.7 \%$ & $66.2 \%$ & $68.3 \%$ & $70.7 \%$ & $79.2 \%$ \\
\hline Non-White & $46.6 \%$ & $43.9 \%$ & $40.1 \%$ & $37.9 \%$ & $36.6 \%$ & $34.3 \%$ & $33.8 \%$ & $31.7 \%$ & $29.3 \%$ & $20.8 \%$ \\
\hline
\end{tabular}


Table 4-8: Lorenz ordinates and subsample decomposition by race (2009)

Panel A of this table presents the decomposed order statistics and the Lorenz ordinates for the 2009 data by race. The standard errors for the decomposed Lorenz ordinates are in parentheses. Panel B presents the additive decomposition in each decile by race.

\begin{tabular}{|c|c|c|c|c|c|c|c|c|c|c|}
\hline & $\begin{array}{l}\text { Bottom } \\
\text { Decile }\end{array}$ & 2 & 3 & 4 & 5 & 6 & 7 & 8 & 9 & $\begin{array}{l}\text { Total } \\
\text { Sample }\end{array}$ \\
\hline \multicolumn{11}{|c|}{ Panel A: Lorenz Ordinates } \\
\hline Order Statistic & 13,947 & 22,116 & 29,886 & 38,851 & 49,810 & 61,760 & 79,696 & 102,011 & 147,039 & - \\
\hline Overall Sample & $\begin{array}{l}0.0111 \\
(0.0013)\end{array}$ & $\begin{array}{l}0.0335 \\
(0.0034)\end{array}$ & $\begin{array}{l}0.0641 \\
(0.0060)\end{array}$ & $\begin{array}{l}0.1076 \\
(0.0096)\end{array}$ & $\begin{array}{l}0.1608 \\
(0.0140)\end{array}$ & $\begin{array}{l}0.2299 \\
(0.0195)\end{array}$ & $\begin{array}{l}0.3158 \\
(0.0263)\end{array}$ & $\begin{array}{l}0.4285 \\
(0.0349)\end{array}$ & $\begin{array}{l}0.5778 \\
(0.0458)\end{array}$ & 1.0000 \\
\hline White & $\begin{array}{l}0.0077 \\
(0.0012)\end{array}$ & $\begin{array}{l}0.0241 \\
(0.0031)\end{array}$ & $\begin{array}{l}0.0492 \\
(0.0059)\end{array}$ & $\begin{array}{l}0.0842 \\
(0.0096)\end{array}$ & $\begin{array}{l}0.1311 \\
(0.0144)\end{array}$ & $\begin{array}{l}0.1946 \\
(0.0209)\end{array}$ & $\begin{array}{l}0.2731 \\
(0.0287)\end{array}$ & $\begin{array}{l}0.3845 \\
(0.0395)\end{array}$ & $\begin{array}{l}0.5358 \\
(0.0528)\end{array}$ & 1.0000 \\
\hline Non-White & $\begin{array}{l}0.0230 \\
(0.0035)\end{array}$ & $\begin{array}{l}0.0659 \\
(0.0079)\end{array}$ & $\begin{array}{l}0.1152 \\
(0.0125)\end{array}$ & $\begin{array}{l}0.1881 \\
(0.0188)\end{array}$ & $\begin{array}{l}0.2629 \\
(0.0249)\end{array}$ & $\begin{array}{l}0.3512 \\
(0.0316)\end{array}$ & $\begin{array}{l}0.4624 \\
(0.0394)\end{array}$ & $\begin{array}{l}0.5799 \\
(0.0465)\end{array}$ & $\begin{array}{l}0.7221 \\
(0.0534)\end{array}$ & 1.0000 \\
\hline \multicolumn{11}{|c|}{ Panel B: Additive Decomposition by Subsample - Percentage Contribution } \\
\hline Group 1 & $53.4 \%$ & $55.7 \%$ & $59.5 \%$ & $60.6 \%$ & $63.2 \%$ & $65.6 \%$ & $67.0 \%$ & $69.5 \%$ & $71.8 \%$ & $77.4 \%$ \\
\hline Group 2 & $46.6 \%$ & $44.3 \%$ & $40.5 \%$ & $39.4 \%$ & $36.8 \%$ & $34.4 \%$ & $33.0 \%$ & $30.5 \%$ & $28.2 \%$ & $22.6 \%$ \\
\hline
\end{tabular}


Table 4-9: Concentration ordinates and subsample decomposition by race (2009)

Panel A of this table presents the decomposed order statistics and the concentration ordinates for the 2009 data by race. The standard errors for the decomposed Concentration ordinates are in parentheses. Panel B presents the additive decomposition in each decile by race.

\begin{tabular}{|c|c|c|c|c|c|c|c|c|c|c|}
\hline & $\begin{array}{l}\text { Bottom } \\
\text { Decile }\end{array}$ & 2 & 3 & 4 & 5 & 6 & 7 & 8 & 9 & $\begin{array}{l}\text { Total } \\
\text { Sample }\end{array}$ \\
\hline \multicolumn{11}{|c|}{ Panel A: Concentration Ordinates } \\
\hline Order Statistic & 13,632 & 22,577 & 31,736 & 39,191 & 49,841 & 63,899 & 77,956 & 102,238 & 149,097 & - \\
\hline Overall Sample & $\begin{array}{l}0.0225 \\
(0.0049)\end{array}$ & $\begin{array}{l}0.0518 \\
(0.0066)\end{array}$ & $\begin{array}{l}0.0935 \\
(0.0097)\end{array}$ & $\begin{array}{l}0.1411 \\
(0.0132)\end{array}$ & $\begin{array}{l}0.2004 \\
(0.0179)\end{array}$ & $\begin{array}{l}0.2724 \\
(0.0233)\end{array}$ & $\begin{array}{l}0.3596 \\
(0.0299)\end{array}$ & $\begin{array}{l}0.4674 \\
(0.0378)\end{array}$ & $\begin{array}{l}0.6221 \\
(0.0478)\end{array}$ & 1.0000 \\
\hline White & $\begin{array}{l}0.0176 \\
(0.0059)\end{array}$ & $\begin{array}{l}0.0387 \\
(0.0072)\end{array}$ & $\begin{array}{l}0.0722 \\
(0.0101)\end{array}$ & $\begin{array}{l}0.1134 \\
(0.0138)\end{array}$ & $\begin{array}{l}0.1668 \\
(0.0191)\end{array}$ & $\begin{array}{l}0.2326 \\
(0.0254)\end{array}$ & $\begin{array}{l}0.3106 \\
(0.0328)\end{array}$ & $\begin{array}{l}0.4158 \\
(0.0427)\end{array}$ & $\begin{array}{l}0.5743 \\
(0.0562)\end{array}$ & 1.0000 \\
\hline Non-White & $\begin{array}{l}0.0396 \\
(0.0068) \\
\end{array}$ & $\begin{array}{l}0.0969 \\
(0.0124) \\
\end{array}$ & $\begin{array}{l}0.1665 \\
(0.0189) \\
\end{array}$ & $\begin{array}{l}0.2365 \\
(0.0241) \\
\end{array}$ & $\begin{array}{l}0.3160 \\
(0.0298) \\
\end{array}$ & $\begin{array}{l}0.4091 \\
(0.0361) \\
\end{array}$ & $\begin{array}{l}0.5282 \\
(0.0434)\end{array}$ & $\begin{array}{l}0.6446 \\
(0.0495) \\
\end{array}$ & $\begin{array}{l}0.7867 \\
(0.0549) \\
\end{array}$ & 1.0000 \\
\hline \multicolumn{11}{|c|}{ Panel B: Additive Decomposition by Subsample - Percentage Contribution } \\
\hline White & $60.4 \%$ & $57.8 \%$ & $59.9 \%$ & $62.2 \%$ & $64.5 \%$ & $66.2 \%$ & $66.9 \%$ & $68.9 \%$ & $71.5 \%$ & $77.4 \%$ \\
\hline Non-White & $39.6 \%$ & $42.2 \%$ & $40.1 \%$ & $37.8 \%$ & $35.5 \%$ & $33.8 \%$ & $33.1 \%$ & $31.1 \%$ & $28.5 \%$ & $22.6 \%$ \\
\hline
\end{tabular}


Table 4-10: Lorenz ordinates and subsample decomposition by gender (2007)

Panel A of this table presents the decomposed order statistics and the Lorenz ordinates for the 2007 data by gender. The standard errors for the decomposed Lorenz ordinates are in parentheses. Panel B presents the additive decomposition in each decile by gender.

\begin{tabular}{|c|c|c|c|c|c|c|c|c|c|c|}
\hline & $\begin{array}{l}\text { Bottom } \\
\text { Decile }\end{array}$ & 2 & 3 & 4 & 5 & 6 & 7 & 8 & 9 & $\begin{array}{l}\text { Total } \\
\text { Sample }\end{array}$ \\
\hline \multicolumn{11}{|c|}{ Panel A: Lorenz Ordinates } \\
\hline Order Statistic & 13,632 & 22,577 & 31,736 & 39,191 & 49,841 & 63,899 & 77,956 & 102,238 & 149,097 & - \\
\hline Overall Sample & $\begin{array}{l}0.0098 \\
(0.0016)\end{array}$ & $\begin{array}{l}0.0301 \\
(0.0044)\end{array}$ & $\begin{array}{l}0.0600 \\
(0.0085)\end{array}$ & $\begin{array}{l}0.0992 \\
(0.0138)\end{array}$ & $\begin{array}{l}0.1473 \\
(0.0203)\end{array}$ & $\begin{array}{l}0.2095 \\
(0.0286)\end{array}$ & $\begin{array}{l}0.2884 \\
(0.0391)\end{array}$ & $\begin{array}{l}0.3862 \\
(0.0520)\end{array}$ & $\begin{array}{l}0.5218 \\
(0.0697)\end{array}$ & 1.0000 \\
\hline Male & $\begin{array}{l}0.0042 \\
(0.0009)\end{array}$ & $\begin{array}{l}0.0149 \\
(0.0026)\end{array}$ & $\begin{array}{l}0.0336 \\
(0.0056)\end{array}$ & $\begin{array}{l}0.0646 \\
(0.0104)\end{array}$ & $\begin{array}{l}0.1051 \\
(0.0165)\end{array}$ & $\begin{array}{l}0.1594 \\
(0.0247)\end{array}$ & $\begin{array}{l}0.2354 \\
(0.0360)\end{array}$ & $\begin{array}{l}0.3349 \\
(0.0508)\end{array}$ & $\begin{array}{l}0.4745 \\
(0.0713)\end{array}$ & 1.0000 \\
\hline Female & $\begin{array}{l}0.0541 \\
(0.0084)\end{array}$ & $\begin{array}{l}0.1505 \\
(0.0199)\end{array}$ & $\begin{array}{l}0.2687 \\
(0.0330)\end{array}$ & $\begin{array}{l}0.3730 \\
(0.0439)\end{array}$ & $\begin{array}{l}0.4809 \\
(0.0547)\end{array}$ & $\begin{array}{l}0.6060 \\
(0.0663)\end{array}$ & $\begin{array}{l}0.7083 \\
(0.0751)\end{array}$ & $\begin{array}{l}0.7925 \\
(0.0815)\end{array}$ & $\begin{array}{l}0.8955 \\
(0.0879)\end{array}$ & \\
\hline \multicolumn{11}{|c|}{ Panel B: Additive Decomposition by Subsample - Percentage Contribution } \\
\hline Male & 0.3819 & 0.4402 & 0.4974 & 0.5783 & 0.6338 & 0.6756 & 0.7246 & 0.7699 & 0.8075 & $88.7 \%$ \\
\hline Female & 0.6181 & 0.5598 & 0.5026 & 0.4217 & 0.3662 & 0.3244 & 0.2754 & 0.2301 & 0.1925 & $11.3 \%$ \\
\hline
\end{tabular}


Table 4-11: Lorenz ordinates and subsample decomposition by gender (2009)

Panel A of this table presents the decomposed order statistics and the Lorenz ordinates for the 2009 data by gender. The standard errors for the decomposed Lorenz ordinates are in parentheses. Panel B presents the additive decomposition in each decile by gender.

\begin{tabular}{|c|c|c|c|c|c|c|c|c|c|c|}
\hline & $\begin{array}{l}\text { Bottom } \\
\text { Decile }\end{array}$ & 2 & 3 & 4 & 5 & 6 & 7 & 8 & 9 & $\begin{array}{l}\text { Total } \\
\text { Sample }\end{array}$ \\
\hline \multicolumn{11}{|c|}{ Panel A: Lorenz Ordinates } \\
\hline Order Statistic & 13,947 & 22,116 & 29,886 & 38,851 & 49,810 & 61,760 & 79,696 & 102,011 & 147,039 & - \\
\hline Overall Sample & $\begin{array}{l}0.0111 \\
(0.0013)\end{array}$ & $\begin{array}{l}0.0335 \\
(0.0034)\end{array}$ & $\begin{array}{l}0.0641 \\
(0.0060)\end{array}$ & $\begin{array}{l}0.1076 \\
(0.0096)\end{array}$ & $\begin{array}{l}0.1608 \\
(0.0140)\end{array}$ & $\begin{array}{l}0.2299 \\
(0.0195)\end{array}$ & $\begin{array}{l}0.3158 \\
(0.0263)\end{array}$ & $\begin{array}{l}0.4285 \\
(0.0349)\end{array}$ & $\begin{array}{l}0.5778 \\
(0.0458)\end{array}$ & 1.0000 \\
\hline Male & $\begin{array}{l}0.0055 \\
(0.0009)\end{array}$ & $\begin{array}{l}0.0180 \\
(0.0023)\end{array}$ & $\begin{array}{l}0.0401 \\
(0.0046)\end{array}$ & $\begin{array}{l}0.0751 \\
(0.0080)\end{array}$ & $\begin{array}{l}0.1171 \\
(0.0120)\end{array}$ & $\begin{array}{l}0.1797 \\
(0.0178)\end{array}$ & $\begin{array}{l}0.2576 \\
(0.0249)\end{array}$ & $\begin{array}{l}0.3743 \\
(0.0352)\end{array}$ & $\begin{array}{l}0.5268 \\
(0.0482)\end{array}$ & 1.0000 \\
\hline Female & $\begin{array}{l}0.0481 \\
(0.0063)\end{array}$ & $\begin{array}{l}0.1358 \\
(0.0137)\end{array}$ & $\begin{array}{l}0.2231 \\
(0.0200)\end{array}$ & $\begin{array}{l}0.3224 \\
(0.0263)\end{array}$ & $\begin{array}{l}0.4499 \\
(0.0332)\end{array}$ & $\begin{array}{l}0.5618 \\
(0.0380)\end{array}$ & $\begin{array}{l}0.7002 \\
(0.0417)\end{array}$ & $\begin{array}{l}0.7866 \\
(0.0424)\end{array}$ & $\begin{array}{l}0.9150 \\
(0.0385)\end{array}$ & 1.0000 \\
\hline \multicolumn{11}{|c|}{ Panel B: Additive Decomposition by Subsample - Percentage Contribution } \\
\hline Male & 0.4313 & 0.4674 & 0.5429 & 0.6063 & 0.6325 & 0.6790 & 0.7087 & 0.7588 & 0.7919 & $86.7 \%$ \\
\hline Female & 0.5687 & 0.5326 & 0.4571 & 0.3937 & 0.3675 & 0.3210 & 0.2913 & 0.2412 & 0.2081 & $13.3 \%$ \\
\hline
\end{tabular}


Table 4-12:Concentration ordinates and subsample decomposition by gender (2009)

Panel A of this table presents the decomposed order statistics and the concentration ordinates for the 2009 data by gender. The standard errors for the decomposed concentration ordinates are in parentheses. Panel B presents the additive decomposition in each decile by gender.

\begin{tabular}{|c|c|c|c|c|c|c|c|c|c|c|}
\hline & $\begin{array}{l}\text { Bottom } \\
\text { Decile }\end{array}$ & 2 & 3 & 4 & 5 & 6 & 7 & 8 & 9 & $\begin{array}{l}\text { Total } \\
\text { Sample }\end{array}$ \\
\hline \multicolumn{11}{|c|}{ Panel A: Concentration Ordinates } \\
\hline Order Statistic & 13,632 & 22,577 & 31,736 & 39,191 & 49,841 & 63,899 & 77,956 & 102,238 & 149,097 & - \\
\hline Overall Sample & $\begin{array}{l}0.0225 \\
(0.0049)\end{array}$ & $\begin{array}{l}0.0518 \\
(0.0066)\end{array}$ & $\begin{array}{l}0.0935 \\
(0.0097)\end{array}$ & $\begin{array}{l}0.1411 \\
(0.0132)\end{array}$ & $\begin{array}{l}0.2004 \\
(0.0179)\end{array}$ & $\begin{array}{l}0.2724 \\
(0.0233)\end{array}$ & $\begin{array}{l}0.3596 \\
(0.0299)\end{array}$ & $\begin{array}{l}0.4674 \\
(0.0378)\end{array}$ & $\begin{array}{l}0.6221 \\
(0.0478)\end{array}$ & 1.0000 \\
\hline Male & $\begin{array}{l}0.0132 \\
(0.0051)\end{array}$ & $\begin{array}{l}0.0283 \\
(0.0060)\end{array}$ & $\begin{array}{l}0.0555 \\
(0.0080)\end{array}$ & $\begin{array}{l}0.0943 \\
(0.0112)\end{array}$ & $\begin{array}{l}0.1468 \\
(0.0159)\end{array}$ & $\begin{array}{l}0.2090 \\
(0.0212)\end{array}$ & $\begin{array}{l}0.2949 \\
(0.0287)\end{array}$ & $\begin{array}{l}0.4076 \\
(0.0383)\end{array}$ & $\begin{array}{l}0.5741 \\
(0.0512)\end{array}$ & 1.0000 \\
\hline Female & $\begin{array}{l}0.0842 \\
(0.0121) \\
\end{array}$ & $\begin{array}{l}0.2067 \\
(0.0210) \\
\end{array}$ & $\begin{array}{l}0.3446 \\
(0.0290) \\
\end{array}$ & $\begin{array}{l}0.4507 \\
(0.0336) \\
\end{array}$ & $\begin{array}{l}0.5549 \\
(0.0373) \\
\end{array}$ & $\begin{array}{l}0.6913 \\
(0.0398) \\
\end{array}$ & $\begin{array}{l}0.7879 \\
(0.0400) \\
\end{array}$ & $\begin{array}{l}0.8627 \\
(0.0386) \\
\end{array}$ & $\begin{array}{l}0.9400 \\
(0.0350)\end{array}$ & 1.0000 \\
\hline \multicolumn{11}{|c|}{ Panel B: Additive Decomposition by Subsample - Percentage Contribution } \\
\hline Male & 0.5089 & 0.4755 & 0.5156 & 0.5805 & 0.6363 & 0.6666 & 0.7122 & 0.7575 & 0.8015 & $86.7 \%$ \\
\hline Female & 0.4911 & 0.5245 & 0.4844 & 0.4195 & 0.3637 & 0.3334 & 0.2878 & 0.2425 & 0.1985 & $13.3 \%$ \\
\hline
\end{tabular}


Table 4-13: Lorenz ordinates and subsample decomposition by retirement status (2007)

Panel A of this table presents the decomposed order statistics and the Lorenz ordinates for the 2007 data by retirement status. The standard errors for the decomposed Lorenz ordinates are in parentheses. Panel B presents the additive decomposition in each decile by retirement status.

\begin{tabular}{|c|c|c|c|c|c|c|c|c|c|c|}
\hline & $\begin{array}{l}\text { Bottom } \\
\text { Decile }\end{array}$ & 2 & 3 & 4 & 5 & 6 & 7 & 8 & 9 & $\begin{array}{l}\text { Total } \\
\text { Sample }\end{array}$ \\
\hline \multicolumn{11}{|c|}{ Panel A: Lorenz Ordinates } \\
\hline Order Statistic & 13,632 & 22,577 & 31,736 & 39,191 & 49,841 & 63,899 & 77,956 & 102,238 & 149,097 & - \\
\hline Overall Sample & $\begin{array}{l}0.0098 \\
(0.0016)\end{array}$ & $\begin{array}{l}0.0301 \\
(0.0044)\end{array}$ & $\begin{array}{l}0.0600 \\
(0.0085)\end{array}$ & $\begin{array}{l}0.0992 \\
(0.0138)\end{array}$ & $\begin{array}{l}0.1473 \\
(0.0203)\end{array}$ & $\begin{array}{l}0.2095 \\
(0.0286)\end{array}$ & $\begin{array}{l}0.2884 \\
(0.0391)\end{array}$ & $\begin{array}{l}0.3862 \\
(0.0520)\end{array}$ & $\begin{array}{l}0.5218 \\
(0.0697)\end{array}$ & 1.0000 \\
\hline Retired & $\begin{array}{l}0.0183 \\
(0.0067)\end{array}$ & $\begin{array}{l}0.0621 \\
(0.0214)\end{array}$ & $\begin{array}{l}0.1160 \\
(0.0392)\end{array}$ & $\begin{array}{l}0.1740 \\
(0.0583)\end{array}$ & $\begin{array}{l}0.2334 \\
(0.0583)\end{array}$ & $\begin{array}{l}0.2945 \\
(0.0777)\end{array}$ & $\begin{array}{l}0.3677 \\
(0.0977)\end{array}$ & $\begin{array}{l}0.4348 \\
(0.1214)\end{array}$ & $\begin{array}{l}0.5218 \\
(0.1430)\end{array}$ & 1.0000 \\
\hline Non-Retired & $\begin{array}{l}0.0083 \\
(0.0015)\end{array}$ & $\begin{array}{l}0.0245 \\
(0.0040)\end{array}$ & $\begin{array}{l}0.0500 \\
(0.0079)\end{array}$ & $\begin{array}{l}0.0860 \\
(0.0132)\end{array}$ & $\begin{array}{l}0.1320 \\
(0.0200)\end{array}$ & $\begin{array}{l}0.1944 \\
(0.0292)\end{array}$ & $\begin{array}{l}0.2744 \\
(0.0408)\end{array}$ & $\begin{array}{l}0.3776 \\
(0.0557)\end{array}$ & $\begin{array}{l}0.5217 \\
(0.0762)\end{array}$ & 1.0000 \\
\hline (ด) & DC & $n$ by Subs & - Percen & Contribut & & & & & & \\
\hline Retired & 0.2807 & 0.3097 & 0.2910 & 0.2638 & 0.2384 & 0.2115 & 0.1918 & 0.1694 & 0.1504 & $15.0 . \%$ \\
\hline Non-Retired & 0.7193 & 0.6903 & 0.7090 & 0.7362 & 0.7616 & 0.7885 & 0.8082 & 0.8306 & 0.8496 & $85.0 \%$ \\
\hline
\end{tabular}


Table 4-14: Lorenz ordinates and subsample decomposition by retirement status (2009)

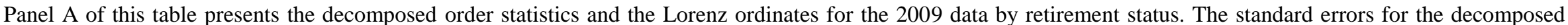
Lorenz ordinates are in parentheses. Panel B presents the additive decomposition in each decile by retirement status.

\begin{tabular}{|c|c|c|c|c|c|c|c|c|c|c|}
\hline & $\begin{array}{l}\text { Bottom } \\
\text { Decile }\end{array}$ & 2 & 3 & 4 & 5 & 6 & 7 & 8 & 9 & $\begin{array}{l}\text { Total } \\
\text { Sample }\end{array}$ \\
\hline \multicolumn{11}{|c|}{ Panel A: Lorenz Ordinates } \\
\hline Order Statistic & 13,947 & 22,116 & 29,886 & 38,851 & 49,810 & 61,760 & 79,696 & 102,011 & 147,039 & - \\
\hline Overall Sample & $\begin{array}{l}0.0111 \\
(0.0013)\end{array}$ & $\begin{array}{l}0.0335 \\
(0.0034)\end{array}$ & $\begin{array}{l}0.0641 \\
(0.0060)\end{array}$ & $\begin{array}{l}0.1076 \\
(0.0096)\end{array}$ & $\begin{array}{l}0.1608 \\
(0.0140)\end{array}$ & $\begin{array}{l}0.2299 \\
(0.0195)\end{array}$ & $\begin{array}{l}0.3158 \\
(0.0263)\end{array}$ & $\begin{array}{l}0.4285 \\
(0.0349)\end{array}$ & $\begin{array}{l}0.5778 \\
(0.0458)\end{array}$ & 1.0000 \\
\hline Retired & $\begin{array}{l}0.0240 \\
(0.0068)\end{array}$ & $\begin{array}{l}0.0703 \\
(0.0182)\end{array}$ & $\begin{array}{l}0.1278 \\
(0.0322)\end{array}$ & $\begin{array}{l}0.2120 \\
(0.0522)\end{array}$ & $\begin{array}{l}0.2723 \\
(0.0664)\end{array}$ & $\begin{array}{l}0.3523 \\
(0.0851)\end{array}$ & $\begin{array}{l}0.4381 \\
(0.1049)\end{array}$ & $\begin{array}{l}0.5255 \\
(0.1248)\end{array}$ & $\begin{array}{l}0.5971 \\
(0.1407)\end{array}$ & 1.0000 \\
\hline Non-Retired & $\begin{array}{l}0.0090 \\
(0.0012) \\
\end{array}$ & $\begin{array}{l}0.0273 \\
(0.0030) \\
\end{array}$ & $\begin{array}{l}0.0535 \\
(0.0055) \\
\end{array}$ & $\begin{array}{l}0.0901 \\
(0.0088) \\
\end{array}$ & $\begin{array}{l}0.1422 \\
(0.0133) \\
\end{array}$ & $\begin{array}{l}0.2094 \\
(0.0191) \\
\end{array}$ & $\begin{array}{l}0.2953 \\
(0.0262) \\
\end{array}$ & $\begin{array}{l}0.4123 \\
(0.0356) \\
\end{array}$ & $\begin{array}{l}0.5745 \\
(0.0482) \\
\end{array}$ & 1.0000 \\
\hline \multicolumn{11}{|c|}{ Panel B: Additive Decomposition by Subsample - Percentage Contribution } \\
\hline Retired & 0.3096 & 0.3006 & 0.2853 & 0.2821 & 0.2424 & 0.2194 & 0.1986 & 0.1756 & 0.1479 & $14.3 \%$ \\
\hline Non-Retired & 0.6904 & 0.6994 & 0.7147 & 0.7179 & 0.7576 & 0.7806 & 0.8014 & 0.8244 & 0.8521 & $85.7 \%$ \\
\hline
\end{tabular}


Table 4-15: Concentration ordinates and subsample decomposition by retirement status (2009)

Panel A of this table presents the decomposed order statistics and the concentration ordinates for the 2009 data by retirement status. The standard errors for the decomposed concentration ordinates are in parentheses. Panel B presents the additive decomposition in each decile by retirement status.

\begin{tabular}{|c|c|c|c|c|c|c|c|c|c|c|}
\hline & $\begin{array}{l}\text { Bottom } \\
\text { Decile }\end{array}$ & 2 & 3 & 4 & 5 & 6 & 7 & 8 & 9 & $\begin{array}{l}\text { Total } \\
\text { Sample }\end{array}$ \\
\hline \multicolumn{11}{|c|}{ Panel A: Concentration Ordinates } \\
\hline Order Statistic & 13,632 & 22,577 & 31,736 & 39,191 & 49,841 & 63,899 & 77,956 & 102,238 & 149,097 & - \\
\hline Overall Sample & $\begin{array}{l}0.0225 \\
(0.0049)\end{array}$ & $\begin{array}{l}0.0518 \\
(0.0066)\end{array}$ & $\begin{array}{l}0.0935 \\
(0.0097) \\
\end{array}$ & $\begin{array}{l}0.1411 \\
(0.0132)\end{array}$ & $\begin{array}{l}0.2004 \\
(0.0179) \\
\end{array}$ & $\begin{array}{l}0.2724 \\
(0.0233) \\
\end{array}$ & $\begin{array}{l}0.3596 \\
(0.0299) \\
\end{array}$ & $\begin{array}{l}0.4674 \\
(0.0378) \\
\end{array}$ & $\begin{array}{l}0.6221 \\
(0.0478)\end{array}$ & 1.0000 \\
\hline Retired & $\begin{array}{l}0.0365 \\
(0.0270)\end{array}$ & $\begin{array}{l}0.0935 \\
(0.0336)\end{array}$ & $\begin{array}{l}0.1588 \\
(0.0452)\end{array}$ & $\begin{array}{l}0.2310 \\
(0.0602)\end{array}$ & $\begin{array}{l}0.3076 \\
(0.0772)\end{array}$ & $\begin{array}{l}0.3764 \\
(0.0921)\end{array}$ & $\begin{array}{l}0.4542 \\
(0.1090)\end{array}$ & $\begin{array}{l}0.5168 \\
(0.1227)\end{array}$ & $\begin{array}{l}0.6582 \\
(0.1305)\end{array}$ & 1.0000 \\
\hline Non-Retired & $\begin{array}{l}0.0202 \\
(0.0035) \\
\end{array}$ & $\begin{array}{l}0.0448 \\
(0.0056) \\
\end{array}$ & $\begin{array}{l}0.0825 \\
(0.0090) \\
\end{array}$ & $\begin{array}{l}0.1261 \\
(0.0126)\end{array}$ & $\begin{array}{l}0.1825 \\
(0.0173) \\
\end{array}$ & $\begin{array}{l}0.2550 \\
(0.0232) \\
\end{array}$ & $\begin{array}{l}0.3438 \\
(0.0304) \\
\end{array}$ & $\begin{array}{l}0.4591 \\
(0.0394) \\
\end{array}$ & $\begin{array}{l}0.6161 \\
(0.0511) \\
\end{array}$ & 1.0000 \\
\hline 4⿴囗十 & A & $\begin{array}{ll}0 y \\
0\end{array}$ & $-1 \mathrm{ch}$ & . & & & & & & \\
\hline Retired & 0.2319 & 0.2586 & 0.2432 & 0.2342 & 0.2197 & 0.1978 & 0.1808 & 0.1583 & 0.1514 & $14.3 \%$ \\
\hline Non-Retired & 0.7681 & 0.7414 & 0.7568 & 0.7658 & 0.7803 & 0.8022 & 0.8192 & 0.8417 & 0.8486 & $85.7 \%$ \\
\hline
\end{tabular}


Table 4-16: Lorenz ordinates decomposition for the overall sample (2006 vs. 2012)

This table presents the order statistics (upper cutoff values) and the Lorenz ordinates for the 2006 and 2012 PSID data. The standard errors for the Lorenz ordinates are in parentheses.

\begin{tabular}{|c|c|c|c|c|c|c|c|c|c|c|}
\hline & $\begin{array}{l}\text { Bottom } \\
\text { Decile }\end{array}$ & 2 & 3 & 4 & 5 & 6 & 7 & 8 & 9 & $\begin{array}{l}\text { Total } \\
\text { Sample }\end{array}$ \\
\hline \multicolumn{11}{|c|}{ Panel A: Lorenz Ordinates 2006} \\
\hline Order Statistic & 14553 & 24387 & 34234 & 45801 & 57576 & 72294 & 89427 & 114259 & 159054 & \\
\hline Overall Sample & 0.0099 & 0.0340 & 0.0705 & 0.1205 & 0.1851 & 0.2656 & 0.3655 & 0.4906 & 0.6577 & 1.0000 \\
\hline \multicolumn{11}{|c|}{ Panel B : Lorenz Ordinates 2012} \\
\hline $\begin{array}{l}\text { Order Statistic } \\
\text { Overall Sample }\end{array}$ & $\begin{array}{l}13633 \\
0.0097\end{array}$ & $\begin{array}{l}23129 \\
0.0329\end{array}$ & $\begin{array}{l}32849 \\
0.0689\end{array}$ & $\begin{array}{l}43423 \\
0.1179\end{array}$ & $\begin{array}{l}56958 \\
0.1820\end{array}$ & $\begin{array}{l}70403 \\
0.2627\end{array}$ & $\begin{array}{l}87696 \\
0.3631\end{array}$ & $\begin{array}{l}111595 \\
0.4896\end{array}$ & $\begin{array}{l}154945 \\
0.6559\end{array}$ & 1.0000 \\
\hline
\end{tabular}


Table 4-17: Lorenz ordinates and subsample decomposition by race (2006)

Panel A of this table presents the decomposed order statistics and the Lorenz ordinates for the 2006 PSID data by race. The standard errors for the decomposed Lorenz ordinates are in parentheses. Panel B presents the additive decomposition in each decile by race.

\begin{tabular}{|c|c|c|c|c|c|c|c|c|c|c|}
\hline & Bottom Decile & 2 & 3 & 4 & 5 & 6 & 7 & 8 & 9 & $\begin{array}{l}\text { Total } \\
\text { Sample }\end{array}$ \\
\hline \multicolumn{11}{|c|}{ Panel A: Lorenz Ordinates } \\
\hline Order Statistic & 14553 & 24387 & 34234 & 45801 & 57576 & 72294 & 89427 & 114259 & 159054 & - \\
\hline Overall Sample & $\begin{array}{l}0.0099 \\
(0.0012)\end{array}$ & $\begin{array}{l}0.0340 \\
(0.0029)\end{array}$ & $\begin{array}{l}0.0705 \\
(0.0051)\end{array}$ & $\begin{array}{l}0.1205 \\
(0.0078)\end{array}$ & $\begin{array}{l}0.1851 \\
(0.0110)\end{array}$ & $\begin{array}{l}0.2656 \\
(0.0146)\end{array}$ & $\begin{array}{l}0.3655 \\
(0.0186)\end{array}$ & $\begin{array}{l}0.4906 \\
(0.0228)\end{array}$ & $\begin{array}{l}0.6577 \\
(0.0270)\end{array}$ & 1.0000 \\
\hline White & $\begin{array}{l}0.0072 \\
(0.0011)\end{array}$ & $\begin{array}{l}0.0283 \\
(0.0028)\end{array}$ & $\begin{array}{l}0.0597 \\
(0.0050)\end{array}$ & $\begin{array}{l}0.1030 \\
(0.0077)\end{array}$ & $\begin{array}{l}0.1651 \\
(0.0112)\end{array}$ & $\begin{array}{l}0.2402 \\
(0.0150)\end{array}$ & $\begin{array}{l}0.3373 \\
(0.0194)\end{array}$ & $\begin{array}{l}0.4651 \\
(0.0244)\end{array}$ & $\begin{array}{l}0.6369 \\
(0.0294)\end{array}$ & 1.0000 \\
\hline Non-White & $\begin{array}{l}0.0268 \\
(0.0053) \\
\end{array}$ & $\begin{array}{l}0.0695 \\
(0.0112) \\
\end{array}$ & $\begin{array}{l}0.1378 \\
(0.0192) \\
\end{array}$ & $\begin{array}{l}0.2298 \\
(0.0286) \\
\end{array}$ & $\begin{array}{l}0.3098 \\
(0.0359) \\
\end{array}$ & $\begin{array}{l}0.4246 \\
(0.0449) \\
\end{array}$ & $\begin{array}{l}0.5416 \\
(0.0523) \\
\end{array}$ & $\begin{array}{l}0.6498 \\
(0.0573) \\
\end{array}$ & $\begin{array}{l}0.7874 \\
(0.0594) \\
\end{array}$ & 1.0000 \\
\hline \multicolumn{11}{|c|}{ Panel B: Additive Decomposition by Subsample - Percentage Contribution } \\
\hline \multirow{2}{*}{$\begin{array}{ll}\text { White } & 6 \\
\text { Non-White } & 3 \\
\end{array}$} & $62.7 \%$ & $71.8 \%$ & $73.1 \%$ & $73.7 \%$ & $76.9 \%$ & $78.0 \%$ & $79.6 \%$ & $81.7 \%$ & $83.5 \%$ & $86.2 \%$ \\
\hline & $37.3 \%$ & $28.2 \%$ & $26.9 \%$ & $26.3 \%$ & $23.1 \%$ & $22.0 \%$ & $20.4 \%$ & $18.3 \%$ & $16.5 \%$ & $13.8 \%$ \\
\hline
\end{tabular}


Table 4-18: Lorenz ordinates and subsample decomposition by race (2012)

Panel A of this table presents the decomposed order statistics and the Lorenz ordinates for the 2012 PSID data by race. The standard errors for the decomposed Lorenz ordinates are in parentheses. Panel B presents the additive decomposition in each decile by race.

\begin{tabular}{|c|c|c|c|c|c|c|c|c|c|c|}
\hline & $\begin{array}{l}\text { Bottom } \\
\text { Decile }\end{array}$ & 2 & 3 & 4 & 5 & 6 & 7 & 8 & 9 & $\begin{array}{l}\text { Total } \\
\text { Sample }\end{array}$ \\
\hline \multicolumn{11}{|c|}{ Panel A: Lorenz Ordinates } \\
\hline Order Statistic & 13633 & 23129 & 32849 & 43423 & 56958 & 70403 & 87696 & 111595 & 154945 & - \\
\hline Overall Sample & $\begin{array}{l}0.0097 \\
(0.0012)\end{array}$ & $\begin{array}{l}0.0329 \\
(0.0030)\end{array}$ & $\begin{array}{l}0.0689 \\
(0.0054)\end{array}$ & $\begin{array}{l}0.1179 \\
(0.0083)\end{array}$ & $\begin{array}{l}0.1820 \\
(0.0119)\end{array}$ & $\begin{array}{l}0.2627 \\
(0.0161)\end{array}$ & $\begin{array}{l}0.3631 \\
(0.0209)\end{array}$ & $\begin{array}{l}0.4896 \\
(0.0263)\end{array}$ & $\begin{array}{l}0.6559 \\
(0.0322)\end{array}$ & 1.0000 \\
\hline White & $\begin{array}{l}0.0072 \\
(0.0012)\end{array}$ & $\begin{array}{l}0.0258 \\
(0.0028)\end{array}$ & $\begin{array}{l}0.0561 \\
(0.0051)\end{array}$ & $\begin{array}{l}0.1000 \\
(0.0082)\end{array}$ & $\begin{array}{l}0.1609 \\
(0.0082)\end{array}$ & $\begin{array}{l}0.2368 \\
(0.0082)\end{array}$ & $\begin{array}{l}0.3365 \\
(0.0121)\end{array}$ & $\begin{array}{l}0.4649 \\
(0.0166)\end{array}$ & $\begin{array}{l}0.6307 \\
(0.0220)\end{array}$ & 1.0000 \\
\hline Non-White & $\begin{array}{l}0.0263 \\
(0.0051)\end{array}$ & $\begin{array}{l}0.0792 \\
(0.0121) \\
\end{array}$ & $\begin{array}{l}0.1532 \\
(0.0121) \\
\end{array}$ & $\begin{array}{l}0.2361 \\
(0.0203) \\
\end{array}$ & $\begin{array}{l}0.3205 \\
(0.0284) \\
\end{array}$ & $\begin{array}{l}0.4332 \\
(0.0358) \\
\end{array}$ & $\begin{array}{l}0.5381 \\
(0.0440) \\
\end{array}$ & $\begin{array}{l}0.6519 \\
(0.0500)\end{array}$ & $\begin{array}{l}0.8219 \\
(0.0543) \\
\end{array}$ & 1.0000 \\
\hline \multicolumn{11}{|c|}{ Panel B: Additive Decomposition by Subsample - Percentage Contribution } \\
\hline Group 1 & $64.3 \%$ & $68.2 \%$ & $70.7 \%$ & $73.6 \%$ & $76.8 \%$ & $78.2 \%$ & $80.4 \%$ & $82.4 \%$ & $83.5 \%$ & $86.8 \%$ \\
\hline Group 2 & $35.7 \%$ & $31.8 \%$ & $29.3 \%$ & $26.4 \%$ & $23.2 \%$ & $21.8 \%$ & $19.6 \%$ & $17.6 \%$ & $16.5 \%$ & $13.2 \%$ \\
\hline
\end{tabular}


Table 4-19: Concentration ordinates and subsample decomposition by race (2012)

Panel A of this table presents the decomposed order statistics and the concentration ordinates for the 2012 PSID data by race. The standard errors for the decomposed concentration ordinates are in parentheses. Panel B presents the additive decomposition in each decile by race.

\begin{tabular}{|c|c|c|c|c|c|c|c|c|c|c|}
\hline & $\begin{array}{l}\text { Bottom } \\
\text { Decile }\end{array}$ & 2 & 3 & 4 & 5 & 6 & 7 & 8 & 9 & $\begin{array}{l}\text { Total } \\
\text { Sample }\end{array}$ \\
\hline \multicolumn{11}{|c|}{ Panel A: Concentration Ordinates } \\
\hline Order Statistic & 14553 & 24387 & 34234 & 45801 & 57576 & 72294 & 89427 & 114259 & 159054 & - \\
\hline Overall Sample & $\begin{array}{l}0.0309 \\
(0.0056)\end{array}$ & $\begin{array}{l}0.0685 \\
(0.0080)\end{array}$ & $\begin{array}{l}0.1122 \\
(0.0099)\end{array}$ & $\begin{array}{l}0.1679 \\
(0.0126)\end{array}$ & $\begin{array}{l}0.2386 \\
(0.0126)\end{array}$ & $\begin{array}{l}0.3231 \\
(0.0160)\end{array}$ & $\begin{array}{l}0.4271 \\
(0.0197)\end{array}$ & $\begin{array}{l}0.5517 \\
(0.0240)\end{array}$ & $\begin{array}{l}0.7084 \\
(0.0285)\end{array}$ & 1.0000 \\
\hline White & $\begin{array}{l}0.0259 \\
(0.0060)\end{array}$ & $\begin{array}{l}0.0610 \\
(0.0085)\end{array}$ & $\begin{array}{l}0.0996 \\
(0.0104)\end{array}$ & $\begin{array}{l}0.1484 \\
(0.0130)\end{array}$ & $\begin{array}{l}0.2176 \\
(0.0168)\end{array}$ & $\begin{array}{l}0.2965 \\
(0.0207)\end{array}$ & $\begin{array}{l}0.3988 \\
(0.0256)\end{array}$ & $\begin{array}{l}0.5250 \\
(0.0309)\end{array}$ & $\begin{array}{l}0.6868 \\
(0.0365)\end{array}$ & 1.0000 \\
\hline Non-White & $\begin{array}{l}0.0640 \\
(0.0143))\end{array}$ & $\begin{array}{l}0.1178 \\
(0.0217) \\
\end{array}$ & $\begin{array}{l}0.1951 \\
(0.0284) \\
\end{array}$ & $\begin{array}{l}0.2963 \\
(0.0361) \\
\end{array}$ & $\begin{array}{l}0.3765 \\
(0.0414) \\
\end{array}$ & $\begin{array}{l}0.4977 \\
(0.0479) \\
\end{array}$ & $\begin{array}{l}0.6131 \\
(0.0520) \\
\end{array}$ & $\begin{array}{l}0.7276 \\
(0.0531) \\
\end{array}$ & $\begin{array}{l}0.8502 \\
(0.0502) \\
\end{array}$ & 1.0000 \\
\hline \multicolumn{11}{|c|}{ Panel B: Additive Decomposition by Subsample - Percentage Contribution } \\
\hline White & $72.7 \%$ & $77.3 \%$ & $77.1 \%$ & $76.7 \%$ & $79.2 \%$ & $79.7 \%$ & $81.1 \%$ & $82.6 \%$ & $84.2 \%$ & $86.8 \%$ \\
\hline Non-White & $27.3 \%$ & $22.7 \%$ & $22.9 \%$ & $23.3 \%$ & $20.8 \%$ & $20.3 \%$ & $18.9 \%$ & $17.4 \%$ & $15.8 \%$ & $13.2 \%$ \\
\hline
\end{tabular}


Table 4-20: Lorenz ordinates and subsample decomposition by race (1986)

Panel A of this table presents the decomposed order statistics and the Lorenz ordinates for the 1986 PSID data by race. The standard errors for the decomposed Lorenz ordinates are in parentheses. Panel B presents the additive decomposition in each decile by race.

\begin{tabular}{|c|c|c|c|c|c|c|c|c|c|c|}
\hline & $\begin{array}{l}\text { Bottom } \\
\text { Decile }\end{array}$ & 2 & 3 & 4 & 5 & 6 & 7 & 8 & 9 & $\begin{array}{l}\text { Total } \\
\text { Sample }\end{array}$ \\
\hline \multicolumn{11}{|c|}{ Panel A: Lorenz Ordinates } \\
\hline Order Statistic & 12975 & 23489 & 32580 & 43215 & 52616 & 64992 & 78647 & 96000 & 126048 & - \\
\hline Overall Sample & $\begin{array}{l}0.0035 \\
(0.0006)\end{array}$ & $\begin{array}{l}0.0248 \\
(0.0025)\end{array}$ & $\begin{array}{l}0.0641 \\
(0.0051)\end{array}$ & $\begin{array}{l}0.1195 \\
(0.0082)\end{array}$ & $\begin{array}{l}0.1928 \\
(0.0118)\end{array}$ & $\begin{array}{l}0.2827 \\
(0.0155)\end{array}$ & $\begin{array}{l}0.3940 \\
(0.0194)\end{array}$ & $\begin{array}{l}0.5275 \\
(0.0230)\end{array}$ & $\begin{array}{l}0.7005 \\
(0.0259)\end{array}$ & 1.0000 \\
\hline White & $\begin{array}{l}0.0017 \\
(0.0005)\end{array}$ & $\begin{array}{l}0.0170 \\
(0.0021)\end{array}$ & $\begin{array}{l}0.0478 \\
(0.0046)\end{array}$ & $\begin{array}{l}0.0953 \\
(0.0077)\end{array}$ & $\begin{array}{l}0.1652 \\
(0.0116)\end{array}$ & $\begin{array}{l}0.2529 \\
(0.0157)\end{array}$ & $\begin{array}{l}0.3628 \\
(0.0201)\end{array}$ & $\begin{array}{l}0.4990 \\
(0.0244)\end{array}$ & $\begin{array}{l}0.6783 \\
(0.0280)\end{array}$ & 1.0000 \\
\hline Non-White & $\begin{array}{l}0.0175 \\
(0.0043) \\
\end{array}$ & $\begin{array}{l}0.0871 \\
(0.0141) \\
\end{array}$ & $\begin{array}{l}0.1939 \\
(0.0261) \\
\end{array}$ & $\begin{array}{l}0.3126 \\
(0.0367) \\
\end{array}$ & $\begin{array}{l}0.4121 \\
(0.0440)\end{array}$ & $\begin{array}{l}0.5196 \\
(0.0499) \\
\end{array}$ & $\begin{array}{l}0.6424 \\
(0.0537) \\
\end{array}$ & $\begin{array}{l}0.7540 \\
(0.0534) \\
\end{array}$ & $\begin{array}{l}0.8772 \\
(0.0464) \\
\end{array}$ & 1.0000 \\
\hline \multicolumn{11}{|c|}{ Panel B: Additive Decomposition by Subsample - Percentage Contribution } \\
\hline White & $44.0 \%$ & $60.8 \%$ & $66.2 \%$ & $70.8 \%$ & $76.1 \%$ & $79.5 \%$ & $81.8 \%$ & $84.0 \%$ & $86.0 \%$ & $88.3 \%$ \\
\hline Non-White & $56.0 \%$ & $39.2 \%$ & $33.8 \%$ & $29.2 \%$ & $23.9 \%$ & $20.5 \%$ & $18.2 \%$ & $16.0 \%$ & $14.0 \%$ & $11.2 \%$ \\
\hline
\end{tabular}


Table 4-21: Lorenz ordinates and subsample decomposition by race (1988)

Panel A of this table presents the decomposed order statistics and the Lorenz ordinates for the 1988 PSID data by race. The standard errors for the decomposed Lorenz ordinates are in parentheses. Panel B presents the additive decomposition in each decile by race.

\begin{tabular}{|c|c|c|c|c|c|c|c|c|c|c|}
\hline & $\begin{array}{l}\text { Bottom } \\
\text { Decile }\end{array}$ & 2 & 3 & 4 & 5 & 6 & 7 & 8 & 9 & $\begin{array}{l}\text { Total } \\
\text { Sample }\end{array}$ \\
\hline \multicolumn{11}{|c|}{ Panel A: Lorenz Ordinates } \\
\hline Order Statistic & 12573 & 21876 & 32347 & 42016 & 51966 & 64343 & 78358 & 96690 & 132546 & 1.0000 \\
\hline Overall Sample & $\begin{array}{l}0.0116 \\
(0.0014)\end{array}$ & $\begin{array}{l}0.0382 \\
(0.0034)\end{array}$ & $\begin{array}{l}0.0806 \\
(0.0061)\end{array}$ & $\begin{array}{l}0.1376 \\
(0.0094)\end{array}$ & $\begin{array}{l}0.2097 \\
(0.0130)\end{array}$ & $\begin{array}{l}0.2987 \\
(0.0170)\end{array}$ & $\begin{array}{l}0.4055 \\
(0.0212)\end{array}$ & $\begin{array}{l}0.5308 \\
(0.0253)\end{array}$ & $\begin{array}{l}0.6961 \\
(0.0295)\end{array}$ & \\
\hline White & $\begin{array}{l}0.0071 \\
(0.0012)\end{array}$ & $\begin{array}{l}0.0264 \\
(0.0030)\end{array}$ & $\begin{array}{l}0.0583 \\
(0.0055)\end{array}$ & $\begin{array}{l}0.1085 \\
(0.0089)\end{array}$ & $\begin{array}{l}0.1736 \\
(0.0128)\end{array}$ & $\begin{array}{l}0.2561 \\
(0.0172)\end{array}$ & $\begin{array}{l}0.3631 \\
(0.0221)\end{array}$ & $\begin{array}{l}0.4906 \\
(0.0272)\end{array}$ & $\begin{array}{l}0.6624 \\
(0.0326)\end{array}$ & 1.0000 \\
\hline Non-White & $\begin{array}{l}0.0385 \\
(0.0065) \\
\end{array}$ & $\begin{array}{l}0.1092 \\
(0.0147) \\
\end{array}$ & $\begin{array}{l}0.2144 \\
(0.0244)\end{array}$ & $\begin{array}{l}0.3127 \\
(0.0318) \\
\end{array}$ & $\begin{array}{l}0.4262 \\
(0.0386) \\
\end{array}$ & $\begin{array}{l}0.5545 \\
(0.0439) \\
\end{array}$ & $\begin{array}{l}0.6604 \\
(0.0460)\end{array}$ & $\begin{array}{l}0.7727 \\
(0.0451) \\
\end{array}$ & $\begin{array}{l}0.8985 \\
(0.0373) \\
\end{array}$ & 1.0000 \\
\hline \multicolumn{11}{|c|}{ Panel B: Additive Decomposition by Subsample - Percentage Contribution } \\
\hline White & $52.7 \%$ & $59.2 \%$ & $62.0 \%$ & $67.6 \%$ & $71.0 \%$ & $73.5 \%$ & $76.8 \%$ & $79.2 \%$ & $81.6 \%$ & $85.7 \%$ \\
\hline Non-white & $47.3 \%$ & $40.8 \%$ & $38.0 \%$ & $32.4 \%$ & $29.0 \%$ & $26.5 \%$ & $23.2 \%$ & $20.8 \%$ & $18.4 \%$ & $14.3 \%$ \\
\hline
\end{tabular}


Table 4-22: Concentration ordinates and subsample decomposition by race (1988)

Panel A of this table presents the decomposed order statistics and the concentration ordinates for the 1988 PSID data by race. The standard errors for the decomposed concentration ordinates are in parentheses. Panel B presents the additive decomposition in each decile by race.

\begin{tabular}{|c|c|c|c|c|c|c|c|c|c|c|}
\hline & $\begin{array}{l}\text { Bottom } \\
\text { Decile }\end{array}$ & 2 & 3 & 4 & 5 & 6 & 7 & 8 & 9 & $\begin{array}{l}\text { Total } \\
\text { Sample }\end{array}$ \\
\hline \multicolumn{11}{|c|}{ Panel A: Concentration Ordinates } \\
\hline Order Statistic & 12573 & 21876 & 32347 & 42016 & 51966 & 64343 & 78358 & 96690 & 132546 & 1.0000 \\
\hline Overall Sample & $\begin{array}{l}0.0448 \\
(0.0062)\end{array}$ & $\begin{array}{l}0.0707 \\
(0.0072)\end{array}$ & $\begin{array}{l}0.1169 \\
(0.0095)\end{array}$ & $\begin{array}{l}0.1765 \\
(0.0123)\end{array}$ & $\begin{array}{l}0.2492 \\
(0.0154)\end{array}$ & $\begin{array}{l}0.3374 \\
(0.0189)\end{array}$ & $\begin{array}{l}0.4439 \\
(0.0227)\end{array}$ & $\begin{array}{l}0.5629 \\
(0.0262)\end{array}$ & $\begin{array}{l}0.7248 \\
(0.0295)\end{array}$ & 1.0000 \\
\hline White & $\begin{array}{l}0.0047 \\
(0.0015)\end{array}$ & $\begin{array}{l}0.0253 \\
(0.0037)\end{array}$ & $\begin{array}{l}0.0656 \\
(0.0072)\end{array}$ & $\begin{array}{l}0.1191 \\
(0.0106)\end{array}$ & $\begin{array}{l}0.1918 \\
(0.0146)\end{array}$ & $\begin{array}{l}0.2809 \\
(0.0189)\end{array}$ & $\begin{array}{l}0.3913 \\
(0.0236)\end{array}$ & $\begin{array}{l}0.5179 \\
(0.0282)\end{array}$ & $\begin{array}{l}0.6925 \\
(0.0329)\end{array}$ & 1.0000 \\
\hline Non-White & $\begin{array}{l}0.2863 \\
(0.0364) \\
\end{array}$ & $\begin{array}{l}0.3433 \\
(0.0377) \\
\end{array}$ & $\begin{array}{l}0.4249 \\
(0.0399) \\
\end{array}$ & $\begin{array}{l}0.5217 \\
(0.0425) \\
\end{array}$ & $\begin{array}{l}0.5943 \\
(0.0439)\end{array}$ & $\begin{array}{l}0.6770 \\
(0.0441) \\
\end{array}$ & $\begin{array}{l}0.7598 \\
(0.0432) \\
\end{array}$ & $\begin{array}{l}0.8336 \\
(0.0405) \\
\end{array}$ & $\begin{array}{l}0.9189 \\
(0.0328) \\
\end{array}$ & 1.0000 \\
\hline \multicolumn{11}{|c|}{ Panel B: Additive Decomposition by Subsample - Percentage Contribution } \\
\hline White & $8.9 \%$ & $30.7 \%$ & $48.1 \%$ & $57.8 \%$ & $66.0 \%$ & $71.4 \%$ & $75.6 \%$ & $78.9 \%$ & $81.9 \%$ & $85.7 \%$ \\
\hline Non-White & $91.1 \%$ & $69.3 \%$ & $51.9 \%$ & $42.2 \%$ & $34.0 \%$ & $28.6 \%$ & $24.4 \%$ & $21.1 \%$ & $18.1 \%$ & $14.3 \%$ \\
\hline
\end{tabular}


Table 4-23: Chi-Squared test results by race (2007 vs. 2009)

This table provides the chi-squared test results for the differences in the decomposition ordinates by race.

\begin{tabular}{ll}
\hline Comparison of Lorenz Ordinates across Subgroups in 2007 & Test Statistics: \\
\hline White vs. Non-White & 32,602 \\
\hline Comparison of Lorenz Ordinates across Subgroups in 2009 & Test Statistics: \\
\hline White vs. Non-White & 50,321 \\
\hline & \\
\hline Comparison of Concentration Ordinates within Subgroups (2007 vs.) 2009 & Test Statistics: \\
\hline White & 22,360 \\
Non-White & 38,641 \\
\hline
\end{tabular}

Table 4-24: Chi-Squared test results by gender (2007 vs. 2009)

This table provides the chi-squared test results for the differences in the decomposition ordinates by gender.

\begin{tabular}{|c|c|}
\hline Comparison of Lorenz Ordinates across Subgroups in 2007 & Test Statistics: \\
\hline Male vs. Female & 92,704 \\
\hline $\begin{array}{l}\text { Comparison of Lorenz Ordinates across Subgroups in } 2009 \\
\text { Male vs. Female }\end{array}$ & $\begin{array}{l}\text { Test Statistics: } \\
17,414\end{array}$ \\
\hline Comparison of Concentration Ordinates within Subgroups (2007 vs.) 2009 & Test Statistics: \\
\hline Male & 24,579 \\
\hline
\end{tabular}


Table 4-25: Chi-Squared test results by retirement status (2007 vs. 2009)

This table provides the chi-squared test results for the differences in the decomposition ordinates by retirement status. Comparison of Lorenz Ordinates across Subgroups in $2007 \quad$ Test Statistics: Retired vs. Non-Retired

33,536

\begin{tabular}{ll}
\hline Comparison of Lorenz Ordinates across Subgroups in 2009 & Test Statistics: \\
Retired vs. Non-Retired & 52,042 \\
\hline & \\
\hline Comparison of Concentration Ordinates within Subgroups (2007 vs.) 2009 & Test Statistics: \\
\hline Retired & 14,831 \\
Non-Retired & 48,256 \\
\hline
\end{tabular}


Figure 4-1 : Decomposed Lorenz ordinates by race (2007)

This figure displays the overall and the decomposed Lorenz ordinates for the 2007 data by race.

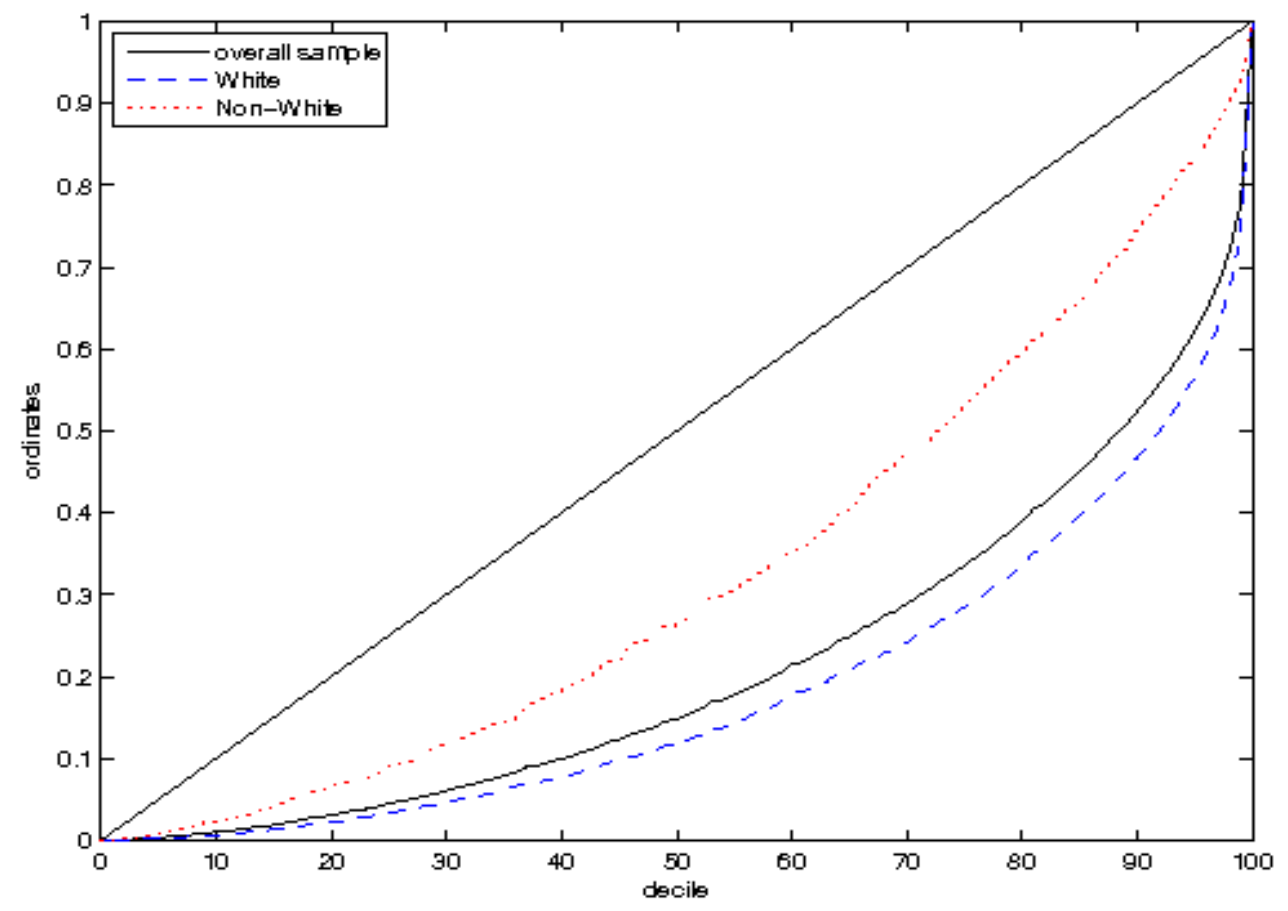


Figure 4-2: Decomposition histogram (by race)

This figure displays the contribution to each income decile by the white group and the non-white group for the 2007 and 2009 data, respectively.
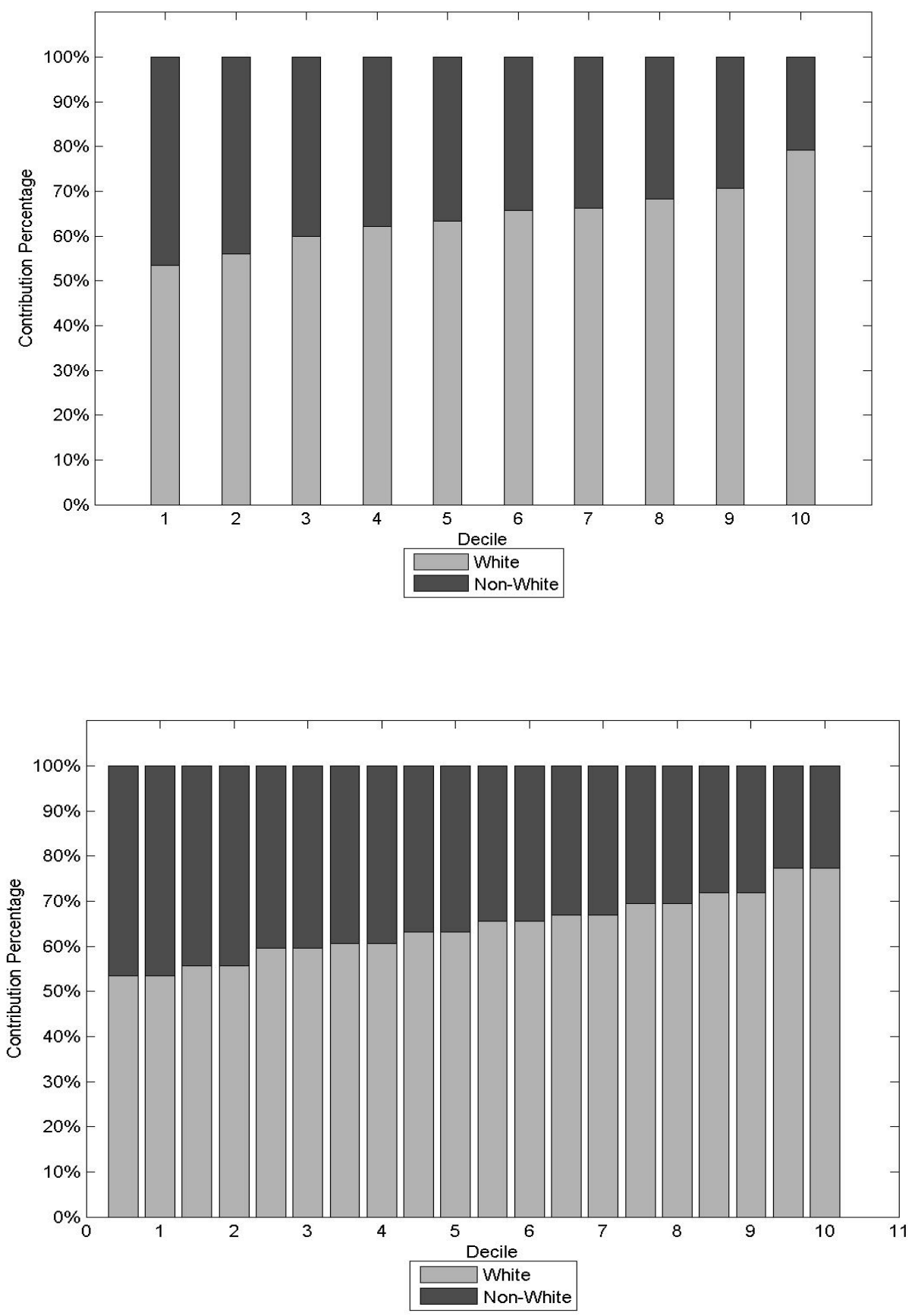


\section{REFERENCES}

Addabbo, T., Aziz, F., \& Reardon, J. (2010). Income distribution and the effect of the financial crisis on the Italian and USA labor markets. IZA/OECD Workshop.

Alan, S. (2004). Precautionary Wealth and Portfolio Allocation: Evidence from Canadian microdata. No. 117. McMaster University.

Apergis, N. (2015). Financial portfolio choice: Do business cycle regimes matter? Panel evidence from international household surveys. Journal of International Financial Markets, Institutions and Money, 34, 14-27.

Atkinson, A. B., \& Morelli, S. (2010). Inequality and banking crises: A first look. European Labour Forum in Turin Organised by the International Training Centre of the International Labor Organization (ILO),

Atkinson, A. B., Piketty, T., \& Saez, E. (2011). Top incomes in the long run of history. Journal of Economic Literature, 49(1), 3-71.

Attanasio, O. P., \& Weber, G. (2010). Consumption and saving: Models of intertemporal allocation and their implications for public policy. Journal of Economic Literature, 48(3), 693-751.

Attanasio, Orazio P., and Martin Browning. 1995. "Consumption over the Life Cycle and over the Business Cycle.” American Economic Review, 85(5): 1118-37.

Baldacci, E., De Mello, L., \& Inchauste, G. (2002). Financial crises, poverty, and income distribution International Monetary Fund.

Barro, R. J. (2009). Rare disasters, asset prices, and welfare costs. The American Economic Review, 99(1), 243-264.

Berkman, H., Jacobsen, B., \& Lee, J. B. (2011). Time-varying rare disaster risk and stock returns. Journal of Financial Economics, 101(2), 313-332.

Bernheim, B. D., Skinner, J., \& Weinberg, S. (2001). What accounts for the variation in retirement wealth among US households? American Economic Review, 832-857.

Berkowitz, M. K., \& Qiu, J. (2006). A further look at household portfolio choice and health status. Journal of Banking \& Finance, 30(4), 1201-1217. 
Bilias, Y., Georgarakos, D., \& Haliassos, M. (2010). Portfolio inertia and stock market fluctuations. Journal of Money, Credit and Banking, 42(4), 715-742.

Bishop, J. A., Chow, K. V., \& Formby, J. P. (1994). Testing for marginal changes in income distributions with lorenz and concentration curves. International Economic Review, 35(2), 479-488.

Bishop, J. A., Chow, K. V., \& Zeager, L. A. (2003). Decomposing lorenz and concentration curves. International Economic Review, 44(3), 965-978.

Bishop, J. A., Zeager, L. A., \& Zheng, B. (2011). Interdistributional inequality, stochastic dominance, and poverty. Working Paper.

Blank, R. (1989). Disaggregating the effect of the business cycle on the distribution of income. Economica, 56(222), 141-163.

Blau, D. M. (2008). Retirement and consumption in a life cycle model. Journal of Labor Economics, 26(1), 35-71.

Bollerslev, T., \& Todorov, V. (2011). Tails, fears, and risk premia. The Journal of Finance, 66(6), 2165-2211.

Bosworth, B. (2012). Economic consequences of the great recession: Evidence from the panel study of income dynamics. Boston College Center for Retirement Research Working Paper, (4)

Bricker, J., Bucks, B., Kennickell, A., Mach, T., \& Moore, K. (2011). Surveying the aftermath of the storm: Changes in family finances from 2007 to 2009. FEDS Working Paper,

Broer, T. (2013). The wrong shape of insurance? what cross-sectional distributions tell us about models of consumption-smoothing. American Economic Journal: Macroeconomics, 5(4)

Brown, J., Ivkovic, Z., Smith, P., Weisbenner, S. (2008). Neighbors matter: Causal community effects and stock market participation. The Journal of Finance, 63(3), 1509-1531.

Burkhauser, R. V., Feng, S., \& Jenkins, S. P. (2009). Using the P90/P10 index to measure US inequality trends with current population survey data: A view from inside the census bureau vaults. Review of Income and Wealth, 55(1), 166-185.

Cagetti, M. (2003). Wealth accumulation over the life cycle and precautionary savings. Journal of Business \& Economic Statistics, 21(3), 339-353. 
Calvet, L. E., \& Sodini, P. (2014). Twin picks: Disentangling the determinants of Risk-Taking in household portfolios. The Journal of Finance, 69(2), 867-906.

Campbell, J. Y., \& Cocco, J. F. (2007). How do house prices affect consumption? evidence from micro data. Journal of Monetary Economics, 54, 591-621.

Carroll, Christopher D., Robert E. Hall, and Stephen P. Zeldes (1992). The buffer-stock theory of saving: Some macroeconomic evidence, Brookings papers on economic activity, 61-156.

Carroll, Christopher D., and Andrew A. Samwick (1998,). How Important is precautionary saving, Review of Economics and Statistics, 80(3), 410-419.

---. 1997. The nature of precautionary wealth, Journal of Monetary Economics, 40(1), 41-71.

Carroll, Christopher D. (1997). Buffer-stock saving and the life cycle/permanent income hypothesis, The Quarterly Journal of Economics, 112(1), 1-55.

---. 1994, How does future income affect current consumption? The Quarterly Journal of Economics, 109(1), 111-147.

Catalano, R. (2009). Health, medical care, and economic crisis. New England Journal of Medicine, $360(8), 749-751$.

Cerra, V., \& Saxena, S. C. (2008). Growth dynamics: The myth of economic recovery. The American Economic Review, 98(1), 439-457.

Chen, S., \& Ravallion, M. (2009). The impact of the global financial crisis on the world's poorest. Vox: Research-Based Policy Analysis and Commentary from Leading Economists, www.Voxeu.org/index.Php

Christelis, D., Jappelli, T., Padula, M. (2010). Cognitive abilities and portfolio choice. European Economic Review 54(1), 18-38.

Cocco, J. (2005). Portfolio choice in the presence of housing. Review of Financial Studies, 18, 535-567.

Cocco, J. F., Gomes, F. J., \& Maenhout, P. J. (2005). Consumption and portfolio choice over the life cycle. Review of Financial Studies, 18(2), 491-533.

Coile, C., \& Milligan, K. (2009). How household portfolios evolve after retirement: The effect of aging and health shocks. Review of Income and Wealth, 55(2), 226-248. 
Cotti, C., Dunn, R., \& Tefft, N. (2013). The Dow is killing me: Risky health behaviors and the stock market. Available at SSRN,

Deaton, A. (1991). Saving and liquidity constraints. Econometrica, 59(5), 1221-1248.

De Beer, P. (2012). The impact of the crisis on earnings and income distribution in the EU. Working Paper.

De Nardi, M., French, E., \& Jones, J. B. (2010). Why do the elderly save? the role of medical expense. Journal of Political Economy, 118(1), 39-75.

Deidda, Manuela (2013). Precautionary saving, financial risk, and portfolio choice, Review of Income and Wealth, 59(1), 133-156.

Deutsch, J., \& Silber, J. (1999). Inequality decomposition by population subgroups and the analysis of interdistributional inequality. In J. Silber (Ed.), Handbook of income inequality measurement (pp. 363-403). Netherlands: Springer.

Dikhanov, Y. (1996). Decomposition of inequality based on incomplete information. Paper presented at the A Contributed Paper to the IARIW 24th General Conference, Norway.

Dimmock, S. G., \& Kouwenberg, R. (2010). Loss-aversion and household portfolio choice. Journal of Empirical Finance, 17(3), 441-459.

Ding, J. (2014). Australian retirees' choice between consumption, age, pension, bequest and housing. Working Paper, University of Wisconsin-Madison.

Domeij, D., \& Johannesson, M. (2006). Consumption and health.

Edwards, R. (2008). Health risk and portfolio choice. Journal of Business \& Economic Statistics, 26(4), 472-485.

Emmons, W. R., \& Noeth, B. J. (2013). The economic and financial status of older Americans: Trends and prospects. Federal Reserve Bank of St.Louis Review.

Faik, J. (2012). Income inequality and poverty in front of and during the economic Crisis-An empirical investigation for Germany 2002-2010. Working Paper.

Fallon, P. R., \& Lucas, R. E. (2002). The impact of financial crises on labor markets, household incomes, and poverty: A review of evidence. The World Bank Research Observer, 17(1), 2145. 
Finkelstein, A., Luttmer, E. F., \& Notowidigdo, M. J. (2013). What good is wealth without health? the effect of health on the marginal utility of consumption. Journal of the European Economic Association, 11(s1), 221-258.

French, E., \& Jones, J. B. (2011). The effects of health insurance and self-insurance on retirement behavior. Econometrica, 79, 693-732.

Friedman, J., \& Levinsohn, J. (2002). The distributional impacts of Indonesia's financial crisis on household welfare: A "rapid response" methodology. The World Bank Economic Review, 16(3), 397-423.

Friedman, Milton (1957). A Theory of the Consumption.

Gabaix, X. (2012). Variable rare disasters: An exactly solved framework for ten puzzles in macrofinance. The Quarterly Journal of Economics, 127(2), 645-700.

Gentry, W. M., \& Hubbard, R. G. (2004). Entrepreneurship and household saving. Advances in Economic Analysis \& Policy, 4(1)

Gerrans, P., Clark-Murphy, M., \& Speelman, C. (2010). Asset allocation and age effects in retirement savings choices. Accounting \& Finance, 50(2), 301-319.

Goda, G. S., Shoven, J. B., \& Slavov, S. N. (2011). What explains changes in retirement plans during the great recession? American Economic Review, 101, 29-34.

Goldman, D., \& Maestas, N. (2013). Medical expenditure risk and household portfolio choice. Journal of Applied Econometrics, 28(4), 527-550.

Gomes, F., \& Michaelides, A. (2005). Optimal life-cycle asset allocation: Understanding the empirical evidence. The Journal of Finance, 60(2), 869-904.

Gordon, R. J. (2009). Has the rise in American inequality been exaggerated? Challenge, 52(3), $92-$ 120.

Gordon, R. J., \& Dew-Becker, I. (2008). Controversies about the rise of American inequality: A survey. No. w13982, National Bureau of Economic Research, (w13982)

Gourinchas, P., \& Parker, J. A. (2002). Consumption over the life cycle. Econometrica, 70(1), $47-$ 89.

Grossman, S., \& Laroque, G. (1990). Asset pricing and optimal portfolio choice in the presence of illiquid durable consumption goods. Econometrica, 58(1), 25-52. 
Guariglia, Alessandra (2001). Saving behavior and earnings uncertainty: evidence from the British Household Panel Survey, Journal of Population Economics, 14, 619-634.

Guiso, Luigi, Tullio Jappelli, and Daniele Terlizzese (1996). Income risk, borrowing constraints, and portfolio choice, The American Economic Review, 86(1), 158-172.

Guiso, L., Haliassos, M., Jappelli, T. (2003). Household stockholding in Europe: Where do we stand and where do we go? Economic Policy 18(36), 123-170.

Guiso, L., Sapienza, P., Zingales, L. (2008). Trusting the stock market. The Journal of Finance 63(6), 2557-2600.

Gustman, A. L., Steinmeier, T. L., \& Tabatabai, N. (2009). How do pension changes affect retirement preparedness? the trend to define contribution plans and the vulnerability of the retirement age population to the stock market decline of 2008-2009. Working Paper, Michigan Retirement Research Center,

Gyllenram, A., Hellström, J., \& Hanes, N. (2014). Psychological ability to cope with stress and stock market participation. Working Paper, Umea University, Sweden.

Haan, P., \& Myck, M. (2009). Dynamics of health and labor market risks. Journal of Health Economics, 28(6), 1116-1125.

Habib, B., Narayan, A., Olivieri, S., \& Sanchez, C. (2010). The impact of the financial crisis on poverty and income distribution: Insights from simulations in selected countries. World Bank.

Hall, R. E., \& Jones, C. We. (2007). The value of life and the rise in health spending. The Quarterly Journal of Economics, 122(1), 39-72.

Hall, R. E. (1978). Stochastic implications of the life cycle-permanent income hypothesis: Theory and evidence. Journal of Political Economy, 86(6), 971-987.

Haliassos, M., \& Bertaut, C. C. (1995). Why do so few hold stocks? Economic Journal, 105 (432), 1110-1129.

Haugh, D., Ollivaud, P., \& Turner, D. (2009). The macroeconomic consequences of banking crises in OECD countries. OECD Economics Department Working Papers, No.683.

Heathcote, J., Perri, F., \& Violante, G. L. (2010). Unequal we stand: An empirical analysis of economic inequality in the United States, 1967-2006. Review of Economic Dynamics, 13(1), $15-51$. 
Heaton, J., \& Lucas, D. (2000). Portfolio choice and asset prices: The importance of entrepreneurial risk. The Journal of Finance, 55(3), 1163-1198.

Hochguertel, Stefan (2003). Precautionary motives and portfolio decisions, Journal of Applied Econometrics 18(1), 61-77.

Hsu, J. C. (2012). What drives equity market non-participation? The North American Journal of Economics and Finance, 23(1), 86-114.

Huang, H., Milevsky, M. A., \& Salisbury, T. S. (2012). Optimal retirement consumption with a stochastic force of mortality. Insurance: Mathematics and Economics, 51(2), 282-291.

Hugonnier, J., St-Amour, P., \& Pelgrin, F. (2012). Health and (other) asset holdings. Swiss Finance Institute Research Paper, (09-18)

Hurst, E., Kennickell, A., Lusardi, A., \& Torralba, F. (2005). Precautionary Savings and the Importance of Business Owners. No.w11731. National Bureau of Economic Research.

Iacoviello, M. (2008). Household debt and income inequality, 1963-2003. Journal of Money, Credit and Banking, 40(5), 929-965.

Jäntti, M., \& Jenkins, S. P. (2010). The impact of macroeconomic conditions on income inequality. The Journal of Economic Inequality, 8(2), 221-240.

Jappelli, Tullio, Mario Padula, and Luigi Pistaferri (2008). A direct test of the buffer stock model of saving, Journal of the European Economic Association, 6(6), 1186-1210.

Jappelli, Tullio, Luigi Pistaferri, and Guglielmo Weber (2007). Health care quality, economic inequality, and precautionary saving, Health Economics, 16(4), 327-346.

Julliard, C., \& Ghosh, A. (2012). Can rare events explain the equity premium puzzle? Review of Financial Studies, 25(10), 3037-3076.

Jenkins, S. P., Brandolini, A., Micklewright, J., \& Nolan, B. (2012). The great recession and the distribution of household income. Oxford University Press.

Kennickell, Arthur, and Annamaria Lusardi (2004). Disentangling the importance of the precautionary saving mode. No.w10888. National Bureau of Economic Research.

Kennickell, A. B. (2008). Evidence on the distribution of wealth, health, life expectancy, and health insurance coverage. Statistics in Medicine, 27(20), 3927-3940. 
Kolusheva, D. (2011). Life-cycle portfolio allocation when disasters are possible. Available at SSRN 1781043,

Kremer, A., Liese, F., Homölle, S., \& Clausen, J. (2014). Optimal consumption and portfolio choice of retirees with longevity risk. Journal of Pension Economics and Finance, 13(03), 227-249.

Kimball, M. S. (1990). Precautionary saving in the small and in the large. Econometrica, 58(1), 53-73.

Krueger, D., \& Perri, F. (2006). Does income inequality lead to consumption inequality? evidence and theory. The Review of Economic Studies, 73(1), 163-193.

Laporte, A., \& Ferguson, B. S. (2007). Investment in health when health is stochastic. Journal of Population Economics, 20(2), 423-444.

Lillard, L. A., \& Weiss, Y. (1997). Uncertain health and survival: Effects on end-of-life consumption. Journal of Business \& Economic Statistics, 15(2), 254-268.

Liu, J., Pan, J., \& Wang, T. (2005). An equilibrium model of rare-event premia and its implication for option smirks. The Review of Financial Studies, 18(1)

Lusardi, Annamaria (1998). On the importance of the precautionary saving motive, American Economic Review, 88(2) 449-453.

Maurer, R., Mitchell, O. S., Rogalla, R., \& Kartashov, V. (2013). Lifecycle portfolio choice with systematic longevity risk and variable Investment Linked deferred annuities. Journal of Risk and Insurance, 80(3), 649-676.

Merton, R. C. (1971). Optimum consumption and portfolio rules in a continuous-time model. J.Econ.Theory, 3(4), 373-413.

Merton, R. C. (1973). An intertemporal capital asset pricing model. Econometrica: Journal of the Econometric Society, 867-887.

Michaelides, A., \& Zhang, Y. (2015). Stock market mean reversion and portfolio choice over the life cycle. Available at SSRN 2564447,

Milanovic, B. (2002). True world income distribution, 1988 and 1993: First calculation based on household surveys alone. The Economic Journal, 112(476), 51-92. 
Moore, K. B., \& Palumbo, M. G. (2010). The finances of American households in the past three recessions: Evidence from the survey of consumer finances Division of Research \& Statistics and Monetary Affairs, Federal Reserve Board.

Morelli, S. (2011). Banking crises and stock market crashes in US: The response of top shares in historical perspective. Unpublished Manuscript, Oxford University.

Orazio, P. A., \& Martin, B. (1995). Consumption over the life cycle and over the business cycle. American Economic Review, 85(5), 1118-1137.

Palia, D., Qi, Y., \& Wu, Y. (2014). Heterogeneous background risks and portfolio choice: Evidence from Micro-level data. Journal of Money, Credit and Banking, 46(8), 1687-1720.

Palumbo, M. G. (1999). Uncertain medical expenses and precautionary saving near the end of the life cycle. The Review of Economic Studies, 66(2), 395-421.

Parker, J. A., \& Vissing-Jorgensen, A. (2010). The increase in income cyclicality of high-income households and its relation to the rise in top income shares. Working Paper.

Parker, J. A., \& Vissing-Jørgensen, A. (2009). Who bears aggregate fluctuations and how? The American Economic Review, 99(2), 399-405.

Picone, G., Uribe, M., \& Mark Wilson, R. (1998). The effect of uncertainty on the demand for medical care, health capital and wealth. Journal of Health Economics, 17(2), 171-185.

Piketty, T., \& Saez, E. (2003). Income inequality in the United States, 1913-1998*. The Quarterly Journal of Economics, 118(1), 1-41. (with update to 2002)

Piketty, T., \& Saez, E. (2014). Inequality in the long run. Science, 344(6186), 838-843.

Polkovnichenko (2007). Life-cycle Portfolio Choice with Additive Habit Formation Preferences and Uninsurable Labor Income Risk. Review of Financial Studies, 20 (1), 83-124.

Poterba, J. M., Venti, S. F., \& Wise, D. A. (2012). The nexus of social security benefits, health, and wealth at death. National Bureau of Economic Research,

Poterba, J., Rauh, J., Venti, S., \& Wise, D. (2007). Defined contribution plans, defined benefit plans, and the accumulation of retirement wealth. Journal of Public Economics, 91(10), 20622086. 
Robilliard, A., Bourguignon, F., \& Robinson, S. (2001). Crisis and income distribution: A micromacro model for Indonesia. Washington, DC, International Food Policy Research Institute (IFPRI),

Rosen, H., Wu, S. (2004). Portfolio choice and health status. Journal of Financial Economics 72(3), 457-484.

Saez, E., \& Zucman, G. (2014). Wealth Inequality in the United States since 1913: Evidence from Capitalized Income Tax Data. No. w20625. National Bureau of Economic Research.

Samuelson, P. A. (1969). Lifetime portfolio selection by dynamic stochastic programming. The Review of Economics and Statistics, 51(3), 239-246.

Scholz, J. K., \& Seshadri, A. Health and wealth in a life cycle model. Working Paper, University of Wisconsin-Madison.

Sen, A. (1997). On economic inequality. London: Oxford University Press.

Shorrocks, A. F. (1984). Inequality decomposition by population subgroups. Econometrica, 52(6), 1369-1385.

Sinai, T., \& Souleles, N. (2008). Net worth and housing equity in retirement. In J. Ameriks, \& O. Mitchell (Eds.), Recalibrating retirement spending and saving. New York: Oxford University Press.

Stockhammer, E. (2012). Rising inequality as a root cause of the present crisis. University of Massachusetts Amherst Political Economy Research Institute Working Paper, (282)

Sundén, A., Surette, B. (1998). Gender differences in the allocation of assets in retirement savings plans. American Economic Review, 88(2), 207-211.

Tien, J. J., \& Miao, J. C. (2013). How households adjust their consumption and investment plans under longevity risk: An experimental approach-based study in taiwan. The Geneva Papers on Risk and Insurance-Issues and Practice, 38(4), 803-823.

Van Rooij, M., Lusardi, A., \& Alessie, R. (2011). Financial literacy and stock market participation. Journal of Financial Economics, 101(2), 449-472.

Wachter, J. A. (2013). Can time-varying risk of rare disasters explain aggregate stock market volatility? The Journal of Finance, 68(3), 987-1035. 
Wachter, J. A., \& Yogo, M. (2010). Why do household portfolio shares rise in wealth? Review of Financial Studies, 23(11), 3929-3965.

Wenzlow, A. T., Mullahy, J., Robert, S. A., \& Wolfe, B. L. (2004). An empirical investigation of the relationship between wealth and health using the survey of consumer finances.

Yilmazer, T., \& Scharff, R. L. (2014). Precautionary savings against health risks evidence from the health and retirement study. Research on Aging, 36(2), 180-206.

Yogo, M. (2009). Portfolio choice in retirement: Health risk and the demand for annuities, housing, and risky assets. National Bereau of Economic Research.

Zhan, J. C. (2015). Who holds risky assets and how much? Empirica, 42(2), 323-370.

Zietz, J., \& Zhao, X. (2009). The short-run impact of the stock market appreciation of the 1980s and 1990s on US income inequality. The Quarterly Review of Economics and Finance, 49(1), 42-53. 